\title{
U.S. Offshore Wind Manufacturing and Supply Chain Development
}

\section{Prepared for:}

U.S. Department of Energy

Navigant Consulting, Inc.

77 Bedford Street

Suite 400

Burlington, MA 01803-5154

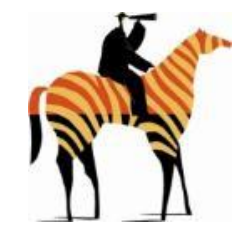

781.270 .8314

www.navigant.com

February 22, 2013 


\section{NAVIGANT}

\section{U.S. Offshore Wind Manufacturing and Supply Chain Development}

Document Number DE-EE0005364

Prepared for:

U.S. Department of Energy

Michael Hahn

Cash Fitzpatrick

Gary Norton

Prepared by:

Navigant Consulting, Inc.

Bruce Hamilton, Principal Investigator

Lindsay Battenberg

Mark Bielecki

Charlie Bloch

Terese Decker

Lisa Frantzis

Aris Karcanias

Birger Madsen

Jay Paidipati

Andy Wickless

Feng Zhao

Navigant Consortium member organizations

American Wind Energy Association

Great Lakes Wind Collaborative

Green Giraffe Energy Bankers

National Renewable Energy Laboratory

Ocean \& Coastal Consultants (a COWI company)

Tetra Tech EC, Inc. $\underline{\text { Key Contributors }}$

Jeff Anthony and Chris Long John Hummer and Victoria Pebbles

Marie DeGraaf, Jérôme Guillet, and Niels Jongste David Keyser and Eric Lantz Brent D. Cooper, P.E., Joe Marrone, P.E., and Stanley M. White, P.E., D.PE, D.CE

Michael D. Ernst, Esq. 


\section{NAVIGANT}

\section{Notice and Disclaimer}

This report was prepared by Navigant Consulting, Inc. for the use of the U.S. Department of Energy who supported this effort under Award Number DE-EE0005364. The work presented in this report represents our best efforts and judgments based on the information available at the time this report was prepared. Navigant Consulting, Inc. is not responsible for the reader's use of, or reliance upon, the report, nor any decisions based on the report. NAVIGANT CONSULTING, INC. MAKES NO REPRESENTATIONS OR WARRANTIES, EXPRESSED OR IMPLIED. Readers of the report are advised that they assume all liabilities incurred by them, or third parties, as a result of their reliance on the report, or the data, information, findings and opinions contained in the report.

Neither the United States Government nor any agency thereof, nor any of their employees, makes any warranty, express or implied, or assumes any legal liability or responsibility for the accuracy, completeness, or usefulness of any information, apparatus, product, or process disclosed, or represents that its use would not infringe privately owned rights. Reference herein to any specific commercial product, process, or service by trade name, trademark, manufacturer, or otherwise does not necessarily constitute or imply its endorsement, recommendation, or favoring by the United States government or any agency thereof.

This report is being disseminated by the Department of Energy. As such, the document was prepared in compliance with Section 515 of the Treasury and General Government Appropriations Act for Fiscal Year 2001 (Public Law 106-554) and information quality guidelines issued by the Department of Energy. Though this report does not constitute "influential" information, as that term is defined in DOE's information quality guidelines or the Office of Management and Budget's Information Quality Bulletin for Peer Review (Bulletin), the study was reviewed both internally and externally prior to publication. For purposes of external review, the study benefited from the advice and comments of a panel of offshore wind industry stakeholders. That panel included representatives from private corporations, national laboratories, and universities. 


\section{NAVIGANT}

\section{Acknowledgments}

For their support of this report, the authors thank the entire U.S. Department of Energy (DOE) Wind \& Water Power Program team, and in particular Cash Fitzpatrick and Gary Norton. For reviewing elements of this report or providing key input, we also acknowledge: Walt Musial, National Renewable Energy Laboratory (NREL); and Robin Newmark, NREL.

Navigant would also like to thank the following for their contributions to this report: Matt Aldeman, Illinois State University; Tim Axelsson, Fishermen's Energy; Rick Bergman, Aquilo Wind Development; Jessica Bowling, Baltimore Helicopter Services; David Bradley, Lake Effect Energy; Randy Brown, Metal Trades, Inc.; Kyoo Sung Byun, LS Cable America, Inc.; Guy Chapman, Dominion; Fara Courtney, U.S. Offshore Wind Collaborative; Michael Crist, Moffatt \& Nichol; Alexander DePillis, Wind Energy Systems Engineering, Inc.; Timothy D. Downey, Saint Lawrence Seaway Development Corporation; Heinrich Duden, ep4 offshore GmbH; Dennis Duffy, Energy Management Inc.; Juan Lopez-Doriga Escalante, Rockford Berge; Fort Felker, NREL; Patrick Fullenkamp, Global Wind Network; Alice Fuchs, Mishilsolarplus; Russ Germick, Vestas Americas; Ryan Greenfield, Schaeffler Group; Parveen Gupta, Bosch Rexroth; Kim Gyr, Green Millennium; Christopher Hardy, U.S. Offshore Wind Collaborative; Christopher Haugen, ITW WindGroup; John F. Hill, GE Energy Converteam; Matthias Hofmann, SINTEF; William L. Hurley, Jr., The Glosten Associates, Inc.; Mike Ireland, Larkin Enterprises, Inc.; Philip Jacobs, Alstom Grid Solutions USA; Andrew Jacus, Dillinger Hütte GTS; David L. Jansen P.E., Janseneering, Inc.; George Kendrick, Stantec Consulting; Paul J. Kerman MS; Bradley Kerr, Detyen's Shipyards, Inc.; Steven Kopits, Douglas-Westwood; Kerman Consulting Services; Kenneth L Kraemer, University of California, Irvine; Doug Lindsey, Lakeshore Technical College; Hao Ling, The University of Texas at Austin; Simon Mahan, Southern Alliance for Clean Energy; Todd Main, Illinois Department of Natural Resources; Christian Mertens, Bosch Rexroth; Lawrence H. Mott, SgurrEnergy Inc.; Gary Murphy, Case Western Reserve University; Natalia Nagree, Douglas-Westwood; Dennis L. Nielson, DOSECC Exploration Services, LLC; John Nikoloff, PA Energy Resources Group, LLC; Brian O'Hara, North Carolina Offshore Wind Coalition; Kris Ohleth, Atlantic Wind Connection; Rick Palmer, Weeks Marine, Inc.; Katherine Peretick, Vestas; Raoul Raffagli, Siemens Wind Power A/S; Bonnie Ram, Ram Power LLC; Jay Robison, Arkansas Economic Development Commission; Tim Ryan, Apex Offshore Wind, LLC; Stephane Sanchez, Consulate-General Kingdom of the Netherlands; Hans-Christian Schimmelmann, ABB; Philipp Schmid, SKF; Bob Schubert, Siemens; Stephan Schwab, Siemens Energy, Inc.; Geoff Sharples, CPE; Steve Sheik, Baltimore Helicopter Services; Robert Sherwin, EAPC Wind Energy; Benjamin B. Smith, Stevens Towing, Inc.; Larry Shirley, NC Department of Commerce; Duncan Sokolowski, Global Marine Energy, Inc.; Larry Viterna, Nautica Windpower LLC; Andreas Wagner, German Offshore Wind Energy Foundation; Lorry Wagner, LeedCo; Carl F. Wegener, Signal International, Inc.; Dale Williamson, Alstom Power; Chris Wissemann, Freshwater Wind; Thomas Zirngibl, TUV SUD America Inc. 


\section{NAVIGANT}

\section{Table of Contents}

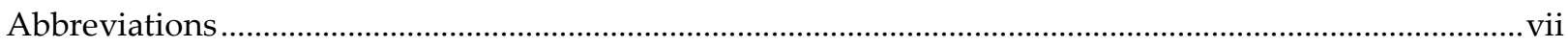

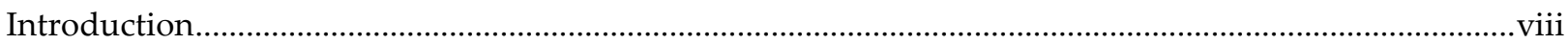

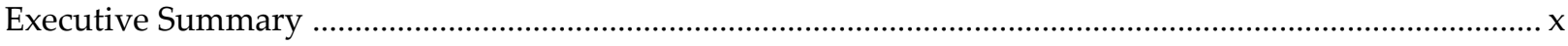

Chapter 1. Offshore Wind Plant Costs and Anticipated Technology Advancements ........................ xi

Chapter 2. Potential Supply Chain Requirements and Opportunities ................................................iii

Chapter 3. Strategy for Future Development............................................................................................ii

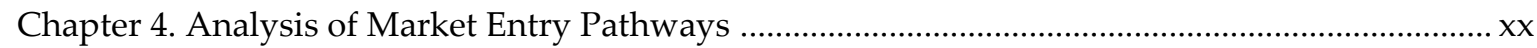

1. Offshore Wind Plant Costs and Technology Advancements ....................................................... 1

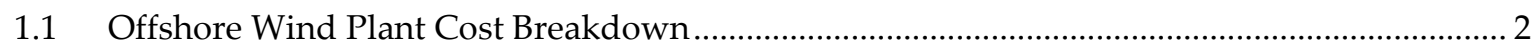

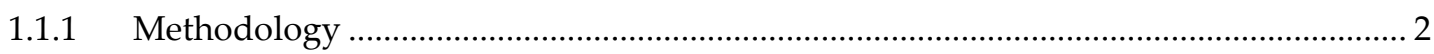

1.1.2 Plant Capital Cost Breakdown ................................................................................... 3

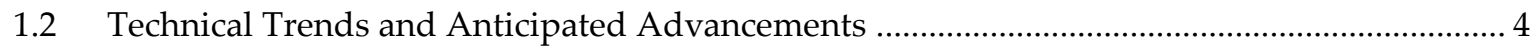

2. Supply Chain Needs to Support U.S. Offshore Industry …....................................................... 17

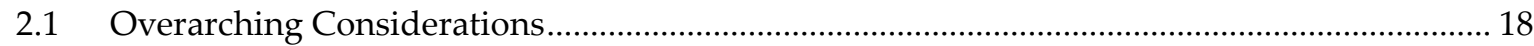

2.1.1 U.S. Suppliers' Role in the Global Wind Market ............................................................ 18

2.1.2 Regional Considerations for Offshore Wind Plant Design and Supply ...................... 20

2.2 Assumptions for Estimating Supply Chain Requirements ...................................................... 24

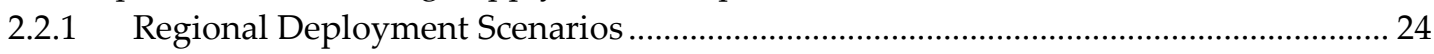

2.2.2 Component and Material Requirement Assumptions................................................... 29

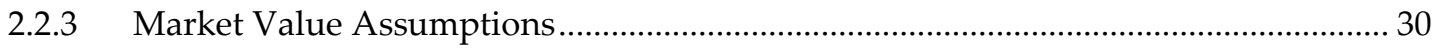

2.3 Component-level Requirements and Opportunities ................................................................ 30

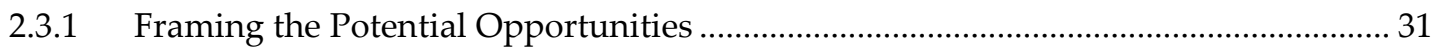

2.3.2 Offshore Wind Turbine Generators............................................................................... 33

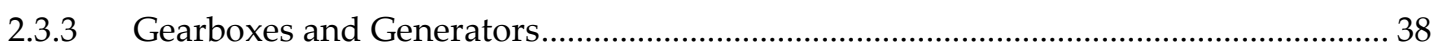

2.3.4 Turbine Electronics: Power Converters and Power Transformers .............................. 43

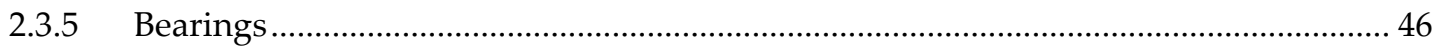

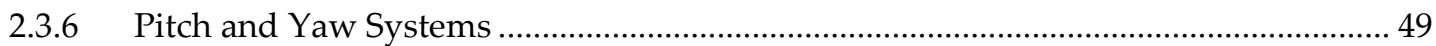

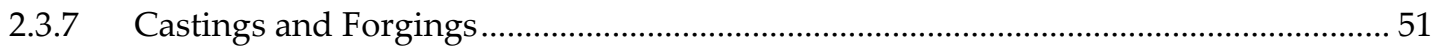

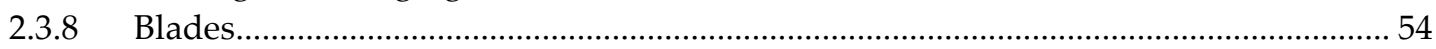

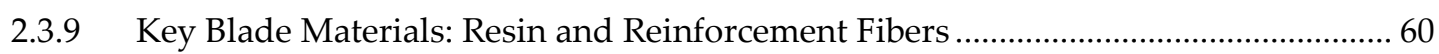

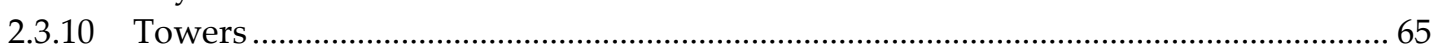

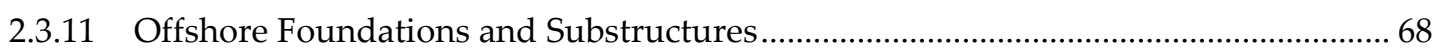

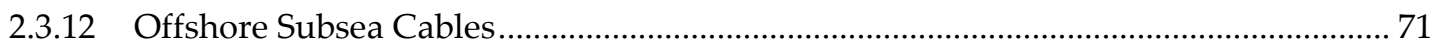

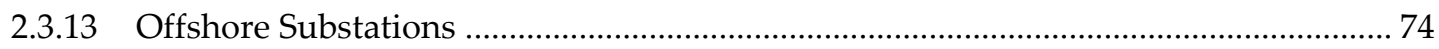

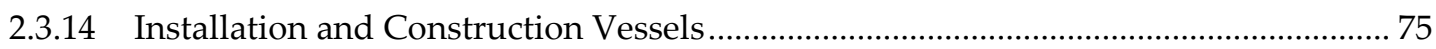

2.4 Labor and Economic Impacts and Opportunities................................................................... 77

2.4.1 Potential Requirements for Co-located Port and Manufacturing Facilities ................ 77

2.4.2 Potential Labor and Economic Impacts: Port and Manufacturing Facility

Construction 80 


\section{NAVIGANT}

2.4.3 Potential Labor Requirements: Manufacturing Activities

2.4.4 Ability to Meet Potential Labor Demands from Port and Manufacturing Facilities . 89

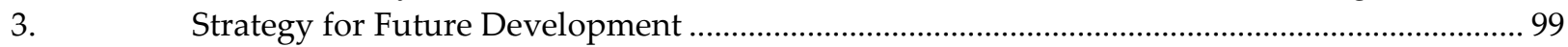

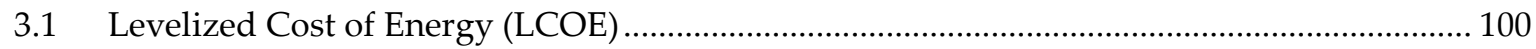

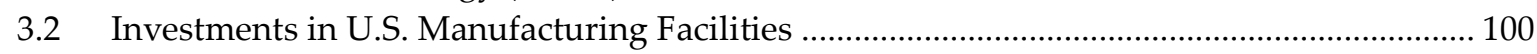

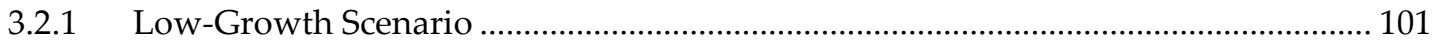

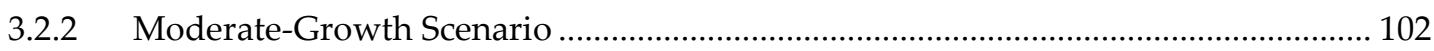

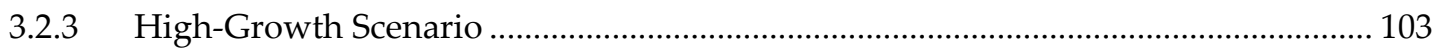

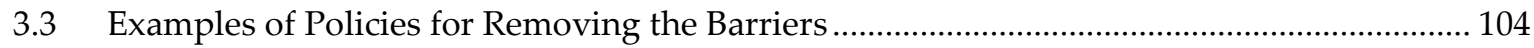

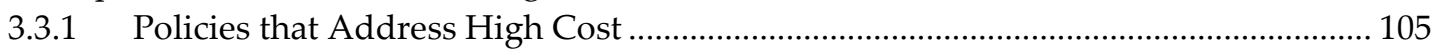

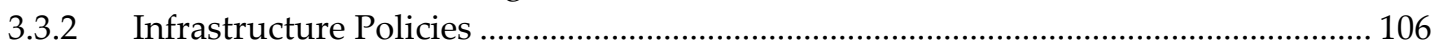

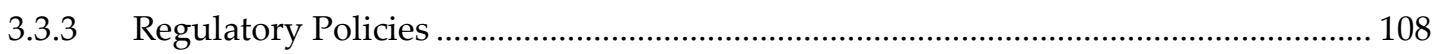

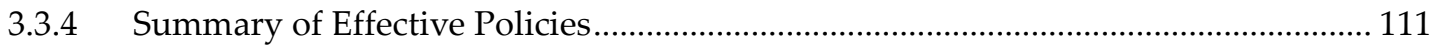

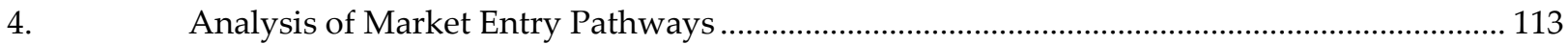

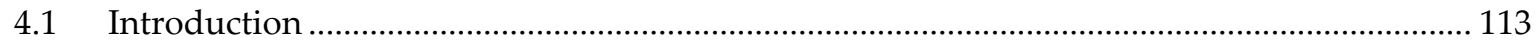

4.2 Suppliers' Decision-Making Process for Entering the Offshore Market.................................. 113

4.2.1 Market Demand: Market Size and Growth Rates................................................... 114

4.2.2 Supply: Competitive Rivalry, Barriers to Entry, and Risk ......................................... 115

4.3 WTG OEM Decision-Making Process for Evaluating Suppliers ............................................. 119

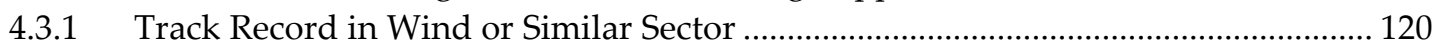

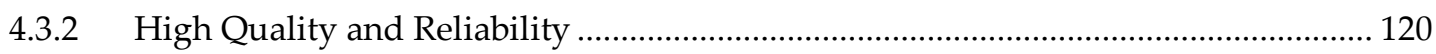

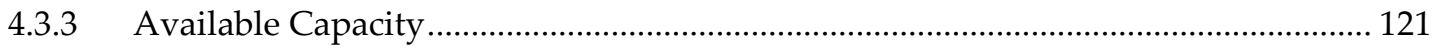

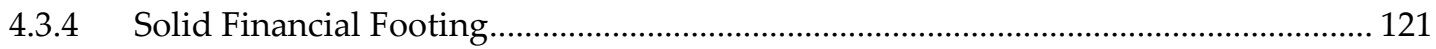

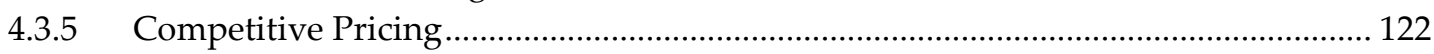

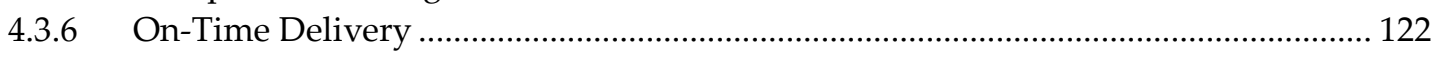

4.3.7 Flexibility in Production Schedules and Ability to Meet Short Lead Times............. 122

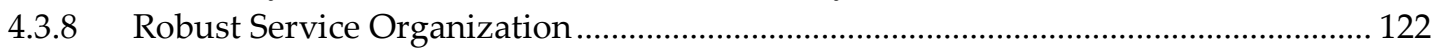

4.3.9 Willingness to Engage in Joint Development with OEM ........................................... 122

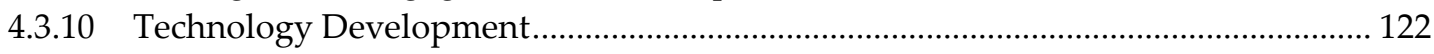

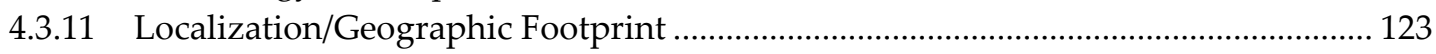

4.4 Current and Future Pathways to Market ........................................................................... 123

4.4.1 Supplier and Manufacturer Make Initial Contact ...................................................... 123

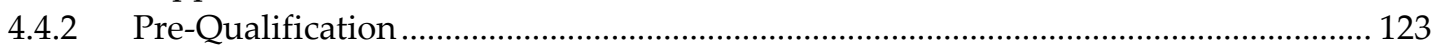

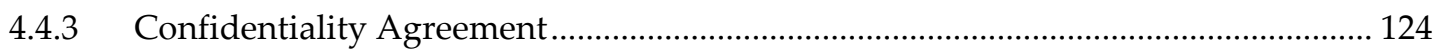

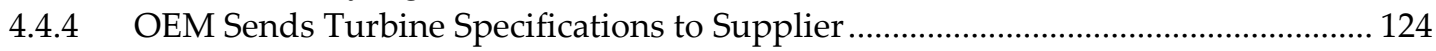

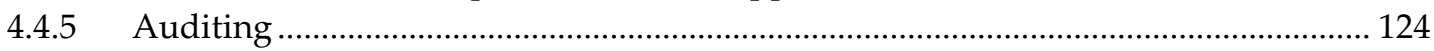

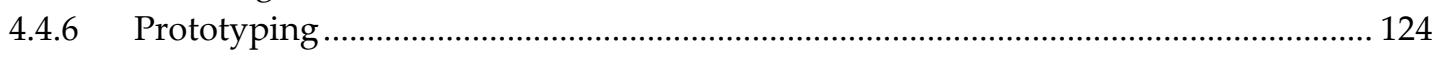

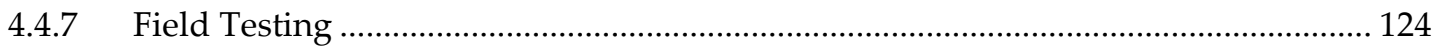

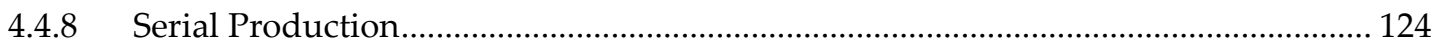

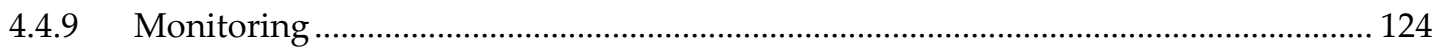

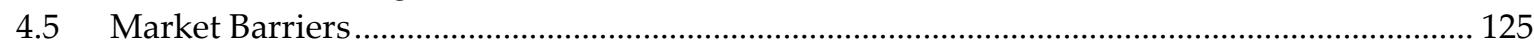

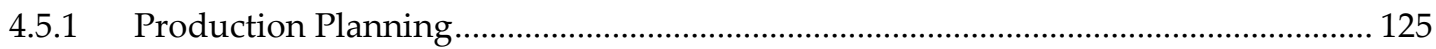

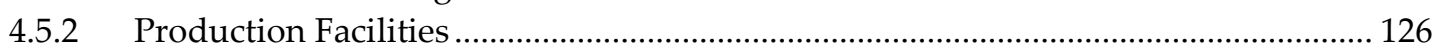

4.6 Recommendations to Remove the Identified Barriers .......................................................... 127 


\section{NAVIGANT}

4.6.1 Strong and Consistent Market Demand ....................................................................... 127

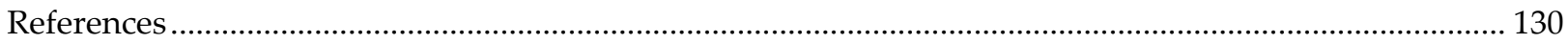

Appendix A. $\quad$ Project and Turbine Cost Assumption Details.............................................................. 136

Appendix B. $\quad$ Learning Curve and Cost-Reduction Estimates ............................................................ 137

Appendix C. Technology Trend Ranking Methodology ..................................................................... 139

Appendix D. $\quad$ Assumptions Supporting Supply Chain Analysis ...................................................... 142

D.1 Detailed Deployment Scenario Assumptions ............................................................................ 142

D.2 Component and Material Requirement Assumptions ……………......................................... 146

D.3 Approach to Top-Down Estimates of Component Values .................................................. 149

Appendix E. $\quad$ Sample Demand Growth Curves................................................................................. 153

Appendix F. $\quad$ Port Industry Trends and the Offshore Wind Market ................................................ 154

F.1 Basic Port Selection Criteria and Industry Trends among Existing Facilities........................ 154

F.2 Examples of Required Port Investments for Serving Offshore Wind ..................................... 156

Appendix G. Details on Indirect Job Impacts of Modeled Port Facility Investments ...................... 161

G.1 Distribution of Indirect Employment by Industry ……............................................................ 161

Appendix H. Local Content Assumptions for Modeling Labor Requirements ............................... 164 


\section{NAVIGANT}

\section{List of Figures}

Figure 1. Offshore Wind Plant Capital Cost Breakdown ...........................................................................ii

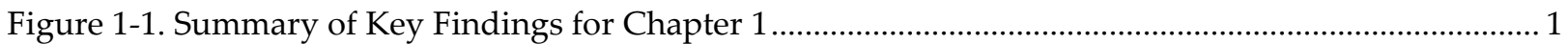

Figure 1-2. Offshore Wind Plant Capital Cost Breakdown............................................................................. 3

Figure 1-3. Offshore Wind Plant Capital Cost Breakdown (without Construction Financing) ...................... 4

Figure 1-4. Indexed Composite Score for Offshore Wind Innovation Opportunities ................................... 11

Figure 1-5. Change in Indexed Composite Score when Moving from Scores that Consider Impacts in $<5$

Years to Scores that Consider Impacts in 5-10 Years ................................................................................. 12

Figure 1-6. Average Impact to LCOE by Industry Segment ................................................................... 13

Figure 1-7. Indexed Scores for the Ten Innovations Observed to have the Greatest Impact to LCOE ....... 14

Figure 1-8. Indexed Scores for Top Ten Innovations Observed to have the Greatest Impact on

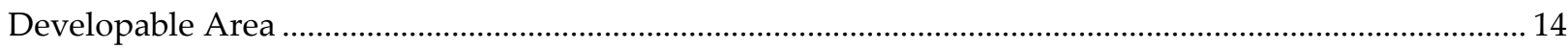

Figure 2-1. Summary of Key Findings for Chapter 2 ........................................................................... 18

Figure 2-2. U.S. Offshore Wind Resource at 80 Meters above the Surface .................................................. 22

Figure 2-4. Modeled Annual Capacity Additions by Region: High-growth Scenario .................................. 28

Figure 2-5. Modeled Annual Capacity Additions by Region: Moderate-Growth Scenario ......................... 29

Figure 2-6. Modeled Annual Capacity Additions by Region: Low-growth Scenario .................................. 29

Figure 2-7. Modeled Annual Turbine Demand: Moderate-Growth Scenario ................................................ 34

Figure 2-8. Share of Installed Global Offshore Wind Capacity by OEM - Year-End 2011 ......................... 38

Figure 2-14. Current Employment in Sectors Relevant to Offshore Wind Blade Manufacturing ............... 92

Figure 2-15. Current Employment in Sectors Relevant to Offshore Wind Electrical Systems and

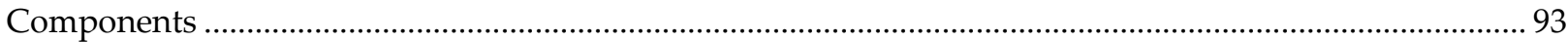

Figure 2-16. Current Employment at Foundries within the Contiguous United States ............................. 94

Figure 2-17. Current Employment in Sectors Relevant to Offshore Wind Mechanical Systems and

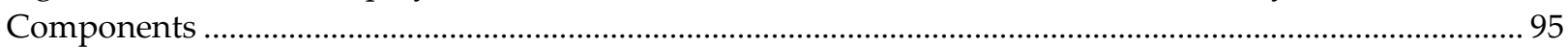

Figure 2-18. Current Employment in Sectors Relevant to Offshore Wind Towers and Foundations......... 96

Figure 3-1. Summary of Key Findings for Chapter 3 ................................................................................... 99

Figure 3-2. U.S. Manufacturing of Offshore Wind in the Low-Growth Scenario ....................................... 103

Figure 3-3. Average Domestic Content in the Low-Growth Scenario.......................................................... 102

Figure 3-4. U.S. Manufacturing of Offshore Wind in the Moderate-Growth Scenario ............................... 103

Figure 3-5. Average Domestic Content in the Moderate-Growth Scenario................................................. 103

Figure 3-6. U.S. Manufacturing of Offshore Wind in the High-Growth Scenario ....................................... 104

Figure 3-7. Average Domestic Content in the High-Growth Scenario........................................................ 104

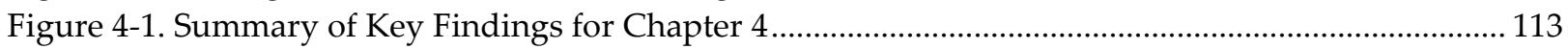

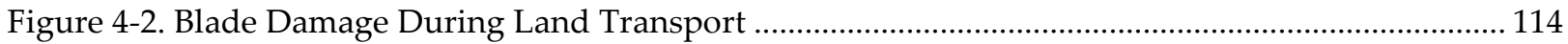

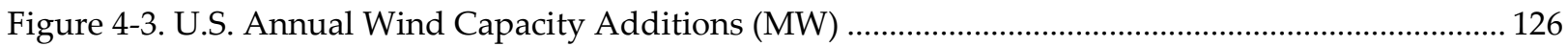

Figure B-1. Projected Changes in the LCOE of Offshore Wind over Time .................................................. 138

Figure E-1. Modeled Annual Turbine Demand: High-Growth Scenario.................................................... 153

Figure E-2. Modeled Annual Turbine Demand: Low-Growth Scenario.................................................... 153

Figure G-1. Distribution of Average Supply Chain and Material Input Jobs (FTE) by Sector.................... 161

Figure G-2. Distribution of Average Job (FTE) Impacts from Local Expenditures by Sector ..................... 162 


\section{NAVIGANT}

\section{List of Tables}

Table 1. Regional Deployment Scenario Targets and Technology Profiles $\mathrm{xV}$

Table 2. . Summary of Near-Term (2020) Domestic Supply Chain Opportunities under a ModerateGrowth Scenario xvi

Table 1-1. Baseline Assumptions for Example Offshore Wind Farm 2

Table 2-1. Regional Characteristics Affecting Offshore Wind Development in the U.S............................. 23

Table 2-2. Regional Deployment Scenario Targets and Technology Profiles ................................................. 25

Table 2-3. Supply Chain Opportunity Framework ....................................................................................... 32

Table 2-4. Modeled 2020 Wind Turbine Requirements ............................................................................ 34

Table 2-6. Current Global Suppliers of Offshore Wind Turbines ……........................................................... 37

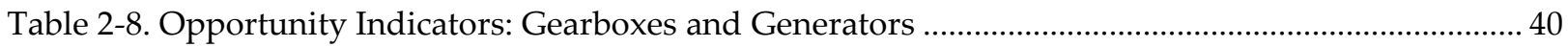

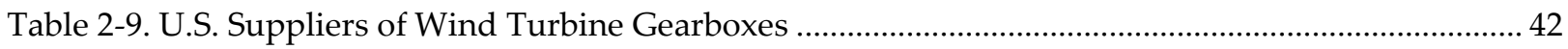

Table 2-10. U.S. Suppliers of Electric Generators for Wind Turbines........................................................ 43

Table 2-11. Modeled 2020 Power Converter and Power Transformer Requirements.................................. 44

Table 2-12. Opportunity Indicators: Power Converters and Power Transformers ....................................... 44

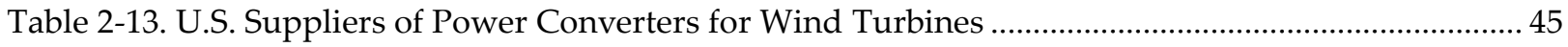

Table 2-14. U.S. Suppliers of Power Transformers for Land-based Wind Turbines ...................................... 46

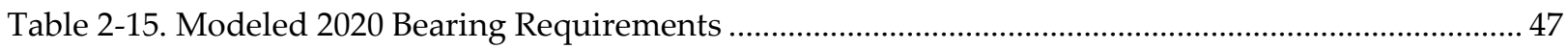

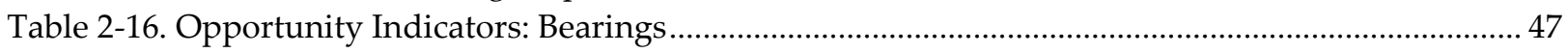

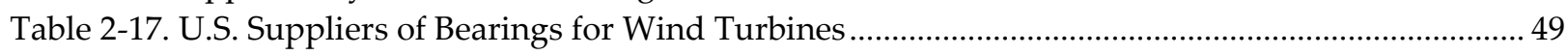

Table 2-18. Modeled 2020 Yaw and Pitch System Requirements.................................................................. 50

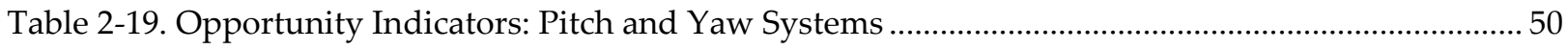

Table 2-20. U.S. Suppliers of Pitch and Yaw Systems for Wind Turbines .................................................. 51

Table 2-21. Modeled 2020 Casting and Forging Material Requirements ..................................................... 52

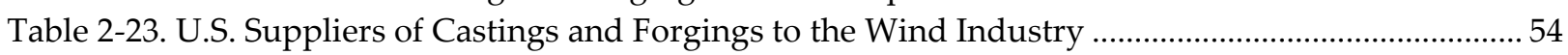

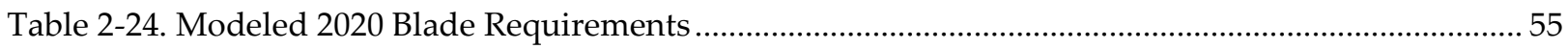

Table 2-26. U.S. Suppliers of Blades for Land-based Wind Turbines............................................................ 59

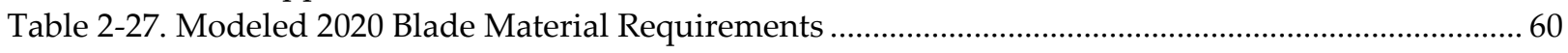

Table 2-29. U.S. Suppliers of Epoxy Resin and Unsaturated Polyester for Wind Turbine Blades .............. 63

Table 2-30. Major U.S. Suppliers of Glass Fiber for Wind Turbine Blades ................................................... 64

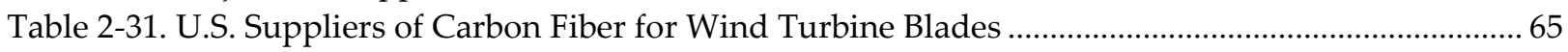

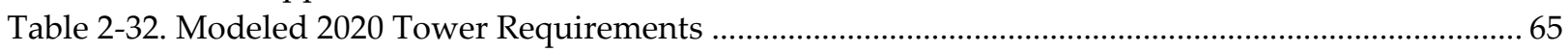

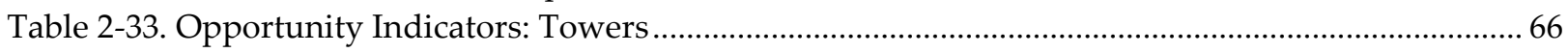

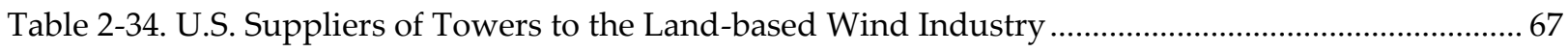

Table 2-36. Opportunity Indicators: Foundations and Substructures .......................................................... 70

Table 2-37. Modeled 2020 Requirements for Subsea Cable (distance in miles) ............................................ 71

Table 2-38. Opportunity Indicators: Inter-array Cable ........................................................................... 72

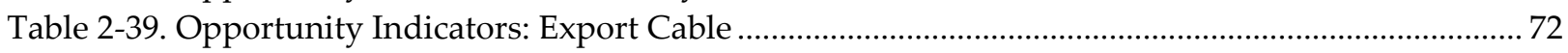

Table 2-40. Global Suppliers of Subsea Cable to the Offshore Wind Industry ............................................ 74

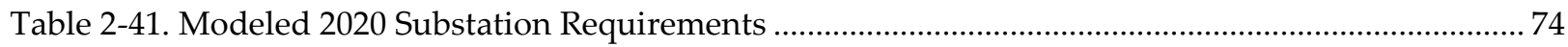

Table 2-42. Opportunity Indicators: Offshore Substations ............................................................................. 75

Table 2-43. Global Suppliers of Offshore Substations to the Offshore Wind Industry ................................. 75 


\section{NAVIGANT}

Table 2-44. Suggested Minimum Port Requirements for Serving the Offshore Wind Industry .................. 78

Table 2-45. Selected Port Requirements by Component ........................................................................ 78

Table 2-46. Incremental Port Infrastructure Investment Scenarios.............................................................. 81

Table 2-47. Average Economic Impacts of Port and Manufacturing Facility Investment by Scenario....... 83

Table 2-48. Estimated Labor Impacts by Type of Manufacturing Facility ..................................................... 86

Table 2-49. Summary of Modeled Annual Regional Demand (MW/year) by Scenario ................................ 86

Table 2-50. Regional Local Content Assumptions for Modeling Labor Requirements - Nacelles.............. 87

Table 2-51. Estimated Regional Direct Labor Impacts (FTEs) by Component and Scenario ...................... 88

Table 2-52. U.S. Census Occupations Sampled for Underutilization Analysis ............................................. 97

Table 2-53. Non-working Individuals with Skills Relevant to Offshore Wind by Region and State .......... 98

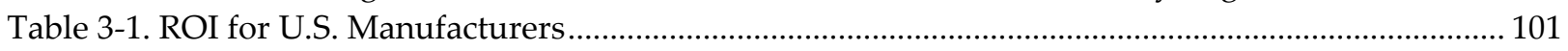

Table 3-2. Examples of Effective Offshore Wind Policies ...................................................................... 111

Table 4-1. Market Concentration and Barriers to Entry for Offshore Wind Components......................... 119

Table 4-2. WTG OEM Decision-Making Drivers for Evaluating Suppliers ................................................ 120

Table 4-3. Comparison of Major Land-based and Offshore Turbine Component Weights (tons) ............. 126

Table A-1. Project Capital Cost Breakdown Estimate................................................................................... 136

Table C-1. Technology Innovation Opportunities Considered for Ranking .............................................. 139

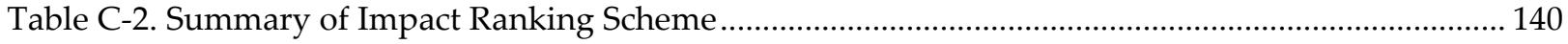

Table D-1. Technology Profile Key for Deployment Scenarios ................................................................. 142

Table D-2. Modeled Incremental Capacity Additions (MW) by Region: High-Growth Scenario............. 143

Table D-3. Modeled Incremental Capacity Additions (MW) by Region: Moderate-Growth Scenario..... 144

Table D-4. Modeled Incremental Capacity Additions (MW) by Region: Low-Growth Scenario.............. 145

Table D-5. Component and Material Assumptions Used to Estimate Market Sizes

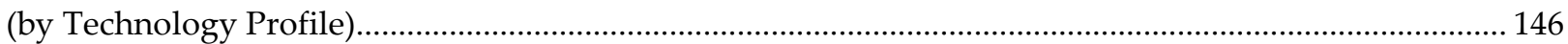

Table D-6. Detailed Estimate of Turbine Capital Costs by Component for the U.K. Market (2010£) ...... 150

Table D-7. Per-MW Turbine Component Costs for Hypothetical U.S. Offshore Wind Project .................. 151

Table D-8. Cost Assumptions Used to Estimate Component and Material Market Values....................... 152

Table F-1. Large Ports in the Continental U.S. and Vessel Size Capabilities ............................................... 155

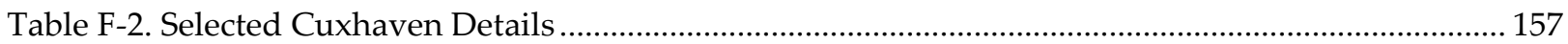

Table F-3. Offshore Wind-Related Industrial Activity at or Near the Port of Cuxhaven .......................... 157

Table F-4. Selected Bremerhaven Details ................................................................................................. 158

Table F-5. Offshore Wind-Related Industrial Activity at or Near the Port of Bremerhaven...................... 159

Table H-1. Regional Local Content Assumptions for Modeling Labor Requirements: Nacelles .............. 164

Table H-2. Regional Local Content Assumptions for Modeling Labor Requirements:

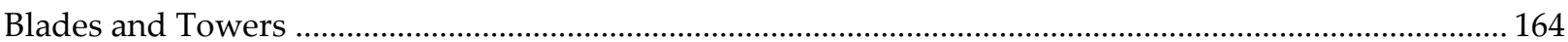

Table H-3. Regional Local Content Assumptions for Modeling Labor Requirements:

Substructures and Foundations. 


\section{NAVIGANT}

\section{Abbreviations}

$\begin{array}{ll}\text { ABP } & \text { Associated British Ports } \\ \text { AC } & \text { alternating current } \\ \text { AIAA } & \text { American Institute of Aeronautics and } \\ & \text { Astronautics } \\ \text { AWC } & \text { Atlantic Wind Connection } \\ \text { BLM } & \text { Bureau of Land Management } \\ \text { BOEM } & \text { Bureau of Ocean Energy Management } \\ \text { CEQ } & \text { Council on Environmental Quality } \\ \text { DC } & \text { direct current } \\ \text { DD } & \text { Direct Drive } \\ \text { DFIG } & \text { Doubly fed induction generators } \\ \text { DOE } & \text { Department of Energy } \\ \text { EA } & \text { environmental assessment } \\ \text { EERE } & \text { Energy Efficiency \& Renewable Energy } \\ \text { EIS } & \text { environmental impact statement } \\ \text { EPACT } & \text { Energy Policy Act of 2005 } \\ \text { EWEA } & \text { European Wind Energy Association } \\ \text { FERC } & \text { Federal Energy Regulatory Commission } \\ \text { FiT } & \text { Feed-in Tariff } \\ \text { FONSI } & \text { Finding of No Significant Impacts } \\ \text { FTE } & \text { full-time equivalent } \\ \text { GBS } & \text { gravity-based structure } \\ \text { GDP } & \text { gross domestic product } \\ \text { GE } & \text { General Electric } \\ \text { GW } & \text { gigawatt } \\ \text { GWEC } & \text { Global Wind Energy Council } \\ \text { HVDC } & \text { high-voltage direct current } \\ \text { ISO } & \text { independent system operator } \\ \text { ITC } & \text { investment tax credit } \\ \text { JEDI } & \text { Jobs \& Economic Development Impact } \\ \text { kV } & \text { kilovolt } \\ \text { kW } & \text { kilowatt } \\ \text { LCOE } & \text { levelized cost of energy } \\ \text { LIPA } & \text { Long Island Power Authority } \\ \text { m/s } & \text { meters per second } \\ \text { MI } & \text { mass impregnated } \\ & \end{array}$

MMS Minerals Management Service

MOU Memorandum of Understanding

mph miles per hour

MW megawatt

MWh megawatt-hour

NCF net capacity factor

NEPA National Environmental Policy Act

NIP National Infrastructure Plan

Nmi nautical mile

NREL National Renewable Energy Laboratory

NRIP National Renewable Infrastructure Plan

NYISO New York Independent System Operator

NYPA New York Power Authority

O\&M operations and maintenance

OEM original equipment manufacturer

OREC offshore wind renewable energy credit

OTB Offshore Terminal Bremerhaven

PEIS programmatic EIS

PJM Pennsylvania-Jersey-Maryland

PMG permanent magnetic generator

PPA power purchase agreement

PTC production tax credit

R\&D research and development

ReEDs Regional Energy Deployment System

REO rare earth oxide

ROI return on investment

RPS renewable portfolio standard

RTO regional transmission organization

SAP site assessment plan

UPR unsaturated polyester resin

WAB Wind Agency Bremerhaven

WEA Wind Energy Area

WTG wind turbine generator

XLPE cross-linked polyethylene 


\section{NAVIGANT}

\section{Introduction}

This report was produced on behalf of the Wind and Water Power Program within the U.S. Department of Energy's (DOE) Office of Energy Efficiency and Renewable Energy (EERE), as an award resulting from Funding Opportunity Announcement DE-FOA-0000414, entitled U.S. Offshore Wind: Removing Market Barriers; Topic Area 3: Manufacturing and Supply Chain Development.

The objective of the report is to provide an assessment of the domestic supply chain and manufacturing infrastructure supporting the U.S. offshore wind market. The report provides baseline information and develops a strategy for future development of the supply chain required to support projected offshore wind deployment levels. A brief description of each of the key chapters includes:

" Chapter 1: Offshore Wind Plant Costs and Anticipated Technology Advancements. Determines the cost breakdown of offshore wind plants and identifies technical trends and anticipated advancements in offshore wind manufacturing and construction.

» Chapter 2: Potential Supply Chain Requirements and Opportunities. Provides an organized, analytical approach to identifying and bounding the uncertainties associated with a future U.S. offshore wind market. It projects potential component-level supply chain needs under three demand scenarios and identifies key supply chain challenges and opportunities facing the future U.S. market as well as current suppliers of the nation's land-based wind market.

» Chapter 3: Strategy for Future Development. Evaluates the gap or competitive advantage of adding manufacturing capacity in the U.S. vs. overseas, and evaluates examples of policies that have been successful .

» Chapter 4: Pathways for Market Entry. Identifies technical and business pathways for market entry by potential suppliers of large-scale offshore turbine components and technical services.

The report is intended for use by the following industry stakeholder groups:

(a) Industry participants who seek baseline cost and supplier information for key component segments and the overall U.S. offshore wind market (Chapters 1 and 2). The component-level requirements and opportunities presented in Section 2.3 will be particularly useful in identifying market sizes, competition, and risks for the various component segments.

(b) Federal, state, and local policymakers and economic development agencies, to assist in identifying policies with low effort and high impact (Chapter 3). Section 3.3 provides specific policy examples that have been demonstrated to be effective in removing barriers to development.

(c) Current and potential domestic suppliers in the offshore wind market, in evaluating areas of opportunity and understanding requirements for participation (Chapter 4). Section 4.4 provides a step-by-step description of the qualification process that suppliers looking to sell components into a future U.S. offshore wind market will need to follow.

The report was produced by the Navigant Consortium, led by Navigant Consulting, Inc. Additional members of the Navigant Consortium include the American Wind Energy Association, the Great Lakes 


\section{NAVIGANT}

Wind Collaborative, Green Giraffe Energy Bankers, National Renewable Energy Laboratory (NREL), Ocean \& Coastal Consultants (a COWI company), and Tetra Tech EC, Inc. NREL's primary contributions were in the areas of technical trends and anticipated advancements (Chapter 1), regional deployment scenarios, and labor and economic impacts and opportunities (Chapter 2).

The team based its research on a variety of sources, including: a survey of industry participants; followup interviews with selected manufacturers, developers, and regulators; data leveraged from extensive primary research by Navigant's subsidiary BTM consult; and the collective experience of the members of the Navigant Consortium. The team also disseminated information and collected feedback at two offshore wind workshops that were co-located at major industry conferences. Readers should use care when reviewing the report's assumptions and models, as changes in the assumptions to reflect the uncertain evolution of the offshore wind market could lead to a wide range of reasonable values and outcomes. 


\section{NAVIGANT}

\section{Executive Summary}

U.S. policymakers, market actors, and the general public need a reasonable idea of the potential size and value of the domestic offshore wind supply chain, as well as the unique challenges and opportunities facing the development of an offshore wind market in the U.S. This report seeks to provide an organized, analytical approach to identifying and bounding those uncertainties; projecting potential component-level supply chain needs under three demand scenarios; and identifying key supply chain challenges and opportunities facing the future U.S. market and current suppliers of the nation's landbased wind market.

The total potential market value to the U.S. offshore wind supply chain is primarily a function of the market volume. In this study, market volume is fixed according to three scenarios. The value of the offshore wind industry to the supply chain is also impacted by changes in capital and operational costs. These costs are influenced by improvements in industry efficiency, fabrication technology, and wind turbine and foundation technology, as well as changes in material costs, market demand, commodity prices, and other factors.

The supply chain is evolving in a number of areas. Larger rotors allow for increased energy capture and production. Next-generation drivetrains will result in increasing turbine efficiency and reliability. Offshore wind towers in the future may employ concrete, composites, or other alternative materials to help combat corrosion and reduce steel content while simultaneously enabling taller hub heights. Shifting to High-Voltage Direct Current (HVDC) interconnection lines will reduce electrical losses, and higher voltage array cabling and larger turbines will allow for project layouts that minimize array cabling needs. Such advancements will help to reverse the recent trend of increasing offshore wind power prices, which are driven largely by a movement toward deeper-water sites located farther offshore; increased siting complexity; and higher contingency reserves that result from greater uncertainty when working in the offshore environment. As the industry matures and uncertainties are reduced, both capital costs and the levelized cost of electricity (LCOE) from offshore wind facilities are expected to plateau and trend downward.

The potential exists for significant domestic supply of a future U.S. offshore wind market. A lack of current U.S. offshore demand means no domestic manufacturing facilities are currently serving the offshore wind market. However, strong domestic supply capacity for the U.S. land-based wind market suggests that potential also exists to supply significant portions of the future offshore market domestically.

The magnitude of U.S.-based offshore wind manufacturing capacity will depend on turbine suppliers perceiving stable, long-term policy support and subsequent demand for offshore wind in the U.S. market. Three major barriers combine to have a dampening effect on the development of the U.S. offshore wind supply chain: the high cost of offshore wind energy; infrastructure challenges such as transmission and purpose-built ports and vessels; and regulatory challenges such as new and uncertain leasing and permitting processes. The result is that European and Asian suppliers who are currently supplying offshore wind turbines and components have a competitive advantage over their U.S. counterparts. The U.S. offshore wind industry faces a "chicken-and-egg" problem where plants will not 


\section{NAVIGANT}

be built unless the cost is reduced, and local factories (which will help bring down the cost) will not be built until there is a proven domestic market.

In deciding whether to enter the U.S. offshore wind market, potential suppliers will assess the supply and demand dynamics. Suppliers will assess whether the market will be large enough to warrant dedicating manufacturing capacity to offshore wind-related products. European-based suppliers will use demand forecasts to determine whether it is financially attractive to build manufacturing plants in the U.S. On the supply side, potential suppliers will assess the competitive rivalry, the barriers to entry, and the risk for each component. Market entry will be more attractive with higher fragmentation, lower barriers to entry, and lower overall risk.

\section{Chapter 1. Offshore Wind Plant Costs and Anticipated Technology Advancements}

Analysis of the capital costs and required labor inputs for offshore wind help illustrate the significant economic impact that a future U.S. offshore market could have. They also provide important context for evaluating the offshore wind industry supply chain and the opportunities that may arise for domestic suppliers of that market. This chapter describes the roles that various cost categories and equipment play in a project's installed cost and potential future directions in turbine and installation technologies that could affect those costs. Notably, this background serves as the basis for many of the assumptions about near- and long-term technology trends and equipment costs made in subsequent chapters of this report.

The Navigant Consortium's bottom-up analysis estimates a total baseline installed capital cost of approximately $\$ \mathbf{6 , 0 8 0} / \mathbf{k W}$. This study sought to provide a clear and replicable approach to estimating the capital cost breakdown for a hypothetical $500 \mathrm{MW}$ offshore wind plant with 3-5 MW turbines. As noted by Tegen et al (2012), however, the lack of any installed offshore projects in the U.S. subjects current estimates to a high level of uncertainty. Figure 1 shows the resulting breakdown of capital costs, with turbine equipment costs (including the nacelle, tower and blades) comprising the largest share (33 percent). Some offshore wind studies exclude construction financing costs from their capital cost analyses. To be able to compare costs across studies, the authors also performed a breakdown of capital costs prior to construction financing. Under this assumption, the turbine's share of the overall capital cost (before installation) jumps to 38 percent, while the foundation and substructure increases to 25 percent. 


\section{NAVIGANT}

Figure 1. Offshore Wind Plant Capital Cost Breakdown

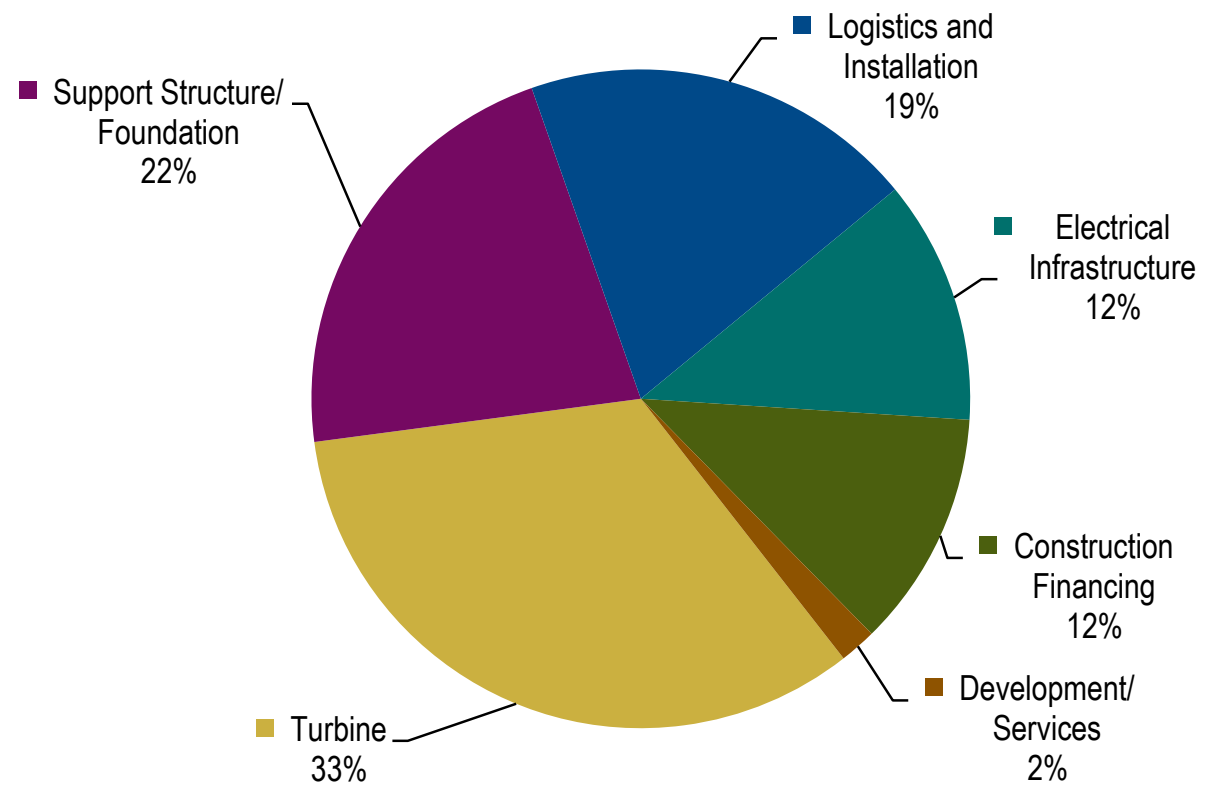

To gain additional insights into the anticipated future cost trajectories of the capital costs of offshore wind, the Navigant Consortium conducted a subjective ranking and prioritization exercise involving a list of approximately $\mathbf{5 0}$ offshore wind technology innovations and trends. Specific innovations or trends were considered for overall turbine design, rotors, drivetrains, power electronics, substructure and foundations, electrical infrastructure, and across vessel, port, manufacturing, and operations and maintenance strategies. The team quantified potential impacts against three criteria: the impact on future LCOE; the probability for success within specific periods in the future (within 5 years, within 10 years, and in more than 10 years); and each trend's ability to open new markets to development. A composite score from these three criteria also enabled the team to identify those innovations and trends with the anticipated greatest overall impact on the industry.

The results of the exercise suggest the following key findings:

» Greatest Overall Impact: Moving to larger turbines, first 5 to $7 \mathrm{MW}$ machines and then 7 to 10 MW machines, is likely to have the most significant overall impact on the industry (i.e., the highest composite score). The development of floating and transitional water-depth foundations is also expected to have a dramatic overall impact, with the probability of floating foundations increasing significantly over the next 10 years.

" Innovations with Near-term Impact: In addition to larger turbines and floating foundations, innovations and trends expected to have the greatest increase in probability over the next ten years (i.e., the increase in likelihood when moving from the $<5$ year timeframe to the 10 year timeframe) include superconducting generators and advanced tower materials. High-voltage circuitry and power converters, the development of active load-shedding rotor controls, 


\section{NAVIGANT}

movement to serial production volumes, and preemptive turbine response to changing wind conditions are also perceived to increase in likelihood in the five- to ten-year timeframe.

» Greatest Impact on Cost of Energy: When examining the different categories of innovation, cost of energy will most likely be impacted by innovations in turbines (e.g., turbine size and tolerance to adverse conditions), foundations, and substructures. Drivetrain (e.g., direct-drive generators) and manufacturing improvements are also expected to have substantial impacts on cost of energy. When examining individual innovations, floating foundations, direct-drive generators, advanced materials and dedicated, purpose-built vessels were ranked highly for cost impact, followed by larger turbines, increased production volumes, and HVDC trunk lines.

» Ability to Open New Markets: Innovations including floating substructures, hurricane tolerance, sea- and surface-ice tolerance, and transitional water-depth foundations are anticipated to have the greatest ability to open up new markets to offshore wind technology.

Given the breadth of ongoing research and innovation opportunities, there could be significant changes in the supply chain as the offshore wind industry grows and matures. For example, firms specializing in monopile foundation production may need to diversify into pipe production for jacket structures, and subsequently floating assemblies, should they desire to continue to serve the offshore wind sector. However, the technology ranking exercise demonstrates that progress in the industry will take time; many innovations see a notable increase into their potential impact as one moves five, ten, or even more than ten years into the future.

Moreover, many of the more promising innovations such as scaling to larger turbines, moving to serial production, and developing increasingly specialized installation vessels are likely to manifest as incremental changes to conventional industry approaches. These trends bode well for suppliers considering an entry to the market, as they suggest that dramatic changes in the makeup of the industry in the near term are unlikely. They also suggest that the competitive advantages will go to firms that can envision and implement process improvements or work within the existing technology spheres to advance the state of the art.

\section{Chapter 2. Potential Supply Chain Requirements and Opportunities}

While the U.S. is not yet an established player in the offshore wind market, the U.S. land-based wind market has historically been a focal point for many wind turbine manufacturers and suppliers. China and the U.S. are the world's two largest markets in terms of installed wind power capacity (BTM 2012). Following dramatic growth in installations, leading European turbines and key components suppliers shifted part of their manufacturing capacities to these two countries. In addition, many of the large European turbine suppliers are increasingly outsourcing components and materials to Asia, particularly to China, which has the world's largest wind power equipment manufacturing base. Although some original equipment manufacturers (OEMs) hesitate to move away from established suppliers due to concerns over quality, economic pressures from declining turbine prices are driving manufacturers to accept higher risks to remain competitive (BTM 2011).

The potential exists for significant domestic supply of a future U.S. offshore wind market. A lack of current U.S. offshore demand means no domestic manufacturing facilities are currently serving the 


\section{NAVIGANT}

offshore wind market. However, recent estimates indicate that about $67 \%$ of land-based wind turbine content (as a fraction of total equipment-related turbine costs) installed in the U.S. was domestically sourced in 2011 (Wiser 2012b). ${ }^{1}$ This strong domestic supply capacity for the U.S. land-based wind market suggests that potential also exists to supply significant portions of the future offshore market domestically, particularly among global leaders in the offshore wind supply chain that have already established a presence in the U.S. to serve the country's land-based demand.

A future U.S. offshore wind market would have to compete with the European offshore market as well as emerging land-based markets for manufacturers' investment dollars. Recently, manufacturers have been facing important strategic decisions in diversifying their markets due to uncertainty in the U.S. market and the challenge of overcapacity in China. As a result, many suppliers are moving into new strategic markets such as India, Eastern Europe, Latin America, and the U.K., while focusing their offshore efforts in particular in the U.K. and Germany. Recently launched local-content requirements in Brazil, Canada, and India are also encouraging such a trend. Each of these global markets - whether for land-based or offshore wind-represent direct competition for manufacturers' potential investments in a future U.S. offshore market.

A trend toward larger components intended solely for the offshore wind market may require a significant ramp up in new capacity. Recent studies suggest there is enough capacity in the supply chain to cater to expected growth in the land-based wind market, with some potential concerns over supplies of rare earth elements (for permanent magnet generators) and larger-sized bearings and forgings (BTM 2011). For the offshore market, however, the recent introduction of multi-MW turbines (mostly 5-6 MW) by turbine manufacturers in both Europe and China increases such supply concerns over the strategic components (e.g., bearings and forgings) for these larger turbines. This is partly because it takes time for the supply chain to prepare for mass production of such large parts that can meet OEMs' increased quality requirements for offshore turbines.

In some cases, U.S. manufacturing facilities operating at part load may have opportunities to shift or retool some capacity to serve the offshore market, particularly if those facilities are well-positioned near coasts where offshore projects are being developed. For facilities located further inland, logistical concerns associated with larger components (e.g., feasibility and cost of overland transportation) may preclude the plant from serving as a cost-effective option to OEMs. In the case of shifting or adding capacity for the offshore market, manufacturers will require additional investments and will need to verify that they can meet OEMs' stringent quality requirements for offshore turbine components. The duration of such facility ramp-up and product qualification may be lessened for U.S.-based facilities that are directly linked to OEMs already serving the offshore wind market in Europe or Asia.

The development of U.S.-based offshore wind manufacturing capacity may also depend on turbine suppliers perceiving stable, long-term support and demand for offshore wind in the U.S. market. In addition, suppliers may require access to (or need to train) a sufficiently skilled workforce and appropriate logistical and installation capabilities. Manufacturers will likely weigh these factors in the context of the global offshore market. For example, under a moderate-growth scenario, the U.S. would

\footnotetext{
${ }^{1}$ Specific percentages of domestic sourcing versus imports on a component-by-component basis are not available due to limited trade reporting requirements (Wiser and Bollinger 2011). 


\section{NAVIGANT}

add approximately 3.5 GW of offshore capacity by 2020. Some forecasts expect same-year offshore capacity additions in Europe to approach 10 GW (BVG 2012) while China has a goal to install 30 GW of cumulative offshore capacity by 2020 (Global Wind Energy Council (GWEC) 2012). While other forecasts show a somewhat slower increase in global offshore capacity additions, the European market's head start and momentum is more likely to continue to attract near-term investments in offshore manufacturing. Even with its established track record and ability to share resources across several countries, the European market continues to face a short supply of skilled staff that are trained and capable of installing and maintaining offshore wind projects.

The Navigant Consortium evaluated domestic supply chain opportunities using three scenarios that estimate potential offshore market demand growth in each of four main regions (the Atlantic Coast, Great Lakes, Gulf Coast and Pacific Coast) with a total market size of 1 to 7 GW in 2020 and 10 to 54 GW in 2030. The primary goal of these scenarios is to provide a basis for comparing the effects on supply chain requirements of changes in either technological advancements or increasing demand for offshore wind. The team worked with the DOE and other teams working on DOE-funded offshore wind research to optimize the differences between scenarios in a way that would best illustrate the impact of those changes. Readers should note that none of the scenarios are intended as a forecast of future demand for offshore wind. Rather, the scenarios estimate realistic rates of regional capacity growth under varying sets of assumptions for cumulative demand in each region by 2020 and 2030. Table 1 lists these cumulative capacity targets for each region in each of three scenarios: high growth, moderate growth, and low growth.

Table 1. Regional Deployment Scenario Targets and Technology Profiles

\begin{tabular}{|c|c|c|c|c|c|c|c|}
\hline \multirow{2}{*}{\multicolumn{2}{|c|}{ Scenario }} & \multicolumn{2}{|c|}{$\begin{array}{l}\text { High Growth } \\
54 \mathrm{GW} \text { by } 2030\end{array}$} & \multicolumn{2}{|c|}{$\begin{array}{l}\text { Moderate Growth } \\
28 \mathrm{GW} \text { by } 2030\end{array}$} & \multicolumn{2}{|c|}{$\begin{array}{l}\text { Low Growth } \\
10 \mathrm{GW} \text { by } 2030\end{array}$} \\
\hline & & 2020 & 2030 & 2020 & 2030 & 2020 & 2030 \\
\hline \multicolumn{2}{|c|}{$\begin{array}{l}\text { Total Capacity Deployed } \\
\text { by Milestone Date (in GW) }\end{array}$} & 7 & 54 & 3.5 & 28 & 1 & 10 \\
\hline \multirow{4}{*}{$\begin{array}{l}\text { Regional } \\
\text { Distribution }\end{array}$} & Atlantic & 4 & 28 & 2.0 & 12 & 1 & 8 \\
\hline & Great Lakes & 1 & 6 & 0.5 & 4 & 0 & 1 \\
\hline & Gulf Coast & 1 & 5 & 0.5 & 4 & 0 & 1 \\
\hline & Pacific Coast & 1 & 15 & 0.5 & 8 & 0 & 0 \\
\hline
\end{tabular}

Source: Navigant 2012

The opportunity for suppliers to enter a U.S. offshore wind market is highest in foundations/substructures, towers, blade materials, and power converters and transformers. Navigant considered the relative opportunity for suppliers of each component based on three key factors: 1) the expected timing of sufficient demand to support domestic manufacturing under a moderate-growth scenario; 2) the probability of shortfall in global offshore supply through 2015; and 3) the ease of transferability of land-based supply to serving the offshore wind market. Table 2 presents the relative level of opportunity for domestic suppliers of each component by 2020 using a stoplight scheme (green = favorable; yellow = moderate/cautious; red = high-risk). 


\section{NAVIGANT}

Table 2. Summary of Near-Term (2020) Domestic Supply Chain Opportunities under a Moderate-Growth Scenario

Component Opportunity

Moderate

Wind Turbine Assembly

Gearboxes and Generators

Moderate

Power Converters and

Transformers

Bearings

Castings and Forgings

Pitch and Yaw Systems

Blades

Blade Materials: Resin and

Glass/Carbon Fiber

Towers

Foundations/ Substructures

Substations

Array Cable

Export Cable

Moderate

Moderate
Notes

Despite potential global shortages for larger turbines (> $6 \mathrm{MW}$ ), a new nacelle assembly facility represents a moderately risky near-term opportunity. However such facilities are likely as firm demand develops in each region.

Established overseas supply and uncertainty on the future design of offshore turbines (i.e., conventional versus direct drive) weakens the near-term opportunity for U.S.-based gearbox or generator manufacturing. The best opportunity may lie with established suppliers with coastal facilities who can serve both the U.S. and overseas offshore markets.

The diversity of the power electronics market gives suppliers flexibility to shift capacity to other uses if offshore wind demand falters. Notably, U.S. firms already serve the offshore power converter market. Offshore transformer demand is currently met by European firms; however, U.S. supply is likely as domestic demand materializes.

Limited transferability and large upfront investments for manufacturing larger bearings create risk. However, growing global demand and a limit on the number of qualified suppliers may offset that risk for experienced manufacturers. Concern exists over the availability of large-scale forgings; however, new capacity is emerging in Asia. Large upfront investments in the equipment required for supplying larger components poses a risk if demand falls short.

Offshore wind turbines will require larger units than are currently manufactured for land-based demand, but facilities should be able to shift capacity. Existing firms serving the overseas market may hinder entry of new competitors.

Despite the slow ramp up of adequate demand, the need for manufacturing proximal to final project sites creates a moderate near-term opportunity for blade manufacturing.

High transferability, the ability to serve global markets, and potential shortfalls in global supply creates a relatively strong opportunity for suppliers who have relationships with manufacturers or can meet quality requirements.

While adequate demand to support a dedicated facility may not occur until 2020 or later, risk is lower for experienced manufacturers that can serve both landbased and offshore demand from a single coastal facility.

Logistics encourage domestic supply; however, limited transferability poses some risk to investment should consistent demand fail to develop. Synergies may exist with the offshore oil and gas market.

Near-term supply will likely be met by established European firms; however, several have a U.S. presence.

Current global supply is adequate to meet anticipated demand. However, the ability to convert land-based supply to meet undersea requirements could provide near-term opportunities for facilities already located on coasts.

The supply chain faces a potential bottleneck for meeting planned European demand (assuming projects meet target dates). However, reliance on the offshore wind market poses a significant risk for near-term investment. 


\section{NAVIGANT}

Based on the three growth scenarios, the estimated nationwide employment impacts for domestic manufacturing of major components (turbines, towers, blades and foundations) for the U.S. offshore wind market range from 2,000 FTE jobs (low growth of $10 \mathrm{GW}$ cumulative capacity) to almost 14,000 FTE jobs (high growth of $\mathbf{5 4} \mathrm{GW}$ cumulative capacity) by 2030. These job estimates reflect the expected timing and share of demand met through imports versus domestic supply. They do not include jobs related to subcomponents and materials or project development and operations.

Estimates for the economic impacts of upgrades to a single port that wishes to serve the U.S. offshore wind market include incremental employment ranging from 600 to over 17,000 FTE jobs and incremental state GDP ranging from $\$ 48$ million to $\$ 1,333$ million. These estimates depend largely on the extent of upgrades the port makes and whether it also constructs co-located component manufacturing facilities. In a scenario where a port makes moderate upgrades and adds a single component manufacturing facility, it could generate up to an estimated 6,000 total FTE jobs, with $\$ 843$ million circulating through the economy and \$449 million in incremental state GDP. Most of these new positions (3,300 jobs) are directly related to the development of port facilities. Materials suppliers, subcontractors, consultants, and others in the supply chain provide an additional 900 jobs, while the remaining 1,600 jobs are in industries that capture local expenditures.

\section{Chapter 3. Strategy for Future Development}

The LCOE of an offshore wind plant that is sourced domestically (i.e., excluding transportation costs) is estimated to be approximately $\$ 197 / \mathrm{MWh}$ in 2015 and approximately $\$ 167 / \mathrm{MWh}$ in 2030 . LCOE estimates are used in this report to assess the potential value of the total offshore supply chain and key component groups under various industry growth scenarios. These baseline estimates may not reflect the long term targets of DOE, NREL, the Crown Estate (U.K.) and other organizations supporting initiatives intended to reduce offshore wind LCOE through technology innovation and market development. These LCOE estimates are based on the following inputs:

» Total current capital cost of approximately $\$ 6,080$ per $\mathrm{kW}$ installed

» Initial operations cost of approximately $\$ 135,000$ per $\mathrm{kW}$ per year

» Costs are likely to decrease by at least $25 \%$ by 2030

» Average Net Capacity Factor (NCF) is initially $40 \%$ and will grow slowly over time

Since there is very little offshore wind manufacturing in the U.S., most of the components will initially be sourced from Europe. Transportation costs for offshore wind turbine components sourced from Europe are expected to be $17 \%$ of the turbine costs. Therefore, the LCOE of a U.S. offshore wind plant that is sourced in Europe is expected to be $17 \%$ higher than the domestic cost, or approximately $\$ 205 / \mathrm{MWh}$ in 2015 and approximately \$174/MWh in 2030.

Research shows that a demand of 100 to 150 turbines per year (or 500 to $800 \mathrm{MW}$ per year) for a minimum of five years may be required to justify an investment in a full-scale turbine manufacturing plant. While a U.S.-based manufacturer will have a cost advantage over a European-based manufacturer due to savings in transportation costs, a manufacturer will not build a factory in the U.S. unless there is a stable and growing U.S. offshore wind market. The Navigant team estimates that a regional market demand of approximately $300 \mathrm{MW}$ per year is required to support a factory that manufactures a single 


\section{NAVIGANT}

component such as towers or blades. However, these market-driven trigger points are only part of the decision criteria that affect a manufacturer's decision to invest; other criteria include levels of competition, geography constraints, and the ability to serve additional markets such as land-based wind or other industries.

The authors developed three scenarios to estimate the timing of factories being built in the U.S. that are dedicated to offshore wind. Under a low-growth scenario, a single component plant could be started up in the Atlantic region by 2021, when that market reaches $300 \mathrm{MW}$ per year. A full wind turbine generator (WTG) manufacturing facility could be started up by2027, when the Atlantic market reaches $800 \mathrm{MW}$ per year. Recognizing that investment decisions will not be made purely based on these market trigger points, percentages of domestic sourcing were estimated to slowly ramp up from $40 \%$ in 2015 to $53 \%$ in 2030. The LCOE based on a blended average of U.S. and European sourcing is expected to decrease from \$202/MWh in 2015 to $\$ 170 / \mathrm{MWh}$ in 2030. Although certain factors may cause LCOE to decrease more rapidly, particularly in the high-growth scenario, this analysis is based on a common LCOE forecast for all scenarios.

Under a moderate-growth scenario, a single component plant could be started up in the Atlantic region by 2018, the Pacific region by 2021, and the Great Lakes and Gulf Coast regions by 2023, when those markets reach $300 \mathrm{MW}$ per year. A full WTG manufacturing facility could be started up in the Atlantic region by 2023 and in the Pacific region by 2026, when those markets reach 800 MW per year. The resulting percentages of domestic sourcing for the moderate-growth scenario, after adjustments for smoothing the timing of investment decisions, range from $40 \%$ in 2015 to $70 \%$ in 2030 .

Under a high-growth scenario, a single component plant could be started up in the Atlantic region by 2015, the Great Lakes and Pacific regions by 2020, and the Gulf Coast region by 2023, when those markets reach $300 \mathrm{MW}$ per year. A full WTG manufacturing facility could be started up in the Atlantic region by 2019 and in the Pacific region by 2022, when those markets reach 800 MW per year. The resulting percentages of domestic sourcing for the high-growth scenario, after adjustments for smoothing the timing of investment decisions, range from $40 \%$ in 2015 to $79 \%$ in 2030.

A survey of industry participants, combined with the authors' other research, indicates that there are three major categories of barriers to development of the U.S. offshore wind market.

1) High cost of offshore wind energy. Offshore wind energy currently has a higher LCOE than conventional and other renewable technologies.

2) Infrastructure challenges. The specialized infrastructure required to install and operate offshore wind farms most cost-effectively, such as expanded transmission and purpose-built ports and vessels, does not currently exist in the U.S.

3) Regulatory challenges. Offshore wind projects in the U.S. are facing new and uncertain leasing and permitting processes.

In interviews, industry stakeholders stated that in order to promote offshore wind manufacturing and supply chain growth, efficient and effective state and federal policies are needed to overcome barriers in all of these areas. 


\section{NAVIGANT}

The authors identified seven policies that have improved the competitiveness of offshore wind vs. other technologies based on research of various jurisdictions. These policies were effective in addressing high initial cost. While the policies do not reduce the cost of offshore wind per se, they help level the playing field so that its LCOE is closer to long-established and previously subsidized competing technologies:

1) Mandatory long-term power contracts

2) Offshore Renewable Energy Credits (ORECs)

3) Investment Tax Credit (ITC) for developers

4) Production Tax Credit (PTC)

5) Low-interest loans and loan guarantees to developers

6) Accelerated depreciation for developers

7) State Feed-in Tariffs (FiTs)

European policies to promote domestic manufacturing were long-term which gave manufacturers and their investors' confidence that the market is here to stay. A stop-start policy may be useful in stimulating year-to-year demand, but there is too much uncertainty for a manufacturer to invest potentially hundreds of millions of dollars.

The authors identified five policies to deal primarily with transmission infrastructure. They are based on some existing state and federal programs and policies plus recommendations made in recent policy studies such as the Great Lakes Wind Collaborative's 2011 study Transmission-Related Policy Options to Facilitate Offshore Wind in the Great Lakes (Balachander et al, 2011).

1) Establish clear permitting criteria and guidelines for transmission planning and siting

2) Establish clear and consistent cost allocation and cost recovery mechanisms for transmission development

3) Promote utilization of existing transmission capacity reservations to integrate offshore wind

4) Designate offshore wind energy resources zones for targeted grid investments

5) Offshore transmission planning should take into account public policy mandates, such as Renewable Portfolio Standards (RPSs)

Based on interviews and other research, the authors identified effective state and federal offshore wind regulatory policies in the following subcategories: site leasing, permitting, and operations.

1) Site Leasing: the BOEM "Smart from the Start" process, in which regulators identify suitable lease areas based on an initial environmental review process, conduct early environmental reviews, and coordinate federal and state permitting of specific wind farm and cables. Initiating earlier environmental reviews expedites the lease and permit process because National Environmental Policy Act (NEPA) reviews are the most time consuming aspects of the approval process. 


\section{NAVIGANT}

2) Permitting: use programmatic environmental reviews for a broad geographic area followed by more limited, detailed EISs or Environmental Assessments (EAs) for specific individual projects

3) Operations: self-monitoring of environmental and safety compliance by developers/operators

The most critical near-term need is to stimulate demand (i.e., address the high cost of offshore wind). A portfolio approach that incorporates multiple policy elements has shown to be effective in the U.S. land-based wind market, which has been stimulated through a mix of Power Purchase Agreements (PPAs) with PTCs, ITCs, and RPSs. However, other examples such as the Feed-in Tariff, which many European countries have used to stimulate offshore wind demand, have also proven to be effective. Secondary to creating demand is the need to ensure the demand can be filled. Policies that streamline siting and permitting processes and put in place critical infrastructure components such as transmission and ports support meeting demand.

In the medium to long term, there is a need to instill confidence in the U.S. market. Manufacturers are unlikely to build new U.S.-based manufacturing capacity without confidence in U.S. long-term, stable demand. Only after the U.K. and Germany signaled that long-term demand would exist did manufacturers begin to build port-side manufacturing capacity in those countries, with the help of manufacturing incentives such as tax credits.

State and federal governments often provide R\&D investment support as a long-term policy. R\&D support helps to drive down the total installed system cost and the LCOE, which is critical to the longerterm success of offshore wind market development.

\section{Chapter 4. Analysis of Market Entry Pathways}

In deciding whether to enter the U.S. offshore wind market, potential suppliers will assess the supply and demand dynamics before establishing dedicating manufacturing. Suppliers will assess whether the market will be large enough to warrant dedicating manufacturing capacity to offshore wind-related products. European-based suppliers will use demand forecasts to determine whether it is financially attractive to build manufacturing plants in the U.S. On the supply side, potential suppliers will assess the competitive rivalry, the barriers to entry, and the risk for each component. Market entry will be more attractive with higher fragmentation, lower barriers to entry, and lower overall risk.

The greatest driver for the development of a U.S.-based offshore wind supply chain is credible evidence of a strong and sustainable U.S. offshore wind market. Until there is greater certainty around future demand in the U.S. offshore market, major turbine components will likely come from Europe or Asia. OEMs and major suppliers will likely be unwilling to invest in new, offshore-specific manufacturing capacity without market certainty.

If the U.S. offshore wind market were expected to show steady long-term growth, major turbine components would likely be built in the U.S. When the U.S. land-based wind market began to show strong growth, OEMs and major suppliers invested in U.S. manufacturing facilities. Given the size and relative lack of intellectual property in towers, they are often the first components manufactured locally. Growing blade sizes will also necessitate local manufacturing in a growing U.S. market. 


\section{NAVIGANT}

While the majority of land-based wind manufacturing facilities are located in the wind-heavy Midwest, offshore facilities will be located near ports, as they have been in Europe. While the domestic content in wind turbines deployed in the U.S. has risen, some components will continue to be imported. High-value, complex nacelle internals would likely be the last components to be sourced locally.

To meet Jones Act requirements, a thriving U.S. market could spark construction of U.S.-built vessels. Specialized U.S.-built and -flagged vessels would greatly facilitate efficiency of the offshore construction process in U.S. waters. As converted oil and gas barges will be insufficient for offshore wind over the long run, U.S. shipbuilders will construct wind-specific vessels. These vessels will be similar to those currently being produced in China, South Korea, and the UAE.

Domestic suppliers of offshore wind turbine and balance of plant components will be more likely to enter the U.S. offshore market in areas where the competitive rivalry is less fierce and where barriers to entry and risk are relatively lower. The entry of new suppliers into a U.S. offshore wind supply chain will be very difficult for the majority of key component areas. In 10 of 14 areas, including blades, gearboxes, bearings, and foundations, market concentration is high as are entry barriers. High market concentration refers to an environment in which a relatively small number of suppliers supply a relatively large proportion of market demand. The areas providing the most promise for potential new entrants are towers (low market concentration and market entry barriers) and generators (low market concentration and medium market entry barriers). While the market entry barriers for castings and forgings are high, market concentration in both areas is medium.

Wind turbine OEMs will take into account numerous criteria when evaluating potential suppliers for a U.S. offshore wind industry. The Navigant Consortium have categorized these criteria into primary and secondary. Among the primary criteria are:

1) Track record in wind or similar sector

2) High quality and reliability

3) Available capacity

4) Solid financial footing

5) Competitive pricing

6) On-time delivery

The secondary criteria include:

1) Flexibility in production schedules and ability to meet short lead times

2) Robust service organization

3) Willingness to engage in joint development with OEM

4) Technology development

5) Localization/geographic footprint 


\section{NAVIGANT}

Suppliers looking to sell components into a future U.S. offshore wind market will need to follow a similar qualification process found in other manufacturing sectors. While different turbine manufacturers will likely use slightly varied processes, the following steps articulate a typical supplier qualification process:

1) Supplier and manufacturer make initial contact

2) Pre-qualification

3) Confidentiality agreement

4) OEM sends turbine specifications to supplier

5) Auditing

6) Prototyping

7) Field testing

8) Serial production

9) Monitoring

Market barriers faced by new suppliers in the offshore wind industry fall into two primary categories: production planning and production facilities. In terms of production planning, the offshore wind sector has three major barriers to entry: low production volumes, batch production requirements, and widely fluctuating demand. The wind sector and the offshore segment in particular require lower volumes than many other manufacturing sectors. This makes achieving economies of scale challenging. Suppliers may be reluctant to enter the market as shifting production capacity away from larger volume products may prove financially unattractive. The wind sector also requires a relatively small batch production process with more ordering and receiving cycles, leading to high inventory turnover. The nimbleness required for this type of production can be challenging for many suppliers. Lastly, the incentive-driven nature of the wind sector has often created boom and bust cycles. These large swings in demand for wind turbines make production planning difficult. Suppliers do not want to be left with extra inventory. OEMs do not want to lack the necessary components to fill their orders.

In terms of production facilities, the offshore wind sector also has three major barriers to entry: equipment size, capital requirements, and logistics challenges. Offshore turbines are typically larger than land-based turbines and are growing even larger. Suppliers must have manufacturing equipment large enough to produce these large components. This can often prove difficult as some castings and forgings can weigh over 10 tons. Many potential suppliers could also find it difficult to secure the capital necessary to retool a manufacturing plant for the production of offshore wind components. Lending institutions may be reluctant to make a loan for capital improvements without firm orders. Lastly, in the offshore wind sector, a supplier's location is even more critical than in the land-based sector as components are typically larger. Nacelle assembly and pre-assembly of the rotor typically occur in coastal areas at or near ports to reduce transportation costs. Suppliers not near ports, like many found in the U.S. Midwest, will need to conduct transportation studies to determine whether it is technically and financially feasible to deliver the components to port locations. 


\section{NAVIGANT}

As mentioned in other parts of this report, strong and consistent demand for offshore wind projects is the best antidote for most of the supply chain barriers. The previous chapter, Strategy for Future Development, discusses approaches for driving demand. These approaches deal with lowering the cost of offshore wind, lowering or removing technical and infrastructure-related challenges, and removing regulatory challenges involved with siting and permitting of projects.

Thriving U.S. and global markets will create sufficient demand for new suppliers to enter the market. Consistent policy will reduce the market fluctuation and supply chain disruptions seen with the onagain, off-again application of the PTC. Strong and consistent demand will also make it more attractive for banks to lend to suppliers who want to invest in new equipment to build the larger components required by the offshore market. With a strong backlog of orders, suppliers will find it attractive to build port-side manufacturing facilities to reduce transportation costs and improve delivery times. Finally, strong demand for offshore components will allow some suppliers to capture economies of scale, reducing costs and thus their delivered prices. 


\section{NAVIGANT}

\section{Offshore Wind Plant Costs and Technology Advancements}

This chapter provides important context for evaluating the offshore wind industry supply chain and the opportunities that may arise for suppliers of a future U.S. market. In particular, it describes the role each equipment category plays in a project's installed cost and potential future directions in turbine and installation technologies that could affect those costs. Notably, this background serves as the basis for many of the assumptions about near- and long-term technology trends and equipment costs made in subsequent chapters of this report. Readers should consider this information when reviewing the report's assumptions and models, as the uncertain evolution of the offshore wind market could lead to a wide range of reasonable values and outcomes. The chapter is broken down as follows:

» Chapter 1.1 presents a breakdown of the capital costs for a typical offshore wind plant, including an estimate of various components' share of turbine costs. This breakdown provides context to the role that individual systems and components play in the overall cost of energy.

" Chapter 1.2 identifies the key technical trends and anticipated advancements facing the offshore wind market in the coming years, including their potential influence on project costs and supply chain requirements.

Figure 1-1 summarizes the key findings from this chapter.

Figure 1-1. Summary of Key Findings for Chapter 1

\section{Summary of Key Findings: Offshore Wind Plant Costs and}

\section{Technology Advancements}

» Navigant's baseline cost assumption for a generic $500 \mathrm{MW}$ plant using $5 \mathrm{MW}$ turbines was $\sim \$ 6,000 / \mathrm{kW}$ for U.S. offshore wind.

» Pre-installation costs for turbines, support structures, and foundations collectively represent $55 \%$ of the capital cost for a 500-MW offshore wind farm. Much of this cost is directly tied to the cost of equipment. This increases to $68 \%$ if the cost of construction financing is excluded.

» The cost of construction financing, therefore, has a significant impact on the total capital cost of offshore wind.

» A structured ranking exercise of potential technology advancements to lower life cycle costs identified the following key findings:

- Scaling to larger turbines (first to 5-7 MW machines and subsequently to 7-10 MW machines) is likely to have the most substantial impact on the industry.

- The development of floating and transitional water-depth foundations is also expected to have a substantial impact and is expected to become increasingly likely over time.

- Individual innovations anticipated to have the greatest impact on reducing the cost of energy include floating foundations, direct drive generators, advanced materials, and dedicated, purpose-built vessels. These were followed by larger turbines, increased production volumes, and HVDC trunk lines. 


\section{NAVIGANT}

\subsection{Offshore Wind Plant Cost Breakdown}

This section presents an estimate of the overall plant capital cost breakdown as well as relative share and per-MW cost estimates of the various equipment and components comprising a generic 5-MW offshore wind turbine.

\subsubsection{Methodology}

Any review of recent offshore wind cost studies immediately highlights the fact that plant capital cost estimates can vary based on several factors. In addition to varying assumptions about project characteristics (e.g., the number and size of turbines, water depth, and distance to shore), turbine equipment costs are subject to changing market conditions. Since the turbine costs are the single largest capital cost category, such changes can significantly affect the cost breakdown. Development and supply chain-related costs may also vary depending on regional permitting requirements and equipment transportation distances, respectively. Finally, industry analysts have yet to agree upon any single cost reporting structure, and the costs included in various categories may differ between reports. In particular, some reports exclude construction financing costs, which can represent a substantial cost component.

In the face of these challenges, this study seeks to provide a clear and replicable approach to the plant capital cost breakdown. First, the team determined a set of generic baseline characteristics for an offshore wind farm likely to be installed in U.S. waters within the next five years. These assumptions, listed in Table 1-1, consider both recent industry and technology trends as well as the assumptions used by other recent cost studies.

Table 1-1. Baseline Assumptions for Example Offshore Wind Farm

\begin{tabular}{lc}
\hline Characteristic & Assumption \\
\hline Plant Capacity & $500 \mathrm{MW}$ \\
\hline Turbine Size & $5 \mathrm{MW}$ \\
\hline Distance to Staging Port & $\leq 100$ miles \\
\hline Distance to Interconnection & $\leq 50$ miles \\
\hline Distance to Servicing Port & $<30$ miles \\
\hline Water Depth & 20 to 30 meters \\
\hline Installed Capital Cost & $\$ 6,080 / \mathrm{kW}$ \\
\hline
\end{tabular}

The Navigant Consortium used a bottom-up approach, estimating potential capital expenditures for each of 29 individual line items that appear in NREL's Jobs and Economic Development Impact (JEDI) model. Data was collected from recent market and supply chain studies, vendor quotes, and the team's collective experience from recent industry projects. Once data was gathered for each cost category, the Navigant Consortium selected the data points for each line item that were most representative of the hypothetical project described in Table 1-1. The team's bottom-up analysis estimates a total installed capital cost of approximately $\$ 3$ billion or $\$ 6,080 / \mathrm{kW}$.

The team used a review of recent literature (Arwas et al 2012; BVG Associates 2010a, 2010b, 2011; NREL 2010, 2012; Tegen et al 2012) to verify the reasonableness of our estimates. As discussed by Tegen, et al 


\section{NAVIGANT}

(2012), however, the lack of any installed offshore projects in the U.S. subjects these estimates to a high level of uncertainty. To facilitate comparisons with these other studies and enable future updates to these estimates, we grouped the above costs into each of six high-level categories. The full list of these categories and assumptions appears in Appendix A. In response to the discrepancy among other studies' inclusion of construction financing costs, we have calculated the capital cost breakdown both with and without those financing requirements.

\subsubsection{Plant Capital Cost Breakdown}

Figure 1-2 shows the resulting all-in capital cost breakdown for the hypothetical $500 \mathrm{MW}$ offshore wind farm. As shown, the turbine equipment costs (including the nacelle, tower and blades) comprise the largest share (33 percent) of the capital cost, with the foundation and substructure representing an additional 22 percent.

Figure 1-2. Offshore Wind Plant Capital Cost Breakdown

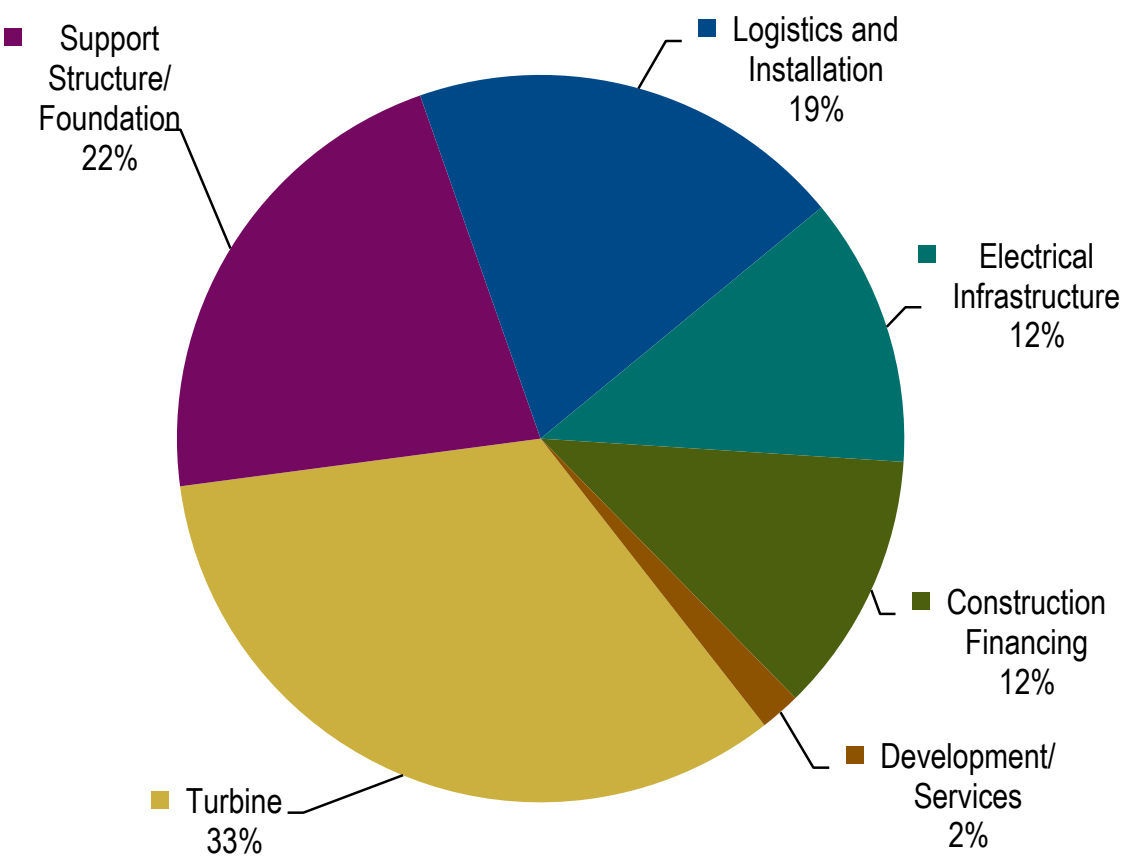

Notably, the bottom-up estimates conducted for this study resulted in construction finance-related costs that comprise 12 percent of the overall plant capital cost (see Appendix A for a detailed list of these costs). As previously mentioned, however, some offshore wind studies exclude construction financing costs from their capital cost analyses. Figure 1-3 presents this study's breakdown of overnight capital costs (which exclude construction financing). Under this assumption, the turbine's share of the overall capital cost (before installation) jumps to 38 percent, while the foundation and substructure increases to 25 percent. 


\section{NAVIGANT}

Figure 1-3. Offshore Wind Plant Capital Cost Breakdown (without Construction Financing)

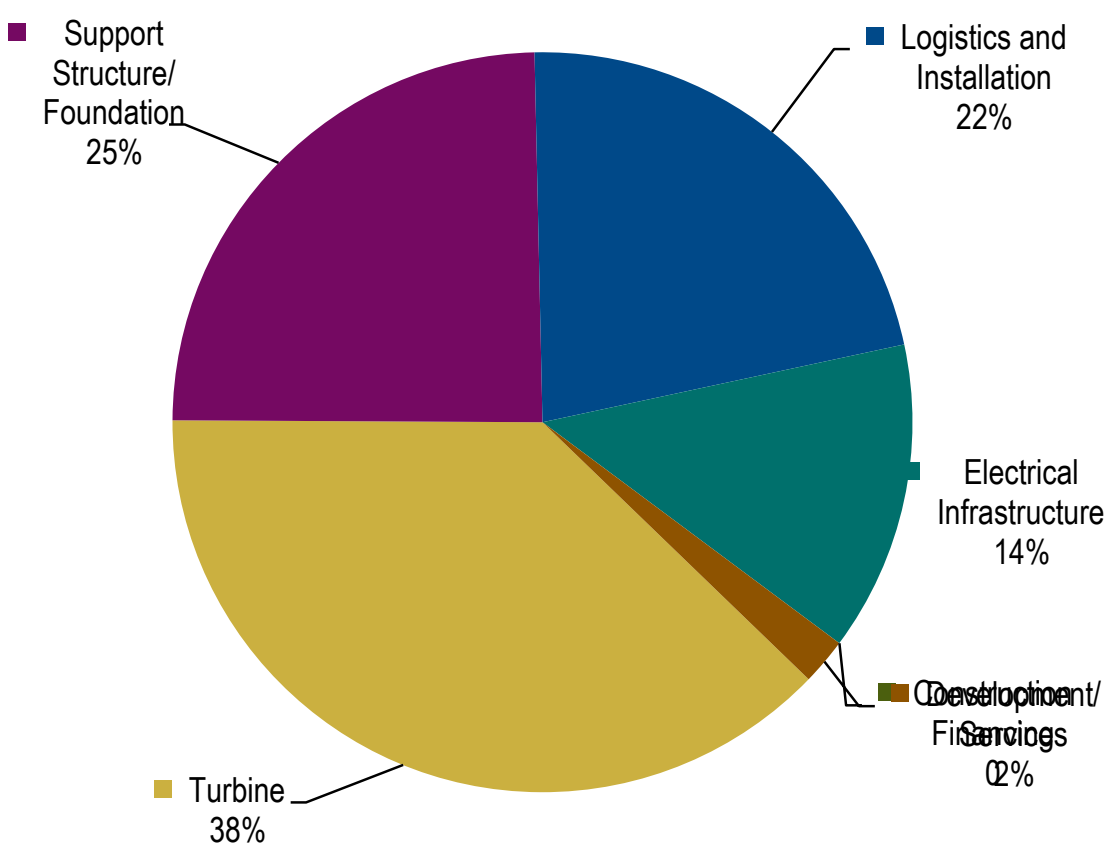

\subsection{Technical Trends and Anticipated Advancements}

This section examines the future trends in offshore wind power costs and sources of future cost reduction. It also examines the potential impact and probability of success for an array of innovation opportunities and discusses the potential ramifications these technological changes might have in facilitating or discouraging supply chain investment.

The total potential market value to the supply chain is primarily a function of the market volume. In this study, market volume is fixed according to three scenarios outlined in Chapter 2. The value of the offshore wind industry to the supply chain is also impacted by changes in capital and operational costs. These costs are influenced by improvements in industry efficiency, fabrication technology, and wind turbine and foundation technology (UKERC 2010; ARUP 2011; Doyle 2011; Wiser et al. 2011; Chapman et al. 2012), as well as changes in material costs, market demand, commodity prices, and other factors (Bolinger and Wiser 2011; Greenacre et al. 2010; van der Zwaan et al. 2012). A more mature and efficient industry will likely result in reduced value per MW of installed capacity to the supply chain and might also apply downward pressure to supplier margins. 


\section{NAVIGANT}

\subsubsection{Anticipated Future Cost Trajectories}

Recently, offshore wind power prices (both historical and announced costs for proposed projects) have been increasing (Musial and Ram 2010; UKERC 2010; Wiser et al. 2011). Such cost increases are a function of several trends: a movement toward deeper-water sites located farther offshore; increased siting complexity; and higher contingency reserves that result from more limited operational reserves and greater uncertainty when working in the offshore environment (Chapman et al. 2012). Other recent estimates of the capital cost for offshore wind power in the United States are on the order of $\$ 5,000 / \mathrm{kW}$ to $\$ 6,000 / \mathrm{kW}$, with a levelized cost of energy (LCOE) estimated to be on the order of $\$ 200 / \mathrm{MWh}$ to \$250/MWh (Tegen et al. 2012).

As the industry matures and uncertainties are reduced, both capital costs and the LCOE from offshore wind facilities are expected to plateau and trend downward. Historically, the learning curve has been the primary method used to estimate the future cost of technology. Learning curves assume that cost reductions are a function of future increases in technology deployment. Typically a learning rate is calculated for a specific technology from historical data (e.g., the percent reduction in capital cost or LCOE associated with every

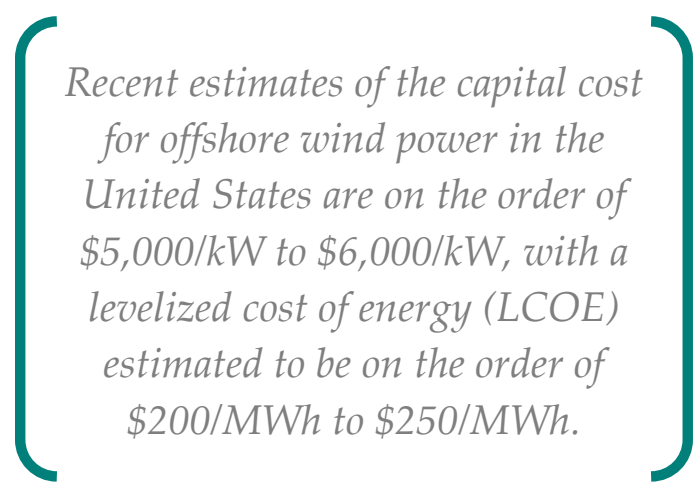
doubling of deployed MW or turbines). To forecast future costs, the learning rate is combined with market projections and extrapolated into the future. With the range of learning rates reported in the literature $(3 \%$ to $15 \%)$ and the status of offshore wind as a relatively nascent industry, learning curves are of somewhat limited use in understanding the future cost of offshore wind technology. Moreover, because they require estimates of future offshore wind deployment at the global scale, deriving a reasonable reduction in costs over an extended period of time is a challenge. Appendix B includes further discussion of recent published estimates of offshore wind industry learning rates and other methods for predicting future cost reductions for the offshore wind market.

To determine the impact of future cost changes on the industry's value to the supply chain, it was determined that the supply chain modeling conducted here would rely on the offshore wind costreduction trajectory developed for the recent NREL Renewable Electricity Futures Study (Chapman et al. 2012), which uses the renewable electricity-evolutionary technology improvement scenario. We

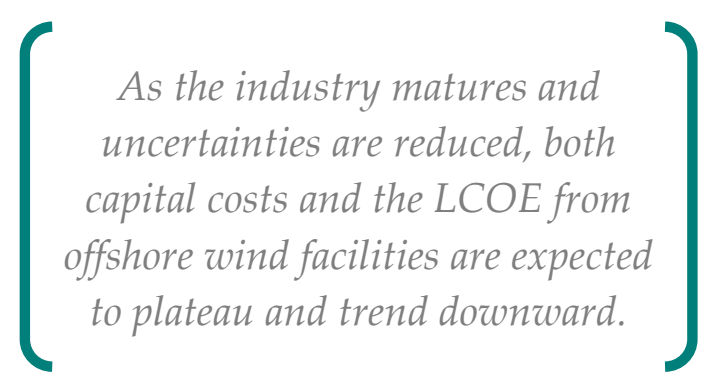
preferred this approach in light of the perceived challenges associated with developing a reliable learning curve for offshore wind as well as the plethora of existing projections that combine learning curve and alternative methods for projecting costs. In addition, it relies heavily on analysis work incorporated in the U.S. DOE report 20\% Wind Energy by 2030 (DOE 2008) and as such, is a well-documented cost reduction trajectory for offshore wind.

The cost-reduction curve for the renewable electricity-evolutionary technology improvement scenario couples reductions in capital cost on the order of $26 \%$ by 2030, with increases in turbine performance on 


\section{NAVIGANT}

the order of $6 \%$ to $10 \%$, depending on the wind regime (Chapman et al. 2012). ${ }^{2}$ A $26 \%$ reduction in capital costs falls well within the $10 \%$ to $45 \%$ reduction in capital cost noted in the literature and summarized by Chapman et al. (2012). It also reflects the greater cost-reduction potential anticipated for offshore wind relative to land-based wind. After adjusting this trajectory to current capital costs expected for initial projects in the U.S. in the latter part of this decade, an approximately $22 \%$ reduction in LCOE is estimated by 2030. This estimated reduction falls well within the $20^{\text {th }}$ to $80^{\text {th }}$ percentile of estimates reviewed by Tegen et al. (2012) (see Appendix B).

Notably, different offshore wind systems and components (e.g., turbines and foundations) will likely decline in cost at variable rates (Musial and Butterfield 2004; Junginger et al. 2004). However, insufficient data prevents a parsing of the assumed $26 \%$ overall reduction in capital cost to explicit project elements. Instead, this reduction in capital cost is applied evenly across offshore wind capital costs. Although this approach is simplistic, it was determined that, for the purposes of quantifying the value of the industry to the supply chain, the uncertainty introduced by this approach was inconsequential relative to uncertainties that exist in terms of total industry volume and long-term capital costs.

\subsubsection{Potential Sources of Future Cost Reductions}

Significant technical advancement will be required to achieve the $26 \%$ cost reduction and $6 \%$ to $10 \%$ performance improvement noted above and to address the multiple technology challenges posed by variable site conditions in each of the United States' coastal regions. Future innovations will be fundamental not only to the success of the industry, but also for it to penetrate into the multiple regions and markets where offshore wind is anticipated. The following pages highlight some of the general areas of focus that are expected to help the industry explore and deliver on the technology advancements presented above.

\section{Rotor Improvements}

Building machines with larger rotors allows for increased energy capture and production. A significant trend over the past decade has been the expansion of turbine rotors for land-based machines (Wiser et al. 2012). This is already carrying over into the offshore space, where rotors upwards of 150 meters are under active development at Vestas, Siemens and Alstom. However, designing the blades necessary to achieve these dimensions will be a challenge based on classical scaling laws, which suggest increases in blade mass and material use will make continued scaling cost prohibitive without further innovation. Such innovations might include the use of advanced materials (Ashwill 2009; UpWind 2011); changes to blade architecture such as fore-bending or curved blades (UpWind 2011); passive load-shedding

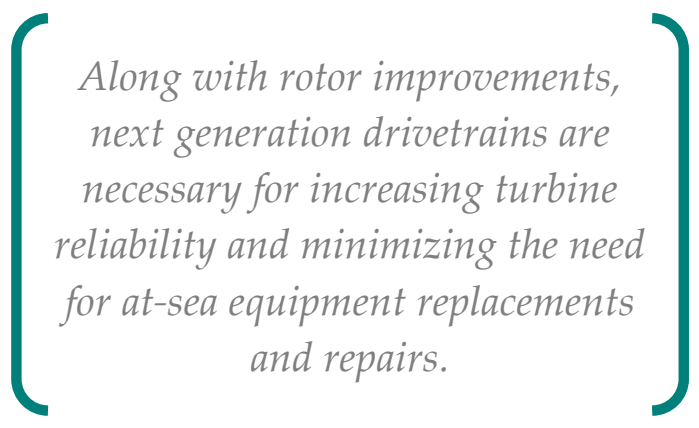
strategies such as bend-twist coupling (Ashwill 2009); and active load-shedding such as individual blade pitch control, partial blade-span actuation, active control surfaces, and trailing edge flaps (Buhl et al. 2005; Lackner and van Kuik 2009; UpWind 2011). In addition, sensors embedded in the blade that are

\footnotetext{
${ }^{2}$ Lower wind speed regimes are anticipated to see more significant improvements in turbine and project performance.
} 


\section{NAVIGANT}

capable of providing real-time adaptation to loads, or turbine-mounted LIDAR to allow for advanced positioning of the turbine at the most effective load-shedding and performance-enhancing yaw angle, may also help to facilitate the development of larger rotor diameter machines (Andersen et al. 2006; Berg et al. 2009; UpWind 2011).

\section{Drivetrains}

Along with rotor improvements, next-generation drivetrains are necessary for increasing turbine efficiency and reliability, and minimizing the need for at-sea equipment replacements and repairs. Conventionally geared drivetrains still dominate offshore technology, and research to reduce gear loading, distribute loads (e.g., Winergy's multi-duored gearbox) (Cohen et al. 2008) and incorporate advanced condition monitoring technology is expected to make geared machines more reliable. Some designers, including Siemens (2011), however, have chosen to pursue direct-drive technology that utilizes permanent magnets to resolve the historical barriers to conventional direct-drive machines, such as large generator diameter and mass. As a compromise, Vestas has chosen to pursue a medium-speed gearbox and generator design for its V164 turbine (Vestas 2011b). Research by the European Unionfunded UpWind effort suggests permanent magnet transversal flux generators would be optimal in terms of weight reduction (UpWind 2011), while designers of very large (10 MW or higher) machines may start to consider superconducting generators (Maples et al. 2010). Larger advanced generators and drivetrains, along with utility and system operator expectations for enhanced grid services, are expected to continue to drive movements toward higher-voltage, higher-capacity power conversion and even greater levels of grid support (UpWind 2011).

\section{Towers, Support Structures and Foundations}

Towers, support structures, and foundations are also expected to continue to evolve. At present, offshore wind towers are exclusively tubular steel structures. In the future, towers may employ concrete, composites, or other alternative materials to help combat corrosion and reduce steel content while simultaneously enabling taller hub heights (Musial and Ram 2010). Future towers may also employ alternative design architectures such as wider diameters to minimize wall thickness and steel content, something that is not implemented today due to transport and highway or rail underpass requirements.

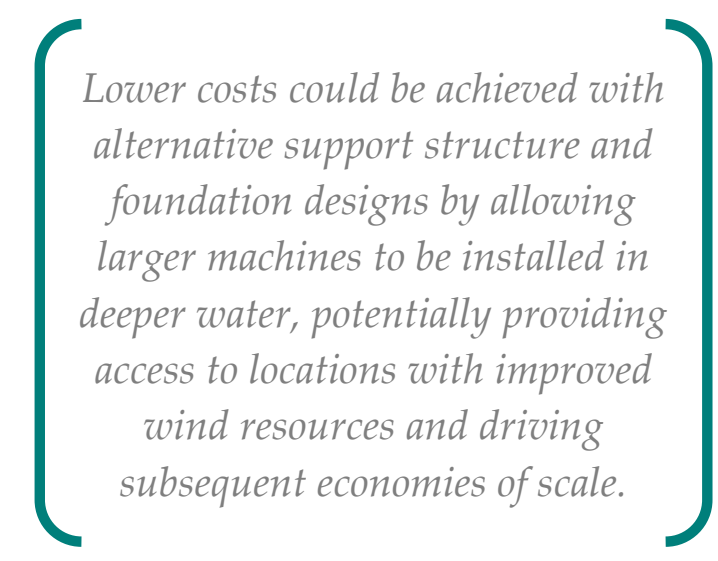

In terms of fixed-bottom foundations and their associated substructures, monopiles, jackets, and gravitybased structures (GBS) will likely dominate the market, with suction caissons, tripiles, and tripods also offering potential alternatives. Lower costs could be achieved with these alternative technology designs by allowing for larger machines to be installed in deeper water, potentially providing access to locations with improved wind resources and driving subsequent economies of scale. Lower costs might also be achieved with GBS where applicable due to their relatively easier installation and potentially lower material costs. ${ }^{3}$

\footnotetext{
${ }^{3}$ Although GBS material content is much greater by mass, the use of materials such as gravel and concrete may offer a lower-cost foundation package depending on site conditions and steel commodity prices.
} 


\section{NAVIGANT}

Widespread deployment off the Pacific Coast of the U.S. and the Gulf of Maine, which are characterized by deeper near-shore water depths, will likely require floating foundations. Depending on the specific design, floating foundations offer the combined benefits of reduced material use (particularly in regards to deep-water, fixed-bottom solutions), simplified vessel requirements, and access to high-quality wind resource sites. There are two full-scale floating designs in testing today - the Statoil Hywind test turbine off the coast of Norway (Statoil 2011) and the Principle Power WindFloat concept off the coast of Portugal (Principle Power 2011). The former utilizes a ballast-stabilized spar buoy deployed with a Siemens 2.3-MW turbine while the latter relies on a ballast-stabilized, triangular-framed, semisubmersible structure deployed with a Vestas 2.0 MW turbine. Other concepts, including a tension leg platform and a buoyancy-stabilized barge, represent oil rig concepts that have been proposed for floating offshore wind but that have not yet been tested at scale. Despite the theoretical benefits of floating platforms, it is not yet clear whether floating platforms are technically or economically viable over the long term. However, continued at-scale testing is being planned (Turkel 2012). Statoil has submitted an unsolicited lease request to the U.S. Bureau of Ocean Energy Management (BOEM) for four floating 3.0-MW Siemens turbines 20 miles off Boothbay Harbor, Maine, and has begun environmental surveys to lease and permit the site (BOEM 2012).

\section{Other Balance of Plant Infrastructure}

Along with foundation and support structures, other balance of plant infrastructure, including submarine cabling, substations, and converter stations, are expected to undergo technological advances that could reduce costs. Cost savings on these elements will be increasingly important as projects move further from shore, necessitating longer export cables and more offshore infrastructure. Greater global volume is expected to lead to increased industry standardization, which should in turn result in both production and installation efficiencies. Shifting to High-Voltage Direct Current (HVDC) interconnection lines will reduce electrical losses for facilities more than 40 nautical miles offshore. New innovations in HVDC technology and conversion are also anticipated to allow for modular deployment of HVDC technology. Higher voltage array cabling and larger turbines will allow for project layouts that minimize array cabling needs. Modular substations could push down the labor intensity of building and installing offshore substations while self-elevating stations could bring down crane lift requirements.

\section{Improvements in Resource Assessments}

Improvements in resource assessment via remote sensing and enhanced array modeling could allow for projects to be sited in the best wind resource areas while simultaneously facilitating a reduction in wake losses, thereby boosting overall plant output. Integration of LIDAR technology into turbine blades or nacelles could allow turbines to better position themselves to reduce loads and maximize output. Developments in condition monitoring should allow preventative maintenance efforts to be more effective while also potentially allowing for real-time load response, self-diagnoses, and an enhanced ability to control individual turbine performance from a remote off-site control room. Turbines designed specifically to optimize offshore maintenance and repair, as well as better weather forecasting, should facilitate a more efficient repair process and access in a more diverse set of weather and sea conditions (van Bussel and Bierbooms 2003). 


\section{NAVIGANT}

Vessels, Manufacturing, and Installation Logistics

Perhaps one of the more promising areas for innovations and industry efficiency improvements is in vessels, manufacturing, and installation logistics. Specialized vessels and integrated manufacturing and port facilities offer the potential for significant cost savings by creating space for new efficiencies in transport, logistics, and installation and allowing the industry to capture economies of scale (assuming sufficient volume). Moreover, both specialized vessels and new logistics solutions are increasingly important as the industry moves towards larger turbines upwards of $10 \mathrm{MW}$.

\section{Coastal Manufacturing}

Growth of offshore wind turbines and their components is anticipated to make it increasingly difficult, if not impossible, to move turbine components over land. Coastal manufacturing for blades and nacelle assembly as well as tower, foundation, and substructure fabrication may be an industry requirement in the near future. As the industry moves from prototype to commercial to serial production, manufacturing facilities will likely employ increasing levels of automation to help drive down defects and allow for tighter design margins by minimizing component mass (Cohen et al. 2008). Under ideal circumstances, component storage and staging activities would occur alongside manufacturing and fabrication at an integrated manufacturing and port facility. However, this will require very large swaths of coastal land-Vestas' recently abandoned Sheerness U.K. proposed facility was planned to be on the order of 70 hectares (Vestas 2011a). Even with fully integrated manufacturing and port facilities, it is likely that component designers will be increasingly forced to consider more modular storage-oriented concepts such as segmented blades (UpWind 2011).

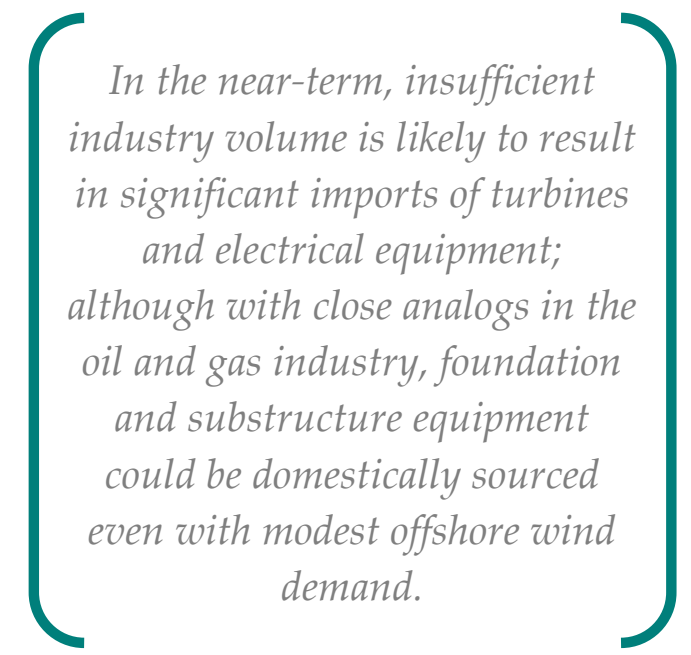

Future manufacturing and staging concepts could follow an incremental investment path with a set of dispersed facilities, each serving a niche within the industry. To some extent this could parallel port developments that have occurred in Germany along the North and Baltic Seas (Brautigam 2011). Alternatively, manufacturing and staging could follow a more centralized regional hub model along the lines of the concepts in various stages of planning in the U.K. (NLC 2010; Vestas 2011b) or potentially the German facility in Bremerhaven (Brautigam 2011). In the near term, insufficient industry volume is likely to result in significant imports of turbines and electrical equipment; although with close analogs in the oil and gas industry, foundation and substructure equipment could be domestically sourced even with modest offshore wind demand. 


\section{NAVIGANT}

\section{Installation Vessels}

Historically, vessels converted from other analogous industries (e.g., oil and gas) have served the majority of the marine construction and transport needs of the industry. The lower cost of entry to convert an existing vessel, and the versatility of these machines has been attractive (Musial and Ram 2010). However, offshore wind differs from offshore oil and gas; there are far more units (foundations, pilings, and turbines) to be installed and significantly more movement from one turbine site to the next. More recently, dedicated offshore wind installation vessels have been constructed and are playing an increasing role in the European offshore wind market. Initially, U.S. projects may also be dependent on vessel conversions (Musial and Ram 2010). However, with projects potentially being further from staging ports in the U.S., concepts of the future envision specialized installation vessels offloading and installing equipment from dedicated transport vessels. As the industry grows and matures, the development of assembly-line style vessel coordination - where one vessel installs the foundation and is followed by a series of vessels installing the tower, nacelle, and blades in order -is considered to be a possibility. Depending on specific design specifications, floating foundations will likely require simpler vessel designs; turbines could be fully assembled on land and then simply towed with traditional or modestly modified tugs.

\section{Infrastructure Development and Investment}

Despite the advantages of specialized vessels and integrated logistics solutions, realizing these opportunities requires significant infrastructure development and investment. Existing German ports have invested $\$ 100$ million to $\$ 250$ million in upgrades and infrastructure to support offshore wind ([Brautigam 2011]; see also Chapter 2.4). More fully integrated conceptual designs in Hull and Sheerness in the U.K. or Edinburgh, Scotland, could result in new infrastructure investment on the order of $\$ 500$ million (NLC 2010). Dedicated installation vessels are estimated to be on the order of $\$ 100$ million and higher (Musial and Ram 2010), with some recent estimates exceeding $\$ 250$ million per vessel. Generating the demand volume to drive the level of investment that will be needed to realize the cost-reduction potential of more sophisticated and integrated manufacturing and vessel fleets will be a challenge moving forward.

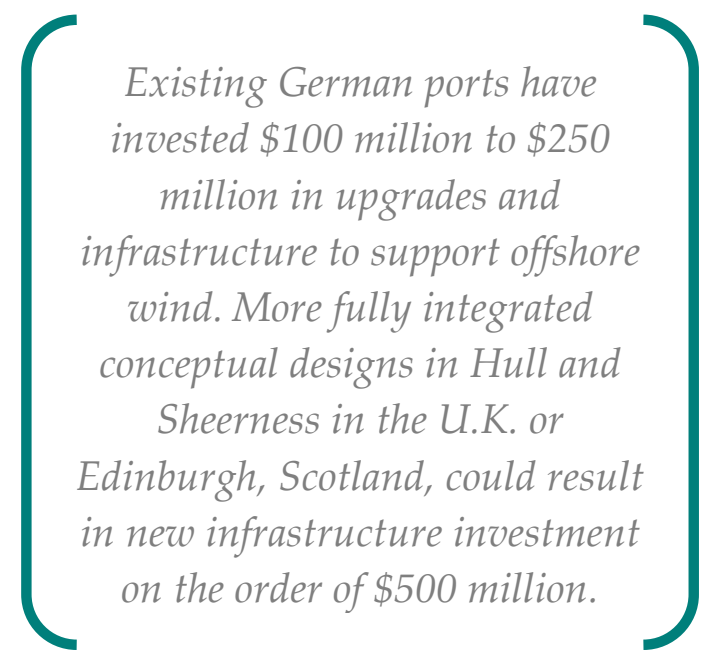

\subsubsection{Innovations Likely to Impact Future Costs}

To gain further insights into the cost impact and market potential presented by the above opportunities, the Navigant team conducted a subjective ranking and prioritization exercise through technical opinion surveys with market experts. ${ }^{4}$ This exercise examined individual innovation opportunities throughout the offshore wind space for the purpose of quantifying their potential impact on future LCOE, their

\footnotetext{
${ }^{4}$ Technical opinions were solicited from researchers and analysts at NREL, Navigant, and other public and private sector organizations. All respondents received the same guidance and survey template to complete. Data were collected from 13 different industry analysts representing seven organizations located in Europe and North America.
} 


\section{NAVIGANT}

probability for success within specific periods in the future (within 5 years, within 10 years, and in more than 10 years), and their ability to open new markets to development. Data were also collected from respondents on the specific aspects of offshore wind costs that were likely to be affected. Appendix C provides a list of the technology concepts that were considered in this analysis as well as the ranking scheme used in their evaluation.

Figure 1-4 shows the composite indexed scoring results for all innovations across all time periods and variables. The left-hand side of the range reflects the composite indexed score for innovations when considering the probability of realization within the next five years. The right hand side of the bar reflects the composite indexed score when considering the probability that a given innovation will be realized in more than ten years.

Figure 1-4. Indexed Composite Score for Offshore Wind Innovation Opportunities

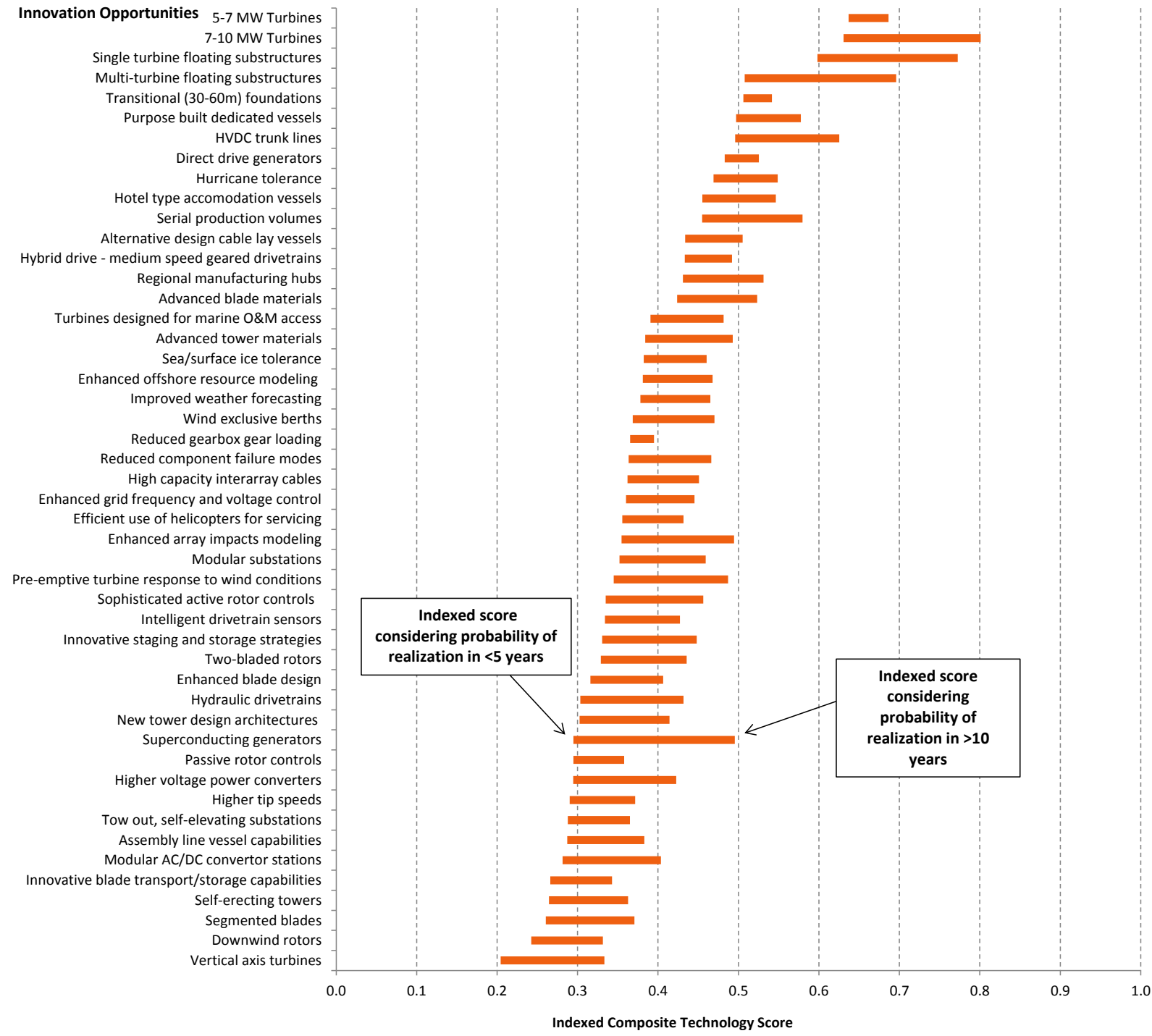




\section{NAVIGANT}

Based on the composite responses and the change in scores across the three time periods for which data were collected, scaling to larger turbines (first to 5-7 MW machines and subsequently to 7-10 MW machines) is generally believed to have the most substantial impact on the industry. The development of floating and transitional water-depth foundations is also expected to have a substantial impact and is expected to become increasingly likely over time. Purpose-built, dedicated vessels and the emergence of HVDC trunk lines are expected to have somewhat lesser impacts but still ranked highly in terms of overall impact. Innovations that this scoring exercise suggested would have a lesser impact include vertical-axis turbines, downwind rotors, segmented blades, self-erecting towers, and innovative storage and staging capabilities.

Respondents were asked about the potential impact of each innovation in each of three time periods. Figure 1-5 presents the ten innovations that experienced the greatest increase in expected impact when considering mid-term (impact in 5-10 years) rather than near-term (impact in $<5$ years) impact. These data do not suggest that these innovations are expected to be realized in 5-10 years, but that the likelihood of their impacting the industry in 5-10 years increased more significantly than other potential innovations. The results reveal that superconducting generators are more likely to produce impacts in 510 years than they are in the next five. Similarly, 7-10 MW turbines and floating substructures also demonstrate a notable increase in likelihood over this time period. Other key trends such as serial production volumes, enhanced turbine controls, and HVDC trunk lines were also believed by these respondents to have a substantially greater chance of impact in 5-10 years. These trends suggest that, should such innovations occur in the mid-term, the next 5-10 years will produce substantial maturation of offshore wind technology and the industry as a whole, potentially resulting in significant changes in supply chain demands relative to today.

Figure 1-5. Change in Indexed Composite Score when Moving from Scores that Consider Impacts in $<5$ Years to Scores that Consider Impacts in 5-10 Years

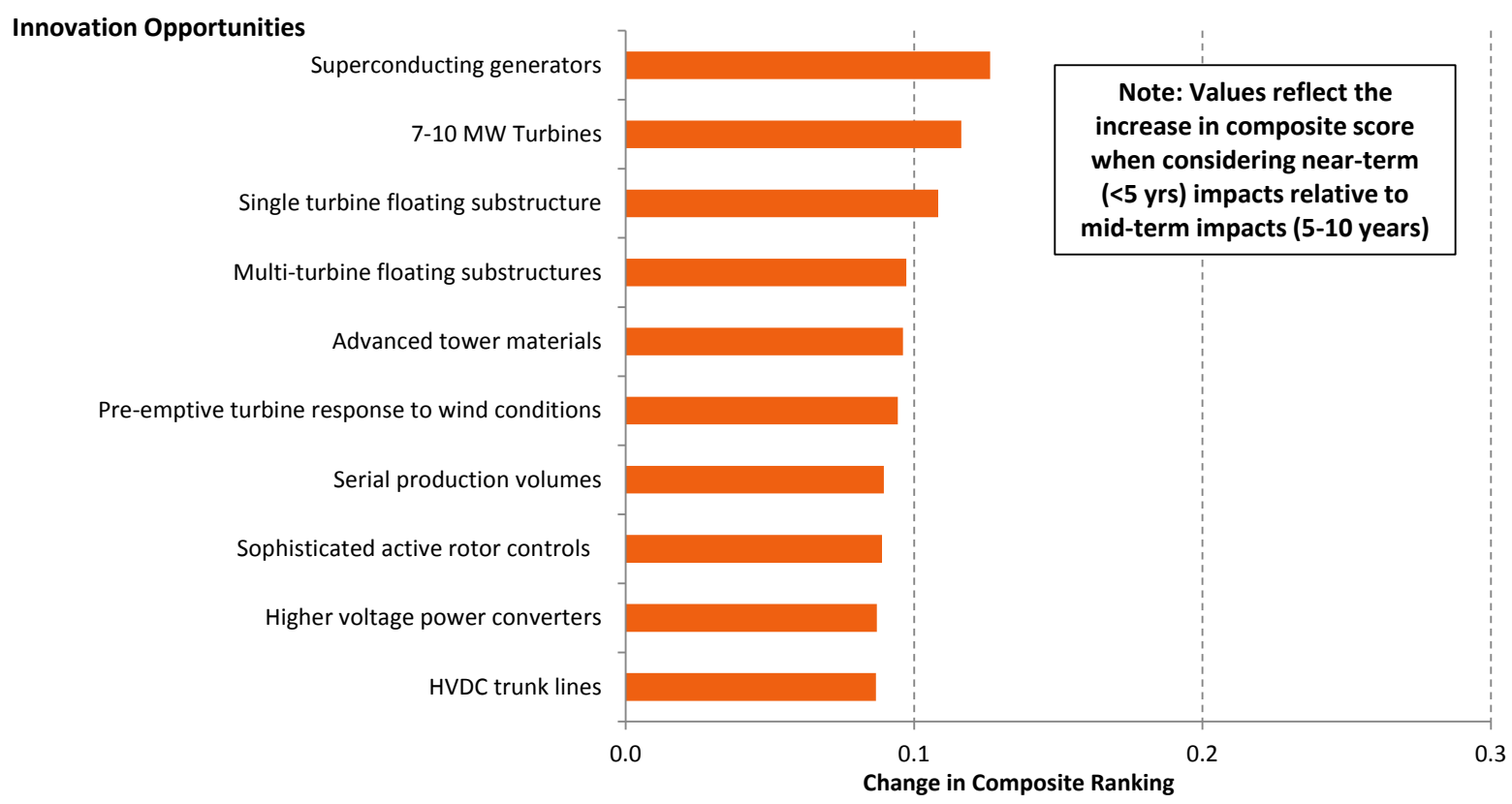




\section{NAVIGANT}

Figure 1-6 shows the categories of innovations that are expected to have the greatest effect on LCOE. Of these, changes in turbine topology, including rotor diameter, machine rating, and other aspects, have the greatest potential to reduce LCOE over time. Innovations in foundations and substructures, drivetrains, and manufacturing are also ranked relatively high for impact to LCOE. In contrast, innovations around tower concepts and power electronics are anticipated to have lesser impacts. However, with the exception of turbine-related innovations, the difference in impact between the lowest and highest score is relatively small. This suggests that there is no one industry segment where innovations are notably less beneficial in terms of their impact to LCOE and that, broadly speaking, innovations across the industry are expected to support reductions in LCOE.

Figure 1-6. Average Impact to LCOE by Industry Segment

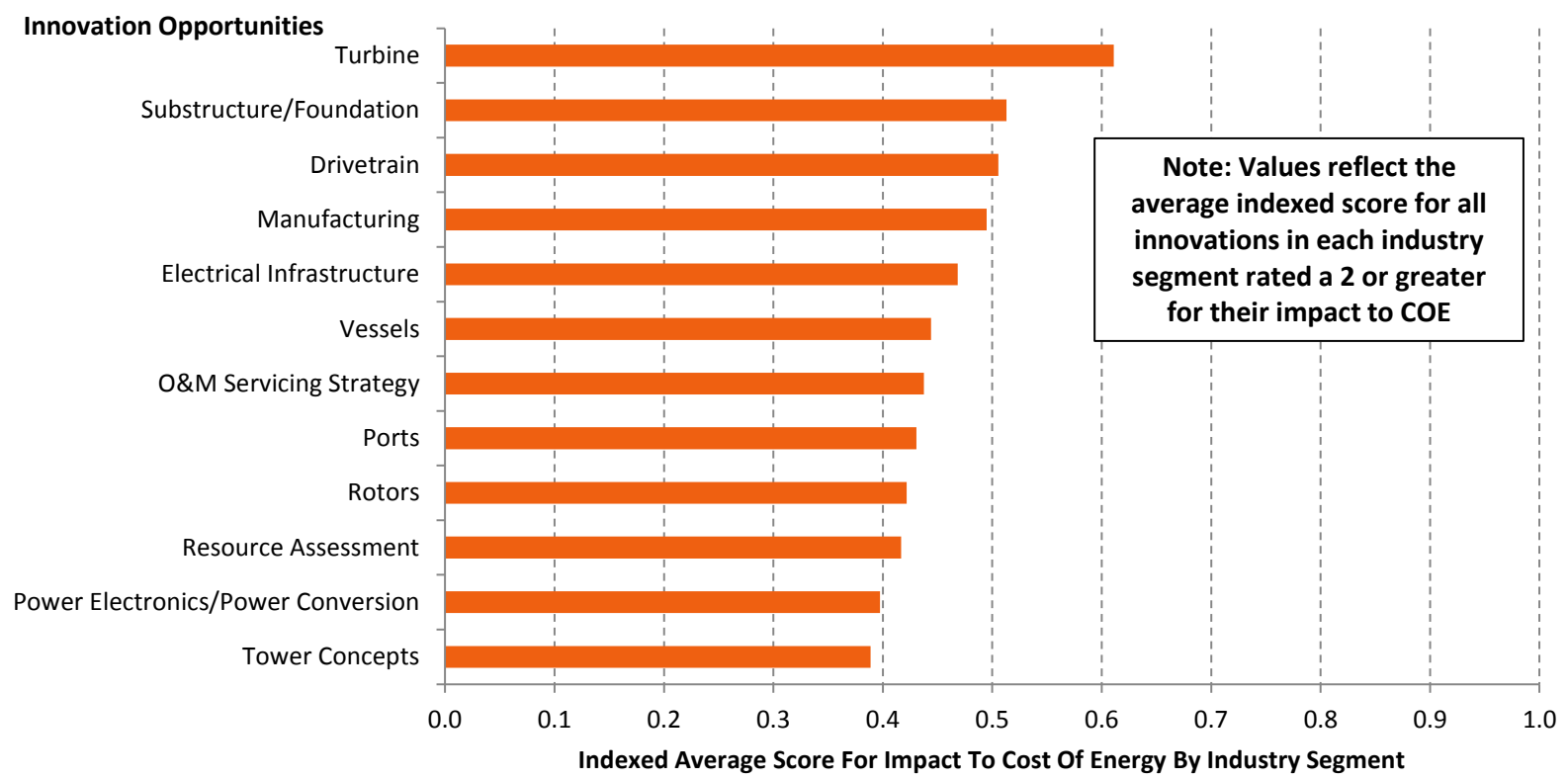

Figure 1-7 shows the ten highest-rated individual innovations based on their expected impact to LCOE. Focusing on specific innovations supports the conclusion that the industry expects turbine typology changes, substructure advancements, manufacturing improvements, and drivetrain evolution to have the most significant impact on LCOE. In addition, these data highlight the importance of transmission planning and development by illustrating that HVDC trunk lines could be critical to driving down LCOE. The role that purpose-built vessels have to play in terms of driving down LCOE is also captured. 


\section{NAVIGANT}

Figure 1-7. Indexed Scores for the Ten Innovations Observed to have the Greatest Impact to LCOE

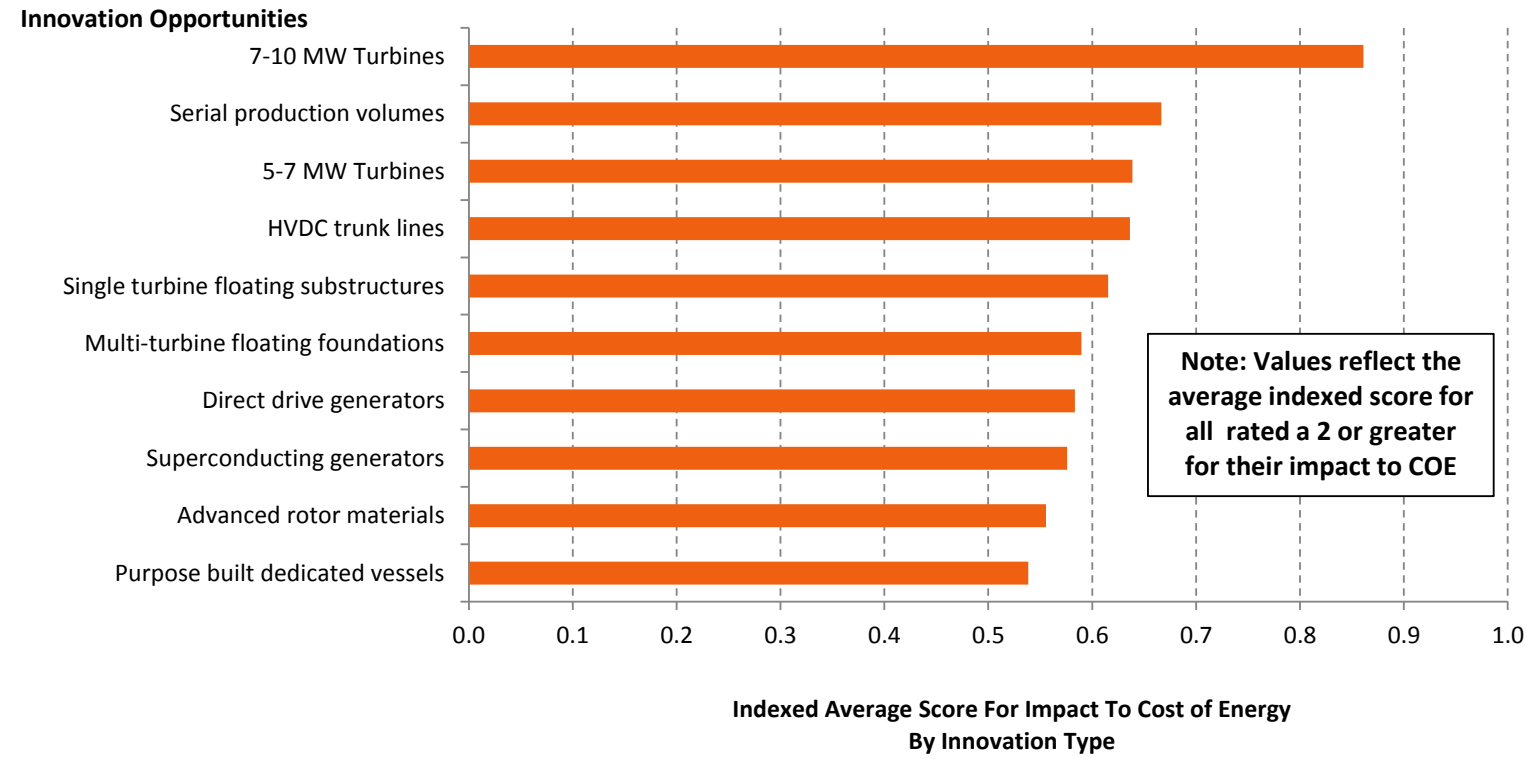

Finally, Figure 1-8 shows the innovations expected to have the most substantial impact on the ability to develop areas for which current technology is unsuited (e.g., deeper waters or regions exposed to extreme weather). These include floating substructures, hurricane-tolerant technology, and ice-tolerant technology. Innovations including larger 7-10 MW turbines, purpose-built vessels, and HVDC trunk lines were also ranked highly for their ability to open up new markets to development.

Figure 1-8. Indexed Scores for Top Ten Innovations Observed to have the Greatest Impact on Developable Area

\section{Innovation Opportunities}

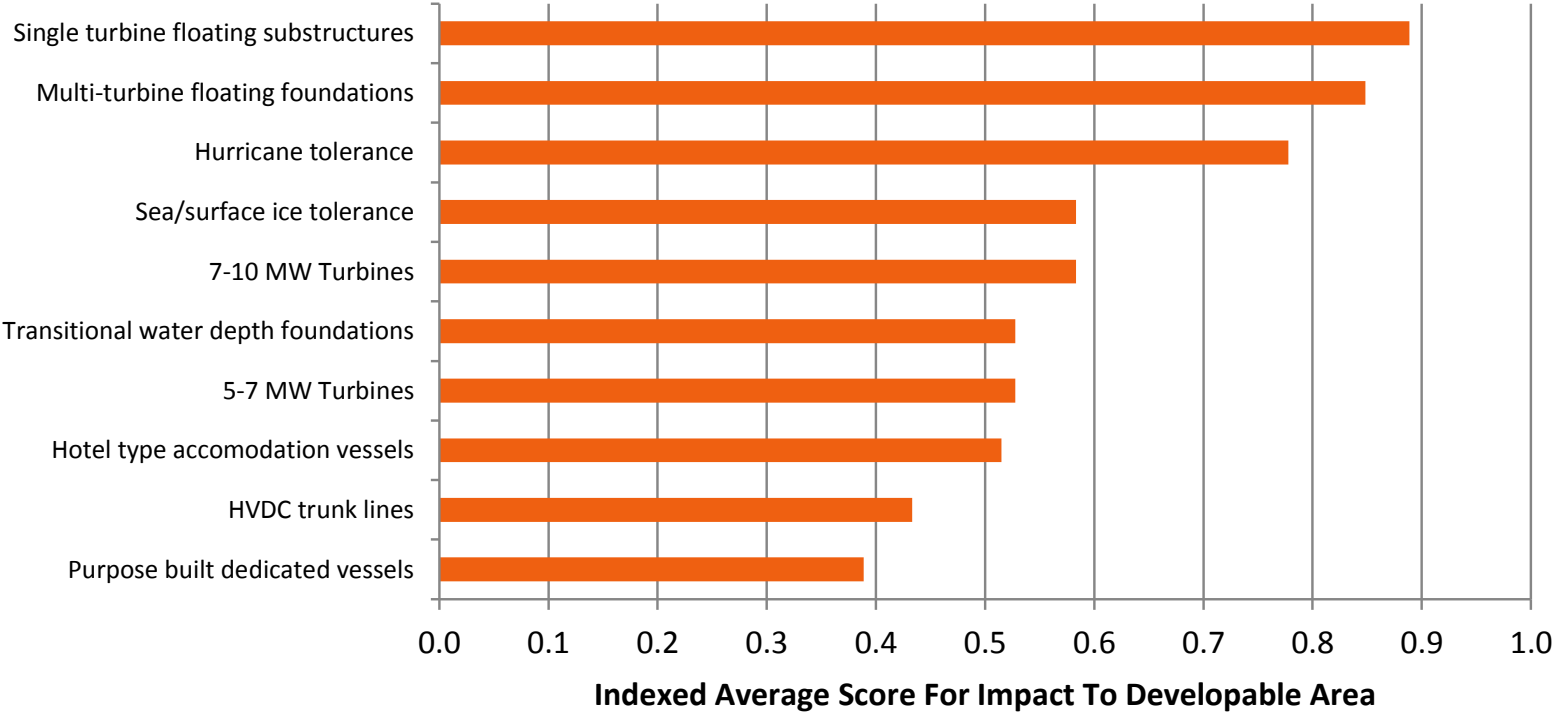




\section{NAVIGANT}

Among the variables affecting offshore wind's LCOE that are likely to be influenced by the innovations listed in Appendix C, respondents most frequently noted an expectation of improved turbine or plant performance. After increased performance, innovations were most often expected to result in lower operations expenditures. From there, innovations are expected to affect (in descending order) installed costs, materials use, and financing costs.

\section{Discussion of Ranking Results}

Given the breadth of ongoing research and innovation opportunities, there could be significant changes in the supply chain as the offshore wind industry grows and matures. For example, firms specializing in monopile production may need to diversify into pipe production for jackets, and subsequently floating assemblies, should they desire to continue to serve the offshore wind sector. However, the technology ranking exercise demonstrates that progress in the industry will take time, many innovations see a notable increase into their potential impact as one moves 5-10 or even more than 10 years into the future.

Moreover, many of the more promising innovations such as scaling to larger turbines, moving to serial production, and developing increasingly specialized installation vessels are likely to manifest as incremental changes to conventional industry approaches. These trends bode well for suppliers considering the space, as they suggest that dramatic changes in the makeup of the industry in the near term are unlikely. They also suggest that the competitive advantages will go to firms that can envision and implement process improvements or work within the existing technology spheres to advance the state of the art. These trends are also relatively encouraging from an infrastructure and investment perspective. Offshore wind is a capital-intensive industry, and significant investments will be required to realize the efficiencies offered by opportunities such as integrated manufacturing and port facilities or assembly-line vessels. Stability in both demand and the overall technology platform will likely be needed for such sizable investments to occur.

Apart from growth to 7-10 MW turbines, foundations and substructures appear to be the subsector of the industry most likely to see dramatic changes in technology over time. The move to future generations of larger turbines will require significant changes in foundation design and performance, and a long-term shift towards jackets or other space-framed alternatives to the monopile and gravity-based foundation are very likely. A future that relies extensively on standardized, modular floating foundations could look quite different and exert new and different vessel and quayside lift demands on the industry. Nevertheless, the long-range

These trends bode well for suppliers considering the offshore wind space, as they suggest that dramatic changes in the make-up of the industry in the near-term are unlikely. They also suggest that the competitive advantages will go to

firms that can envision and implement process improvements

or work within the existing technology spheres to advance the state of the art. practicality of widespread deployment of floating foundations is still uncertain given the current status of the technology; a 500-MW floating wind farm is not anticipated before 2020. Such floating turbines may be key to large-scale wind development on the Pacific Coast and the coast of Maine, as well as outside of congested shallow waters along the Atlantic Coast. 


\section{NAVIGANT}

Drivetrains are also likely to undergo substantial changes over time, and larger turbines will likely require castings and forgings that could go beyond the limits of existing foundries. In addition, the emergence of a broader set of drivetrain platforms means that the demand for drivetrain components will also be more diverse. From the perspective of the supply chain, however, it is unlikely that the current platforms will disappear quickly. Investors will be hesitant to invest heavily in new technology platforms until a proven track record is achieved. Nevertheless, the suppliers of drivetrain components can reasonably expect the type of components that are in demand to evolve and develop as the industry matures. Suppliers who are unwilling to develop the capacity to serve new drivetrain platforms as they emerge may find it difficult to maintain market share into the future.

This analysis suggests that significant need exists for continued research and development investment in offshore wind technology. Composite scores for critical

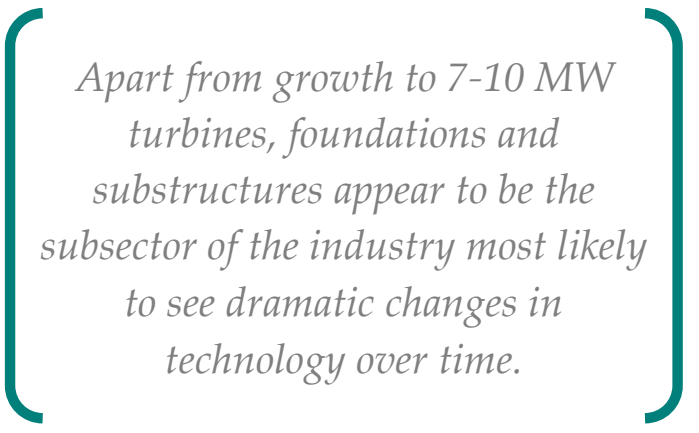
innovations increase as one moves out 5-10 years and increase even further 10 years into the future, suggesting that the timing of some impacts could be accelerated. Moreover, broad-based funding for research activities throughout the industry is likely to be effective in advancing the state of the art, as there is significant potential for impactful innovations throughout all segments of the industry. 


\section{NAVIGANT}

\section{Supply Chain Needs to Support U.S. Offshore Industry}

Market demand is difficult to predict, particularly given the unique challenges and considerations (many of them site-specific) facing offshore wind turbine and wind farm design. This dynamism introduces greater uncertainty to any attempt to forecast the need for specific types and sizes of components or contributions of materials to a particular future demand scenario.

Nonetheless, U.S. policymakers, market actors, and the general public need a reasonable idea of the potential size and value of the domestic offshore wind supply chain, as well as the unique challenges and opportunities facing the development of an offshore wind market in the U.S. This chapter provides an organized, analytical approach to identifying and bounding those uncertainties; projecting potential component-level supply chain needs under three demand scenarios; and identifying key supply chain challenges and opportunities facing the future U.S. market and current suppliers of the nation's landbased wind market. It includes the following sections:

» Chapter 2.1 provides some high-level context and considerations for the potential challenges and opportunities facing potential suppliers of a future U.S. offshore wind market, including a discussion of issues that may influence supply chain development in different parts of the U.S.

» Chapter 2.2 describes the assumptions used to estimate the potential requirements for and market values of major offshore wind turbine components and materials.

» Chapter 2.3 estimates these component requirements and market values for varying levels of demand; provides a snapshot of the current global supply chain situation for each major component or material; and indicates a relative level of potential opportunity for current domestic suppliers of the U.S. land-based wind industry to support the future offshore market.

» Chapter 2.4 describes the potential level of investment and labor demand required for domestic manufacturing and port facilities to support differing demand scenarios. It then uses regional workforce data to evaluate each region's ability to provide the necessary labor and skill sets.

Figure 2-1 summarizes the key findings from this chapter. 


\section{NAVIGANT}

Figure 2-1. Summary of Key Findings for Chapter 2

\section{Summary of Key Findings: Supply Chain Requirements and Opportunities}

» The potential exists for at least partial domestic supply of a future U.S. offshore wind market. Under a moderate-growth scenario, demand levels on the Atlantic Coast could reasonably support new manufacturing facilities for larger components (e.g., nacelles, blades, towers and foundations) by between 2017 and 2022 depending on the component. Opportunities for suppliers of materials and smaller components may occur earlier.

» A future U.S. offshore wind market would have to compete with the European and Asian offshore markets as well as emerging land-based markets for manufacturer investment dollars.

» While some U.S. manufacturing that supplies the land-based wind market is running at part load, manufacturing larger components for the offshore market may require significant investments in re-tooling or an altogether new facility located near the coasts where offshore projects are being developed.

» The likelihood of U.S.-based offshore manufacturing capacity will depend on turbine suppliers perceiving stable, long-term policy support and subsequent demand for offshore wind in the U.S. market.

» Based on the three market growth scenarios that Navigant assessed, the near-term opportunity for suppliers to serve a U.S. offshore wind market is greatest in foundations/substructures, towers, blade materials, and power converters and transformers.

» Based on these same growth scenarios, the estimated nationwide employment impacts for domestic manufacturing of components for the U.S. offshore wind market range from 2,000 FTE jobs (low growth of $10 \mathrm{GW}$ cumulative capacity ) to almost 14,000 FTE jobs (high growth of 54 GW cumulative capacity) by 2030 .

» Estimates for the average economic impacts of upgrades to a single port that wishes to serve the U.S. offshore wind market include incremental employment ranging from 600 to over 17,000 FTE jobs and incremental state GDP ranging from $\$ 48$ million to $\$ 1,333$ million. These estimates depend largely on the extent of upgrades the port makes and whether it also constructs co-located component manufacturing facilities.

\subsection{Overarching Considerations}

This section provides some context around the future U.S. offshore wind market, including some considerations for U.S. suppliers' potential role in the global market and region-specific issues that may affect supply chain development in different parts of the U.S.

\subsubsection{U.S. Suppliers' Role in the Global Wind Market}

While the U.S. is not yet an established player in the offshore wind market, the U.S. land-based wind market has historically been a focal point for many wind turbine manufacturers and suppliers. China and the U.S. are the world's two largest markets in terms of installed wind power capacity. Following dramatic growth in installations, leading European turbines and key components suppliers shifted part of their manufacturing capacities to these two countries. In addition, many of the large European turbine suppliers are increasingly outsourcing components and materials to Asia, particularly to China, which 


\section{NAVIGANT}

has the world's largest wind power equipment manufacturing base. Although some OEMs hesitate to move away from established suppliers due to concerns over quality, economic pressures from declining turbine prices are driving manufacturers to accept higher risks to remain competitive (BTM 2011).

A lack of current U.S. offshore demand means few domestic manufacturing facilities are currently serving the global offshore wind market, with most opportunities limited to upstream materials (e.g., blade resins and reinforcement fibers) and subcomponents. However, recent estimates indicate that about $67 \%$ of land-based wind turbine content (as a fraction of total equipment-related turbine costs) installed in the U.S. was domestically sourced in 2011 (Wiser 2012b). Unfortunately, specific percentages of domestic sourcing versus imports on a component-bycomponent basis are not available due to limited trade reporting requirements (Wiser and Bollinger 2011). While this limits the ability to assess the strength and depth of domestic supply for specific components, strong overall domestic supply capacity for the U.S. land-based wind market suggests that potential exists to supply significant portions of the future offshore market domestically. This may particularly be the case among global leaders in the offshore wind supply chain that have an established presence in the U.S. to serve landbased demand.

Due to uncertainty in the U.S. market and overcapacity in China, many global wind suppliers are moving into new strategic markets such as India, Eastern Europe, Latin America and the U.K., while focusing offshore efforts on the U.K. and Germany. Activity in these markets represents direct competition for manufacturers' potential investments in a future

U.S. offshore market.
U.S. manufacturing facilities that serve the land-based wind market may have opportunities to add or shift capacity to serve the offshore market, particularly if those facilities are well-positioned near coasts where offshore projects are being developed. Manufacturers will need to spend the time to verify that they can meet OEM's higher quality requirements for offshore turbine components.
Recently, manufacturers have been facing important strategic decisions in diversifying their markets due to uncertainty in the U.S. market and the challenge of overcapacity in China. As a result, many suppliers are moving into new strategic markets such as India, Eastern Europe, Latin America, and the U.K., while focusing their offshore efforts in particular on the U.K. and Germany. Recently launched local-content requirements in Brazil, Canada, and India are also encouraging such a trend. Each of these global markets-whether for land-based or offshore windrepresent direct competition for manufacturers' potential investments in a future U.S. offshore market.

As a result of the above trends, many manufacturing facilities that were geared to the fast-growing U.S. and Chinese markets are now running at part load. For the land-based wind market, therefore, recent studies

suggest there is enough capacity in the supply chain to serve expected near-term growth, with some potential concerns over supplies of rare earth elements (for permanent magnet generators) and larger- 


\section{NAVIGANT}

sized bearings and forgings (BTM 2011). For the offshore market, however, the recent introduction of multi-MW turbines (mostly 5-6 MW) by turbine manufacturers in both Europe and China increases such supply concerns over these strategic components (e.g., bearings and other forgings) for these larger turbines. This is partly because it takes time for the supply chain to prepare for mass production of such large parts that can meet OEMs' increased quality requirements for offshore turbines. Moreover, in some cases these components are larger than have ever been produced for any industry.

In some cases, U.S. manufacturing facilities operating at part load may have opportunities to shift or retool some capacity to serve the offshore market, particularly if those facilities are well-positioned near coasts where offshore projects are being developed. For facilities located further inland, logistical concerns associated with larger components (e.g., feasibility and cost of overland transportation) may preclude the plant from serving as a cost-effective option to OEMs. In the case of shifting or adding capacity for the offshore market, manufacturers will require additional investments and will need to spend the time to verify that they can meet OEMs' higher quality requirements for offshore turbine components. The duration of such facility ramp-up and product qualification may be lessened for U.S.based facilities that are directly linked to OEMs already present in the offshore wind markets of Europe and Asia.

The likelihood of U.S.-based offshore manufacturing capacity will also depend on turbine suppliers perceiving stable, long-term policy support and subsequent demand for offshore wind in the U.S. market. In addition, they must have access to (or train) a sufficiently skilled workforce and appropriate logistical and installation capabilities. Manufacturers must then weigh these factors in the context of the global offshore market. For example, under a moderate-growth scenario (see Chapter 2.2), the U.S. would add approximately 3.5 GW of offshore capacity in 2020. Some forecasts expect same-year offshore capacity additions in Europe to approach 10 GW (BVG 2012). While no annual capacity forecast yet exists for China, the country has a stated goal of reaching $30 \mathrm{GW}$ of cumulative offshore capacity by 2020 (GWEC 2012), which would require an average of 3 to $4 \mathrm{GW}$ per year beginning in 2012.

While other forecasts show a somewhat slower increase in global offshore capacity additions, the European market's head start and momentum is more likely to continue to attract near-term investments in offshore manufacturing. Even with its established track record and ability to share resources across several countries, the European market continues to face a short supply of skilled staff that are trained and capable of installing and maintaining offshore wind projects.

The likelihood of U.S.-based offshore manufacturing capacity will depend on turbine suppliers perceiving stable, long-term policy support and subsequent demand for offshore wind in the U.S. market. As a result, the European market's head start and momentum is more likely to continue to attract nearterm investments in offshore wind turbine manufacturing.

\subsubsection{Regional Considerations for Offshore Wind Plant Design and Supply}

Developing offshore wind in the U.S. introduces the possibility for additional technical considerations that developers and manufacturers might need to address in each of five different regions (the North 


\section{NAVIGANT}

Atlantic, South Atlantic, Great Lakes, Gulf Coast, and the Pacific Coast). Principally, these include hurricane risk that persists along the southern portions of the Eastern seaboard and Gulf Coast regions and surface and blade icing in the freshwater Great Lakes and potentially other northern latitudes. Additional considerations such as floating platform technology will also come into play for areas of greater water depth.

Icing risks primarily manifest in the form of surface ice, which can place significant additional loads on turbine foundations and towers (Musial and Ram 2010). Turbines placed in the Baltic Sea have successfully managed icing loads, but icing in the Baltic Sea has likely been mitigated by the salt content of the water there (Musial and Ram 2010). The first freshwater offshore wind installation was completed in Lake Vanern, Sweden, in 2009 (4C Offshore 2012). As of the time of this writing, no significant icing issues had been announced. Nevertheless, parts of the Great Lakes frequently observe significant surface-ice buildup, and this factor will need to be incorporated into both the siting and design of offshore turbines placed in the Great Lakes or in other northern latitudes. Engineering solutions do exist to overcome icing risks; however, it is not unreasonable to think that an incremental cost will be added for projects placed in localities with a potential for significant surface icing or turbine and blade coating.

Hurricanes pose a different set of risks, the greatest of which is extreme wind gusts. Extreme loads might also result from hurricane-generated waves, sustained high winds, increased wave frequency, rapid directional wind changes, and other forces (Musial and Ram 2010). Some OEMs (e.g., Vestas) have begun to offer anti-cyclonic technologies designed to address the extreme gust conditions created by hurricanes and typhoons for land-based installations in coastal regions and tropical island environments such as the Caribbean or South Pacific (Vestas 2012). Such approaches typically allow for the turbine to maintain yaw and pitch control at wind speeds up to $150 \mathrm{mph}$. By keeping the turbine blades feathered and faced into the wind the turbine is able to shed much of the potential extreme loading that could result from hurricane-force winds (Vestas 2012). Manufacturers may also utilize tower reinforcement strategies or rely on smaller rotors (with a subsequent penalty on energy production) in order to further reduce loads from extreme wind events (Vestas 2011a). Similar to icing risks, the ability to address and resolve the challenges presented by hurricane-force winds is primarily an engineering one, but will also depend on the ability to analyze risks in a uniform and consistent way. An incremental increase in cost and potentially lower energy production may result in future designs geared towards withstanding hurricane conditions.

From a wind resource perspective, NREL has completed a preliminary offshore study of coastal states using similar geographic regions: the East Coast (including New England, the mid-Atlantic states, and the South Atlantic Bight); the West Coast (California and the Pacific Northwest); the Great Lakes region; the Gulf of Mexico; and Hawaii (Schwartz, et al. 2010). New resource maps (see Figure 2-2) indicate immense areas of suitable wind resources (average wind speeds $7.5 \mathrm{~m} / \mathrm{s}$ and higher) within $50 \mathrm{Nmi}$ of shore. Table 2-1 provides an overview of key characteristics of each of the five regions. 


\section{NAVIGANT}

Figure 2-2. U.S. Offshore Wind Resource at 80 Meters above the Surface

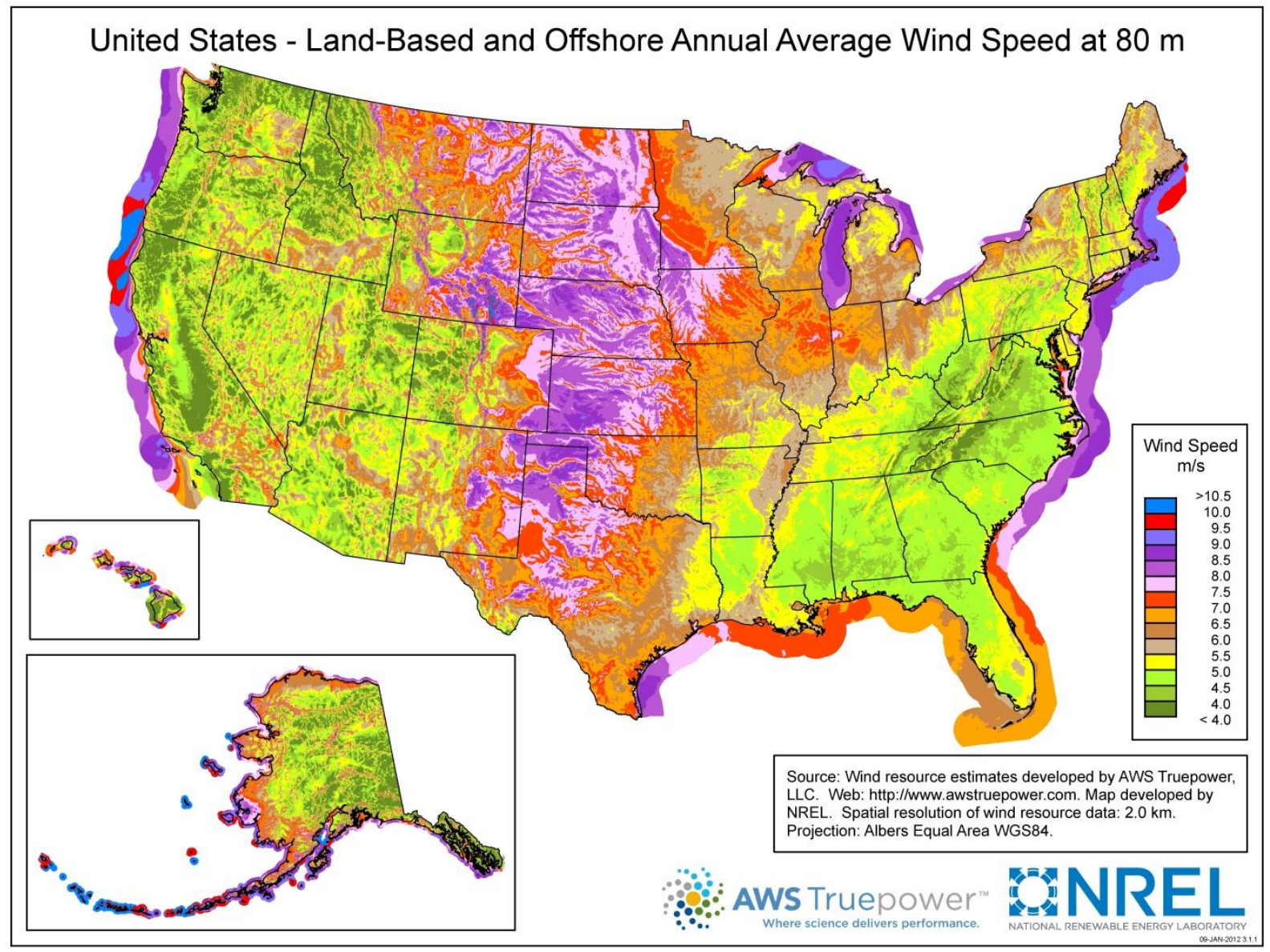

Source: Contributed by NREL. 


\section{NAVIGANT}

Table 2-1. Regional Characteristics Affecting Offshore Wind Development in the U.S.

Region States Wind Resource Key Characteristics

» Location of near-shore wind-speed gradients and specific areas of higher-wind classes are unclear.

$\begin{array}{ll}\text { North Atlantic } & \text { CT, DE, ME, MD, } \\ \text { MA, NH, NJ, NY, RI } \quad 8-10 \mathrm{~m} / \mathrm{s}\end{array}$

» Large areas of shallow water are well suited to current technology; however, waters are generally deeper than in the South Atlantic, especially in Maine.

» Extreme conditions are driven by lower intensity hurricanes and frequent and widespread winter storms that are usually within currently prescribed design standards.

» The offshore area known as the South Atlantic Bight (comprising SC, GA, and FL) forms a large area of shallow-water resource farther from shore. Despite lower wind speeds than further north, milder climate and shallow water may provide overriding benefits for offshore wind projects.

South Atlantic FL, GA, NC, SC, VA $\quad 6.5-8.5 \mathrm{~m} / \mathrm{s}$

» Thermal changes caused by the Gulf Stream may influence far-shore wind-speed prediction.

» Hurricanes are a concern, but each site must be evaluated with respect to its unique conditions. Storm tracks and intensities are dependent on coastal geography and latitude.

» Each lake has unique bathymetry, environmental, and socioeconomic issues.

» Local and state governments will largely determine offshore wind development parameters.

$\begin{array}{ll}\text { Great Lakes } & \text { IL, IN, MI, MN, NY, } \quad 7.5-9.5 \mathrm{~m} / \mathrm{s}\end{array}$

» Canadian interest may offer market development synergies, though efforts are currently on hold.

» Freshwater surface-ice floes will be a major design driver for any offshore turbines.

» Lower wave heights than ocean areas will lessen hydrodynamic loading requirements.

» Strongest wind potential occurs in the western Gulf, from Corpus Christi to the Mexican border.

» Texas is in a unique position to influence offshore development because its state boundary waters extend 9 Nmi from shore, whereas other coastal state waters end at $3 \mathrm{Nmi}$.

» Hurricanes will not preclude installing offshore wind turbines in the Gulf, but this additional risk factor must be considered in the structural design of any turbines that are installed.

»Some good wind resource areas exist near shore, but a narrow continental shelf limits the shallow-water resource. Deep water technology may be essential to widespread development.

Pacific Coast $\quad$ CA, OR, WA $\quad-10 \mathrm{~m} / \mathrm{s}$

» Sea ice is not an issue; extreme conditions are storm driven, with little risk from hurricanes.

» Potential for earthquakes and higher average sea-states may increase fatigue concerns on offshore wind turbine structures.

Source: Adapted from NREL (2010). 


\section{NAVIGANT}

\subsection{Assumptions for Estimating Supply Chain Requirements}

This section describes assumptions used in estimating potential regional requirements and market values for various offshore wind turbine components and materials under each of three potential scenarios. These scenarios combine varying levels of demand growth and technological advancement to help identify any differential effects these two factors may have on future supply chain requirements, market sizes, and activity. Each technology profile includes a subsequent set of assumptions about the average size, type, or amount of several key components and materials in an effort to approximate the effects of current trends in turbine design (e.g., larger components, direct drives, and new foundation concepts).

The section first discusses the methodology and assumptions used in developing the regional deployment scenarios and technology profiles. It briefly describes some of the region-specific considerations that may affect the development of demand (and regional supply chain opportunities) in each region. It then introduces the general approaches used to define the component and material assumptions underlying each technology profile, as well as the estimated range of those components' and materials' potential future market values. Details for many assumptions appear in Appendix D.

\subsubsection{Regional Deployment Scenarios}

The Navigant Consortium developed three scenarios that estimate potential offshore market demand growth in each of four U.S. coastal regions (the Atlantic Coast, Great Lakes, Gulf Coast and Pacific Coast). The primary goal of these scenarios is to provide a basis for comparing the effects on supply chain requirements of changes in either technological advancements or increasing demand for offshore wind. Readers should note that none of the scenarios are intended as a forecast of future demand for offshore wind. Rather, the scenarios estimate theoretical rates of regional capacity growth under varying sets of assumptions for cumulative demand in each region by 2020 and 2030. Table 2-2 lists these cumulative capacity targets for each region under three scenarios: high growth, moderate growth, and low growth. 


\section{NAVIGANT}

Table 2-2. Regional Deployment Scenario Targets and Technology Profiles

\begin{tabular}{|c|c|c|c|c|c|c|c|}
\hline \multirow{2}{*}{\multicolumn{2}{|c|}{ Scenario }} & \multicolumn{2}{|c|}{$\begin{array}{l}\text { High Growth } \\
54 \text { GW by } 2030\end{array}$} & \multicolumn{2}{|c|}{$\begin{array}{l}\text { Moderate Growth } \\
28 \mathrm{GW} \text { by } 2030\end{array}$} & \multicolumn{2}{|c|}{$\begin{array}{l}\text { Low Growth } \\
10 \text { GW by } 2030\end{array}$} \\
\hline & & 2020 & 2030 & 2020 & 2030 & 2020 & 2030 \\
\hline \multicolumn{2}{|c|}{$\begin{array}{l}\text { Total Capacity Deployed } \\
\text { by Milestone Date (in GW) }\end{array}$} & 7 & 54 & 3.5 & 28 & 1 & 10 \\
\hline \multirow{4}{*}{$\begin{array}{l}\text { Regional } \\
\text { Distribution }\end{array}$} & Atlantic & 4 & 28 & 2.0 & 12 & 1 & 8 \\
\hline & Great Lakes & 1 & 6 & 0.5 & 4 & 0 & 1 \\
\hline & Gulf Coast & 1 & 5 & 0.5 & 4 & 0 & 1 \\
\hline & Pacific Coast & 1 & 15 & 0.5 & 8 & 0 & 0 \\
\hline \multirow{5}{*}{\multicolumn{2}{|c|}{ Technology Profile }} & \multicolumn{2}{|c|}{ Today's Standard } & \multicolumn{2}{|c|}{ Today's Standard } & \multicolumn{2}{|c|}{ Today's Standard } \\
\hline & & \multicolumn{2}{|c|}{ Next Generation } & \multicolumn{2}{|c|}{ Next Generation } & \multicolumn{2}{|c|}{ 1st Generation Floating } \\
\hline & & \multicolumn{2}{|c|}{ Future Advanced } & \multicolumn{2}{|c|}{ Future Advanced } & \multicolumn{2}{|c|}{ Next Generation } \\
\hline & & \multicolumn{2}{|c|}{ 1st Generation Floating } & \multicolumn{2}{|c|}{ 1st Generation Floating } & & \\
\hline & & \multicolumn{2}{|c|}{ 2nd Generation Floating } & \multicolumn{2}{|c|}{ 2nd Generation Floating } & & \\
\hline
\end{tabular}

Source: Navigant 2012

As indicated by the "Technology Profiles" listed in Table 2-2, the team made additional assumptions about the level of technological advancement achieved in each of the three scenarios. Appendix D provides further detail on these technology profile assumptions, including assumed ranges for various turbine specifications (e.g., capacity, rotor size, etc.).

\section{Methodology for Producing Detailed Deployment Scenarios}

The Navigant Consortium based its high-growth scenario on the U.S. DOE's " 20 percent Wind by 2030" report, which indicates that $54 \mathrm{GW}$ of offshore wind would be required to optimize the delivered costs of wind power to meet the 20 percent capacity scenario (U.S. DOE 2008). This wind power capacity was then distributed among the four regions in a manner that would achieve estimated threshold levels of demand that are likely to be necessary to support development of regional supply chains for a given set of technology assumptions. ${ }^{5}$ These capacity allocations ignore the potential impact of or need for some form of national or state policy support.

The scenarios include the following assumptions regarding the development of advanced offshore wind technology:

1) Atlantic Coast: Development on the Atlantic Coast is largely feasible using current technologies.

2) Great Lakes: Development in the Great Lakes is feasible given current technologies; however, both surface icing and blade icing are issues that need to be considered and addressed.

\footnotetext{
${ }^{5}$ Without adequate anticipated demand for annual capacity additions, it is unlikely that manufacturers will build facilities in a particular region. Without a local supply chain and infrastructure, however, building offshore plants in those regions is more likely to be cost prohibitive (e.g., it's likely more expensive to ship blades and towers from Asia to Oregon rather than having some components supplied domestically).
} 


\section{NAVIGANT}

3) Gulf Coast: Siting offshore wind turbines in the Gulf of Mexico may depend on the development of hurricane-resistant designs, changes which may affect turbine and project economics.

4) Pacific Coast: Large-scale development of offshore wind in the deeper waters along the Pacific Coast is expected to depend on the design and demonstration of floating foundations.

The moderate-growth scenario represents a decrease in aggregate demand versus the high-growth scenario (approximately 50 percent), but uses the same assumptions regarding improvements in turbine technology. In addition to further reduced demand, the low-growth scenario also assumes slower development of next-generation technologies and, as a result, delayed deployment of offshore wind in the Great Lakes and Gulf Coast regions. This low-growth scenario also assumes that the industry fails to produce an economically viable floating foundation, effectively negating any capacity additions along the Pacific Coast.

Using the theoretical capacity allocations from these scenarios, the team next used NREL's Regional Energy Deployment System (ReEDs) model to predict where the prescribed capacity is most likely to occur within each region based on several factors. ReEDs is a capacity expansion model that considers wind resource, load growth, costs for new transmission, and costs for technology (among other factors) in determining an economically optimal distribution of new electricity generation resources. The distribution of projects shown in Figure 2-3 indicates the economically optimal sites for the regional offshore wind capacity demand levels prescribed in the high-growth scenario.

Note that this map is not intended as a forecast of future offshore wind capacity; rather, it predicts where installations are likely to occur by 2030 under the theoretical regional capacity targets set for the highgrowth scenario. In this instance, the model was "forced" to build offshore wind in each of the four regions in accordance with the regional capacity totals outlined in Chapter 2.2.1, meaning it shows where capacity is likely to occur within each region if those regional demand levels were achieved. ${ }^{6}$ Notably, it does not consider either current or future policy in allocating this capacity. To the extent that policy, regulatory regimes, technology, or other factors play a role in the future siting of offshore wind facilities in the Continental United States, actual deployment patterns could vary from that modeled herein.

As shown in Figure 2-3, the ReEDs model outputs projected that major offshore wind capacity installations could be located in the Northeast, the mid-Atlantic, the Pacific Northwest, Northern California, Lake Erie, Lake Michigan, and off the coasts of Texas and the Florida panhandle. Installations would likely also occur in other parts of these regions, although they are generally $<1$ GW in capacity.

\footnotetext{
${ }^{6}$ The ReEDS model used the overall capacity targets for the entire Atlantic Coast in its optimization. This means that the model sought the economically optimal location for that capacity between the southern tip of Florida and the northern coast of Maine. As shown, the model placed the majority of this capacity along the mid-Atlantic and New England coasts, based primarily on factors related to expected load growth, electricity costs, and transmission issues.
} 


\section{NAVIGANT}

Figure 2-3. Modeled Distribution of Offshore Wind in the Continental U.S. Assuming Regional Deployment Consistent with the High-Growth Scenario

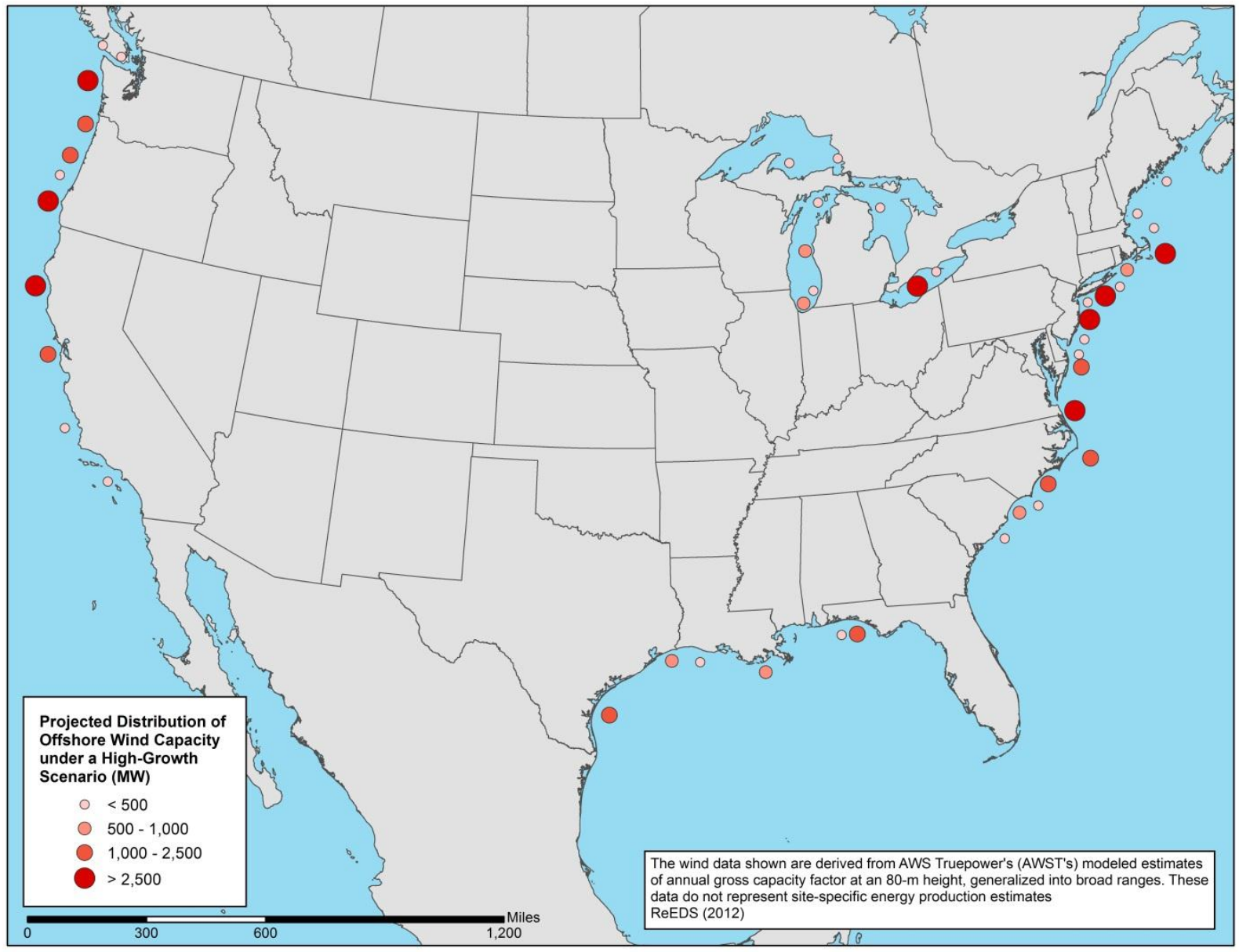

Source: Map courtesy of NREL

Within and between these regions, technology requirements are expected to vary based on wind regimes, seabed conditions, water depth, bathymetry, hurricane risk, icing risk, and other factors. Navigant's analysis has also determined that there will be substantial demand for multiple foundation types including monopiles, jackets, GBS, and floating. Within the various deployment scenarios, analysis of bathymetry and seabed conditions at the points identified as potential locations for development by ReEDs indicates that monopiles, jackets, and GBS are each estimated at roughly one-third of total foundations (by capacity). In the highgrowth scenario, activity is more robust on the West Coast, requiring about $6 \%$ of all foundations nationwide (or $22 \%$ of capacity on the Pacific Coast) to be floating.

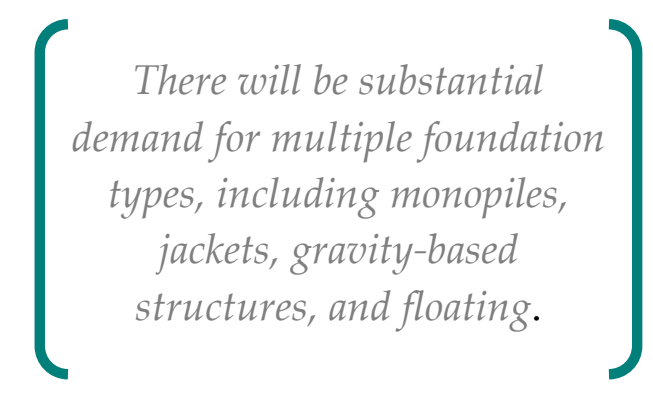




\section{NAVIGANT}

\section{Summary of Modeled Annual Capacity Additions}

Once the team decided on the aggregate regional capacity targets for each of the three scenarios, we developed regional demand growth curves to help allocate the deployment of that capacity over time. The team used the historical growth curves from the U.S. land-based wind market and the European offshore wind market to develop reasonable bounds for the annual rate of growth in the three scenarios used in this analysis. The resulting annual (i.e., incremental) capacity additions modeled for each region appear in Figure 2-4, Figure 2-5, and Figure 2-6 (one for each scenario) on the following pages (note the differing scale in each figure). For the Atlantic Coast, the team created North and South Atlantic subregions and allocated each one a share of targeted capacity based on the location of outputs from the NREL's ReEDs model. Numerical tables detailing the annual incremental capacity additions and cumulative totals in 2020 and 2030 by region appear in Appendix D.

Figure 2-4. Modeled Annual Capacity Additions by Region: High-growth Scenario

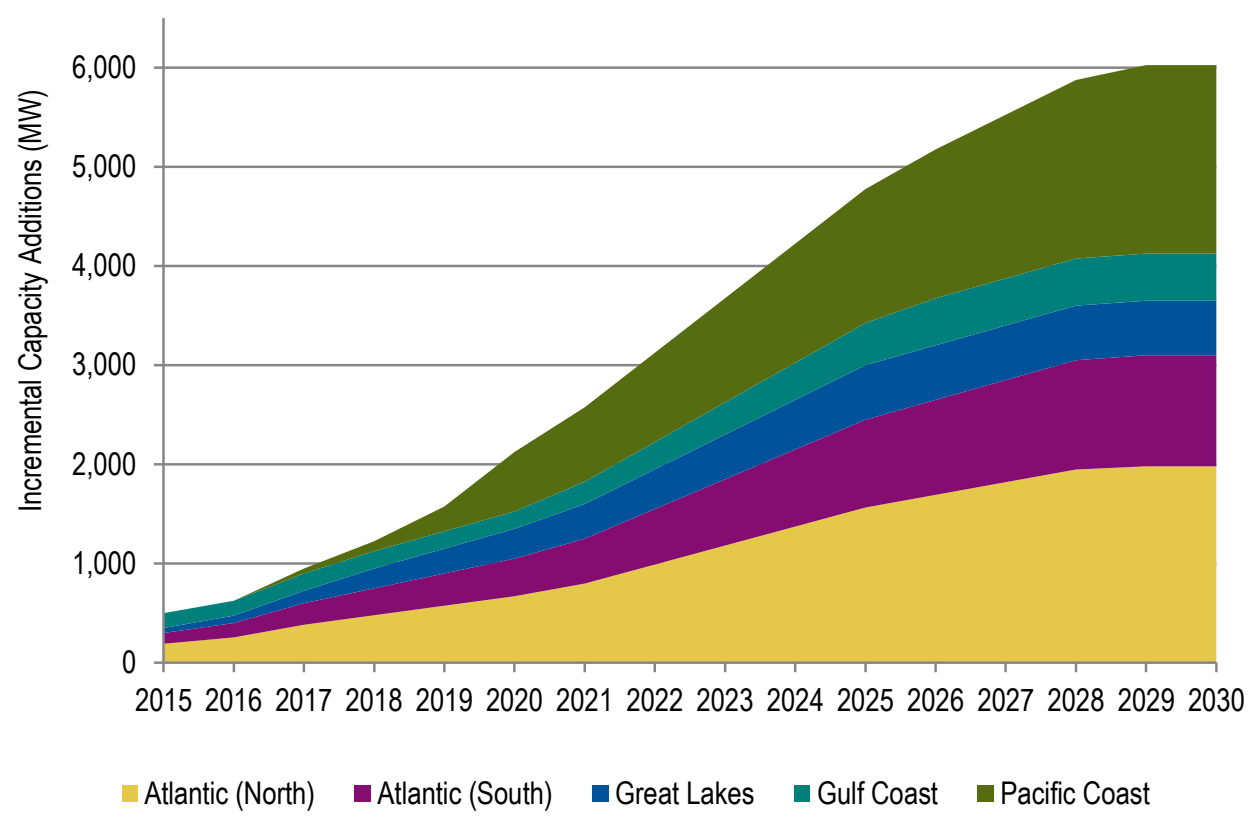




\section{NAVIGANT}

Figure 2-5. Modeled Annual Capacity Additions by Region: Moderate-Growth Scenario

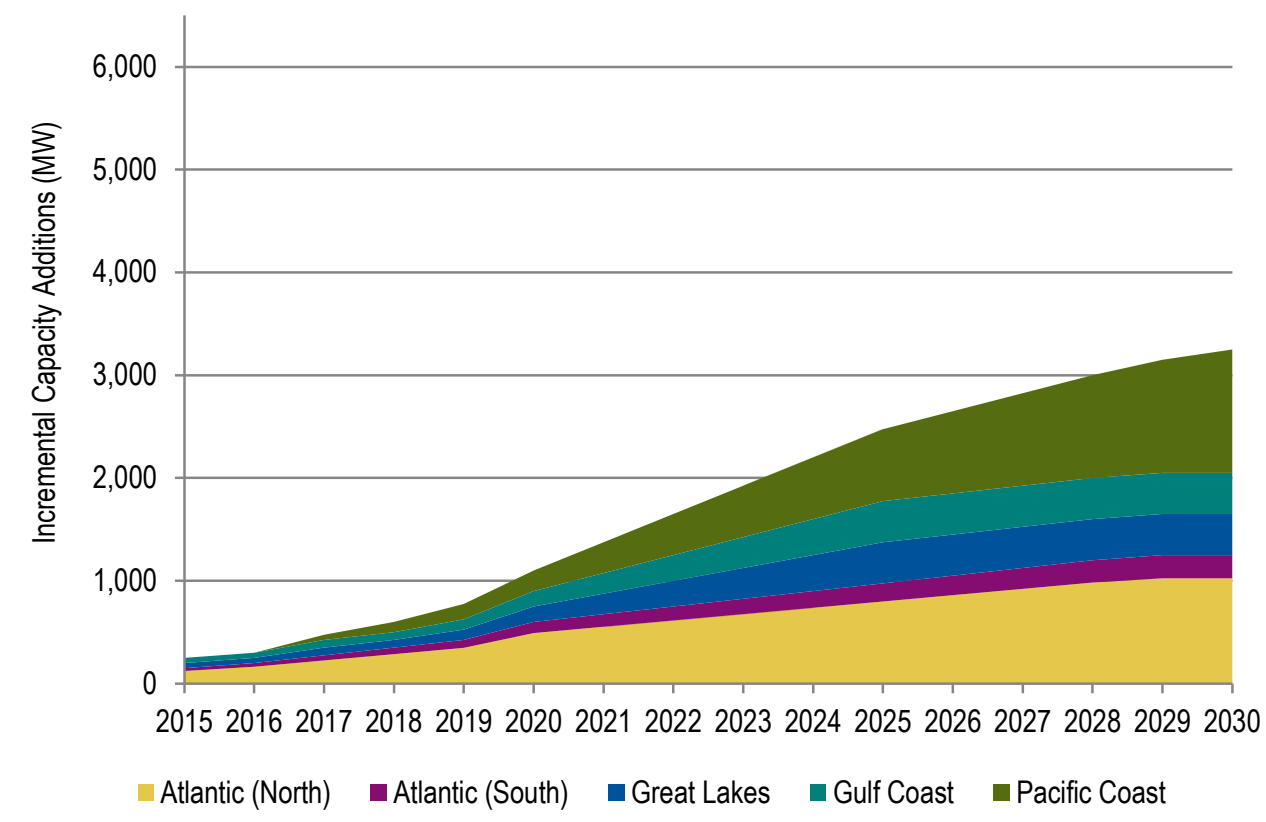

Figure 2-6. Modeled Annual Capacity Additions by Region: Low-growth Scenario

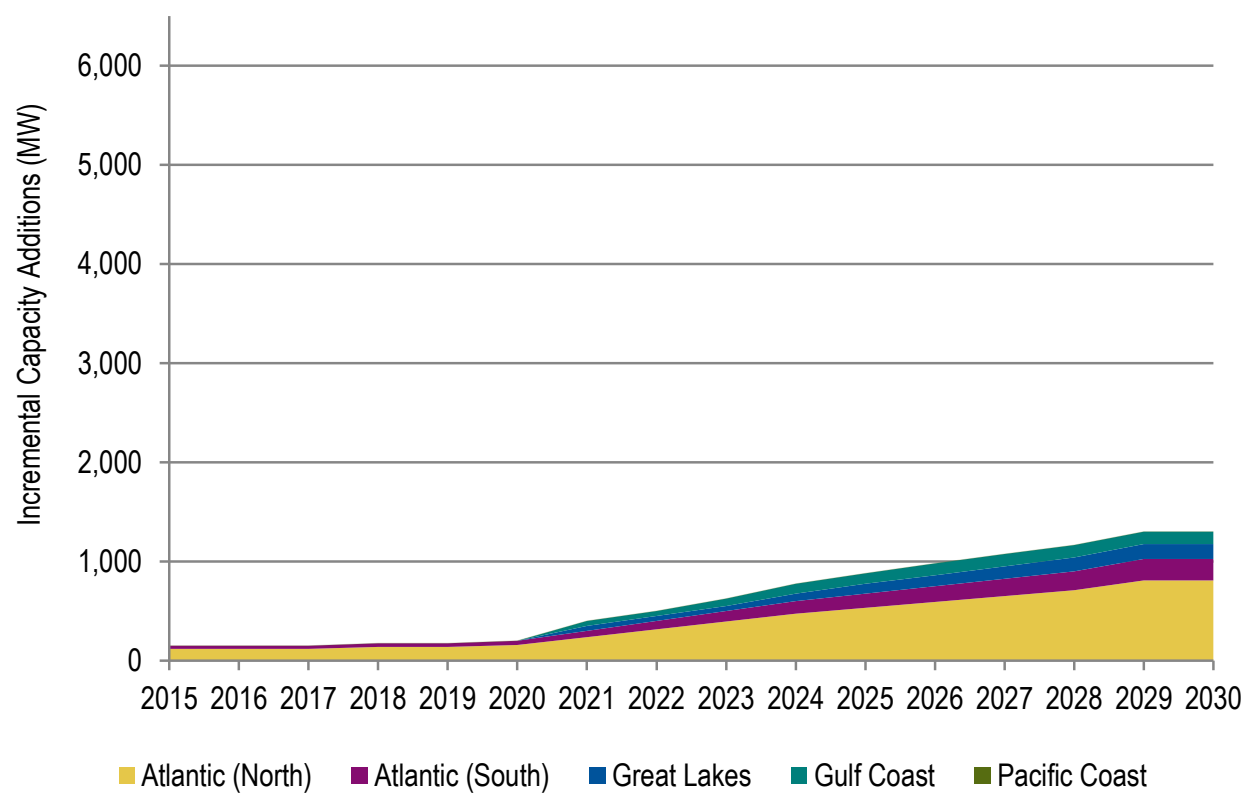

\subsubsection{Component and Material Requirement Assumptions}

Given the relatively early stage of the offshore wind market and the uncertain evolution of the technologies involved, it is impossible to predict with any certainty the average size or configuration of 


\section{NAVIGANT}

components that will be required by the U.S. offshore wind market. However, in order to provide an order-of-magnitude estimate of the potential market size for major turbine components and materials, the team made numerous assumptions about the expected state of offshore wind technology over the model period (2015-2020). Where possible, these assumptions were based on published information from manufacturers and industry literature. In other cases, the team relied on inquiries with manufacturers, NREL's Cost and Scaling Model (NREL 2006), and expert judgments from members of its research consortium. Notably, manufacturers were hesitant to provide explicit details of either current or planned equipment designs, citing intellectual property and confidentiality concerns. In addition, unique design approaches between manufacturers of similar-sized turbines can lead to wide ranges of expected values for details such as blade length or tower height.

In light of this uncertainty, we sought to provide a transparent record of the assumptions used in this analysis. A complete list of these assumptions appears in Appendix D, and includes an estimate of the number or quantity of each component or material required on a per-turbine basis under each of five technology profiles (three for fixed-foundation turbines and two for floating turbines). Note that any deviations from these assumptions may have a significant effect on the per-MW component requirements and market-size estimates discussed in Chapter 2.3. For example, differences in the assumed average turbine size for a particular time period can result in a far different estimate of the number of turbines required in a particular year or region. However, this estimate of the number of turbines required serves as the baseline against which other requirements were calculated (e.g., number of bearings, tons of steel for towers, etc.). Readers are cautioned to review these assumptions carefully and rely on their own judgment when making decisions about the future U.S. offshore wind market.

\subsubsection{Market Value Assumptions}

For each component or material covered by this analysis, the team estimated $\$ / \mathrm{MW}$ (for components) or $\$$ /tonne (for materials) assumptions based on industry literature and historical commodity cost records and projections. These assumptions, and a description of the sources, are listed in Appendix D. We then applied these assumptions to each component or material's corresponding 2020 market-size estimate for the moderate-growth scenario to generate a corresponding order-of-magnitude projection of the potential market value. For simplicity, each market value estimate in Chapter 2.3 reflects the moderategrowth scenario only; however, readers can use the provided assumptions to calculate the same estimate for the low- or high-growth scenarios.

While it is possible that industry learning effects may lower the per-unit costs of some components and materials over time, such effects are generally only estimated for the overall LCOE or, at best, overall turbine capital cost. Attempting to estimate component-level learning effects is likely to introduce unnecessary noise to the analysis. In the interest of acknowledging these potential learning effects and minor variations in turbine designs, market values are reported within $\pm 10 \%$ of the calculated value. Again, readers are cautioned to use their own judgment in making investment or policy decisions based on this analysis.

\subsection{Component-level Requirements and Opportunities}

This section discusses relative levels of opportunity for supplying various components to a future offshore wind industry in the U.S. It begins by presenting the framework used in this report to evaluate 


\section{NAVIGANT}

and summarize component-specific opportunities. It then discusses each major component and ranks the potential opportunity for supplying the associated equipment or materials required for a future U.S. offshore wind market.

\subsubsection{Framing the Potential Opportunities}

This subsection describes the framework under which this report summarizes potential market opportunities for suppliers of various offshore wind components. Each of the following subsections follows the same general outline:

» Introduction: A brief overview of the component and any relevant market trends to consider.

» Potential Market Size: The estimated quantity of each component required to meet regional demand under the three scenarios and approximate ranges of the resulting market value.

» Opportunity Summary: Estimates of three key indicators of potential opportunity to supply the component to the U.S. offshore market: timing of need for domestic manufacturing; current global supply outlook; and the transferability of manufacturing capacity between the land-based and offshore wind markets. Each subsection concludes with a brief summary of the overall opportunity to supply the future U.S. offshore wind market.

» Current U.S. Wind Market Suppliers: For most components, no U.S. facilities currently supply the offshore wind market, as supply chains have developed close to demand centers in Europe and (more recently) China. However, some U.S.-based (i.e., headquartered) firms serve the global offshore wind market from facilities in Europe or Asia. Further, many of the leading global offshore wind suppliers also have a U.S. presence to serve the domestic land-based wind market. Therefore, each subsection includes a list of these companies to help inform where opportunities may exist for suppliers to serve a future U.S. offshore market. For some components with no U.S.-based suppliers (e.g., offshore wind turbine generators), the section lists current global suppliers.

\section{Estimating Market Size: Focus on 2020}

For the purposes of characterizing the near-term market opportunity for U.S.-based suppliers, each subsection focuses on the potential annual (i.e., incremental) component requirements for the year 2020. We chose this date by balancing the following considerations:

» Based on current trends and market conditions, it was assumed that no large-scale capacity additions will occur in U.S. waters until 2015. However, offshore turbine OEMs are unlikely to consider large-scale investments in U.S.-based manufacturing facilities until they see evidence of long-term, stable support policies (e.g., financial incentives) and customer demand in a particular regional market.

» A commitment to build a large-scale turbine facility faces a several-year lag before it will begin production and translate into sourcing opportunities for domestic suppliers. Following a supplier's announcement that it intends to serve a particular market, site selection alone may take up to 1.5 years. From there, permitting, planning, contract negotiations, construction and commissioning may take another two years. 


\section{NAVIGANT}

" Based on the dynamic and uncertain nature of the market, the precision of assumptions about turbine designs (and the components they require), costs, and global supply and demand necessarily decreases over time. As a result, current global supply chain studies for the offshore wind market only attempt to forecast market demand and potential component shortages through 2015 or 2016.

Focusing our projected component requirements on 2020 balances the need to allow potential demand to reach meaningful levels with concerns about the reduced precision of longer-term assumptions. Given the scope of assumptions required for even these nearer-term projections, we intend that the component and material estimates in this chapter serve as order-of-magnitude data points for what may be required under the varying scenarios. Readers are cautioned to use reasonable care in their use of these outputs and scenarios.

\section{Opportunity Indicators}

The definitions and relative ranking scheme used for the three summary indicators are summarized in Table 2-3. Each of the subsequent subsections includes a graphic summarizing each of these indicators for that particular component.

\section{Table 2-3. Supply Chain Opportunity Framework}

\begin{tabular}{|c|c|c|c|c|}
\hline Indicator & Green & Yellow & Red & Notes \\
\hline $\begin{array}{l}\text { Expected timing of sufficient } \\
\text { demand to support domestic } \\
\text { manufacturing under moderate- } \\
\text { growth scenario }\end{array}$ & $2015-2020$ & $2021-2025$ & $\begin{array}{l}\text { Beyond } \\
2025\end{array}$ & $\begin{array}{l}\text { Includes assumptions about the likelihood of } \\
\text { domestic sourcing for large component (e.g., } \\
\text { towers, blades, foundations and nacelles). Earlier } \\
\text { expected timing indicates a more attractive } \\
\text { opportunity. }\end{array}$ \\
\hline $\begin{array}{l}\text { Probability of shortfall in global } \\
\text { offshore supply through } 2015\end{array}$ & High & Medium & Low & $\begin{array}{l}\text { Higher risks of global supply shortfalls indicate } \\
\text { increased opportunities for domestic suppliers. }\end{array}$ \\
\hline $\begin{array}{l}\text { Ease of transferability of land- } \\
\text { based supply to offshore market }\end{array}$ & High & Medium & Low & $\begin{array}{l}\text { Lower transferability indicates a greater risk of } \\
\text { adding or switching capacity to serve the offshore } \\
\text { market. }\end{array}$ \\
\hline Overall opportunity & Favorable & $\begin{array}{l}\text { Moderate/ } \\
\text { Cautious }\end{array}$ & High-Risk & $\begin{array}{l}\text { A summary ranking based on the three previous } \\
\text { indicators. }\end{array}$ \\
\hline
\end{tabular}




\section{NAVIGANT}

Each indicator includes the following assumptions:

» Timing of Domestic Manufacturing: Based on our research and interviews with manufacturers, we estimate that an investment in a full turbine manufacturing plant (including a foundry for large castings, and separate facilities for blade fabrication, tower fabrication, and nacelle assembly) requires regional demand of 100 to 150 turbines per year (or 500 to $800 \mathrm{MW}$ per year) for a minimum of 5 years, while a factory that manufacturers a single component would require market demand of approximately $300 \mathrm{MW}$ per year. Note that these capacity-driven trigger points capture only a portion of the criteria that manufacturers consider in their investment decisions. Other factors such as regional competition and geographic constraints will also come into play. We further assume that no single manufacturer will capture $100 \%$ of market share for any particular component.

» Probability of Global Supply Shortfall: The global supply chain indicator draws on recently published supply chain studies conducted for both the general wind energy market and the offshore wind market (BTM 2011, BVG 2012). Based on the dynamic nature of markets and the uncertainty around the offshore wind market in particular, no studies have attempted to forecast such shortages for a greater than 4-year period. Other offshore wind supply chain studies focus on forecasted European market demand, as that market still represents the majority of expected near-term capacity additions. In either case, accurate estimates of facility- or manufacturer-level supply capacities are very difficult to obtain based on several factors, including companies' confidentiality concerns, differing abilities to split a facility's capacity between the land-based and offshore wind markets, and the fact that factories may not be running at full or announced capacities. This report, therefore, relies on the near-term, high-level analysis provided by these other recent reports. Note that in the component opportunity summary tables, a higher-risk of global supply shortfalls (which indicates a more favorable opportunity for potential U.S. suppliers) is indicated by a green box, while low risk of global supply shortfalls is indicated in red.

» Transferability: Rankings for this indicator are based on conversations with OEMs and market analysts, wind market supply chain reports, and industry news coverage. In some cases (e.g., subcomponents and materials), consideration was given to other markets and industries (e.g., aerospace) that suppliers could also serve.

\subsubsection{Offshore Wind Turbine Generators}

Offshore Wind Turbine Generators (WTGs) initially evolved as marinized versions of existing landbased turbines. Recent growth in offshore demand, however, has enabled the industry to develop further into an independent sector, and today's turbines are engineered more specifically for the offshore environment. These new designs consider issues such as wave loads, saltwater, greater distances from residences, more remote access, assembly processes, and the ability to use overall larger turbines and components. In addition to this increased reliance on offshore-specific designs, a continuing trend toward larger components and nacelles may make overland transport prohibitive from a cost and logistical standpoint. Therefore, future U.S.-based WTG manufacturing and nacelle assembly will likely require the development of new coastal facilities rather than relying on existing inland plants. 


\section{NAVIGANT}

\section{Potential Market Size}

The 2020 modeled turbine requirements for the three growth scenarios across all regions are shown in Table 2-4.

Table 2-4. Modeled 2020 Wind Turbine Requirements

\begin{tabular}{|c|c|c|c|c|c|}
\hline \multirow[b]{2}{*}{ Region } & \multirow[b]{2}{*}{ Unit } & \multicolumn{3}{|c|}{$\begin{array}{l}2020 \text { Annual Requirements by Growth } \\
\text { Scenario }\end{array}$} & \multirow{2}{*}{$\begin{array}{l}\text { Annual Market Value } \\
\text { (\$M/year) Medium- } \\
\text { Growth Scenario }\end{array}$} \\
\hline & & Low & Moderate & High & \\
\hline Incremental Capacity Addition & MW/year & 200 & 1,100 & 2,125 & \\
\hline North Atlantic & \#/year & 26 & 82 & 112 & $\$ 810-\$ 990$ \\
\hline South Atlantic & \#/year & 7 & 18 & 63 & $\$ 180-\$ 220$ \\
\hline Great Lakes & \#/year & 0 & 25 & 50 & $\$ 250-\$ 300$ \\
\hline Gulf Coast & \#/year & 0 & 25 & 29 & $\$ 250-\$ 300$ \\
\hline Pacific Coast & \#/year & 0 & 30 & 78 & $\$ 330-\$ 400$ \\
\hline TOTAL U.S. & \#/year & 33 & 180 & 332 & $\$ 1,820-\$ 2,200$ \\
\hline
\end{tabular}

In the moderate-growth scenario, aggregate U.S. demand would reach $1.1 \mathrm{GW} /$ year in 2020, representing a total market value of $\$ 1.8$ to $\$ 2.2$ billion. More than half of this demand (approximately 100 turbines) would fall along the Atlantic Coast. Figure 2-7 illustrates the modeled annual demand for turbines under the moderate-growth scenario. Readers should note that this growth curve represents, under the moderate-growth scenario, the modeled annual demand for any turbine component for which a single unit is required for each turbine (e.g., drivetrains, power converters, towers, foundations, etc.). Appendix E includes similar graphs of annual turbine demand for the high- and low-growth scenarios.

Figure 2-7. Modeled Annual Turbine Demand: Moderate-Growth Scenario

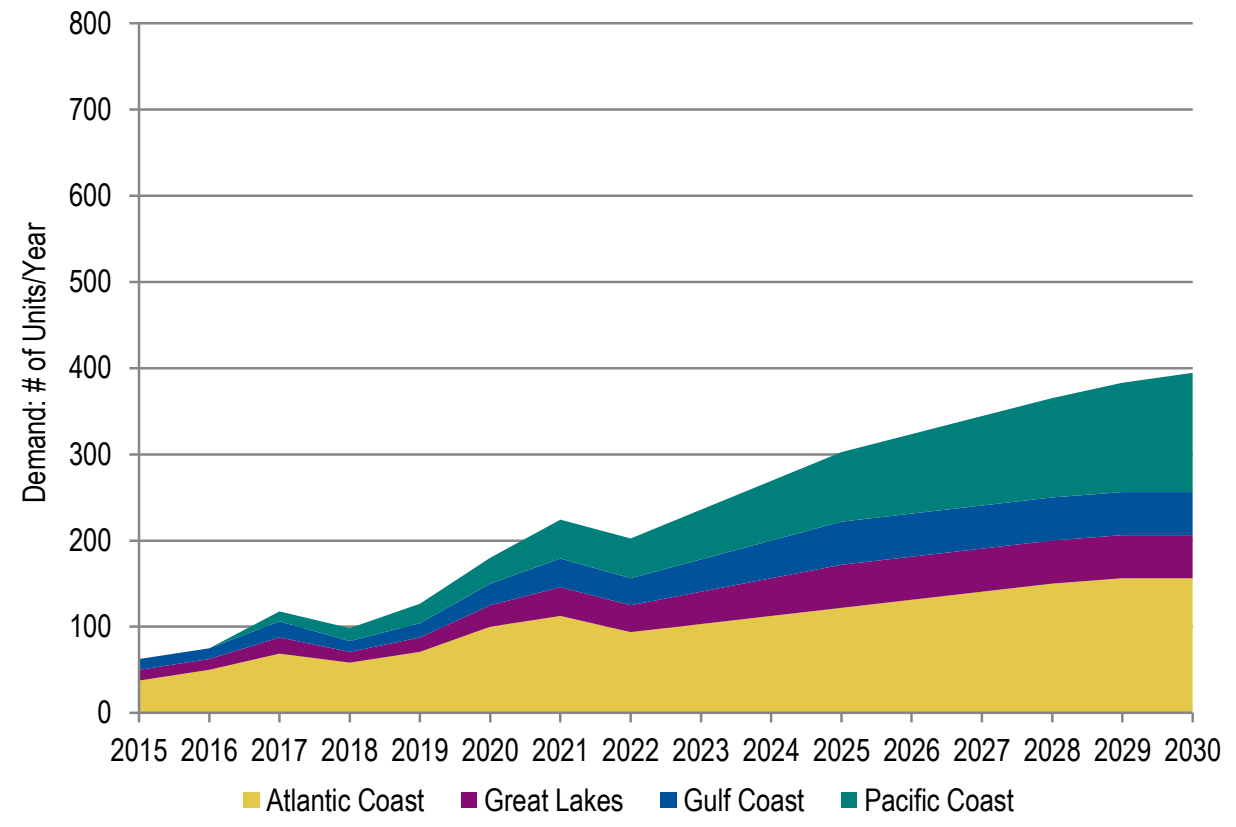




\section{NAVIGANT}

\section{Opportunity Summary}

For the U.S. market, attracting a full-scale, offshore WTG manufacturing facility (including blades, towers, and nacelles) to the Atlantic Coast might not be reasonably expected until 2021 to 2023 in the moderate-growth scenario. These are the projected dates when Atlantic Coast demand reaches 600-800 MW per year, which translates to between approximately 100 and 150 WTGs depending on the assumed average turbine size in each year (6-MW average in 2020, growing to $8 \mathrm{MW}$ by 2022). Capturing $50 \%$ of the Atlantic Coast's market share in either of these years would represent an annual capacity of 50-75 turbines, the low-end of industry estimates for the firm capacity required to support such an investment.

Under the more conservative low-growth scenario, aggregate demand along the Atlantic Coast may not reach sufficient levels to attract a WTG manufacturing facility until 2027. On the other hand, the demand modeled under the high-growth scenario could support such a facility by 2019. Note that this example reflects modeled capacity additions on the Atlantic Coast, which is considered to be the region most likely to see near-term offshore wind development. With anticipated later start dates and slower ramp up in demand, other regions are likely to reach capacity levels sufficient to attract WTG

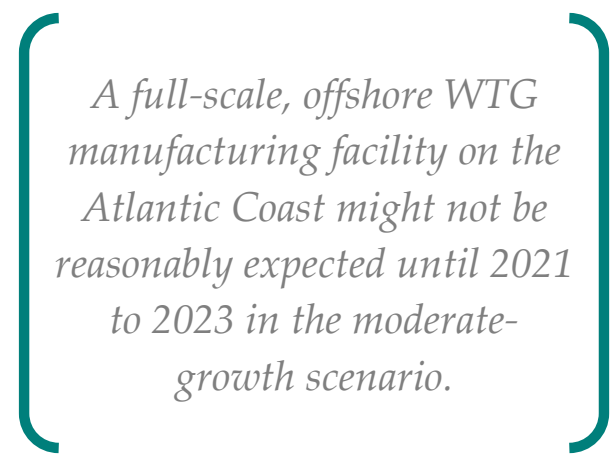
manufacturing facilities later than the Atlantic Coast. Table 2-5 illustrates the three opportunity indicators-including this timing consideration - for wind turbine manufacturing facilities.

\section{Table 2-5. Opportunity Indicators: Wind Turbine Manufacturing}

\begin{tabular}{|c|c|c|}
\hline Indicator & Rating 1 & Notes \\
\hline $\begin{array}{l}\text { Timing of Domestic } \\
\text { Opportunity }\end{array}$ & & $\begin{array}{l}\text { Moderate growth would require } 676 \mathrm{MW} / \text { year on the Northern Atlantic Coast by } 2023 \text {; or } \\
40-60 \text { WTGs/year for a facility with } 50 \% \text { market share. A facility for manufacturing offshore } \\
\text { nacelles requires minimum demand of } 50-200 \text { units/year. }\end{array}$ \\
\hline $\begin{array}{l}\text { Probability of Near-term } \\
\text { Global Shortfall }\end{array}$ & & Larger turbines ( $\geq 5$ MW) may be in short supply by 2015 . \\
\hline Transferability & & $\begin{array}{l}\text { WTGs require offshore-specific design and need to be assembled at coastal facilities due } \\
\text { to weight restrictions on rail transport. }\end{array}$ \\
\hline Overall Opportunity & & $\begin{array}{l}\text { A full nacelle assembly facility represents a riskier near-term opportunity, but will be } \\
\text { required as firm demand develops. }\end{array}$ \\
\hline
\end{tabular}

(1) See Table 2-3 for rating definitions

Table 2-5 also indicates that potential shortfalls in the global supply of larger offshore turbines could bolster the opportunity for domestic manufacturing if sufficient U.S. demand exists. Currently, sufficient capacity exists to meet forecasted European demand with offshore turbines in the 3-5 MW size range. However, if project developers instead show a preference for the larger, next-generation turbines $(\geq 6$ MW) currently under development, a recent report for the U.K. Crown Estate predicts that supplies of such turbines will be inadequate to meet European demand through 2018 (BVG 2012). As the market collectively moves in favor of these larger machines, it could lead to a critical bottleneck in WTG manufacture and assembly. For the U.S. market, the effects of this bottleneck for larger turbines may be 


\section{NAVIGANT}

lessened if initial U.S. projects rely on the smaller (3-5 MW), currently available turbines. Similarly, this issue may be of less concern if some European projects encounter significant delays, which could free some supply capacity for larger turbines for export to the U.S. market.

As China's offshore market is in its early stages, it is difficult to predict the degree to which its supply chain may affect the future U.S. market. While meeting its high-capacity targets ( 5 GW by 2015, and 30 GW by 2020) may leave little excess supply capacity for offshore components and turbines, a combination of overcapacity in the country's land-based wind supply chain, lower labor costs, and perceived tightness in the global supply chain for certain offshore wind components may encourage some manufacturers to consider export potential.

The third indicator for wind turbine manufacturing facilities reflects the limited transferability of production capacity between land-based and offshore WTGs. Single-car weight limits for U.S. railroads are approximately 140 tonnes (BNSF 2012, Union Pacific 2012); however, current weight estimates for assembled WTGs in the 5 to 6-MW range are 280-325 tonnes (4C Offshore 2012). In addition, the offshore wind market is increasingly utilizing offshore-specific turbines designs that are likely to have dedicated manufacturing lines located at or near port facilities. While such a coastal facility could also supply smaller turbines inland by rail, these facilities would be in suboptimal locations when it comes to landbased wind project sites. As a result of these factors, a new nacelle assembly facility represents a risky and unlikely near-term opportunity. However, such facilities are likely as firm demand develops in each region.

\section{Current Offshore Wind Market Suppliers}

Table 2-6 lists current manufacturers of wind turbines supplying the global offshore market, including the turbine sizes offered and the capacity of turbine deliveries confirmed through the end of 2011. Siemens and Vestas represent the majority (86\%) of delivered global capacity, though new firms continue to enter the offshore market, with a number of prototype and pilot projects announced. 


\section{NAVIGANT}

Table 2-6. Current Global Suppliers of Offshore Wind Turbines

\begin{tabular}{lccc} 
Manufacturer & Location & Turbine Sizes & $\begin{array}{c}\text { Confirmed Deliveries } \\
\text { through Year-End 2011 } \\
\text { (MWs) }\end{array}$ \\
\hline Siemens & Europe & $3.6 \mathrm{MW}$ & $2,032.75$ \\
\hline Vestas & Europe & $3.0 \mathrm{MW}$ & $1,396.55$ \\
\hline REpower (Suzlon acquired in 2011) & Europe (India) & $5.0 \mathrm{MW}, 6.15 \mathrm{MW}$ & 210 \\
\hline Sinoval & China & $3.0 \mathrm{MW}$ & 158 \\
\hline BARD & Europe & $5.0 \mathrm{MW}$ & 90 \\
\hline General Electric (GE) Energy ${ }^{1}$ & Europe & $4.1 \mathrm{MW}$ & 35.7 \\
\hline WinWinD & Europe & $3.0 \mathrm{MW}$ & 30 \\
\hline Areva Wind & Europe & $5.0 \mathrm{MW}$ & 30 \\
\hline Sewind & China & $3.6 \mathrm{MW}$ & 3.6 \\
\hline Goldwind & China & $3.0 \mathrm{MW}, 6.0 \mathrm{MW}$ & ${ }^{*}$ \\
\hline Mingyang & China & $3.0 \mathrm{MW}$ & ${ }^{*}$ \\
\hline Alstom & Europe & $6.0 \mathrm{MW}$ & ${ }^{*}$ \\
\hline Gamesa & Europe & $5.0 \mathrm{MW}$ & ${ }^{*}$ \\
\hline XEMC-Darwind & China & $5.0 \mathrm{MW}$ & $3,986.6$ \\
\hline \hline TOTAL & & & \\
\hline NOE: & & &
\end{tabular}

Note: *No capacity delivered by year-end 2011 or capacity could not be confirmed.

${ }^{1} \mathrm{GE}$ Energy is headquartered in the U.S.

Source: BTM 2011, a part of Navigant.

Figure 2-8 shows each manufacturer's share of the offshore turbine market based on confirmed orders for turbines installed by year-end 2011. 


\section{NAVIGANT}

Figure 2-8. Share of Installed Global Offshore Wind Capacity by OEM - Year-End 2011

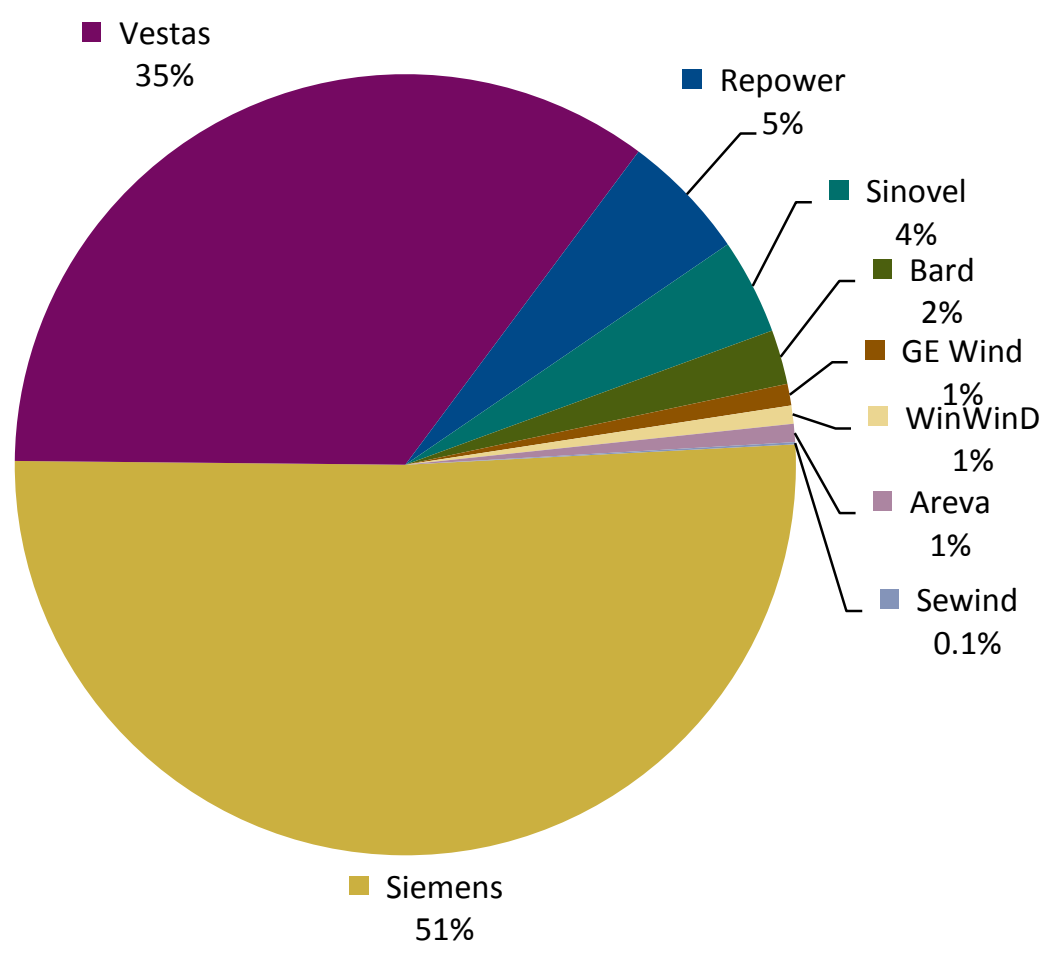

Source: BTM 2012, a part of Navigant.

\subsubsection{Gearboxes and Generators}

The wind turbine gearbox serves the purpose of converting the high torque from the main shaft into the lower-torqued, high-speed shaft that drives the generator. Long-bladed wind turbine rotors produce substantial torque while turning the main drivetrain shaft at relatively low rotational rates. As such, the gearbox is one of the most mechanically advanced components of a wind turbine, consisting of precision gears, bearings, shafts, and other parts that experience extreme forces, operating speeds, and temperatures. Reliability is paramount in offshore applications due to the logistical challenges of maintenance and repair. Offshore gearbox design, therefore, must be robust enough to withstand the torques experienced by large, multi-megawatt machines in marine conditions.

Recently, wind turbine design optimization philosophy has been shifting from a predominant reliance on gearboxes towards an increased use of direct-drive technology with large permanent magnet generators (PMGs). Especially in the growing offshore market, this trend has been motivated by customer demand for increased reliability (following experiences with bearing-related gearbox failures) and the higher power-to-weight ratios attainable in turbines with direct drives. Across the entire wind power market (both land-based and offshore), direct drives (annular and PMGs) represented 17.6\% of market share in 2010 and $21.2 \%$ in 2011. Based on manufacturer announcements, this trend will likely continue toward 25\% market share by 2015 (BTM 2012). A simultaneous shift to full-scale frequency converters is helping newer turbines meet grid compatibility requirements and allowing for more sophisticated operating strategies using variable rotor speed. As discussed in Chapter 1.2, however, 


\section{NAVIGANT}

manufacturers are not committing uniformly to these new technologies, as neither has been sufficiently proven for offshore applications. This is evident in the strategy adopted by Vestas (one of the two largest offshore turbine OEMs) to continue using a more typical geared solution for its offshore turbine designs.

An electric generator is required to convert the mechanical energy from the revolving blades into electrical energy for use on the grid. Three main types of generators-doubly fed induction generators (DFIGs), direct-drive annular generators (DD-Annular), and PMGs-represent the majority of the current global wind generator market.

\section{Potential Market Size}

Accurately forecasting the relative share of each type of gearbox or generator that will be used in a future U.S. offshore wind market is an unlikely task. Navigant relied on assumptions that foresee a gradual trend away from conventional gearboxes and toward direct drive and gearboxes with PMGs (see Appendix D for a list of detailed assumptions). Table 2-7 shows the resulting estimates of demand for each type of gearbox/generator combination in 2020 under the moderate-growth scenario. This table reports national demand levels under the assumption that these components can be shipped to assembly ports via ship or rail.

Table 2-7. Modeled 2020 Requirements for Gearboxes and Generators

\begin{tabular}{|c|c|c|c|c|c|}
\hline \multirow[b]{2}{*}{ Total U.S. } & \multirow[b]{2}{*}{ Unit } & \multicolumn{3}{|c|}{$\begin{array}{l}2020 \text { Annual Requirements by Growth } \\
\text { Scenario }\end{array}$} & \multirow{2}{*}{$\begin{array}{c}\text { Annual Market Value } \\
\text { (\$M/year) Moderate- } \\
\text { Growth Scenario }\end{array}$} \\
\hline & & Low & Moderate & High & \\
\hline Incremental Capacity Addition & MW/year & 200 & 1,100 & 2,125 & \\
\hline Conventional Gearboxes/Generators & \#/year & 17 & 90 & 166 & \\
\hline Gearbox w/ medium- or high-speed PMG & \#/year & 10 & 54 & 100 & \\
\hline Direct-drive Generators & \#/year & 7 & 36 & 66 & \\
\hline TOTAL & \#/year & 34 & 180 & 332 & $\$ 415-\$ 507$ \\
\hline
\end{tabular}

Note: Market value ignores potential split between different drivetrain types (see Appendix D).

\section{Opportunity Summary}

In general, it is likely that domestic supply of gearboxes and generators for the offshore market will coincide with the establishment of U.S.-based nacelle assembly facilities (2021-2023 for the moderategrowth scenario). In addition, the current uncertainty as to the most likely drivetrain configuration for turbines that far in the future (and the possibility of splitting already limited demand among several technologies) poses additional risks to investing in a particular offshore-specific manufacturing line. Table 2-8 shows the results of the three opportunity indicators for these key drivetrain components. 
Table 2-8. Opportunity Indicators: Gearboxes and Generators

\begin{tabular}{|c|c|c|}
\hline Indicator & Rating $^{1}$ & Notes \\
\hline $\begin{array}{l}\text { Timing of Domestic } \\
\text { Opportunity }\end{array}$ & & $\begin{array}{l}\text { Domestic supply of gearboxes and generators for the offshore market will likely coincide with } \\
\text { the establishment of U.S.-based nacelle assembly facilities (2021-2023). }\end{array}$ \\
\hline $\begin{array}{l}\text { Probability of Near- } \\
\text { term Global Shortfall }\end{array}$ & & $\begin{array}{l}\text { In general, global supply of gearboxes and generators (conventional, direct drive and PMG) } \\
\text { is expected to meet demand. Potential concerns exist about the pricing of direct drives and } \\
\text { PMGs stemming from the costs of rare earth minerals. }\end{array}$ \\
\hline Transferability & & $\begin{array}{l}\text { Units must be designed and manufactured specifically for offshore applications and therefore } \\
\text { have limited transferability to land-based turbines. However, a single facility could } \\
\text { reasonably manufacture for both land-based and offshore wind turbines, particularly if } \\
\text { located on the coast. }\end{array}$ \\
\hline Overall Opportunity & & $\begin{array}{l}\text { Established overseas suppliers and uncertainty in market share of conventional drivetrains } \\
\text { versus those with PMGs or direct drives weakens the near-term opportunity for U.S.-based } \\
\text { manufacturing. The best opportunity may lie with established suppliers with coastal facilities } \\
\text { who can serve both the U.S. and overseas offshore markets. }\end{array}$ \\
\hline
\end{tabular}

(1) See Table 2-3 for rating definitions

From a global supply perspective, only a dozen of more than 40 gearbox suppliers are currently serving the offshore wind market. At least five gearbox suppliers (Bevini, Winergy, Moventas, ZF Group, and GE Drivetrain Technologies) that serve the global offshore market also have facilities (though not yet producing offshore-scale gearboxes) in the U.S.

For electric generators, current supply chain capacity is characterized as follows:

» DFIGs. Nearly $90 \%$ of generator suppliers are capable of producing DFIG generators, and with DFIG recently losing market share to PMG, it is unlikely that it will be in short supply over the next 3-4 years. Most multi-MW DFIGs used for offshore turbines are supplied by established European producers with many years' experience of serving the land-based wind market (BTM 2011). Several of these manufacturers also have generator facilities in the U.S.

" Direct Drive (DD) Annular. Enercon is the sole user of a unique annular generator DD design (100\% produced in-house with no intention to outsource).

» PMGs. Permanent magnets are used to varying degrees in both direct-drive turbines (DD-PMG) and fast- or medium-speed, geared turbines (FSG/MSG) fitted with a PMG. Twenty different European and North American firms are capable of supplying PMGs to the wind industry, with three (ABB, The Switch, and Converteam) currently supplying the European offshore market. Notably, Converteam is majority owned by GE.

In general, market actors have indicated an industry shift toward PMGs, whether they be direct drive or FSG/MSG (BTM 2011). As stated above, this shift and the number of global suppliers manufacturing DFIGs makes it unlikely that the market will face a shortage of such generators in the near term. Based on the early stage of direct drives' application to offshore turbines and current manufacturing capacities, the offshore market does not currently face a shortage of capacity for manufacturing PMGs either. 


\section{NAVIGANT}

However, significant concerns do exist over PMGs' reliance on several rare earth elements, particularly neodymium (Nd), dysprosium (Dy), and praseodymium (Pr) (See Rare Earth Mineral Supply below).

Based on the likelihood that units must be designed and manufactured specifically for offshore applications, gearbox and generator manufacturing lines are likely to have limited transferability to land-based turbines. However, an individual facility could reasonably operate multiple lines intended to supply both land-based and offshore wind turbines, particularly if located on the coast. Size restrictions, however, may prevent larger offshore gearboxes and generators from shipping by rail.

\section{Rare Earth Mineral Supply}

Currently, the majority $(97 \%)$ of rare earth elements come from mines in China, and recent material shortages and price increases (largely driven by Chinese export quotas) have drawn attention to the cost risks associated with PMGs' reliance on these materials. For example, the cost index for neodymium has fluctuated by up to $600 \%$ over the past few years (BTM 2012). Assuming that PMG demand increases from its current $10 \%$ share of the overall wind turbine market, global demand may reach 12,200 tons per year of rare earth metals for PMGs by the end of 2016. Currently, the leading global supplier of permanent magnets (PMs) to the wind industry is the Chinese company JLMAG Rare-Earth Co. Ltd, which has a worldwide market share of approximately 60\% (BTM 2011).

Although manufacturers expect a tight market for rare earth elements over the next 2-3 years, current trends suggest both potential increases in supply from mines outside of China as well as adaptive strategies to ease demand among turbine suppliers. Proven reserves of rare earth elements exist in the U.S., Canada, Australia, Malaysia, South Africa, and Brazil, and investors are moving to develop new mines or re-establish prior operations in these locations. In the U.S., this includes the Mountain Pass (California) and Bear Lodge (Wyoming) mines, with investment and development activity from RCF, Goldman Sachs, Traxys, and Rare Element Resources. However, industry consensus suggests that it will take 3-4 years before these new mines are producing significant capacities and 6-10 years to reach maximum capacity. In terms of adaptive strategies, both turbine suppliers and generator manufacturers are exploring opportunities such as hedging, long-term contracts, strategic joint ventures, acquisitions of rare earth mining companies or permanent magnet suppliers, and research into diversification away from rare earth elements (BTM 2011).

In consideration of the above indicators, domestic supply of offshore turbine gearboxes and generators represents a moderate near-term supply chain opportunity. In addition to the logistical and cost benefits of manufacturing near the point of turbine assembly, established overseas suppliers and relative uncertainty as to the future direction of offshore turbine drivetrains weakens the near-term opportunity for U.S.-based supply. The best opportunity may lie with established suppliers with coastal facilities who can serve both the U.S. and overseas offshore markets while continuing to supply domestic land-based demand.

\section{Current U.S. Wind Market Suppliers}

Table 2-9 lists U.S.-based gearbox suppliers currently serving the land-based wind market, including those that are serving the offshore wind market from overseas facilities. For the future U.S. offshore wind market, these suppliers' track record of serving the global offshore wind market could help facilitate the establishment of domestic offshore wind turbine manufacturing facilities if they committed to adding future gearbox capacity near appropriate port facilities. 


\section{NAVIGANT}

Table 2-9. U.S. Suppliers of Wind Turbine Gearboxes

\begin{tabular}{|c|c|c|c|c|}
\hline $\begin{array}{l}\text { U.S. Facilities Serving } \\
\text { Domestic Land-based Market }\end{array}$ & Company HQ & Facility Region & $\begin{array}{l}\text { Facility } \\
\text { State }\end{array}$ & $\begin{array}{l}\text { Offshore Markets Served by } \\
\text { Other Facilities }\end{array}$ \\
\hline Advance Manufacturing Corp & U.S. & Great Lakes & $\mathrm{OH}$ & \\
\hline Bosch Rexrotha & Europe & & & Europe \\
\hline Brad Foote Gearworks & U.S. & Great Lakes & IL & \\
\hline Brevini Wind & Europe & Great Lakes & IN & Europe \\
\hline Citation Corporation & U.S. & Great Lakes & $\mathrm{Ml}$ & \\
\hline Columbia Gear Corporation & U.S. & Great Lakes & MN & \\
\hline GE Drivetrain & U.S. & Great Lakes & PA & Europe \\
\hline Moventas OYb & Europe & Pacific & OR & Europe \\
\hline Moventas $\mathrm{OY}^{\mathrm{b}}$ & Europe & Great Lakes & MN & Europe \\
\hline Premier Gear and Machine Works ${ }^{a}$ & U.S. & & & \\
\hline Three M Tool and Machine & U.S. & Great Lakes & $\mathrm{Ml}$ & \\
\hline Vela Gear Systems & U.S. & Great Lakes & IN & \\
\hline Winergy Drive Systems Corporation & Europe & Great Lakes & IL & Europe \\
\hline ZF Group (acquired Hansen) & Europe & South Atlantic & GA & Europe/Asia \\
\hline $\begin{array}{l}\text { U.S.-Based Companies Serving Global } \\
\text { Offshore Market }\end{array}$ & & HQ State & & Region Served \\
\hline GE Drivetrain & & PA & & Europe \\
\hline
\end{tabular}

Notes: (a) Facility in early operation or planning phase. (b) Acquired by Clyde Blowers in 2011.

Sources: BTM 2011, NREL Data, American Wind Energy Association (AWEA)

Similarly, while no U.S.-based facilities currently supply electric generators to the offshore wind market, several of those companies have overseas facilities serving the offshore market in Europe. Table 2-10 lists current U.S.-based suppliers of electric generators for land-based wind, including several that serve the offshore market from other facilities. 


\section{NAVIGANT}

Table 2-10. U.S. Suppliers of Electric Generators for Wind Turbines

\begin{tabular}{|c|c|c|c|c|}
\hline $\begin{array}{l}\text { U.S. Facilities Serving } \\
\text { Domestic Land-based Market }\end{array}$ & Company HQ & Facility Regions & $\begin{array}{l}\text { Facility } \\
\text { State }\end{array}$ & $\begin{array}{c}\text { Offshore Markets Served by } \\
\text { Other Facilities }\end{array}$ \\
\hline Danotek Motion Technologies & U.S. & Great Lakes & $\mathrm{Ml}$ & \\
\hline GE Drivetrain & U.S. & Great Lakes & PA & \\
\hline GE Energy & U.S. & Gulf Coast & $\mathrm{FL}$ & \\
\hline Genzink Steel & U.S. & Great Lakes & $\mathrm{Ml}$ & \\
\hline Hyundai Ideal Electric Co. & Asia & Great Lakes & $\mathrm{OH}$ & \\
\hline IEC Holden & Canada & $\begin{array}{l}\text { Great Lakes, } \\
\text { Atlantic }\end{array}$ & NY & \\
\hline Ingeteam & Europe & Great Lakes & WI & Europe \\
\hline Leroy Somer & Europe & & & Europe \\
\hline Potencia Industrial & Mexico & & & \\
\hline Power Conversion (formerly Converteam)a & Europe/U.S. & Great Lakes & MN & Europe \\
\hline Swiger Coil Systems & U.S. & Great Lakes & $\mathrm{OH}$ & \\
\hline TECO-Westinghouse & U.S. & Gulf Coast & TX & \\
\hline The Switch & Europe & Atlantic & $\mathrm{NH}$ & Europe \\
\hline TMEIC Corporationb & U.S. & Atlantic & VA & \\
\hline WinGen America & U.S. & Great Lakes & PA & \\
\hline U.S.-Based Company Serving Offshore Market & & HQ State & & Region Served \\
\hline Power Conversion (formerly Converteam)a & & NY & & Europe \\
\hline
\end{tabular}

Notes: (a) Converteam was acquired by GE, and the name was changed to Power Conversion in early 2012.

(b)TMEIC Corporation is a U.S. subsidiary of TMEIC Bearings

Sources: BTM 2011, NREL Data, American Wind Energy Association (AWEA)

\subsubsection{Turbine Electronics: Power Converters and Power Transformers}

The use of power converters in variable-speed wind turbines enables the variable generator frequency and voltage of the turbine to be efficiently converted to the fixed frequency/voltage of the grid. The presence of converters inside modern wind turbines improves their performance and offers enlarged grid-friendly control capabilities. This is a rapidly developing technology whose price/power ratio is still falling. Similarly, in an effort to improve long-term reliability and lower costs, many OEMs are investing in higher-performance power transformer systems designed specifically for the environmental and operational challenges of offshore turbines.

\section{Potential Market Size}

The modeled number of power converters and transformers required for the three growth scenarios in 2020 is shown in Table 2-11, along with market value estimates for the moderate-growth scenario. 


\section{NAVIGANT}

Table 2-11. Modeled 2020 Power Converter and Power Transformer Requirements

\begin{tabular}{|c|c|c|c|c|c|}
\hline \multirow[b]{2}{*}{ Region } & \multirow[b]{2}{*}{ Unit } & \multicolumn{3}{|c|}{$\begin{array}{l}2020 \text { Annual Requirements by Growth } \\
\text { Scenario }\end{array}$} & \multirow{2}{*}{$\begin{array}{c}\text { Annual Market Value } \\
\text { (\$M/year) Moderate- } \\
\text { Growth Scenario }\end{array}$} \\
\hline & & Low & Moderate & High & \\
\hline Incremental Capacity Addition & MW/year & 200 & 1,100 & 2,125 & \\
\hline Power Converters & \#/year & 33 & 180 & 332 & $\$ 81-\$ 99$ \\
\hline Power Transformers & \#/year & 33 & 180 & 332 & $\$ 58-\$ 71$ \\
\hline
\end{tabular}

\section{Opportunity Summary}

Table 2-12 provides a summary of the opportunity indicators for turbine electronics. Navigant expects that opportunities for domestic supply of power converters and transformers could occur before 2020 under moderate-growth conditions. This arises from two key assumptions: that domestic suppliers could reasonably serve demand in any of the U.S. coastal regions and that existing U.S. suppliers for the landbased market could gradually shift capacity to serve the offshore market.

Table 2-12. Opportunity Indicators: Power Converters and Power Transformers

\begin{tabular}{|c|c|c|}
\hline Indicator & Rating ${ }^{1}$ & Notes \\
\hline $\begin{array}{l}\text { Timing of Domestic } \\
\text { Opportunity }\end{array}$ & & $\begin{array}{l}\text { Assuming suppliers could serve demand in any U.S. region (and potentially overseas } \\
\text { demand), moderate market growth could support U.S.-based supply before } 2020 .\end{array}$ \\
\hline $\begin{array}{l}\text { Probability of Near-term } \\
\text { Global Shortfall }\end{array}$ & & $\begin{array}{l}\text { No significant shortages are expected for power converters or transformers for the } \\
\text { offshore market. }\end{array}$ \\
\hline Transferability & & $\begin{array}{l}\text { The size and diversity of the market for power electronics provides flexibility for suppliers } \\
\text { to shift capacity to other end uses if offshore wind demand falters. }\end{array}$ \\
\hline Overall Opportunity & & $\begin{array}{l}\text { U.S. firms already serve the offshore power converter market. Transformer demand is } \\
\text { currently met by European companies, but U.S. supply is likely as domestic demand } \\
\text { materializes. }\end{array}$ \\
\hline
\end{tabular}

(1) See Table 2-3 for rating definitions

In terms of near-term global supply, recent market studies report no concerns of bottlenecks for the supply of either power converters or power transformers for offshore wind in the near future. However, this assumes close collaboration between turbine OEMs and their preferred transformer manufacturers to guarantee investment for the future offshore-specific equipment market. As mentioned in Table 2-12, the size and diversity of the power electronics market also provides suppliers with flexibility to shift capacity to other industries should domestic demand for offshore wind fail to meet expectations. The combination of these factors help rank the power electronics market as one of the more favorable near-term opportunities The power electronics market is
one of the more favorable near-
term opportunities for
suppliers to serve the future
U.S. offshore wind market. for suppliers to serve the future U.S. offshore wind market. In fact, as highlighted in the following subsection, some U.S. firms are already serving the offshore power converter market from overseas facilities. While offshore power transformer demand is currently met by European companies, U.S. supply is likely to develop as domestic demand solidifies. 


\section{NAVIGANT}

\section{Current U.S. Wind Market Suppliers}

Most of the top turbine OEMs (e.g., Vestas and Siemens) have in-house manufacturing capabilities for their power converters; however, many supplement this capacity through independent suppliers. Almost $25 \%$ of such independents serve the offshore market, with ABB, Converteam (renamed Power Conversion following acquisition by GE), and U.S.-based Woodward as the leaders in the 5-6.5 MW turbine class (In 2011, GE acquired a majority stake in Converteam, while IDS acquired Woodward). Table 2-13 lists U.S. suppliers of power converter for the wind industry, including several with facilities in other countries currently serving the offshore market.

Table 2-13. U.S. Suppliers of Power Converters for Wind Turbines

\begin{tabular}{|c|c|c|c|c|}
\hline $\begin{array}{l}\text { U.S. Facilities Serving } \\
\text { Domestic Land-based Market }\end{array}$ & Company HQ & Facility Region & Facility State & $\begin{array}{c}\text { Offshore Markets } \\
\text { Served by Other } \\
\text { Facilities }\end{array}$ \\
\hline ABB & Europe & South Atlantic & NC & Europe \\
\hline American Electric Technologies & U.S. & Gulf Coast & $\mathrm{TX}$ & \\
\hline AMSC (formerly Windtec)a & U.S. & & & Europe \\
\hline $\begin{array}{l}\text { Converteam/Power Conversion } \\
\text { (GE takeover) }^{a}\end{array}$ & U.S. & & & Europe \\
\hline Danotek Motion Technologies & U.S. & Great Lakes & $\mathrm{Ml}$ & \\
\hline Emerson Industrial Automation & U.S. & & & \\
\hline Fairfield Manufacturing (part of Oerlikon) & U.S. & & & \\
\hline General Atomics & Europe & & & \\
\hline Ingeteam & U.S. & & & Europe \\
\hline Magnetek & Europe & & & \\
\hline PCS (Power Converter Solutions) & Europe/U.S. & & & \\
\hline Power One & U.S. & Rockies & $A Z$ & \\
\hline Vacon Inc & Europe & & & \\
\hline Woodward SEG (acquired by IDS in 2011)a & U.S. & & & Europe \\
\hline U.S.-Based Company Serving Offshore Market & & HQ State & & Region Served \\
\hline AMSC (formerly Windtec) & & & & Europe \\
\hline Power Conversion (formerly Converteam) ${ }^{b}$ & & NY & & Europe \\
\hline Woodward SEG (acquired by IDS in 2011) & & & & Europe \\
\hline
\end{tabular}

Notes: (a) Firm is currently capable of supplying power converters for offshore wind. (b) GE acquired Converteam in 2011 and changed its name to Power Conversion in early 2012.

Sources: BTM 2011, NREL Data

Current U.S.-based suppliers of power transformers to the land-based wind industry appear in Table 2-14. For European offshore turbines greater than 3 MW, 90\% of the 2010 market relied on liquid transformers supplied by six manufacturers with experience in the offshore market. All six of these companies are headquartered in Europe, with ABB and Siemens being the world's leading suppliers (BTM 2011). 


\section{NAVIGANT}

Table 2-14. U.S. Suppliers of Power Transformers for Land-based Wind Turbines

\begin{tabular}{|c|c|c|c|c|}
\hline $\begin{array}{l}\text { U.S. Facilities Serving } \\
\text { Domestic Land-based Market }\end{array}$ & Company HQ & Facility Region & Facility State & $\begin{array}{c}\text { Offshore Markets } \\
\text { Served by Other } \\
\text { Facilities }\end{array}$ \\
\hline ACME Electric & U.S. & & & \\
\hline Beta Engineering & U.S. & & & \\
\hline CG Power System (Belgium) & Europe & & & Europe \\
\hline Cooper Power Systems & U.S. & & & \\
\hline Dupont & U.S. & & & \\
\hline Dynapower Corporation & U.S. & & & \\
\hline Efacec & Europe & South Atlantic & GA & \\
\hline ERMCO & U.S. & & & \\
\hline $\begin{array}{l}\text { Maschinenfabrik Reinhausen GmbH (MR) ( } \\
\text { Germany) }\end{array}$ & Europe & & & \\
\hline MTC Transformer & U.S. & & & \\
\hline $\begin{array}{l}\text { Pacific Crest Transformers Inc. (former } \\
\text { Areva T\&D Inc.) }\end{array}$ & U.S. & & & \\
\hline Power Magnetics Inc & U.S. & & & \\
\hline Schaffner MTC Transformer & U.S. & & & \\
\hline SGB & Europe & & & Europe \\
\hline Virginia Transformer Corp & U.S. & & & \\
\hline
\end{tabular}

Sources: BTM 2011, NREL Data

\subsubsection{Bearings}

Bearings play an important role in several key wind turbine systems, including several locations in the drive train (e.g., main shaft, gearbox and generator) and in pitch and yaw systems, which allow for directional control of the blades and the nacelle, respectively. Bearings are subject to a high level of stress over the lifetime of the turbine, and therefore represent significant risk in the case of unexpected failure. This is particularly the case for offshore wind turbines, where downtime and difficult access for maintenance can have expensive repercussions.

\section{Potential Market Size}

Given the differing bearing types used in turbine systems and the varying per-turbine requirements, this report separates ball and roller bearings (typical for drivetrain applications) from slewing bearings (used for pitch and yaw systems). Table 2-15 summarizes the anticipated annual market requirements for each type of bearing under the three growth scenarios and lists the anticipated value of each market under the moderate demand scenario. For bearing demand, we assumed that each turbine would require four sets of slewing bearings (one yaw and three pitch) and either six sets (for turbines with gearboxes) or three sets (for direct drives) of other bearings. 
Table 2-15. Modeled 2020 Bearing Requirements

\begin{tabular}{|c|c|c|c|c|c|}
\hline \multirow[b]{2}{*}{ Region } & \multirow[b]{2}{*}{ Unit } & \multicolumn{3}{|c|}{$\begin{array}{l}2020 \text { Annual Requirements by Growth } \\
\text { Scenario }\end{array}$} & \multirow{2}{*}{$\begin{array}{c}\text { Annual Market Value } \\
\text { (\$M/year) Moderate- } \\
\text { Growth Scenario }\end{array}$} \\
\hline & & Low & Moderate & High & \\
\hline Incremental Capacity Addition & MW/year & 200 & 1,100 & 2,125 & \\
\hline $\begin{array}{l}\text { Bearings for Main Shaft, Gearboxes and } \\
\text { Generators }\end{array}$ & \#/year & 180 & 972 & 1,793 & $\$ 43-53$ \\
\hline Slewing Bearings for Pitch and Yaw Systems & \#/year & 133 & 720 & 1,328 & $\$ 33-\$ 41$ \\
\hline
\end{tabular}

\section{Opportunity Summary}

As with power electronics and other components that can be more easily transported, potential bearing manufacturers' access to all five U.S. coastal regions and overseas markets contributes to nearer-term opportunities to supply the offshore wind market.

Table 2-16. Opportunity Indicators: Bearings

\begin{tabular}{|c|c|c|}
\hline Indicator & Rating $^{1}$ & Notes \\
\hline $\begin{array}{l}\text { Timing of Domestic } \\
\text { Opportunity }\end{array}$ & & $\begin{array}{l}\text { Assuming suppliers could serve demand in any U.S. region (and potentially overseas } \\
\text { demand), moderate market growth could support the entry of U.S.-based supply in the } \\
\text { near term. }\end{array}$ \\
\hline $\begin{array}{l}\text { Probability of Near-term } \\
\text { Global Shortfall }\end{array}$ & & $\begin{array}{l}\text { Concerns exist over a potential shortage for larger-sized bearings by } 2014 \text { if further } \\
\text { investments are not made. This tightness of supply could create early opportunities for } \\
\text { qualified manufacturers. }\end{array}$ \\
\hline Transferability & & $\begin{array}{l}\text { Manufacture of bearings for larger offshore turbines requires dedicated investment in } \\
\text { new machinery (with long lead times). The offshore market represents the primary } \\
\text { source of demand for larger bearings, creating a risk of inconsistent demand. }\end{array}$ \\
\hline Overall Opportunity/Risk & & $\begin{array}{l}\text { Limited transferability and large upfront investments for manufacturing larger bearings } \\
\text { creates risk. However, continued growth in global demand and a limit on the number of } \\
\text { qualified suppliers of large bearings may offset that risk for experienced manufacturers } \\
\text { with reputations for quality. }\end{array}$ \\
\hline
\end{tabular}

(1) See Table 2-3 for rating definitions

According to recent supply chain reports, the global capacity and resources available to cater to increasing demand for larger bearings for the offshore wind market lies in a delicate balance. This is particularly the case for extra-large single- and double-row tapered roller bearings used in the main shaft and gearbox, which were previously a key bottleneck in the supply chain. The supply chain for slewing bearings faces similar concerns, wherein a lack of adequate investment by bearing suppliers in the requisite manufacturing equipment may lead to a shortage in extra-large slewing bearings (primarily yaw bearings) by 2015 (BTM 2011). In general, as turbine sizes continue to trend upward and with forecast demand from the global offshore wind market, the market could face a critical bottleneck in the extra-large bearings market in the next 3-5 years (BTM 2011).

This tightness in global supply represents a potential opportunity for U.S. suppliers, albeit one for which it may be difficult to take advantage. While supply capabilities for standard-sized bearings have 


\section{NAVIGANT}

increased sufficiently over the past several years to meet market demand, fewer manufacturers have been willing to pursue the market for larger bearings for several reasons. First, only a limited number of suppliers in the U.S. and Europe can provide steel at the quality levels preferred by bearing manufacturers. Similarly, quality manufacturing and reliable products supersede cost concerns for the offshore bearing market, where a failure can result in a significant hit to a project's levelized cost. These factors lessen the threat of competition from emerging, lower-cost (but lower quality) suppliers from Asia. U.S. manufacturers may be able to take advantage of this domestic supply of high-quality steel by establishing additional manufacturing capacity for extra-large bearings for either the U.S. or European wind turbine markets.

On the other hand, limited transferability of supply could provide a counterpoint for potential manufacturers and investors. The technical machinery and equipment used to produce and test extralarge bearings requires a significant investment, which poses a potential risk when demand relies almost entirely on the offshore wind market. Current policy uncertainty in the U.S. may discourage the level of investment that would be required to build such a facility in the near term, particularly when local content provisions in India and Brazil are attracting interest from the bearings industry. In addition, supply constraints for specialty steels and large castings and forgings could add greater uncertainty to the mix (BVG 2009, BTM 2011).

Given this complex risk profile, there is a moderate overall opportunity for near-term investment in supplying large-scale bearings for the offshore wind market. However, this opportunity may be limited to firms with demonstrated capabilities or reputations for high-quality manufacturing.

\section{Current U.S. Wind Market Suppliers}

Table 2-17 lists major suppliers of the land-based wind market with a presence in the U.S. Many of these companies also have experience serving the global offshore market, either from U.S. or overseas-based facilities. As state above, however, existing capacity may not be adequate to meet increasing near-term demand for larger bearing sizes. 


\section{NAVIGANT}

Table 2-17. U.S. Suppliers of Bearings for Wind Turbines

\begin{tabular}{lcccc}
$\begin{array}{l}\text { U.S. Facilities Serving } \\
\text { Domestic Land-based Market }\end{array}$ & Company HQ & Facility Regions & Facility States & $\begin{array}{c}\text { Offshore Markets Served by } \\
\text { Other Facilities }\end{array}$ \\
\hline American Roller Bearings Company & U.S. & South Atlantic & NC & Europe/Asia \\
\hline FAG Bearings (Schaeffler) & Europe & Midwest & MO & Europe/Asia \\
\hline IMO Energy & Europe & South Atlantic & SC & North America \\
\hline Kaydona & U.S. & $\begin{array}{c}\text { South Atlantic, } \\
\text { Great Lakes }\end{array}$ & $\begin{array}{l}\text { SC, } \\
\text { OH }\end{array}$ & Europe/Asia \\
\hline LAl-International & U.S. & North Atlantic & MD & Europe/Asia \\
\hline NSK & Asia & Great Lakes & Ml, & OH \\
\hline NTN & Asia & Great Lakes & IL & Europe/Asia \\
\hline RBC Bearings & U.S. & Gulf Coast & TX & Europe/Asia \\
\hline Rothe Erde & Europe & Great Lakes & OH & Asia \\
\hline SKF & Europe & Great Lakes & PA & Region Served \\
\hline Timken & U.S. & Great Lakes, & PA, & Asia \\
\hline \multicolumn{1}{c}{ U.S.-Based Company Serving Offshore Market } & HQ State & &
\end{tabular}

Note: (a) Supplier currently capable of supplying bearings for offshore applications.

Sources: BTM 2011, NREL Data

\subsubsection{Pitch and Yaw Systems}

Pitch systems control the blades on a wind turbine to help maximize energy production under various wind speeds or to turn the blades out of the wind (feather the blades) to avoid damage during adverse conditions. Yaw systems orient the entire nacelle in the direction of the wind and work in concert with the yaw bearing between the tower and the turbine's nacelle. Both systems use either an electric or hydraulic system based primarily on turbine OEMs' historical preferences. For offshore turbine pitch systems, the current system market share is $86 \%$ hydraulic (primarily Vestas and Siemens) and $14 \%$ electric systems, though electric systems' share of the total is expected to increase slowly based on recent trends (BTM 2012). ${ }^{7}$

Electric pitch and yaw systems' main subcomponents comprise electric motors, gears, sensor equipment, and control arms, while hydraulic systems consist primarily of hydraulic cylinders, rods, pumps, filters, and sensor equipment. While each turbine's pitch system includes three sets of primary components (i.e., motors or cylinders), yaw systems for multi-MW offshore turbines may require up to eight individual motors per turbine.

\section{Potential Market Size}

Table 2-18 shows the modeled requirements for complete yaw and pitch systems in 2020.

\footnotetext{
7 Yaw system market share estimates were not available. 


\section{NAVIGANT}

Table 2-18. Modeled 2020 Yaw and Pitch System Requirements

\begin{tabular}{|c|c|c|c|c|c|}
\hline \multirow[b]{2}{*}{ Region } & \multirow[b]{2}{*}{ Unit } & \multicolumn{3}{|c|}{$\begin{array}{l}2020 \text { Annual Requirements by Growth } \\
\text { Scenario }\end{array}$} & \multirow{2}{*}{$\begin{array}{c}\text { Annual Market Value } \\
\text { (\$M/year) Moderate- } \\
\text { Growth Scenario }\end{array}$} \\
\hline & & Low & Moderate & High & \\
\hline Incremental Capacity Addition & MW/year & 200 & 1,100 & 2,125 & \\
\hline Pitch Systems & \#/year & 33 & 180 & 332 & $\$ 44-\$ 54$ \\
\hline Yaw Systems & \#/year & 33 & 180 & 332 & $\$ 39-\$ 47$ \\
\hline
\end{tabular}

\section{Opportunity Summary}

Table 2-19 summarizes the opportunity indicator rankings for pitch and yaw systems. The timing of the potential domestic manufacturing opportunity for these systems is similar to that of the preceding subcomponents. Again, assuming reasonable logistical access to diverse geographic markets, U.S. suppliers could serve either the domestic or global offshore wind markets. However, U.S. offshore demand alone may not be adequate to foster investment in a new manufacturing line.

Table 2-19. Opportunity Indicators: Pitch and Yaw Systems

\begin{tabular}{|c|c|c|}
\hline Indicator & Rating ${ }^{1}$ & Notes \\
\hline $\begin{array}{l}\text { Timing of Domestic } \\
\text { Opportunity }\end{array}$ & & $\begin{array}{l}\text { Assuming suppliers could serve demand in any U.S. region (and potentially overseas demand), } \\
\text { moderate market growth could support the entry of U.S.-based supply in the near term. }\end{array}$ \\
\hline $\begin{array}{l}\text { Probability of Near-term } \\
\text { Global Shortfall }\end{array}$ & & No significant supply shortages are expected for pitch and yaw systems. \\
\hline Transferability & & $\begin{array}{l}\text { Offshore wind turbines will require larger units than are currently manufactured for land-based } \\
\text { demand; however, an individual facility should be able to convert capacity. }\end{array}$ \\
\hline Overall Opportunity/Risk & & $\begin{array}{l}\text { Existing global capacity from firms currently serving the offshore market may hinder entry of new } \\
\text { competitors. }\end{array}$ \\
\hline
\end{tabular}

(1) See Table 2-3 for rating definitions

However, the potential for overseas offshore wind markets to provide additional destinations for U.S.based supply may be limited. With sufficient capacity in the offshore market and potential overcapacity for land-based turbines, it is not expected that the industry will have any supply issues with pitch or yaw systems in the near future. While manufacturers should be able to convert or add new capacity to serve the offshore market with relative ease, the offshore market will likely require larger units than are currently manufactured for land-based demand, indicating the potential need for manufacturing lines dedicated to offshore supply. Given this mix of indicators, the near-term opportunity for domestic manufacturers of pitch and yaw systems may be somewhat limited.

\section{Current U.S. Wind Market Suppliers}

Table 2-20 lists selected current U.S.-based suppliers of pitch systems for the wind industry. A complete list of suppliers of yaw systems was unavailable; however, two of the pitch system suppliers list (Brevini and SIPCO) also supply yaw systems to the wind market. 


\section{NAVIGANT}

Table 2-20. U.S. Suppliers of Pitch and Yaw Systems for Wind Turbines

\begin{tabular}{|c|c|c|c|c|c|c|c|c|}
\hline $\begin{array}{l}\text { U.S. Facilities } \\
\text { Serving } \\
\text { Domestic Land- } \\
\text { based Market }\end{array}$ & $\begin{array}{c}\text { Company } \\
\mathrm{HQ}\end{array}$ & Facility Regions & $\begin{array}{l}\text { Facility } \\
\text { State }\end{array}$ & 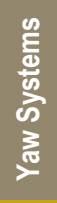 & 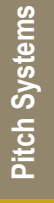 & $\begin{array}{l}\frac{0}{\overline{2}} \\
\frac{\text { 흥 }}{\text { 조 }}\end{array}$ & $\begin{array}{l}\text { 을 } \\
\text { 륨 } \\
\text { II }\end{array}$ & $\begin{array}{c}\text { Offshore Markets } \\
\text { Served by Other } \\
\text { Facilities }\end{array}$ \\
\hline Brevinia & Europe & & & $X$ & $X$ & & $X$ & \\
\hline EATON & U.S. & Various & & & $x$ & $x$ & & \\
\hline Fluitecnik & Europe & & & & $x$ & $x$ & & \\
\hline Glual & Europe & & & & $x$ & $x$ & & \\
\hline HINE Renovables & Europe & & & & $x$ & $x$ & & \\
\hline Hydratech Industries & Europe & & & & $x$ & $x$ & & \\
\hline Parker Hannifin A/S & Europe & & & & $x$ & $x$ & & \\
\hline PMC Technology A/S & Europe & Rockies & $\mathrm{CO}$ & & $x$ & $x$ & & Europe \\
\hline MOOG & U.S. & $\begin{array}{l}\text { Great Lakes, } \\
\text { North Atlantic }\end{array}$ & NY & & $x$ & $x$ & $x$ & Europe \\
\hline SIPCOa & U.S. & Gulf Coast & $\mathrm{TX}$ & $x$ & $x$ & & $x$ & \\
\hline $\begin{array}{l}\text { U.S.-Based Company } \\
\text { Global Offshore Marke }\end{array}$ & ving & & HQ State & & & & & Region Served \\
\hline MOOG & & & NY & & & $x$ & $x$ & Europe \\
\hline
\end{tabular}

Source: BTM 2011

Turbine OEMs typically source pitch systems from independent suppliers. For the offshore wind market, the two leading offshore turbine suppliers, Siemens and Vestas, use the Danish hydraulic pitch technology produced by AVN Energy (now owned by Hydratech Industries), Fritz Schur Energy, and PMC Technology (which has a facility in the U.S.). The remainder of the large offshore turbine companies-REpower, Areva and Sinovel-use electric systems supplied by manufacturers such as Bonfiglioli, Moog, Zollern, and the Chinese DHI DCW Group.

\subsubsection{Castings and Forgings}

The main cast iron components in a wind turbine comprise the nacelle main frame and the rotor hub, followed by housings for the gearbox and bearings. The main forged item in a wind turbine is the main shaft; however, several other forged items contribute to various sub-assemblies, including gear wheels and rims in the gearbox; outer and inner rings for large bearings; tower flanges; and other smaller components. In both cases, OEMs have high-quality demands for the materials used, as the costs of downtime and maintenance for offshore turbines represents a significant risk.

\section{Potential Market Size}

Table 2-21 presents the modeled casting and forging material requirements for the three growth scenarios in 2020. 


\section{NAVIGANT}

Table 2-21. Modeled 2020 Casting and Forging Material Requirements

\begin{tabular}{lccccc} 
& & 2020 Annual Requirements by Growth & Annual Market Value \\
\cline { 3 - 5 } Total U.S. & Unit & Low & Moderate & High & $\begin{array}{c}\text { (\$MlM/year) Moderate- } \\
\text { Growth Scenario }\end{array}$ \\
\cline { 3 - 5 } Incremental Capacity Addition & MW/year & $\mathbf{2 0 0}$ & $\mathbf{1 , 1 0 0}$ & $\mathbf{2 , 1 2 5}$ & \\
\hline Cast Iron (e.g., hubs, main frames) & Tonnes/year & 6,060 & 33,379 & 64,758 & $\$ 100-\$ 122^{1}$ \\
\hline $\begin{array}{l}\text { Forged Material (main shafts, large flanges } \\
\text { and rings) }\end{array}$ & Tonnes/year & 4,500 & 24,774 & 47,991 & $\$ 39-\$ 47^{2}$ \\
\hline
\end{tabular}

${ }^{1}$ Cast iron market value based on main frame and hub only; does not include smaller castings.

${ }^{2}$ Forged material market value based on main shaft only; does not include smaller forgings.

For the moderate-growth scenario, Figure 2-9 shows the modeled growth in annual demand for either type of component based on the amount of iron or steel material required.

Figure 2-9. Modeled Annual Demand (Castings and Forgings): Moderate-Growth Scenario

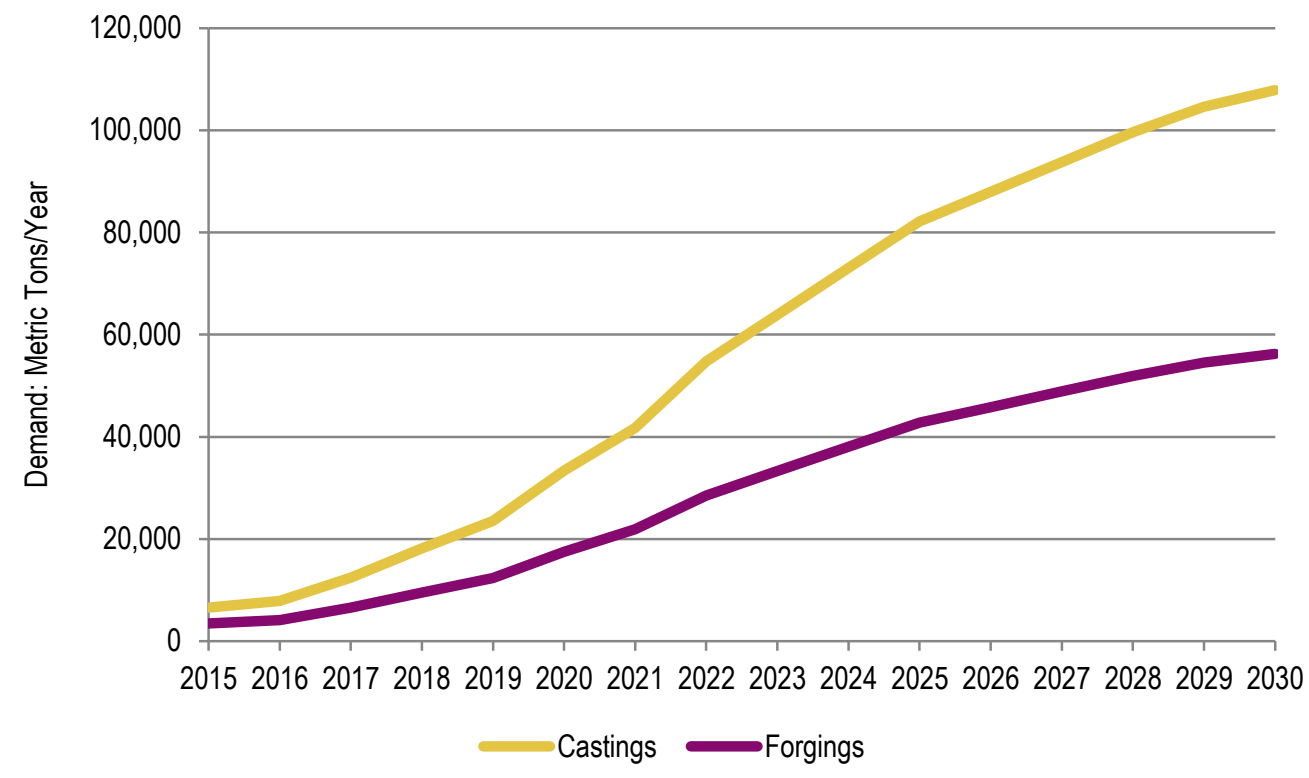

\section{Opportunity Summary}

Table 2-22 summarizes the opportunity indicator rankings for near-term domestic supply of large castings and forgings. The market for these specialized components highlights a key difficulty in planning for domestic supply chains' ability to adequately meet future offshore wind demand. Specifically, in order to secure turbine OEMs' intention to build WTG manufacturing facilities in the U.S., the U.S. castings market may need to establish its capacity to supply large castings in advance. Some European offshore turbine OEMs have expressed hesitation to build WTG facilities in the U.K. based in part on a lack of domestic supply for both large castings and forgings. For the next generation of offshore turbines, minimizing transport of these large subcomponents will play a larger role in terms of logistics and costs (BVG 2009). 
Table 2-22. Opportunity Indicators: Castings and Forgings

\begin{tabular}{l|l}
\hline $\begin{array}{l}\text { Indicator } \\
\begin{array}{l}\text { Timing of Domestic } \\
\text { Opportunity }\end{array}\end{array}$ & $\begin{array}{l}\text { Rating } \\
\text { Assuming suppliers could serve demand in any U.S. region, moderate market growth could } \\
\text { support new U.S.-based supply in the near term. }\end{array}$ \\
\hline $\begin{array}{l}\text { Probability of Near-term } \\
\text { Global Shortfall }\end{array}$ & $\begin{array}{l}\text { Some concerns exist over the availability of large-scale castings and forgings; however, } \\
\text { new capacity is emerging in Asia. }\end{array}$ \\
\hline Transferability & $\begin{array}{l}\text { Supplying castings and forgings for larger turbines may require significant investment in } \\
\text { new machinery that firms would otherwise not need. }\end{array}$ \\
\hline Overall Opportunity/Risk & $\begin{array}{l}\text { The requirement for large investments to meet larger-sized component needs poses a risk } \\
\text { if demand falls short of expectations. }\end{array}$ \\
\hline
\end{tabular}

(1) See Table 2-3 for rating definitions

Unfortunately, this presents a chicken-and-egg dilemma wherein suppliers may not willingly commit to expanding their capacity or product size range (an expensive proposition) without firm signals from relevant governments or agreements from future customers. On the other hand, an early mover in this market may have a better opportunity of securing supply contracts from domestic turbine OEMs if other competitors are unprepared to ramp up supply of larger components. The timing of the domestic supply opportunity in this case will depend largely on an individual manufacturer's overall product portfolio (i.e., whether they could serve demand for similarly large castings in other markets) and risk tolerance.

In general, the global castings market faces significant overcapacity (including in the U.S.) as a result of the economic downturn and recent investments in China. Not all of this surplus, however, can address the need for larger, high-quality castings that will be required to serve the offshore wind market. A recent supply chain study estimated that only $20 \%$ of nearly 100 global wind power casting suppliers are currently capable of serving the offshore wind power market, with roughly half located in each of Europe and China (BTM 2011). Fortunately, because these castings are normally designed by turbine OEMs and manufactured using standard processes, it is relatively simple for a new supplier to enter the market. Furthermore, while emerging Asian suppliers may create downward price pressure for castings supply overall, U.S. suppliers can likely compete on the high-quality production requirements that remain a key distinguishing factor in selecting a castings supplier for offshore wind.

A similar situation exists in the global supply of large forgings that will be required for the offshore wind market. Despite global overcapacity, regional supply imbalances and inadequate supply of large forgings may occur by 2015 . The U.S. forgings market in particular remains in a state of short supply, although new entrants have emerged over the past three years. At the end of 2011, one report estimated that U.S. demand for forgings is in excess of 1.5 times the supply (BTM 2011). For the offshore wind market in particular, the current supply of very large forgings lies solely in Europe, South Korea, and China, with the number of suppliers more than tripling between year-end 2009 and 2011. As with largescale castings, however, transportation costs and quality concerns may drive turbine OEMs to desire local suppliers to serve the U.S. offshore market. In the context of limited capital and new low-cost entrants in Asia, however, high raw material prices and labor costs may discourage the investment required to meet this large-sized product demand in Europe and the U.S. 


\section{NAVIGANT}

Overall, the need for domestic supply of large-scale castings and forgings represents a favorable opportunity for U.S. suppliers; however, the size of the required investment and the potentially limited transferability of supply should offshore wind demand falter present considerable risks.

\section{Current U.S. Wind Market Suppliers}

U.S. suppliers of land-based castings are generally concentrated in the industrial areas of the Great Lakes region, where they also serve other industries such as automotive and heavy machinery. Similarly, a number of established forging suppliers have production facilities in the U.S. Table 2-23 lists key suppliers of castings and forgings for the wind industry, all with headquarters in the U.S.

Table 2-23. U.S. Suppliers of Castings and Forgings to the Wind Industry

\begin{tabular}{|c|c|c|c|c|}
\hline $\begin{array}{l}\text { U.S. Facilities Serving } \\
\text { Domestic Land-based Market }\end{array}$ & Facility Region & Facility States & Castings & Forgings \\
\hline Aarowcast Inc & Great Lakes & WI & $X$ & \\
\hline A Finkle \& Sons Inc & Great Lakes & IL & & $X$ \\
\hline AJAX Rolled Ring \& Machine & South Atlantic & SC & & $x$ \\
\hline ATI Casting & Great Lakes & IN & $X$ & \\
\hline ATI Casting Services & Great Lakes & $\mathrm{Ml}$ & $X$ & \\
\hline CAB Incorporated & Gulf Coast & $\mathrm{TX}$ & & $x$ \\
\hline Canton Drop Forge & Great Lakes & $\mathrm{OH}$ & & $X$ \\
\hline Cast-Fab Technologies, Inc & Great Lakes & $\mathrm{OH}$ & $x$ & \\
\hline Ellwood Group Inc & Multiple & $\mathrm{PA}, \mathrm{MI}, \mathrm{OH}, \mathrm{TX}$ & $X$ & $X$ \\
\hline Genzink Steel & Great Lakes & Ml & $X$ & \\
\hline Hodge Foundry & Great Lakes & PA & $x$ & \\
\hline K\&M Machine Fabricating & Great Lakes & Ml & $x$ & \\
\hline McKees Rocks Forgings & Great Lakes & PA & & $X$ \\
\hline Minster Wind & Great Lakes & $\mathrm{OH}$ & $x$ & \\
\hline Precise Machine and Fabrication & South Atlantic & VA & & $X$ \\
\hline Rotek Inc (a Thussen Krupp company) & Midwest & KY & & $X$ \\
\hline Sumitomo Corporation of America & & & $X$ & \\
\hline Timken & Great Lakes & $\mathrm{OH}$ & & $x$ \\
\hline URV USA & Great Lakes & $\mathrm{Ml}$ & $X$ & \\
\hline WODIN & Great Lakes & $\mathrm{OH}$ & & $X$ \\
\hline
\end{tabular}

Sources: BTM 2011, NREL Data

\subsubsection{Blades}

Turbine blades constitute a key component of wind development and the supply chain due to their sheer size and technological attributes. They dictate the energy capture of the turbine and can define the logistical size constraints for transportation. With blade lengths for next-generation offshore turbines 


\section{NAVIGANT}

anticipated to exceed 60 or even 80 meters, transportation logistics will likely necessitate that those blades be manufactured in coastal locations near the point of final installation.

\section{Potential Market Size}

Table 2-24 shows the modeled blade requirements for the three growth scenarios across all regions in 2020.

Table 2-24. Modeled 2020 Blade Requirements

\begin{tabular}{|c|c|c|c|c|c|}
\hline \multirow[b]{2}{*}{ Region } & \multirow[b]{2}{*}{ Unit } & \multicolumn{3}{|c|}{$\begin{array}{l}2020 \text { Annual Requirements by Growth } \\
\text { Scenario }\end{array}$} & \multirow{2}{*}{$\begin{array}{c}\text { Annual Market Value } \\
\text { (\$M/year) Moderate- } \\
\text { Growth Scenario }\end{array}$} \\
\hline & & Low & Moderate & High & \\
\hline Incremental Capacity Addition & MW/year & 200 & 1,100 & 2,125 & \\
\hline North Atlantic & \#/year & 79 & 246 & 335 & $\$ 143-\$ 175$ \\
\hline South Atlantic & \#/year & 21 & 54 & 190 & $\$ 32-\$ 39$ \\
\hline Great Lakes & \#/year & 0 & 75 & 150 & $\$ 44-\$ 53$ \\
\hline Gulf Coast & \#/year & 0 & 75 & 88 & $\$ 44-\$ 53$ \\
\hline Pacific Coast & \#/year & 0 & 90 & 234 & $\$ 58-\$ 71$ \\
\hline TOTAL U.S. & \#/year & 100 & 540 & 996 & $\$ 320-\$ 391$ \\
\hline
\end{tabular}

Notably, the in the moderate-growth scenario, blade demand on the Atlantic Coast would reach 300 blades per year, or the equivalent demand from 100 5-MW turbines. Figure 2-10 shows the modeled growth in annual blade demand in each region under the moderate-growth scenario. 


\section{NAVIGANT}

Figure 2-10. Modeled Annual Demand (Blades): Moderate-Growth Scenario

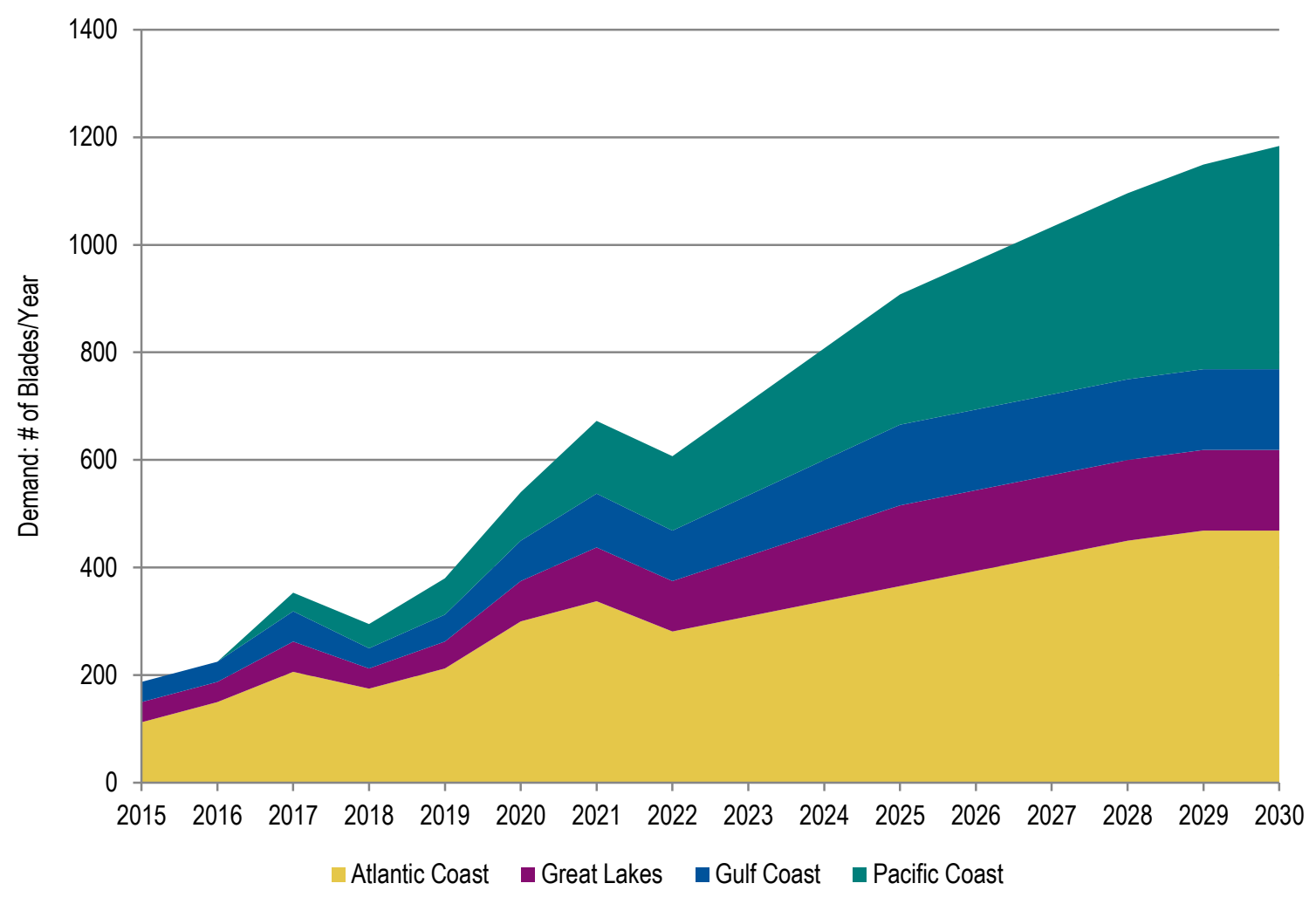

\section{Opportunity Summary}

Table 2-25 summarizes the indicators for U.S. suppliers' potential near-term opportunity to serve the offshore market under moderate-growth assumptions. While the projected annual demand volume for blades along the Atlantic Coast may be adequate to support a dedicated offshore blade facility before 2020, it is unlikely that firms will invest in such a facility before similar investments have been made in coastal offshore nacelle assembly facilities. As discussed in Chapter 2.3.2, this is less likely to occur until after 2020, when consistent annual demand for new capacity has been demonstrated for several years. 
Table 2-25. Opportunity Indicators: Blades

\begin{tabular}{|c|c|c|}
\hline Indicator & Rating1 & Notes \\
\hline $\begin{array}{l}\text { Timing of Domestic } \\
\text { Opportunity }\end{array}$ & & $\begin{array}{l}\text { Moderate growth would require about } 200 \text { blades/year on the Atlantic Coast by } 2019 \\
\text { (about } 66 \text { blades/year for a facility with } 33 \% \text { market share). A single blade facility requires } \\
\text { annual demand of } 50-300 \text { units; however, investment in dedicated offshore blade facilities } \\
\text { is likely to coincide with nacelle assembly facilities. }\end{array}$ \\
\hline $\begin{array}{l}\text { Probability of Near-term Global } \\
\text { Shortfall }\end{array}$ & & $\begin{array}{l}\text { No global supply shortages are expected; however, a need exists for new coastal } \\
\text { facilities to produce increasingly larger blades. }\end{array}$ \\
\hline Transferability & & $\begin{array}{l}\text { Nearer-term opportunities may exist for facilities already located on coasts; however, U.S. } \\
\text { offshore wind potential tends to be located far from inland land-based project sites. } \\
\text { Length limits for ground transportation fall between } 60 \text { and } 75 \text { meters. }\end{array}$ \\
\hline Overall Opportunity/Risk & & $\begin{array}{l}\text { Despite the slow ramp up of adequate demand, the need for manufacturing proximal to } \\
\text { final project sites creates a moderate near-term opportunity for blade manufacturing. }\end{array}$ \\
\hline
\end{tabular}

(1) See Table 2-3 for rating definitions

Based on recent reports (BTM 2011), no near-term global supply shortages are anticipated for the offshore wind blade market. However, as consistent demand develops in new regions of the world (including the U.S.), investments in new coastal facilities will be required to produce increasingly large blades. While turbine OEMs have historically manufactured the majority of turbine blades in-house, the overall share of such in-sourcing fell from $58 \%$ in 2008 to $50 \%$ in 2010 . This trend will likely continue, particularly as new manufacturers for the offshore market seek to partner with independent suppliers with past experience in offshore blade development and global manufacturing presence to share risks and support OEMs' offshore growth plans. Globally, eight such independent blade manufacturers with offshore wind experience had been identified by the end of 2011, with a further four suppliers in the R\&D phase and three more capable of delivering to the offshore industry in the future (BTM 2011).

Although no blades for offshore turbines are currently manufactured in the U.S., many of the companies producing blades for land-based applications have the experience and intellectual know-how to expand into the U.S. offshore market. Presumably, some of these suppliers may shift production facilities from central locations currently serving the U.S. land-based demand to coastal locations that can accommodate the logistics of larger blade sizes for offshore machines. Once relocated, however, this manufacturing capacity will be less likely to continue serving the land-based market due to the added overland distance to those projects. Estimated length limit for ground-based transportation of wind turbine blades range from 60 to 75 meters (BTM 2011, Siemens 2012).

The combination of the above factors suggests that blade manufacturing will present a key opportunity for U.S.-based manufacturing to support the future offshore wind industry, whether through OEMs or independent partners. However, regional demand sufficient to support this opportunity is unlikely before 2020. To be successful, independent blade manufacturers will likely need to have the ability to produce large blades (in excess of 50 meters) at strategically located port-based facilities if they are to cater to the offshore industry. 


\section{Current U.S. Wind Market Suppliers}

Several prominent blade manufacturers have production facilities in the U.S. The total production capacity of wind turbine blades in the U.S. is estimated at about 8,000 MW/year, which has exceeded domestic demand in recent years. ${ }^{8}$ As noted earlier, it is estimated that at least 60 to $70 \%$ of blades installed in the U.S. are produced domestically (although 2012 may be an exception due to potential demand of over $10 \mathrm{GW}$ ). Table 2-26 lists U.S. facilities that supply turbine blades to the domestic landbased wind market. Notably, most the facilities listed in Table 2-26 are located inland, and would therefore face additional logistical challenges and costs to transport blades to the coast, particularly as offshore blade sizes trend upward.

\footnotetext{
8 The production capacities presented here are estimates of possible capacity from both in-house and independent suppliers, and do not reflect the amounts actually produced. By some estimates, wind manufacturing facilities have utilized about $50-60 \%$ of capacity in recent years (Wiser 2011).
} 


\section{NAVIGANT}

Table 2-26. U.S. Suppliers of Blades for Land-based Wind Turbines

\begin{tabular}{|c|c|c|c|c|}
\hline $\begin{array}{l}\text { U.S. Facilities Serving } \\
\text { Domestic Land-based Market }\end{array}$ & Company HQ & Facility Regions & $\begin{array}{l}\text { Facility } \\
\text { States }\end{array}$ & $\begin{array}{c}\text { Offshore Markets Served by } \\
\text { Other Facilities }\end{array}$ \\
\hline AC Wind & U.S. & North Atlantic & MD & \\
\hline Amtech & U.S. & Pacific & WA & \\
\hline Blade Dynamics & Europe & Gulf Coast & LA & Europe \\
\hline Energetx Composites & U.S. & Great Lakes & Ml & \\
\hline Gamesa & Europe & Great Lakes & PA & \\
\hline Global Blade Technology & Europe & Great Lakes & IN & Europe \\
\hline Knight and Carver & U.S. & $\begin{array}{l}\text { Midwest, } \\
\text { Pacific }\end{array}$ & $\begin{array}{l}\mathrm{SD} \\
\mathrm{CA}\end{array}$ & \\
\hline LM Wind Power & Europe & Midwest & $\begin{array}{l}\text { AR, } \\
\text { ND }\end{array}$ & Europe/Asia \\
\hline Molded Fiber Glass (MFG) & U.S. & $\begin{array}{l}\text { Gulf Coast, } \\
\text { Midwest }\end{array}$ & $\begin{array}{l}\mathrm{TX} \\
\mathrm{SD}\end{array}$ & \\
\hline Nordex & Europe & Midwest & AR & \\
\hline Polymarin & U.S. & Midwest & AR & \\
\hline $\begin{array}{l}\text { Renewable Energy Composites } \\
\text { Solution }\end{array}$ & U.S. & Pacific & WA & \\
\hline Siemens (in-house) & Europe & Midwest & IA & Europe \\
\hline Suzlon Rotor Corporation & Asia & Great Lakes & $\mathrm{MN}$ & \\
\hline TPI Composites & U.S. & $\begin{array}{l}\text { Midwest, } \\
\text { North Atlantic }\end{array}$ & $\begin{array}{l}\mid A, \\
\mathrm{RI}\end{array}$ & Europe \\
\hline Vestas (in-house) & Europe & Rockies & $\mathrm{CO}$ & Europe \\
\hline \multicolumn{3}{|c|}{ U.S.-Based Company Serving Offshore Market } & HQ State & Region Served \\
\hline TPI Composites & & & $A Z$ & Europe \\
\hline Blade Dynamics & & & LA & Europe \\
\hline
\end{tabular}

Sources: BTM 2011, NREL Data

Of the independent suppliers headquartered in the U.S., only Blade Dynamics and TPI currently serve the offshore market; however, Tecsis Technology manufactures blades for a 3-MW land-based turbine, the largest blade currently manufactured in the U.S. In addition, Global Blade Technology of The Netherlands recently invested $\$ 17.6$ million in the manufacture of composite rotor blades for wind turbines in Indiana. This is one of a number of companies looking to supply the future U.S. offshore wind market with turbine components (BTM 2011). Thus far, only European manufacturers (Vestas, Siemens, REpower, Areva, and BARD) supply rotor blades for turbine sizes larger than $5 \mathrm{MW}$. All of these OEM offshore blade manufacturing facilities are based in Denmark or Germany. 


\section{NAVIGANT}

\subsubsection{Key Blade Materials: Resin and Reinforcement Fibers}

Epoxy resins are the basic material for most wind turbine blades globally. Notably, Momentive, Huntsman, and Dow (all U.S. based) lead the global epoxy resin market. As complex and lengthy (up to three-year) supplier qualification processes limit the global market primarily to established players, these suppliers stand to benefit from additional growth in the market for turbine blades, whether in the U.S. offshore market or elsewhere. In fact, with the recent slowdown in blade production in the U.S., much of its suppliers' production is being exported to China to serve its growing demand. Some blade manufacturers, including leading supplier LM Wind Power, use unsaturated polyester resins (UPR), a less expensive alternative to epoxy.

In addition to epoxy resin or UPR, wind turbine blades require significant quantities of reinforcement fibers to provide the strength necessary to withstand heavy wind loads. While glass fiber remains the dominant source of reinforcement fiber in the blade market, carbon fiber will likely play an increasing role in longer (>60 meter) offshore turbine blades as manufacturers seek to increase stiffness-to-weight ratios. However, based on the slow growth of the offshore market and pressures to keep capital costs low (carbon fiber is more expensive), glass fibers will likely continue to dominate the market for several years. These fibers are supplied to blade manufacturers as woven and stitched fabrics or, increasingly, as a pre-impregnated (pre-preg) fabric that has a special epoxy impregnated into the glass or carbon weave.

\section{Potential Market Size}

Table 2-30 shows the modeled requirements for these key blade materials in 2020 .

Table 2-27. Modeled 2020 Blade Material Requirements

\begin{tabular}{lccccc} 
& & 2020 & $\begin{array}{c}\text { Annual Requirements by Growth } \\
\text { Scenario }\end{array}$ & \multicolumn{3}{c}{$\begin{array}{c}\text { Annual Market Value } \\
\text { Total U.S. }\end{array}$} & Unit & Low & Moderate & High & $\begin{array}{c}\text { (\$M/lyear) Moderate- } \\
\text { Growth Scenario }\end{array}$ \\
\cline { 2 - 5 } Incremental Capacity Addition & MW/year & $\mathbf{2 0 0}$ & $\mathbf{1 , 1 0 0}$ & $\mathbf{2 , 1 2 5}$ & $\mathbf{\$ 2 4 - \$ 2 9}$ \\
\hline Epoxy or Polyester Resin & Tonnes/year & 1,040 & 5,696 & 10,953 & $\$ 12-\$ 14$ \\
\hline Glass Fiber & Tonnes/year & 1,014 & 5,542 & 10,591 & $\$ 24-\$ 30$ \\
\hline Carbon Fiber & Tonnes/year & 104 & 573 & 1,120 & \\
\hline
\end{tabular}

Under the modeling assumptions used (see Appendix D), total demand for resins and glass fiber will track close to one another through about 2021. Around 2022, we assumed a continuing trend toward larger blades will require greater proportions of carbon fiber in each blade, which would reduce the perblade requirement for glass fibers. As noted above, the timing of this shift will depend largely on carbon fiber costs and overall turbine and plant economics. The estimated timing of this shift under the moderate-growth scenario, as well as the modeled demand growth curves for each material, are shown in Figure 2-11. 


\section{NAVIGANT}

Figure 2-11. Modeled Demand Growth for Key Blade Materials - Moderate-Growth Scenario

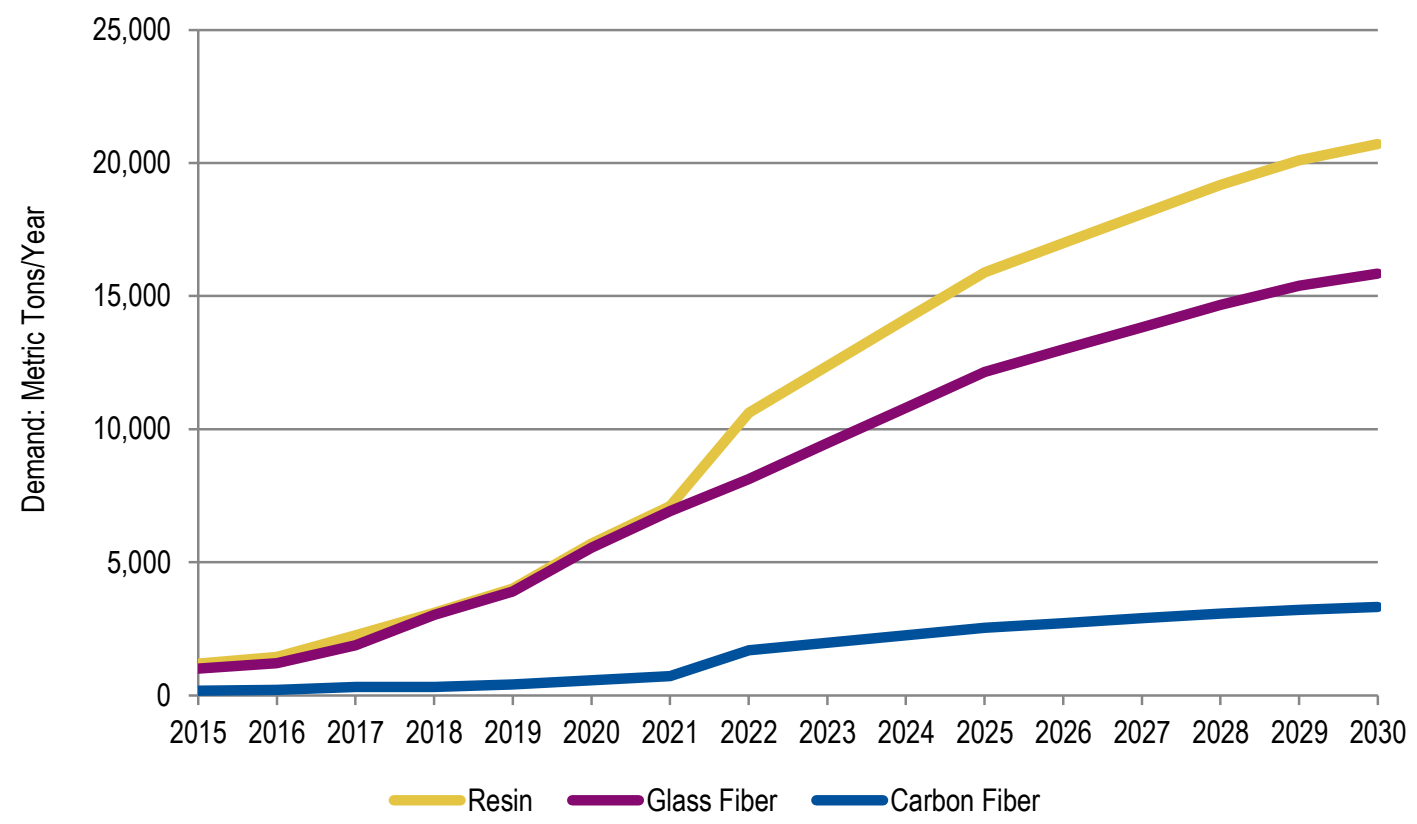

\section{Opportunity Summary}

Table 2-28 summarizes the opportunity indicator rankings for key blade materials. As U.S. suppliers in each of these categories already supply the global wind market, shifting or adding capacity to supply the U.S. offshore wind market is a likely near-term opportunity that will coincide with the arrival of domestic offshore blade manufacturing.

Table 2-28. Opportunity Indicators: Key Blade Materials

\begin{tabular}{ll}
\hline $\begin{array}{l}\text { Indicator } \\
\begin{array}{l}\text { Timing of Domestic } \\
\text { Opportunity }\end{array}\end{array}$ & $\begin{array}{l}\text { Rotes } \\
\text { Timing for offshore-specific U.S. demand tracks blade demand; however, U.S. suppliers } \\
\text { of resin and reinforcement fibers already serve the global offshore market. }\end{array}$ \\
\hline $\begin{array}{l}\text { Probability of Near-term } \\
\text { Global Shortfall }\end{array}$ & $\begin{array}{l}\text { Demand for carbon fiber may become limited toward } 2015 \text { based on increasing blade } \\
\text { lengths and demand from competing industries (e.g., aerospace). Glass fiber and epoxy } \\
\text { are not anticipated to encounter any shortages. }\end{array}$ \\
\hline Transferability & $\begin{array}{l}\text { Suppliers of these materials can generally serve either the land-based or offshore wind } \\
\text { markets (as well as other industries), assuming they meet blade manufacturer quality } \\
\text { requirements. }\end{array}$ \\
\hline Overall Opportunity/Risk & $\begin{array}{l}\text { High transferability, the ability to serve global markets, and potential near-term tightness } \\
\text { in global supply creates a relatively strong opportunity for existing suppliers. New } \\
\text { suppliers will need to go through rigorous manufacturer quality assurance processes. }\end{array}$ \\
\hline
\end{tabular}

(1) See Table 2-3 for rating definitions

For overall near-term global resin supply, the polyester market is expected to keep growing, despite an anticipated increase in resin prices, as it is still seen to be cheaper than its alternative, epoxy. Neither material is expected to face near-term supply shortages. While market actors do not expect a shortage in the supply of glass fibers, a greater-than-expected shift to carbon fiber could limit its supply toward 


\section{NAVIGANT}

2015. However, the higher cost of carbon fiber means that wind industry demand may be more elastic based on the state of the economy or competing demand from other industries. Industry participants anticipate that the carbon and glass fiber industries, which are currently fragmented across the globe, will experience significant consolidation over the next few years (BTM 2011).

Notably, each of these materials is characterized by a relatively high level of transferability, with a diversity of demand sources in several industries (e.g., aerospace, defense, automotive). In addition, once a manufacturer has proven its capability to meet manufacturer quality requirements, it should be able to supply either the land-based or offshore wind blade markets. As with other raw materials and subcomponents, increasing capacity and lower costs from Asian manufacturers could provide significant competition for domestic suppliers (BTM 2011). However, continued global demand growth in both the land-based and offshore wind markets is likely to provide a favorable near-term opportunity for U.S.-based suppliers, particularly once annual offshore capacity additions reach levels sufficient to attract new blade facilities to the U.S.

Once a manufacturer has proven its capability to meet manufacturer quality requirements, it should be able to supply either the land-based or offshore wind blade markets.

\section{Current U.S. Wind Market Suppliers}

Table 2-29 lists epoxy resin and UPR suppliers with U.S. manufacturing facilities. Many of these suppliers have served major turbine and blade manufacturers in Europe and Asia, and presumably have experience in supplying the offshore segment. While some consider UPR to have inferior mechanical properties, LM has a unique blade design adapted to accommodate those concerns. Despite this, DSM, Momentive, and Ashland (the latter two U.S. based) all serve as primary suppliers of UPR to the wind market. 


\section{NAVIGANT}

Table 2-29. U.S. Suppliers of Epoxy Resin and Unsaturated Polyester for Wind Turbine Blades

\begin{tabular}{|c|c|c|c|c|c|}
\hline $\begin{array}{l}\text { U.S. Facilities Serving } \\
\text { Domestic Land-based Market }\end{array}$ & Company HQ & Facility Region & States & $\begin{array}{l}\text { 중 } \\
\text { 윰 }\end{array}$ & $\frac{\alpha}{\frac{\alpha}{g}}$ \\
\hline $\mathrm{AOC}$ & U.S. & Various & $\mathrm{CA}, \mathrm{FL}, \mathrm{IN}, \mathrm{TN}$ & $X$ & $X$ \\
\hline Ashland Performance Materials & U.S. & Great Lakes & $\mathrm{OH}$ & $X$ & $X$ \\
\hline AXSON Technologies & Europe & Great Lakes & $\mathrm{Ml}$ & $X$ & \\
\hline BASF & Europe & Various & & $X$ & \\
\hline CCP Composites & U.S. & Various & $\mathrm{FL}, \mathrm{MO}, \mathrm{OH}, \mathrm{TX}, \mathrm{VA}$ & & $x$ \\
\hline Cytec Engineered Materials & U.S. & Various & $\begin{array}{c}A Z, C A, M D, M N \\
\text { TX, WA }\end{array}$ & $x$ & \\
\hline Dow Formulated Systems & U.S. & Various & & $X$ & \\
\hline DuPont & U.S. & Various & & & $x$ \\
\hline Huntsman Advanced Materials & & Various & $\mathrm{AL}, \mathrm{CA}, \mathrm{Ml}, \mathrm{TX}$ & $X$ & \\
\hline Lindau Chemicals, Inc & U.S. & South Atlantic & SC & $X$ & \\
\hline Momentive & U.S. & Various & & $\mathrm{X}$ & \\
\hline PCCR & U.S. & Various & CA, GA, TX & & $x$ \\
\hline Reichold & U.S. & Various & $\begin{array}{c}\mathrm{CA}, \mathrm{FL}, \mathrm{IL}, \mathrm{MO}, \mathrm{NJ} \\
\mathrm{TX}\end{array}$ & & $x$ \\
\hline Sika Group & Asia & Various & & $X$ & \\
\hline West System & U.S. & Great Lakes & $\mathrm{Ml}$ & $X$ & \\
\hline
\end{tabular}

Source: BTM 2011, various supplier websites

Several U.S. suppliers of glass fiber also currently serve the global wind market, including several leading offshore blade manufacturers. These suppliers play a large role globally in the supply of preimpregnated glass (particularly Hexcel) as well as woven and stitched fabrics. (Owens Corning is a major player.) Table 2-30 lists key U.S. suppliers of glass fiber for the wind industry. 


\section{NAVIGANT}

Table 2-30. Major U.S. Suppliers of Glass Fiber for Wind Turbine Blades

\begin{tabular}{|c|c|c|c|c|c|}
\hline Supplier & Regions & States & $\begin{array}{l}\text { Glass } \\
\text { Fiber }\end{array}$ & $\begin{array}{c}\text { Stitched/ } \\
\text { Woven } \\
\text { Glass }\end{array}$ & $\begin{array}{l}\text { Pre-Preg } \\
\text { Glass Fiber }\end{array}$ \\
\hline AGY & South Atlantic & SC & $x$ & & \\
\hline Ahlstrom & South Atlantic & SC & & & \\
\hline BGF Industries & South Atlantic & SC & $x$ & & \\
\hline Coast-Line International & & & $x$ & & \\
\hline Cytec Engineered Materials & & & & & $x$ \\
\hline Hexcel & & & & $X$ & $x$ \\
\hline Johns Manville & & & $x$ & & \\
\hline Lanxess & & & $X$ & & \\
\hline Owens Corning Composites & N. Atlantic, Great Lakes & $\mathrm{ME}, \mathrm{OH}$ & $x$ & $X$ & \\
\hline PPG Fiberglass & South Atlantic & $\mathrm{NC}$ & $x$ & & \\
\hline Saint Gobain VetroteX & South Atlantic & $\mathrm{NC}$ & & & \\
\hline
\end{tabular}

Source: BTM 2011

Most global suppliers of carbon fiber originally supplied the aerospace, sports, and leisure industries; however, the increasing interest in carbon fiber for large-scale wind turbine blades has caught the industry's attention. Currently, the global carbon fiber market has 20 key suppliers, with production capacity dominated by three Japanese manufacturers (Toray, Toho Tenax, and Mitsubishi-Rayon) who represented an estimated 75\% of global production capacity in 2010 (BTM 2011). They are followed by two U.S. suppliers, Hexcel and Cytec (see Table 2-31). In addition, a number of new companies or existing composite companies in the carbon fiber sector are shifting production and rapidly making up ground in China, Europe, and India. 


\section{NAVIGANT}

Table 2-31. U.S. Suppliers of Carbon Fiber for Wind Turbine Blades

\begin{tabular}{lccc} 
U.S. Facilities Serving & & & \\
Domestic Land-based Market & Company HQ & Facility Region & Facility State \\
\hline BGF Industries & U.S. & South Atlantic & SC \\
\hline Coast-Line International & U.S. & & \\
\hline Cytec Engineered Materials & U.S. & Gulf Coast & TX \\
\hline Grafil & Asia & Pacific & CA \\
\hline Hexcel & U.S. & Multiple & \\
\hline Toho Tenax & Asia & Midwest & TN \\
\hline Toray & Asia & Gulf Coast & AL \\
\hline Vectorply & U.S. & Multiple & \\
\hline Zoltek & U.S. & Gulf Coast & TX \\
\hline Source: BTM 2011 & & &
\end{tabular}

\subsubsection{Towers}

Like blades, wind turbine towers are not combined with other turbine components until they reach the project site. While land-based wind turbine towers are relatively low-tech components, towers for offshore wind turbines generally come with additional quality requirements and risk potential. For example, offshore towers must have an effective anti-corrosion coating to protect the tower against extreme weather conditions and an effective repair system in case of damage during transport. Turbine OEMs, therefore, are more selective in the qualification and selection of firms to supply their projects.

\section{Potential Market Size}

Table 2-32 shows the modeled requirements for towers and the associated steel in 2020 for the three growth scenarios. For this analysis, we assumed the majority of towers would continue to rely on steel construction; however, some firms have discussed the potential for concrete or steel-concrete hybrid towers for shallow-water offshore wind projects.

Table 2-32. Modeled 2020 Tower Requirements

\begin{tabular}{|c|c|c|c|c|c|}
\hline \multirow[b]{2}{*}{ Total U.S. } & \multirow[b]{2}{*}{ Unit } & \multicolumn{3}{|c|}{$\begin{array}{l}2020 \text { Annual Requirements by Growth } \\
\text { Scenario }\end{array}$} & \multirow{2}{*}{$\begin{array}{c}\text { Annual Market Value } \\
\text { (\$M/year) Moderate- } \\
\text { Growth Scenario }\end{array}$} \\
\hline & & Low & Moderate & High & \\
\hline Incremental Capacity Addition & MW/year & 200 & 1,100 & 2,125 & \\
\hline Towers & \#/year & 33 & 180 & 332 & $\$ 371-\$ 454$ \\
\hline Steel & Tonnes/year & 24,933 & 135,306 & 253,219 & $\$ 158-\$ 193$ \\
\hline
\end{tabular}

\section{Opportunity}

As with the larger blades expected for next-generation turbines, the logistics for offshore towers are more critical in terms of location, often requiring the manufacturing facility to be in a coastal area close to the project. In particular, wider-bases for offshore wind towers may exceed underpass requirements for either rail or road transportation. Towers for today's 80-meter land-based turbines (with diameters of 


\section{NAVIGANT}

4.5 meters) already encounter difficulties when it comes to planning trucking routes, and nextgeneration land-based towers (105-meters tall and 5.4 meters in diameter) are likely to face more restrictions (AWEA 2012). Offshore wind turbine towers are likely to range from 5 to 6.75 meters in diameter (Blatiak, A. et al 2012). In addition, as turbine sizes continue to increase, higher-capacity installations may lead to a less-than-proportional increase in tower demand. For example, the 2020 modeled nationwide demand for 1,100 MW/year of capacity in the moderate-growth scenario translates to only 180 towers assuming a 6-MW average turbine size. A dedicated facility for manufacturing offshore wind towers generally requires minimum demand of 100-200 units/year, and is unlikely that a single facility will capture $100 \%$ of market share.

On the other hand, the technologies and capabilities required for offshore turbine manufacturing are highly transferable and could help lower the risk of serving the offshore market. A coastal manufacturing facility may be able to ramp up its offshore tower capacity more slowly, using excess capacity to meet land-based tower demand or related demand in other industries (e.g., oil and gas). Lead times for tower manufacturing facilities are relatively short compared to those for turbine supply, meaning new capacity can likely ramp up in time to meet anticipated demand (BVG 2012).

\section{Table 2-33. Opportunity Indicators: Towers}

\begin{tabular}{|c|c|c|}
\hline Indicator & Rating $^{1}$ & Notes \\
\hline $\begin{array}{l}\text { Timing of Domestic } \\
\text { Opportunity }\end{array}$ & & $\begin{array}{l}\text { Assuming that a coastal tower facility could serve the entire Atlantic Coast, moderate } \\
\text { growth would result in a combined } 600 \text { MW/year of servable demand by } 2020 \text { (about } 100 \\
\text { towers/year assuming 6-MW turbines). }\end{array}$ \\
\hline $\begin{array}{l}\text { Probability of Near-term } \\
\text { Global Shortfall }\end{array}$ & & $\begin{array}{l}\text { While few firms exist with offshore-specific experience, no shortages are expected in either } \\
\text { European or Asian markets. }\end{array}$ \\
\hline Transferability & & $\begin{array}{l}\text { Technologies and capabilities are highly transferable and lower the risk of serving the } \\
\text { offshore market. Nearer-term opportunities may exist for facilities already located on } \\
\text { coasts. }\end{array}$ \\
\hline Overall Opportunity/Risk & & $\begin{array}{l}\text { While adequate demand to support a dedicated facility may not occur until } 2020 \text { or later, } \\
\text { risk is lower for experienced manufacturers that can serve both land-based and offshore } \\
\text { demand from a single coastal facility. }\end{array}$ \\
\hline
\end{tabular}

(1) See Table 2-3 for rating definitions

The need for supply proximal to offshore project locations and the possibility of gradual ramp-up in production capacity present a favorable near-term opportunity for tower manufacturers.
While the market for land-based wind turbine towers faces overcapacity in many parts of the world, the offshore tower market has relatively few current suppliers. Only a limited few tower manufacturers have stepped forward to meet the technical requirements for supplying the offshore market. Given the harsh environment and other complexities facing offshore turbine and tower design, other firms with shipbuilding or offshore oil platform experience may also have an opportunity to participate in this emerging market.

Overall, this need for supply proximal to offshore project locations and the possibility of gradual ramp up in production capacity present a favorable near-term opportunity for tower manufacturers. 


\section{NAVIGANT}

\section{Current U.S. Wind Market Suppliers}

Most established offshore wind tower suppliers are in Northern Europe. In addition to towers, these firms are also pursuing the design and production of offshore turbine foundations, monopiles, and other steel construction materials. Recent demonstration and commercial-scale projects in South Korea and China, respectively, have led to the establishment of local suppliers in those countries as well. In the U.S., Broadwind, Ventower, and Marmen (a major Canadian supplier), plan to enter the North American offshore market based on future demand (BTM 2011). Table 2-34 lists companies that currently have U.S. tower manufacturing facilities serving the land-based wind market. With the exception of Gamesa and Vestas, all have their headquarters in the U.S.

Table 2-34. U.S. Suppliers of Towers to the Land-based Wind Industry

\begin{tabular}{lcc}
\hline U.S. Facilities Serving Domestic Land-based Market & Regions & States \\
Aerisyn (SIAG) & Midwest & TN \\
\hline Ameron & Pacific & CA \\
\hline Barr Fabrication & Gulf Coast & TX \\
\hline Bergen Southwest Steel & Gulf Coast & TX \\
\hline Broadwind (formerly Tower Tech) & Great Lakes & WI \\
\hline DMl & Midwest & ND, OK \\
\hline Dragon Wind & Rockies & CO \\
\hline Eagle Claw Fabrication & Great Lakes & Ml \\
\hline Gamesa & Great Lakes & PA \\
\hline Johnson Plate and Tower Fabrication & Rockies, Gulf Coast & NM, TX \\
\hline Johnson Systems Inc & Great Lakes & Ml \\
\hline Katana Summit & Midwest, Pacific & NE, WA \\
\hline Martifer-Hirschfeld Energy Systems & Gulf Coast & TX \\
\hline Petersen Inc & Rockies & ID \\
\hline RTLC Wind Tower & Gulf Coast & TX \\
\hline Schuff Steel & Midwest & KS \\
\hline SMl Hydraulics & Great Lakes & MN \\
\hline TBailey & Pacific & WA \\
\hline Taller Wind Towers & Midwest & NE \\
\hline Tower Tech & Various & TX, WI, SD \\
\hline Trinity Structural Towers & Various & IA, IL, TX \\
\hline Valmont Wind Energy & Gulf Coast & AL \\
\hline Ventower & Great Lakes & Ml \\
\hline Vestas & Rockies & CO \\
\hline Wind Clean & Gulf Coast & TX \\
\hline Souce: BTM & & \\
\hline
\end{tabular}

Source: BTM 2011, NREL Data 


\section{NAVIGANT}

\subsubsection{Offshore Foundations and Substructures}

Thus far, offshore wind foundations have primarily involved concrete, gravity-based foundations or steel monopiles, which currently account for $75 \%$ of installed offshore wind capacity (European Wind Energy Association (EWEA) 2012). Future offshore foundations, however, are likely to include several alternative designs based on site-specific characteristics such as water depth, seabed conditions, and turbine size. These include tripods, jacket designs, and several experimental types of floating foundation.

Figure 2-12. Share of Foundation Types of European Offshore Wind Turbines: Year-End 2011

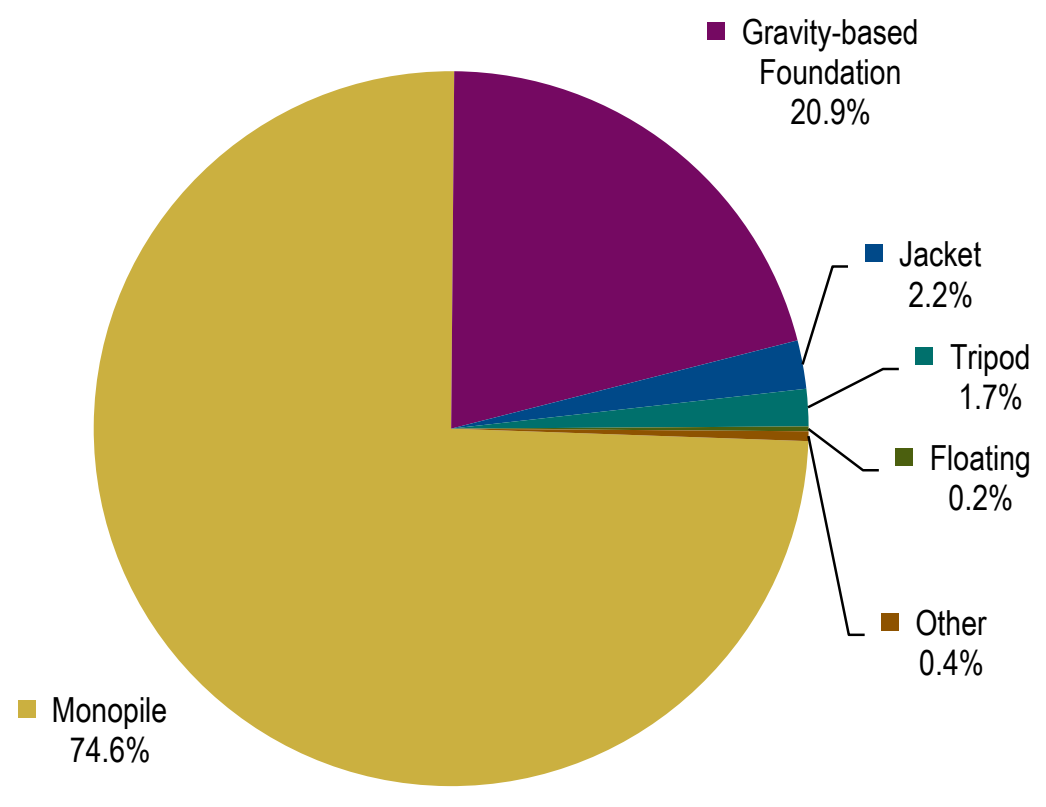

Source: EWEA 2012

Gravity-based concrete structures have primarily been installed in Danish offshore wind projects, including the world's first offshore wind farm installed in 1991. As such, most of the companies that have supplied concrete foundations to the offshore wind market are based in Denmark. However, as demand ramps up in expanding markets like Germany and China, new suppliers (primarily large construction firms with civil, infrastructure, and oil and gas project experience) in those countries have indicated plans to supply domestic projects (BTM 2011). Similarly, most suppliers of steel foundations and substructures for the offshore wind market are based in those European countries with significant installed offshore capacity (e.g., Denmark, the Netherlands, the U.K. and Germany).

\section{Potential Market Size}

Table 2-35 shows the modeled material requirements for U.S. offshore foundations and substructures for the three growth scenarios in 2020. Readers should note that these estimates are sensitive to assumptions about the mix of foundation and substructure types employed in the future U.S. offshore wind market and the subsequent material requirements of each (see Appendix \# for a list of assumptions used). The 


\section{NAVIGANT}

quantities listed in Table 2-35 are intended to give a sense of the potential order-of-magnitude annual demand for foundation materials between each of the three scenarios.

Table 2-35. Modeled 2020 Material Requirements for Foundations and Substructures

\begin{tabular}{|c|c|c|c|c|c|}
\hline \multirow[b]{2}{*}{ Total U.S. } & \multirow[b]{2}{*}{ Unit } & \multicolumn{3}{|c|}{$\begin{array}{l}2020 \text { Annual Requirements by Growth } \\
\text { Scenario }\end{array}$} & \multirow{2}{*}{$\begin{array}{l}\text { Annual Market Value } \\
\text { (\$M/year) Moderate- } \\
\text { Growth Scenario }\end{array}$} \\
\hline & & Low & Moderate & High & \\
\hline Incremental Capacity Addition & MW/year & 200 & 1,100 & 2,125 & \\
\hline Foundations/Substructures & \#/year & 33 & 180 & 332 & $\$ 1,300-1,600$ \\
\hline Primary Steel & Tonnes/year & $\begin{array}{l}25,800- \\
32,800\end{array}$ & $\begin{array}{l}166,600- \\
215,100\end{array}$ & $\begin{array}{l}318,700- \\
494,7000\end{array}$ & $\$ 126-\$ 279$ \\
\hline Secondary Steel & Tonnes/year & 1,431 & 7,077 & 12,118 & $\$ 8-\$ 10$ \\
\hline Concrete & Tonnes/year & $\begin{array}{l}38,200- \\
57,900\end{array}$ & $\begin{array}{c}183,300- \\
278,200\end{array}$ & $\begin{array}{c}335,800- \\
509,500\end{array}$ & $\$ 12-\$ 19$ \\
\hline
\end{tabular}

\section{Opportunity Summary}

Table 2-36 summarizes the opportunity indicator rankings for domestically supplying offshore wind turbine foundations and substructures under the moderate-growth scenario. Notably, the timing of the opportunity for domestic supply is likely to occur earlier than many of the other large turbine components. While some project developers or turbine OEMs may outsource monopiles or other foundation structures, most aim to keep those jobs incountry by building up a domestic supply chain (BTM 2011). As such, future demand in the U.S. offshore wind market has high potential to lead to the addition of domestic manufacturing facilities, whether owned by U.S.based or foreign firms. Based on to-date suppliers of the European and Asian offshore markets, this could include participation from a long list of firms with experience in both land-based and offshore structural engineering and

The timing of the opportunity for domestic supply of foundations and substructures is likely to occur earlier than many of the other large turbine components. heavy construction. 


\section{NAVIGANT}

Table 2-36. Opportunity Indicators: Foundations and Substructures

\begin{tabular}{ll}
\hline $\begin{array}{l}\text { Indicator } \\
\text { Rating }\end{array}$ & Notes \\
\hline $\begin{array}{l}\text { Opportunity } \\
\text { Oppomestic }\end{array}$ & $\begin{array}{l}\text { A facility for manufacturing offshore foundations generally requires minimum demand of } 50 \\
\text { units/year. With moderate growth, aggregate U.S. demand on the Atlantic and Gulf Coasts } \\
\text { could support a single facility with } 60 \% \text { market share by } 2017 .\end{array}$ \\
\hline $\begin{array}{l}\text { Probability of Near-term } \\
\text { Global Shortfall }\end{array}$ & $\begin{array}{l}\text { Lack of demand continuity in Europe may lead to supply shortfalls for jacket substructures. } \\
\text { No shortfall is anticipated for monopoles, where overseas competition may create stiff price } \\
\text { competition. }\end{array}$ \\
\hline Transferability & $\begin{array}{l}\text { Foundations and substructures require offshore-specific design and need to be assembled at } \\
\text { coastal facilities. Synergies may exist, however, with the offshore oil and gas market. }\end{array}$ \\
\hline Overall Opportunity & $\begin{array}{l}\text { Logistics encourage the development of domestic supply; however, limited transferability for } \\
\text { entrants inexperienced with other offshore markets (e.g., oil and gas) poses risk to } \\
\text { investment should consistent demand fail to develop. }\end{array}$ \\
\hline
\end{tabular}

(1) See Table 2-3 for rating definitions

A recent U.K. study anticipates adequate supply of monopiles for the European market (BVG 2012), and additional Chinese suppliers have begun to appear to serve the Asian market (BTM 2011). However, a lack of market continuity (i.e., due to inconsistent demand or policy support) may lead to shortfalls in the supply of steel jacket structures and concrete gravity-based foundations based on the significant investment required for new manufacturing facilities (BVG 2012). Particularly for emerging foundation designs, new manufacturing technologies and capacity takes time (up to two years) to plan, site, and bring online (BVG 2009). In addition, volatile steel prices can add uncertainty to a developer or OEM's selection of the appropriate foundation type for a particular project (BVG 2009).

As with offshore tower suppliers, firms with shipbuilding or offshore oil platform experience may also have an opportunity to participate in this emerging market. Notably, these firms' marine-specific expertise and ability to rely on diverse markets for their revenue could help lower the risk of entering the offshore wind market and allow for a gradual ramp up in capacity. Overall, the logistical benefits of domestic supply may create a favorable near-term opportunity for firms with the right mix of relevant expertise and ability to add capacity over time.

\section{Current U.S. Wind Market Suppliers}

The only U.S.-based company that has shown a visible interest in the market for fixed-bottom offshore wind foundations is Mass Tank Sales Corporation, a longstanding U.S. manufacturer of steel storage tanks. Mass Tank announced its entry into a partnership with Erndtebrucker Eisenwerk GmbH \& Co. KG (EEW) in Germany to establish the first U.S. facility for the manufacture of offshore wind structures. The company hopes to provide monopoles, transition pieces, and transformer platforms for the proposed Cape Wind project off the coast of Massachusetts (BTM 2011). However, beset by delays and with options from potentially lower-cost suppliers in Europe and Asia, Cape Wind's owner had not yet solidified its foundation supply contract as of September 2012. Several U.S.-based companies are also actively developing potential floating foundation designs, including Principal Power, Glosten Associates, and Nautica Wind Power (Maine(e) International Consulting 2012). 


\section{NAVIGANT}

\subsubsection{Offshore Subsea Cables}

Offshore wind plants use two kinds of cables: inter-array cables and export cables. Inter-array cables (rated up to 35 kilovolts $[\mathrm{kV}]$ ) link individual turbines and connect the turbines to the plant's substation. Export cables (rated up to $600 \mathrm{kV}$ ) connect the substation to the land-based grid and are much longer and heavier than inter-array cables. Thus far, most offshore wind projects have relied on alternating current (AC) cables; however, as projects move further from shore, increased distances and potential line losses are encouraging the use of HVDC technology. In general, if an offshore wind farm is more than 80 to $100 \mathrm{~km}$ (43-51 Nmi) from its point of interconnection, HVDC cables are preferred (Pike Research 2012). There are two main types of cable technology suitable for use in HVDC applications - mass impregnated (MI) insulation and cross-linked polyethylene (XLPE). Currently, MI HVDC cables are available up to $600 \mathrm{kV}$, while XLPE for HVDC are only widely accepted for $320 \mathrm{kV}$ applications (BTM 2011).

\section{Potential Market Size}

Table 2-37 shows the modeled 2020 regional requirements for mileage of inter-array and export cables, respectively, under each of the three demand growth scenarios.

Table 2-37. Modeled 2020 Requirements for Subsea Cable (distance in miles)

\begin{tabular}{|c|c|c|c|c|c|}
\hline \multirow[b]{2}{*}{ Region } & \multirow[b]{2}{*}{ Unit } & \multicolumn{3}{|c|}{$\begin{array}{l}2020 \text { Annual Requirements by Growth } \\
\text { Scenario }\end{array}$} & \multirow{2}{*}{$\begin{array}{c}\text { Annual Market Value } \\
\text { (\$M/year) Moderate- } \\
\text { Growth Scenario }\end{array}$} \\
\hline & & Low & Moderate & High & \\
\hline Incremental Capacity Addition & MW/year & 200 & 1,100 & 2,125 & \\
\hline Inter-Array Cable & Miles/year & 37 & 202 & 377 & \\
\hline Export Cable & Miles/year & 13 & 73 & 143 & \\
\hline Total & Miles/year & 50 & 275 & 520 & $\$ 282-\$ 345$ \\
\hline
\end{tabular}

Note: This table expresses demand in terms of estimated transmission distances; however, costs can vary significantly based on specific project designs. For example, a three-phase AC cable may require three cores, while a bipolar HVDC solution may require dual cables. Further, depending on project capacity, multiple cables may also be required. The simplified market value estimate for both inter-array and export cable is based on a $\$ / \mathrm{MW}$ assumption (see Appendix D).

\section{Opportunity Summary}

The opportunity for near-term domestic supply for inter-array and export cables differs under the moderate-growth scenario. This stems primarily from degree to which facilities already exist and the transferability of capacity to markets other than offshore wind. Table 2-38 and Table 2-39 summarize the opportunity indicators for inter-array and export cables, respectively. 
Table 2-38. Opportunity Indicators: Inter-array Cable

\begin{tabular}{|c|c|c|}
\hline Indicator & Rating $^{1}$ & Notes \\
\hline $\begin{array}{l}\text { Timing of Domestic } \\
\text { Opportunity }\end{array}$ & & $\begin{array}{l}\text { Under the moderate-growth scenario, demand may present an opportunity for existing } \\
\text { suppliers, but may not be likely sufficient to support investment in a new facility. }\end{array}$ \\
\hline $\begin{array}{l}\text { Probability of Near-term } \\
\text { Global Shortfall }\end{array}$ & & No significant supply shortages are expected for inter-array cable. \\
\hline Transferability & & $\begin{array}{l}\text { Suppliers can generally convert land-based capacity to serve the offshore market, but } \\
\text { must have water-side access. Nearer-term opportunities may exist for facilities already } \\
\text { located on coasts. }\end{array}$ \\
\hline Overall Opportunity & & $\begin{array}{l}\text { Low relative levels of required supply and the existence of ample global supply will likely } \\
\text { limit near-term opportunities to existing facilities with coastal access. }\end{array}$ \\
\hline
\end{tabular}

(1) See Table 2-3 for rating definitions

Recent studies generally indicate adequate near-term supply of inter-array cables (BTM 2011, BVG 2012). As mentioned above, the scale of cable demand in either the low- or moderate-growth scenarios may not be adequate to attract investment in a new facility to serve the offshore market by 2020; however, there may be opportunities to add capacity to existing facilities in location with access to ships (via port or river) for loading.

Table 2-39. Opportunity Indicators: Export Cable

\begin{tabular}{|c|c|c|}
\hline Indicator & Rating ${ }^{1}$ & Notes \\
\hline $\begin{array}{l}\text { Timing of Domestic } \\
\text { Opportunity }\end{array}$ & & $\begin{array}{l}\text { Under the moderate-growth scenario, the relatively small scale of U.S. demand may face } \\
\text { challenges in attracting investment in a new export cable facility when compared to larger } \\
\text { overseas markets. }\end{array}$ \\
\hline $\begin{array}{l}\text { Probability of Near-term } \\
\text { Global Shortfall }\end{array}$ & & $\begin{array}{l}\text { The global supply chain faces a potential bottleneck for meeting planned European } \\
\text { demand (assuming projects are able to meet target dates). }\end{array}$ \\
\hline Transferability & & $\begin{array}{l}\text { Current demand is driven almost entirely by the offshore wind market, exposing } \\
\text { investment in domestic manufacturing to risk of market instability. }\end{array}$ \\
\hline Overall Opportunity & & $\begin{array}{l}\text { The relatively small scale of modeled demand and reliance on the offshore wind market } \\
\text { poses significant risks for near-term investment in new manufacturing capacity. }\end{array}$ \\
\hline
\end{tabular}

(1) See Table 2-3 for rating definitions

As with inter-array cables, the modeled demand for export cables is less likely to support near-term opportunities for new manufacturing capacity in the U.S. The 146 miles of HVDC cable core that would be required to serve the estimated demand in the moderate scenario (see note in Table 2-37) is approximately 11 percent of the same-year demand as that anticipated for the U.K. market alone (excluding the rest of Europe) (BVG 2012). It is also possible that export cable needs for at least a portion of early-stage U.S. projects can be met with AC cables, further reducing the total market demand available to a new facility. This relatively smaller market opportunity may pose challenges in competing for a limited number of suppliers' investment in manufacturing capacity. In addition, the federal Jones 


\section{NAVIGANT}

Act's requirement that any subsea cable manufactured in the U.S. and destined for U.S. waters be installed by a U.S.-flagged ship may raise additional hurdles to domestic supply (see Chapter 2.3.14).

On the other hand, shortfalls in the supply of large HVDC export cables are already a significant concern for the industry (BTM 2011, BVG 2012), particularly for the larger MI cables. The greater distance to shore anticipated under the U.K.'s Round 3 projects will likely lead to a continued tight supply of HVDC cables through 2016 unless significant investments are made in the next two years. Building and ramping up a new HVDC cable manufacturing facility can take up to four years; however, experienced players indicate that adding capacity to an existing facility can take less time. In addition, firms must test and certify cable produced from a new facility (a two-year process) to address customers' risk and quality concerns (BVG 2012). This European market's response to this issue over the next few years will play a large role in determining the availability of excess supply to serve the new U.S. market (or the need to develop a domestic source of supply).

This growing opportunity to supply cable to the offshore wind industry is also attracting new entrants from Asia, which may help alleviate some of the supply chain concerns. Given that subsea cables need to be loaded onto an installation vessel at the manufacturing facility, future manufacturing capacity can only occur at sites with suitable coastal infrastructure (BTM 2011). Assuming the industry perceives sufficient demand and policy support in the U.S. market, this may contribute to the addition of U.S.based cable facilities; however, European or Asian facilities could conceivably supply U.S. projects based on the global demand situation at the time. An additional concern for the industry lies in the availability of cable laying vessels, further discussed in Chapter 2.3.14.

\section{Current Global Offshore Wind Market Suppliers}

To date, only a few HVDC cable suppliers are serving the offshore wind industry, with the majority of market share held by four European players - ABB, Prysmien, Nexans, and NKT. Notably, three of the top four European suppliers (all but NKT) have significant footprints in the in the U.S. Table 2-40 lists major inter-array and export cable suppliers to the offshore wind industry. 


\section{NAVIGANT}

Table 2-40. Global Suppliers of Subsea Cable to the Offshore Wind Industry

\begin{tabular}{lc} 
Supplier & Region Served \\
\hline ABB* $^{*}$ & Europe \\
\hline AEl Cables & Europe \\
\hline Draka & Europe \\
\hline Fujikura Shanghai Cable & Asia \\
\hline General Cable & Europe \\
\hline JDR Cables & Europe \\
\hline JS Cable & Asia \\
\hline LS Cable & Asia \\
\hline Nexans* & Europe \\
\hline NKT & Europe \\
\hline Parker Scanrope & Europe \\
\hline Prysmien* & Europe \\
\hline Sudkable GmbH & Europe \\
\hline VISCAS & Asia \\
\hline Zhongtian Tech Submarine Optic Fiber & Asia \\
\hline
\end{tabular}

*Also has a presence in the U.S.

Source: BTM 2011

\subsubsection{Offshore Substations}

The substation collects the power generated from a plant's turbines and power transformer and converts it for export over subsea cables to a land-based transformer and the electric grid. The modeled substation requirements in 2020 for each scenario appear in Table 2-41.

Table 2-41. Modeled 2020 Substation Requirements

\begin{tabular}{lccccc} 
& & \multicolumn{2}{c}{2020 Annual Requirements by Growth } & Annual Market Value \\
Scenario & Unit & Low & Moderate & High & $\begin{array}{c}\text { An/year) Moderate- } \\
\text { Growth Scenario }\end{array}$ \\
\cline { 3 - 5 } Incremental Capacity Addition & MW/year & 200 & 1,100 & 2,125 & \\
\hline \hline Total U.S. & \#/year & 2 & 7 & 8 & $\$ 174-\$ 213$ \\
\hline
\end{tabular}

The simplified market value estimate for substations is based on a $\$ / M W$ assumption (see Appendix D).

\section{Opportunity Summary}

Table 2-42 summarizes the near-term opportunity indicator rankings for offshore substations under the moderate-growth scenario. As with export cables, the estimated size of the U.S. offshore market will likely represent a small share of the world market for offshore substation demand in 2020. Therefore, indications of firm long-term demand will likely be required to attract large-scale domestic investment from manufacturers with the experience and capability to meet this demand. As was also the case with subsea cable providers, the leading European suppliers of offshore substations also have a presence in the U.S. and are likely contributors to future domestic supply. 
Table 2-42. Opportunity Indicators: Offshore Substations

\begin{tabular}{|c|c|c|}
\hline Indicator & Rating $^{1}$ & Notes \\
\hline $\begin{array}{l}\text { Timing of Domestic } \\
\text { Opportunity }\end{array}$ & & $\begin{array}{l}\text { The estimated size of the U.S. offshore substation market will represent a small share of } \\
\text { world demand in } 2020 \text {. Indications of firm demand will likely be required to attract large- } \\
\text { scale investment from manufacturers with the requisite experience and capabilities. }\end{array}$ \\
\hline $\begin{array}{l}\text { Probability of Near-term } \\
\text { Global Shortfall }\end{array}$ & & $\begin{array}{l}\text { Relatively few firms serve the offshore substation market, and all are based in Europe. No } \\
\text { significant shortages are currently expected. }\end{array}$ \\
\hline Transferability & & The offshore substation market is highly specialized. \\
\hline Overall Opportunity & & $\begin{array}{l}\text { Near-term supply is likely to be met by established European firms; however, several of } \\
\text { those firms have a presence in the U.S. }\end{array}$ \\
\hline
\end{tabular}

(1) See Table 2-3 for rating definitions

The current supply chain for the offshore wind market involves a limited number of key players, with no current U.S.-based supply. ABB, Siemens, and Alstom Grid (formerly Areva T\&D) comprising the majority of market share (BTM 2011). Despite the global supply for offshore substations being concentrated in a few companies (particularly for DC substations), recent studies do not anticipate any supply shortages, as the offshore wind market represents a relatively small share of overall substation demand (BVG 2012, BTM 2011). As such it is likely that near-term U.S. supply could be met via existing European suppliers. Table 2-43 lists current offshore substation suppliers.

Table 2-43. Global Suppliers of Offshore Substations to the Offshore Wind Industry

\begin{tabular}{ll} 
Supplier & Region \\
\hline ABB & Europe \\
\hline Alstom Grid (formerly Areva T\&D) & Europe \\
\hline CG System Delivery & Europe \\
\hline EDF & Europe \\
\hline SEAS Transmission & Europe \\
\hline Siemens & Europe \\
\hline Strukton Hollandia JV & Europe \\
\hline Source: BTM 2011 &
\end{tabular}

\subsubsection{Installation and Construction Vessels}

Three primary types of vessels are used in the installation of offshore wind turbines and foundations heavy-lift vessels combined with working barges; jack-up barges without propulsion; and self-propelled jack-up vessels. The latter two represent the most common system currently used in the European offshore market (BTM 2011). In addition, subsea cable installation requires a specialized type of vessel. An analysis of the installation and construction vessel market was beyond the scope of this report. A forthcoming report from the U.S. DOE and Douglas-Westwood will provide additional detail about the anticipated requirements and potential supply of such vessels for the future U.S. offshore wind market. This section provides a high-level overview of the current state of the vessels market. 


\section{NAVIGANT}

The availability of offshore installation vessels has historically represented a key area of concern for the European offshore wind market and was cited as a major bottleneck in 2009. At the time, vessels could require up to 2.5 years from the point of investment to being ready for use, with conversion of existing vessels requiring up to 10 months (BTM 2011). Since then, however, responses from investors have alleviated the current bottleneck. Nonetheless, future global vessel supply could face additional shortages based on a few key factors. Most importantly for Europe, planned increases in decommissioning activity in the North Sea oil and gas industry coincides with the scheduled start of the U.K.'s next round of offshore plant construction, with both activities relying on the same pool of vessels. In addition, the continuing trend toward larger offshore turbines adds uncertainty (e.g., what size or type of vessel to construct) for investors and companies looking to build new ships to serve the offshore market (BTM 2011).

As of 2011, 53 vessels were available globally to carry out offshore wind installation, with 42 based in European countries and the remaining 11 based in China (BTM 2011). While many of these vessels can serve multiple purposes, several companies have invested in vessels customized for wind installation, including A2SEA, BARD Engineering, MPI Vroon, Seajacks International, HOCHTIEF, DBB, and RWE Innogy. It is anticipated that the U.K.'s Round 3 projects alone will require 10-12 new vessels with such customization. In addition to contractors and construction firms, some project developers (e.g., DONG energy, RWE Innogy, Fred Olsen, and N.prior energy) and turbine suppliers (e.g., Siemens) have also acquired full or partial ownership of installation vessels to help reduce their own exposure to supply risk. For project developers and turbine OEMs, these investments can provide security and a significant time advantage over competitors while reducing their total costs (BTM 2011).

For the future U.S. offshore wind market, a more important issue facing the vessel supply chain relates to the Jones Act (also known as the Merchant Marine Act of 1920), which requires that cargo shipped between U.S. ports (ostensibly including offshore facilities in U.S. waters) be carried by U.S.-flagged vessels. Precedent from the U.S. offshore oil and gas industry suggests that in spite of the Jones Act, foreign vessels may be utilized for installation purposes so long as they are not moving equipment, but merely offloading and installing the equipment from a fixed location. ${ }^{9}$ Equipment would presumably be required to be brought to the installation vessel by a U.S.-flagged vessel assuming it was staged at a U.S. port. Therefore, the Jones Act will likely require the use of dedicated U.S. transport vessels with non-U.S. installation vessels until U.S.-flagged installation vessels are built. If the U.S. offshore wind industry were to take off rapidly, however, this could lead to a critical bottleneck in vessel supply. At least one firm is taking efforts to prepare for potential demand for U.S. vessels. In September 2012, Weeks Marine Inc., one of the largest vessel owners in the U.S., was busy fitting a 2 million-pound crane to a newly completed barge that it hopes will serve the nation's future offshore market (Gannett 2012).

Another potential bottleneck in the vessel supply chain lies with the availability of cable installation vessels. Currently, only a few fully equipped and highly specialized cable installation vessels exist that

\footnotetext{
9 This potential opportunity for foreign flagged installation vessels exploits the fact that the Jones Act applies to the actual transportation of goods. As such, goods could be moved from a U.S. port to a foreign flagged vessel for the purpose of being installed at an offshore facility so long as that foreign flagged vessel does not transport the equipment. Although there is precedent for such a practice in the offshore oil and gas industry readers are advised to consult with legal counsel for further guidance.
} 


\section{NAVIGANT}

can lay offshore wind power cables. Some investors remain hesitant to build additional vessels without a strong policy support and commitment from relevant government. Cable laying represents one of the highest-risk aspects of offshore wind project construction, comprising approximately $80 \%$ of project insurance claims stemming from damage during or after installation (BTM 2011). Subsea cables are manufactured and loaded directly onto cable installation ships adjacent to foreign coastal manufacturing facilities. These cable ships can then transport and lay the cable off the U.S. shore without first entering a U.S. port, thus avoiding the Jones Act constraint.

\subsection{Labor and Economic Impacts and Opportunities}

This section describes the potential labor requirements and economic impacts likely to arise from the U.S. offshore market's development under a range of scenarios. It considers both the required investment and labor to support the construction of new or upgraded port facilities and co-located manufacturing facilities, as well as the manufacturing labor requirements stemming from modeled levels of domestically sourced capacity in 2020 and 2030. It concludes by examining the regional labor availability in industries that may contribute to the domestic offshore wind industry's development, highlighting any potential areas of concern.

\subsubsection{Potential Requirements for Co-located Port and Manufacturing Facilities}

This section provides a high-level overview of the technical and investment requirements for new or upgraded port and manufacturing facilities to support future offshore wind construction. Readers interested in the details of such requirements should refer to a parallel set of DOE-sponsored reports that provide in-depth analyses of port requirements and potential options for preparing U.S. ports to support the offshore wind industry. ${ }^{10}$

\section{Port Facility Minimum Technical Requirements}

Adequate port infrastructure is a crucial component in the wind industry's ability to domestically manufacture offshore wind components and stage offshore wind project assembly. It also provides significant opportunities to capture economic development and labor benefits associated with future offshore wind deployments. Because of the capital-intensive nature of offshore wind power plants and large component sizes, taking steps to enable the co-location of port and manufacturing facilities will significantly enhance the ability of states and localities to capture such opportunities.

The offshore wind industry involves unique port requirements that may vary depending on the intended use of the facility. For example, the needs associated with a temporary staging or marshaling facility are quite different relative to a permanent, vertically integrated manufacturing, assembly, and staging facility. Nevertheless, there are a few minimum requirements likely to be associated with any port that might serve the offshore wind industry. These minimum requirements are largely determined by components' current or anticipated future size, which generally precludes overland transport (particularly for full or partially assembled pieces of equipment) and necessitates access for large vessels. Such requirements are also a function of land available for both staging and storage of components such

\footnotetext{
${ }^{10}$ See Blatiak, Garrett, \& O’Neill (2012) for a comprehensive description of technical port requirements. In addition, a forthcoming set of reports specific to U.S. port are being prepared by GL Garrad Hassan and are expected to be available by the end of 2012 .
} 


\section{NAVIGANT}

as nacelles, rotors, and foundations. Table 2-44 lists minimum port requirements as indicated by each of three organizations that specialize in wind energy development. A more comprehensive description of technical port requirements can be found in the DOE companion report developed by Blatiak, Garrett, \& O’Neill (2012).

Table 2-44. Suggested Minimum Port Requirements for Serving the Offshore Wind Industry

\begin{tabular}{lcccc} 
Association & $\begin{array}{c}\text { Draft or Harbor } \\
\text { Depth }\end{array}$ & $\begin{array}{c}\text { Wharf/Quay } \\
\text { Length }\end{array}$ & $\begin{array}{c}\text { Staging and } \\
\text { Storage }\end{array}$ & Load Capacity \\
\hline EWEA & 20 feet (draft) & 500 feet & 15 acres & $600 \mathrm{lbs} / \mathrm{ft}^{2}$ \\
\hline Vestas & 20 feet (draft) & 650 feet & 9 acres & $5,000 \mathrm{lbs} / \mathrm{ft}^{2}$ \\
\hline Tetra Tech & 24 feet (depth) & 450 feet & 10 acres & $2,000 \mathrm{lbs} / \mathrm{ft}^{2}$ \\
\hline
\end{tabular}

Sources: EWEA (2009), Vestas Offshore A/s (2010 and 2011), Tetra Tech (2010)

Most of these observed minimum requirements are relatively common among the three reports summarized in Table 2-44, with the principle exception occurring in load capacity. However, some engineering solutions offered by specialized cranes or load-distributing platforms could potentially allow ports that otherwise lack the minimum load capacity to serve offshore wind staging activities (Tetra Tech 2010). Vestas and EWEA also specify the need for 11,000 to $16,000 \mathrm{ft}^{2}$ of available warehousing space, and Tetra Tech highlights substantial air draft or vertical clearance and horizontal clearance in excess of 130 feet as minimum requirements (Tetra Tech 2010). All three groups listed transportation connectivity via rail and a nearby highway as important for smaller inputs. EWEA additionally lists a heliport as desirable.

Existing ports do not commonly have all of these features. Some, but not all, of these requirements are also necessary for receiving container ships, the predominant method of shipping cargo. Given differences in available space and existing infrastructure among ports, different ports could conceivably host the manufacture and staging of different components based on their individual characteristics. Table 2-45 summarizes such varying port requirements by component type.

Table 2-45. Selected Port Requirements by Component

\begin{tabular}{|c|c|c|c|c|c|}
\hline Component & $\begin{array}{l}\text { Wharf } \\
\text { Length }\end{array}$ & $\begin{array}{l}\text { Load Capacity (Wharf, } \\
\text { Transition Area) }\end{array}$ & $\begin{array}{l}\text { Storage Area } \\
\text { (Per Unit) }\end{array}$ & $\begin{array}{l}\text { Mobile Crane } \\
\text { Load Outs }\end{array}$ & $\begin{array}{l}\text { Require Seabed is } \\
\text { Suitable for } \\
\text { Jack-up Vessel }\end{array}$ \\
\hline Blades & $600 \mathrm{ft}$ & $200 \mathrm{lbs} / \mathrm{ft}^{2}$ & 6.2 acres & 100 tons & \\
\hline Nacelle & $600 \mathrm{ft}$ & $2,000 \mathrm{lbs} / \mathrm{ft}^{2}$ & 1.2 acres & 400 tons & $X$ \\
\hline Tower & $600 \mathrm{ft}$ & $200 \mathrm{lbs} / \mathrm{ft}^{2}$ & 12.4 acres & 550 tons & $X$ \\
\hline Monopile & $600 \mathrm{ft}$ & $4,000 \mathrm{lbs} / \mathrm{ft}^{2}$ & 0.2 acres & 1,100 tons & $X$ \\
\hline Jacket & $300 \mathrm{ft}$ & $2,000 \mathrm{lbs} / \mathrm{ft}^{2}$ & 0.3 acres & 800 tons & \\
\hline
\end{tabular}

Source: Blatiak, Garrett, $\mathcal{E}$ O'Neill (2012) 


\section{NAVIGANT}

These data suggest that a port with a large amount of available space and lower load capacity may be suitable to blade manufacturing while a port with limited space, existing heavy-duty cranes, and high load capacity berths and staging areas may be more suited to hosting monopile or other foundation manufacturing or assembly activities.

As the shipping and cargo industry continues to grow in size and load capacity, recent and anticipated changes in port infrastructure are increasingly overlapping with the requirements of the offshore wind industry. For example, larger cargo ships necessitate larger terminals, deeper channels, more cranes, and larger staging areas (Haralambides 2002). An expansion of the Panama Canal, currently scheduled for completion in 2014, will result in even larger "post-Panamax" ships visiting ports along the eastern seaboard (Schwartz 2012). This evolution of port infrastructure could potentially enable more ports to engage in the degree of infrastructure

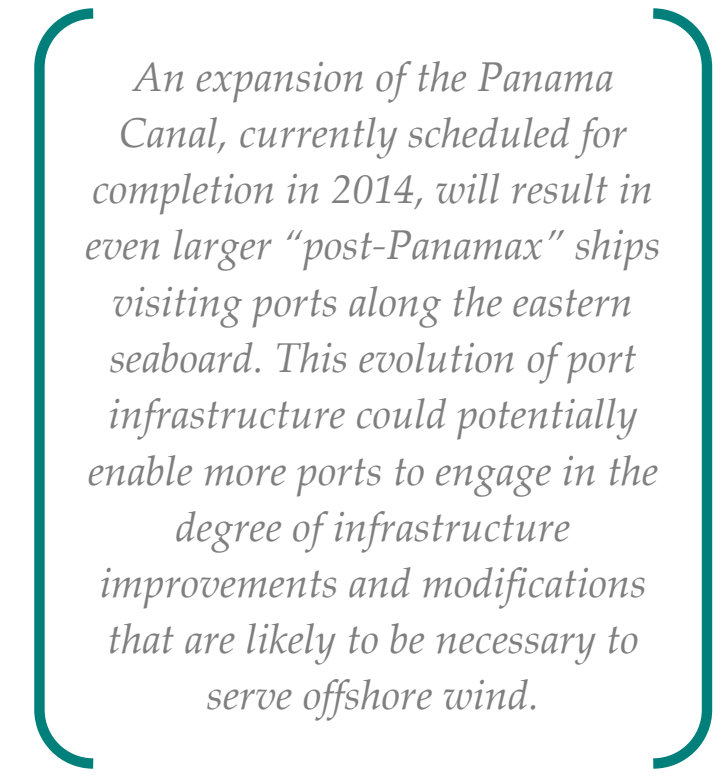
improvements and modifications that are likely to be necessary to serve offshore wind. (For more on basic port selection criteria, industry trends among existing facilities, and examples of investments made in ports serving the offshore market globally, see Appendix F.)

\section{Implications for Port Siting}

Considering existing trends toward larger vessels and higher-volume capacities and the fact that most ports will require significant dedicated investment and improvements to serve the offshore wind industry, technical constraints are unlikely to be primary drivers of offshore wind port siting decisions. Moreover, a robust and thriving offshore wind industry could result in multiple port locations within a given region. ${ }^{11}$

In this context, port development decisions will more likely be a function of the perceived opportunity cost for a given port or port authority; proximity to anticipated projects; and the ability to assemble the collective public and private investment necessary to advance port development. It is plausible that a highvolume container port may see more value in continuing to maximize container volume rather than diversifying into offshore wind. Similarly, in the

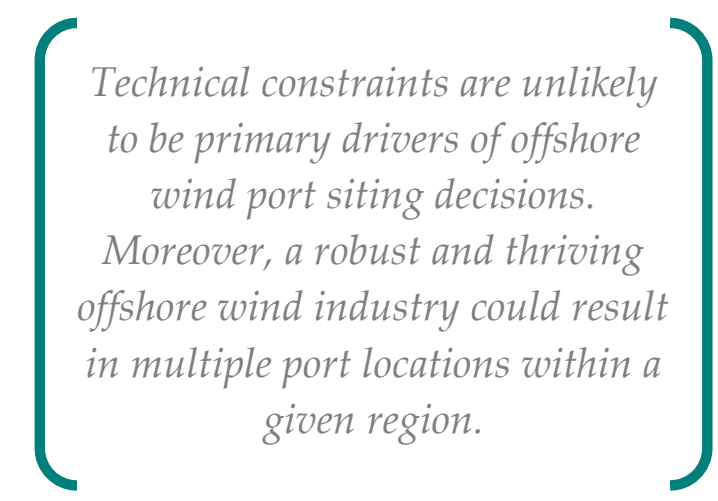

${ }^{11}$ Observations from the current market in Europe suggest that any single port may only be capable of handling 1-2 projects per year. In addition, as competitors move into a given region, it is reasonable to expect that ports that are partially exclusive to an individual OEM and their suppliers could emerge. Such trends have been observed in the U.K. where Vestas, Siemens, and Gamesa have all considered investments in different locations to serve the same primary market. 


\section{NAVIGANT}

absence of breakthrough innovations in transport and installation capabilities, the wind industry will likely continue to seek staging and marshaling ports that allow for minimal at-sea transport of assembled turbine and foundation components.

Assuming market certainty in long-term demand for offshore wind is sufficient to drive public and private investment in port infrastructure, it is not unreasonable to perceive a future where multiple ports at various levels of capability (from temporary staging to vertically integrated manufacturing and staging) are scattered among the North and South Atlantic. In addition, ports distributed among the various Great Lakes and along the Gulf Coast could be possible, although anticipated lower annual demand in these regions may result in more staging- and assembly-oriented port facilities rather than vertically integrated manufacturing and port facilities. Given the theoretical distribution of installations along the Pacific Coast observed in Figure 2-3, and the potential role envisioned for floating turbine technology in this region (which could simplify vessel and staging requirements), port activity on the Pacific Coast may look somewhat different. Probable locations for vertically integrated manufacturing and staging ports would likely comprise the major shipping hubs in Seattle, possibly Oregon, and Northern California.

\subsubsection{Potential Labor and Economic Impacts: Port and Manufacturing Facility Construction}

This section examines the potential labor and economic impacts of port and manufacturing facility construction in the U.S. These investment and labor impacts are heavily influenced by both existing port infrastructure and the scope of a port's intended use as it relates to offshore wind development and operations. As such, this analysis utilizes input-output methodology to estimate cumulative state-level economic impacts from three different investment scenarios across five regions in the U.S.

These scenarios are not meant to model a dominant or sole offshore wind port in any single region of the U.S. It is likely that some level of investment would occur in any region that constructs offshore wind facilities, and different ports may specialize in the manufacture of different components or serve another purpose specific to offshore wind. However, existing port infrastructure is not uniform, and upgrade costs to achieve the same end results will vary. In addition, the potential timing of such investment in each region will be greatly influenced by the offshore wind industry's perception of longterm, stable demand for new capacity, particularly in the context of demand in other global markets. Similarly, existing or planned manufacturing facilities in other parts of the world (e.g., Europe and China) could export offshore wind components to the U.S., further affecting the timing of the need for port improvements in some regions.
The potential timing of investment in each region will be greatly influenced by the offshore wind industry's perception of long-term, stable demand for new capacity, particularly in the context of demand in other global markets. Similarly, existing or planned manufacturing facilities in other parts of the world (e.g., Europe and China) could export offshore wind components to the U.S., further affecting the timing of the need for port improvements in some regions. 


\section{NAVIGANT}

Each scenario in this analysis is discrete and is not representative of overall investment in offshore wind ports in the United States. The cumulative impacts presented represent a total figure that occurs throughout the construction period. An employment impact of 100 full-time equivalent (FTE) jobs over a two-year project, for example, represents an average of 50 employees for each year that the project is in development. The same is true of labor compensation, value added, and gross output.

\section{Upfront Investment Scenario Assumptions}

This report explores three scenarios for port infrastructure and co-located manufacturing facilities, as presented in Table 2-46.

Table 2-46. Incremental Port Infrastructure Investment Scenarios

\begin{tabular}{|c|c|c|c|c|}
\hline \multirow[b]{2}{*}{ Scenario } & \multicolumn{2}{|r|}{ Port Infrastructure } & \multicolumn{2}{|c|}{ Co-located Manufacturing Facilities } \\
\hline & Investment & Prospective Uses & Investment & Assumed Uses \\
\hline Low & $\$ 50$ million & Staging, operations & None & $N / A$ \\
\hline Mid & $\$ 200$ million & Staging, operations, manufacturing & \$270 million & Blade, nacelle manufacturing facilities \\
\hline High & $\$ 700$ million & $\begin{array}{l}\text { Staging, operations, extensive } \\
\text { manufacturing }\end{array}$ & $\$ 700$ million & $\begin{array}{l}\text { Blade, nacelle, tower, and foundation } \\
\text { manufacturing facilities }\end{array}$ \\
\hline
\end{tabular}

Low Scenario: The low scenario assumes that all specialized offshore wind component manufacturing (e.g., gearboxes, towers, blades, and nacelles) will occur overseas, while staging and assembly of the offshore wind facility will occur in the U.S. In this case, nearly $\$ 40$ million in upgrades go toward wharf upgrades, while the remaining $\$ 10$ million is largely for improving or expanding lift capacity and expanding or reinforcing staging areas.

Mid Scenario: The mid scenario represents a \$200-million investment in upgrades similar to those at the German Port of Cuxhaven (see Appendix F). Cuxhaven upgrades included increasing the load capacities of terminals and adding staging area, warehouse space, and heavy-duty crane capacity (Germany Trade and Invest 2011). Approximately half of the $\$ 200$ million spent in this scenario is assumed to go toward wharf upgrades. An additional $\$ 80$ million goes toward high load capacity staging, storage, and transportation infrastructure. This can include additional wharf upgrades or transition areas as well. Approximately $\$ 10$ million is assumed to go toward improving or expanding lift capacity.

In addition to these port infrastructure investments, the mid scenario includes a limited investment in manufacturing facilities. In this case, we assume this would include blade and nacelle manufacturing facilities, although impact results would not change for a facility intended for other components. The construction costs of these manufacturing facilities are comparable to facilities constructed in Europe as well as land-based wind manufacturing facilities in the United States. In this case, the nacelle facility is estimated to cost $\$ 100$ million and the blade facility is estimated at approximately $\$ 170$ million.

High Scenario: The high scenario most closely resembles actual and planned investment in the German Port of Bremerhaven (see Appendix F) and the planned Port of Humber in the United Kingdom. Both of these ports underwent or are planned to undergo significant expansions, including the addition of new cranes, heavy-capacity terminals, staging areas, warehousing space, and infrastructure connecting the 


\section{NAVIGANT}

port with other land-based transportation corridors. This scenario represents a port able to accommodate many different links in the offshore wind supply chain, from either one or multiple producers. ${ }^{12}$

Assumed investments in the high scenario include $\$ 150$ million for dredging and wharf reinforcements; more than $\$ 500$ million for new infrastructure, including berthing space, storage area, and staging area; and nearly $\$ 50$ million to improve lift capacity. An additional $\$ 700$ million investment is assumed to go toward industrial manufacturing facilities. In addition to the blade and nacelle facilities included in the mid scenario, the high scenario includes a $\$ 240$ million tower manufacturing plant and a \$190 million foundation manufacturing facility. ${ }^{13}$

\section{Estimated Direct Impacts of Port and Manufacturing Facility Investments}

The modeled outputs for the direct impacts of each scenario represents an average anticipated statewide impact within a representative state from each of five U.S. coastal regions: north Atlantic, south Atlantic, Great Lakes, Gulf of Mexico, and the Pacific Coast. Variations in impacts should be expected based on differences in states' underlying resources and industries. For example, indirect results will be lower if construction companies have to purchase materials from out of state. In addition, impacts at the national level would be higher than those estimated at a state level. Table 2-47 summarizes the estimated average direct impacts for each scenario, followed by discussion of the results.

12 The planned development of the U.K. Port of Sheerness is an example of a single-producer, integrated supply chain facility. Vestas expressed initial interest, but as of the time of this writing a tenant is yet to be determined. ${ }^{13} € 930.3$ million in commercial investments by business in the offshore wind industry are anticipated at Bremerhaven (Prognos 2011). The $\$ 700$ million figure used in the high scenario only reflects the construction of manufacturing facilities directly related to offshore wind development; it does not include any further investments that might be made by firms specializing in education, training, or logistics. 


\section{NAVIGANT}

Table 2-47. Average Economic Impacts of Port and Manufacturing Facility Investment by Scenario

\begin{tabular}{|c|c|c|c|c|}
\hline Scenario/Metric & $\begin{array}{l}\text { Project } \\
\text { Development and } \\
\text { Onsite Labor }\end{array}$ & $\begin{array}{l}\text { Materials, Equipment, } \\
\text { Contracted Services, } \\
\text { Supply Chain }\end{array}$ & $\begin{array}{l}\text { Induced: Local } \\
\text { Expenditures }\end{array}$ & Total \\
\hline \multicolumn{5}{|l|}{ Low Scenario } \\
\hline Employment (FTEs) & 315 & 116 & 169 & 600 \\
\hline Labor Income (\$ million) & $\$ 17.6$ & $\$ 7.3$ & $\$ 8.1$ & $\$ 33.0$ \\
\hline Average Compensation & $\$ 55,800$ & $\$ 63,000$ & $\$ 47,900$ & $\$ 55,000$ \\
\hline Value Added to GDP (\$ million) & $\$ 22.1$ & $\$ 11.0$ & $\$ 14.9$ & $\$ 47.9$ \\
\hline Gross Output (\$ million) & $\$ 50$ & $\$ 20$ & $\$ 24$ & $\$ 93$ \\
\hline \multicolumn{5}{|l|}{ Mid Scenario } \\
\hline Employment (FTEs) & 3,312 & 866 & 1,610 & 5,788 \\
\hline Labor Income (\$ million) & $\$ 182.3$ & $\$ 54.8$ & $\$ 77.1$ & $\$ 314.2$ \\
\hline Average Compensation & $\$ 55,000$ & $\$ 63,300$ & $\$ 47,900$ & $\$ 54,300$ \\
\hline Value Added to GDP (\$ million) & $\$ 223.5$ & $\$ 83.7$ & $\$ 141.4$ & $\$ 448.6$ \\
\hline Gross Output (\$ million) & $\$ 470$ & $\$ 146$ & $\$ 223$ & $\$ 843$ \\
\hline \multicolumn{5}{|l|}{ High Scenario } \\
\hline Employment (FTEs) & 9,623 & 2,728 & 4,779 & 17,130 \\
\hline Labor Income (\$ million) & $\$ 530.5$ & $\$ 173.5$ & $\$ 228.9$ & $\$ 933.0$ \\
\hline Average Compensation & $\$ 55,100$ & $\$ 63,600$ & $\$ 47,900$ & $\$ 54,500$ \\
\hline Value Added to GDP (\$ million) & $\$ 650.1$ & $\$ 262.8$ & $\$ 420.1$ & $\$ 1,332.9$ \\
\hline Gross Output (\$ million) & $\$ 1,400$ & $\$ 461$ & $\$ 673$ & $\$ 2,534$ \\
\hline
\end{tabular}

Note: Appendix G provides additional details about the distribution of indirect employment impacts across affected industries.

Low Scenario: Estimated economic impacts arising from a $\$ 50$-million investment in port upgrades vary slightly by region, but represent an overall gross output of $\$ 93$ million (Table 2-47). An average of $\$ 50$ million in value added or state GDP would be supported over the life of the port upgrades. ${ }^{14}$ This investment would support an average of 600 FTE jobs over the life of the construction, although estimates range from 520 to 650 . Overall labor compensation of $\$ 33$ million represents average annual compensation per worker of nearly $\$ 55,000$.

Project development and onsite labor tied directly to the port upgrades are responsible for the largest share of impacts, representing more than half of supported jobs and nearly half of value added. Worker compensation averages about $\$ 56,000$ annually for these jobs. Positions related to the supply chain tend to be slightly better compensated, while positions that are supported by local expenditures (largely service and retail jobs) provide the lowest salaries.

\footnotetext{
${ }^{14}$ Gross output represents all purchases or expenditures made as a result of an economic impact scenario. Value added represents purchases made as a result of an impact scenario less expenditures on inputs. For this reason value added can be used to represent GDP. For further discussion see the Bureau of Economic Analysis report "Measuring the Economy: A Primer on GDP and the National Income Product Accounts" (BEA 2007).
} 


\section{NAVIGANT}

Mid Scenario: The $\$ 470$ million investment assumed for the mid scenario is considerably larger than the $\$ 50$ million base case. However, its use also differs, with $\$ 270$ million in industrial manufacturing facilities in addition to $\$ 200$ million in port upgrades. While these differences in the types of expenditures produce some variation in estimated impacts among the five regions, the variation is relatively small.

This scenario is estimated to support nearly 6,000 total FTE jobs, with $\$ 843$ million circulating through the economy and $\$ 449$ million in state GDP. Most of these positions $(3,300)$ are directly related to the development of port facilities. Materials suppliers, subcontractors, consultants, and others in the supply chain provide an additional 900 jobs, while the remaining 1,600 are in industries that capture local expenditures.

High Scenario: A \$700-million investment in port infrastructure and additional \$700-million investment in industrial manufacturing facilities would support approximately $\$ 2.5$ billion in gross economic output. After removing payments for inputs (e.g., \$933 million for labor and payments for materials), this provides approximately $\$ 1.3$ billion in state GDP.

Over 17,000 FTE jobs would be created or supported as a result of this investment, with the majority (nearly 10,000) onsite or otherwise directly involved with the development of the projects. This scenario would support an additional 3,000 jobs in the supply chain, and the local workers who fill these and onsite positions would support nearly 5,000 additional positions through local expenditures.

Appendix $G$ provides additional details about the distribution of indirect employment impacts across affected industries.

\section{Other Economic Impact Considerations}

Note that job creation as a result of construction, operations, and maintenance is only a piece of the economic development potential arising from investments in offshore wind infrastructure. Capital growth can cause numerous impacts beyond multipliers due to productivity improvements and sector relationships that extend beyond purchases and sales. Investment and growth in one industry can have a cascading impact that drives further regional investment. Many factors can drive firms to locate nearby one another, but the most common and widely accepted reasons include access to a similar (and often specialized) labor market, natural advantages such as waterways, access to inputs, shipping costs, and information sharing between companies (Rosenthal and Strange 2001, Ellison and Glaeser 1997).

Establishments in the offshore wind supply chain are inherently likely to locate close to one another. This regional agglomeration is most often seen in industries that are particularly sensitive to labor availability, inputs, transportation costs, and natural resources (Rosenthal and Strange 2001). All of these, along with infrastructure, are significant factors in offshore development.

The Wind Agency Bremerhaven came together as a partnership of public, private, and educational institutions to coordinate offshore wind activity in Bremerhaven and strengthen ties between those in the industry. 


\section{NAVIGANT}

The German Port of Bremerhaven, for example, hosts competing offshore component manufacturers as well as research and development facilities and institutions whose goal is to educate the labor force in fields related to offshore development. One of the primary reasons given by the Spanish manufacturer Gamesa in its decision to construct a manufacturing facility at the Scottish Port of Leith was its proximity to a research and development facility (Offshorewind 2012). Indeed, agglomeration was a central tenet of the strategy implemented to develop Bremerhaven for offshore wind activity. The Wind Agency Bremerhaven (WAB), formed in 2002, serves as a key element of this effort. The WAB came together as a partnership of public, private, and educational institutions to coordinate offshore wind activity in Bremerhaven and strengthen ties between those in the industry. It promotes offshore development as well as growth and implementation of the latest science and technology.

\subsubsection{Potential Labor Requirements: Manufacturing Activities}

This section examines the average regional labor inputs anticipated to be required in each of the three capacity deployment scenarios used to model potential component requirements in Chapter 2.3. Unlike the above analysis of labor impacts stemming from the construction of port and manufacturing facilities, this analysis incorporates the modeled timing of potential regional demand in each of the three scenarios.

Notably, this manufacturing labor impact analysis focuses only on the four major component categories (nacelles, blades, towers, and foundations and substructures) due to the complexities of generating reliable assumptions for the supply of various subcomponents and materials (e.g., bearings, epoxy resin, etc.). Given that the smaller subcomponents do not face the logistical challenges of the larger components and their ability to share suppliers with the land-based wind market, it is more likely that they can be supplied from anywhere in the country (or the world). Therefore, attempting to estimate domestic market share or the location and timing of labor impact with any degree of accuracy is unlikely. For U.S.-based suppliers of these subcomponents and materials, the most useful output from this particular analysis may be the assumptions regarding the amount and timing of domestic market share for the category of component manufacturers they are likely to supply.

\section{Labor Impacts by Facility Type}

Using the labor categories and assumptions for offshore wind manufacturing in NREL's JEDI model, we developed facility-level labor impact assumptions for each of the four categories of major components. These impacts, listed in Table 2-48, assume each facility produces components equivalent to 300 MW/year of capacity and uses a modeled 2020 plant capital cost of $\$ 5,179 / \mathrm{kW}$. 


\section{NAVIGANT}

Table 2-48. Estimated Labor Impacts by Type of Manufacturing Facility

\begin{tabular}{lccc} 
& \multicolumn{3}{c}{ Employment (FTEs) } \\
Component & Direct & Indirect & Induced \\
Nacelle & 206 & 513 & 581 \\
\hline Blade & 415 & 1032 & 1169 \\
\hline Tower & 198 & 425 & 503 \\
\hline Foundation/Substructure & 153 & 328 & 389 \\
\hline
\end{tabular}

Notably, the employment requirements and impacts are highest for manufacturing turbine blades, which are characterized as being highly labor intensive and require extensive manual operations (Nolet 2011).

\section{Timing of Demand Sufficient to Attract Domestic Manufacturing}

As discussed in Chapter 2.3.1, our research and interviews with manufacturers informed our assumptions about the potential timing of investments in domestic manufacturing capacity to serve the U.S. offshore market. This research indicated that a fully integrated turbine manufacturing plant (including a foundry for large castings, and separate facilities for blade fabrication, tower fabrication, and nacelle assembly) would require minimum regional demand of 100 to 150 turbines per year (or 500 to $800 \mathrm{MW}$ per year) in order to attract potential investment from an OEM. However, a factory that manufacturers a single component (e.g., towers or blades) may only require minimum regional demand of approximately $300 \mathrm{MW}$ per year. As previously noted, these capacity-driven trigger points capture only a portion of the criteria that manufacturers consider in their investment decisions. Other factors such as regional competition and geographic constraints will also come into play. We further acknowledged that no single manufacturer would likely capture $100 \%$ of national market share for any particular component. As a point of reference, Table 2-49 provides a summary of the modeled annual demand for each region and scenario in 2020 and 2030.

Table 2-49. Summary of Modeled Annual Regional Demand (MW/year) by Scenario

\begin{tabular}{lcccccc} 
& \multicolumn{2}{c}{ Low Growth } & \multicolumn{2}{c}{ Moderate Growth } & \multicolumn{3}{c}{ High Growth } \\
Region & 2020 & 2030 & 2020 & 2030 & 2020 & 2030 \\
North Atlantic & 158 & 808 & 492 & 1,024 & 671 & 1,980 \\
\hline South Atlantic & 42 & 217 & 108 & 226 & 379 & 1,120 \\
\hline Great Lakes & 0 & 150 & 150 & 400 & 300 & 550 \\
\hline Gulf Coast & 0 & 125 & 150 & 400 & 175 & 475 \\
\hline Pacific Coast & 0 & 0 & 200 & 1,200 & 600 & 1,900 \\
\hline
\end{tabular}

\section{Regional and Domestic Content Assumptions}

In addition to the above assumptions on the potential timing of domestic manufacturing capacity, the team generated additional assumptions about the amount and timing of domestic market share for each major component category. These assumptions sought to acknowledge that a longer track record of demand in Europe (and potentially in Asia by 2015) provides these regions a significant head start in developing their offshore wind supply chains. The relationships, past performance, economies of scale, 


\section{NAVIGANT}

and learning effects achieved by these overseas suppliers and facilities may provide them a competitive advantage in the early stages of supplying the U.S. offshore wind market.

In addition to regional demand thresholds, the team also considered the degree to which industry expertise may be concentrated in a particular region. In the case of foundations and substructures, the Gulf Coast region's concentration of offshore oil and gas construction expertise led us to assume that a large share of the U.S. market's early supply of foundation and substructures will come from that region. Otherwise, the team generally assumed that the 300-MW/year demand threshold would only make an initial $25-30 \%$ of a region's modeled demand capacity available to a domestic component supplier. This rate would then generally increase over time. Table 2-50 provides these regional content assumptions for nacelle manufacturing facilities for three time periods in each of the three scenarios. Additional tables of assumptions for blade, tower, and foundation manufacturing are included in Appendix $\mathrm{H}$.

Table 2-50. Regional Local Content Assumptions for Modeling Labor Requirements - Nacelles

\begin{tabular}{|c|c|c|c|c|c|c|c|c|c|}
\hline \multirow[b]{2}{*}{ Region } & \multicolumn{3}{|c|}{ Low Growth } & \multicolumn{3}{|c|}{ Moderate Growth } & \multicolumn{3}{|c|}{ High Growth } \\
\hline & 2020 & 2025 & 2030 & 2020 & 2025 & 2030 & 2020 & 2025 & 2030 \\
\hline North Atlantic & $32 \%$ & $41 \%$ & $80 \%$ & $35 \%$ & $75 \%$ & $95 \%$ & $65 \%$ & $88 \%$ & $100 \%$ \\
\hline South Atlantic & $0 \%$ & $0 \%$ & $0 \%$ & $0 \%$ & $0 \%$ & $25 \%$ & $35 \%$ & $80 \%$ & $95 \%$ \\
\hline Great Lakes & $0 \%$ & $0 \%$ & $0 \%$ & $0 \%$ & $35 \%$ & $45 \%$ & $25 \%$ & $35 \%$ & $50 \%$ \\
\hline Gulf Coast & $0 \%$ & $0 \%$ & $0 \%$ & $0 \%$ & $33 \%$ & $45 \%$ & $0 \%$ & $33 \%$ & $45 \%$ \\
\hline Pacific Coast & $0 \%$ & $0 \%$ & $0 \%$ & $25 \%$ & $65 \%$ & $95 \%$ & $50 \%$ & $85 \%$ & $100 \%$ \\
\hline United States & $25 \%$ & $25 \%$ & $50 \%$ & $25 \%$ & $60 \%$ & $85 \%$ & $55 \%$ & $80 \%$ & $90 \%$ \\
\hline
\end{tabular}

Note: Each output represents the share of that region's content that is supplied within that region in the year shown.

\section{Regional Direct Labor Impact Estimates}

Combining the modeled regional capacity demand in each scenario with the demand threshold and domestic content assumptions described above, the team estimated regional labor impacts by scenario for each of the four major turbine components. Table 2-51 summarizes the results. 


\section{NAVIGANT}

Table 2-51. Estimated Regional Direct Labor Impacts (FTEs) by Component and Scenario

\begin{tabular}{|c|c|c|c|c|c|c|}
\hline \multirow[b]{2}{*}{ Region/Component } & \multicolumn{2}{|c|}{ Low Growth } & \multicolumn{2}{|c|}{ Moderate Growth } & \multicolumn{2}{|c|}{ High Growth } \\
\hline & 2020 & 2030 & 2020 & 2030 & 2020 & 2030 \\
\hline \multicolumn{7}{|l|}{ North Atlantic } \\
\hline Nacelles & 70 & 690 & 314 & 1032 & 836 & 2101 \\
\hline Blades & 14 & 494 & 85 & 514 & 139 & 993 \\
\hline Towers & 13 & 468 & 108 & 486 & 131 & 934 \\
\hline Foundation/Substructure & 0 & 94 & 0 & 198 & 0 & 535 \\
\hline North Atlantic Subtotal & 97 & 1,746 & 507 & 2,230 & 1,106 & 4,563 \\
\hline \multicolumn{7}{|l|}{ South Atlantic } \\
\hline Nacelles & 0 & 0 & 0 & 71 & 222 & 1351 \\
\hline Blades & 0 & 0 & 0 & 35 & 32 & 672 \\
\hline Towers & 0 & 0 & 0 & 0 & 0 & 222 \\
\hline Foundation/Substructure & 0 & 0 & 0 & 29 & 26 & 546 \\
\hline South Atlantic Subtotal FTEs & 0 & 0 & 0 & 135 & 280 & 2,791 \\
\hline \multicolumn{7}{|l|}{ Great Lakes } \\
\hline Nacelles & 0 & 0 & 0 & 194 & 124 & 297 \\
\hline Blades & 0 & 0 & 0 & 118 & 0 & 148 \\
\hline Towers & 0 & 0 & 0 & 101 & 0 & 139 \\
\hline Foundation/Substructure & 0 & 0 & 0 & 0 & 0 & 0 \\
\hline Great Lakes Subtotal FTEs & 0 & 0 & 0 & 413 & 124 & 584 \\
\hline \multicolumn{7}{|l|}{ Gulf Coast } \\
\hline Nacelles & 0 & 0 & 0 & 199 & 0 & 236 \\
\hline Blades & 0 & 0 & 0 & 110 & 0 & 131 \\
\hline Towers & 0 & 0 & 0 & 102 & 0 & 121 \\
\hline Foundation/Substructure & 62 & 283 & 341 & 660 & 659 & 882 \\
\hline Gulf Coast Subtotal & 62 & 283 & 341 & 1,071 & 659 & 1,370 \\
\hline \multicolumn{7}{|l|}{ Pacific Coast } \\
\hline Nacelles & 0 & 0 & 74 & 1,283 & 444 & 2,139 \\
\hline Blades & 0 & 0 & 0 & 638 & 110 & 1,011 \\
\hline Towers & 0 & 0 & 0 & 557 & 96 & 883 \\
\hline Foundation/Substructure & 0 & 0 & 0 & 204 & 0 & 467 \\
\hline Pacific Coast Subtotal & 0 & 0 & 74 & 2,682 & 650 & 4,500 \\
\hline National Total & 159 & 2,029 & 922 & 6,531 & 2,819 & 13,808 \\
\hline
\end{tabular}

As shown in Table 2-51, relatively few manufacturing jobs are likely to be created by 2020 in the lowgrowth scenario, with only a modest increase (about 2,000 jobs nationally) expected by 2030 . The majority of this employment (about 1,700 jobs) is expected in the North Atlantic region. In the moderategrowth scenario, however, demand for manufacturing labor is significantly higher, with more than 900 


\section{NAVIGANT}

jobs expected by 2020, and more than 6,500 supported by 2030. The results of the high-growth scenario provide nearly double the impact of the moderate growth.

Some regional variations can also be observed. In particular, the team's assumption regarding the Gulf Coast's role in manufacturing foundation and substructure components for other regions provides for a noticeably larger share of that region's potential impacts. The assumption that development of economically viable floating foundations will support accelerated demand growth on the Pacific Coast in the moderate- and high-growth scenarios also creates the potential for a high-level of regional manufacturing employment. This may also reflect the relative geographic isolation of the Pacific Coast from the other regions, meaning that it is less likely that facilities in these other regions will be able to serve Pacific demand.

\subsubsection{Ability to Meet Potential Labor Demands from Port and Manufacturing Facilities}

This section considers the potential direct labor impacts for port and manufacturing facility construction as well as major component manufacturing activity in the context of each region's mix of existing labor and skill sets. As with other analyses included in this report, the anticipated timing of potential demand from the U.S. offshore wind market makes this a more challenging task. In particular, as domestic manufacturing activity is not anticipated to ramp up significantly until 2020 or later for most regions and scenarios (excluding the high-growth scenario), it is difficult to anticipate any potential shortfalls in specific labor categories or skill sets based on today's labor market. On the other hand, the analysis does provide the opportunity to highlight potential areas of regional advantage in regard to the availability of certain types of labor.

\section{Labor Force Considerations}

The existing labor force represents a critical element of a region's ability to develop and sustain an offshore wind port. It also has a strong influence on how economic impacts from within a given industry flow through the community. Whether employment growth utilizes an existing labor force or pulls in workers from outside, overall regional economic activity increases. Workers who migrate, though, tend to also bring their families and increase demand for property. This subsequently leads to growth in housing or increased property values, but can have mixed effects on overall wages throughout the economy. Use of an existing labor force tends to increase wages throughout the economy, not solely in affected industries (Cutler \& Davies 2007). Both migration and in-commuters have the potential to create additional revenue for local business. From the perspective of the local community, a skilled and competent labor force keeps a population in place, increases employment opportunities for residents, and makes regional planning easier for local governments.

From the manufacturer's perspective, an existing labor force can drive down recruiting and training costs. For specialized industries such as offshore wind, recruiting can be a significant problem. Specialized skills require the employer to increase its geographic scope when searching for workers and may result in employers paying higher wages, relocation expenses, or both. Similarly, workers with specialized skills may be reluctant to relocate to an area where there is only one or very few employers who use their skillset. This may create a risk that they will be locked-in to a particular job or employer. Younger workers, however, may tend to be more mobile than their older counterparts. 


\section{NAVIGANT}

This portion of the report examines existing manufacturing employment in sectors of the economy that are potentially relevant to offshore wind within each of the regions considered in this study. A review of existing employment in these industries provides for a reasonable indication of where an existing labor force could be utilized by the offshore wind industry. The simple availability of labor does not mean that offshore wind manufacturers would necessarily hire these workers, although it is possible. Offshore wind firms may also choose to purchase products or services from the employers of that labor pool.

\section{Methodology for Labor Force Analysis}

This report used two different approaches to characterize the potential offshore wind workforce in each region. In the first, we identified five specific categories of manufactured goods: blades, electrical systems, foundries, mechanical systems, and towers. For each of these categories, we reviewed U.S. Census Bureau County Business Pattern data and identified sectors that provide goods and services that could reasonably supply each category of manufactured good. Figure 2-13 describes the specific industries associated with each of the categories of manufactured goods for this analysis. With the exception of foundries, all categories contain multiple and sometimes overlapping industries. Mechanical systems and electronics, for example, share electrical equipment manufacturing. Due to the potential shortage of large-scale castings and forgings, foundry data was examined independently, but is also a part of the mechanical systems category.

Figure 2-13. Industries Relevant to Selected Offshore Wind Components

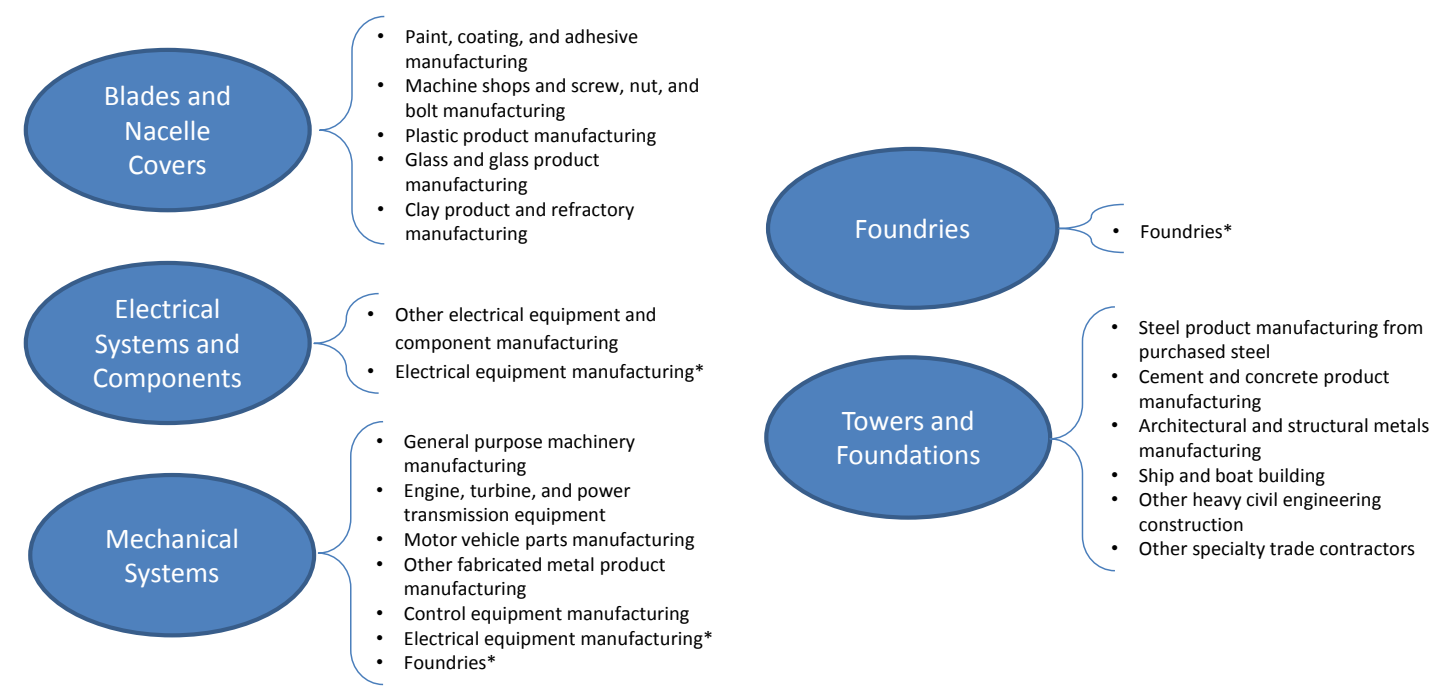

*Indicates that NAICS category appears in more than one turbine component category

Source: Navigant analysis

In the second approach, the Navigant Consortium analyzed labor force underutilization data by occupation. In this case, we reviewed data from U.S. Census Bureau's American Community Survey Public Use Microdata Sample to identify the available workforce not currently employed within occupations relevant to offshore wind in each of the regions. 


\section{NAVIGANT}

\section{Existing Employment by Sector}

Total employment within all industries relevant to offshore wind is highest in California, Michigan, and Ohio. This reflects a total of unique industries (it does not double-count industries such as electrical equipment manufacturing that could supply multiple components). This result should not be surprising, as large, populous states will tend to have higher employment numbers. Within the Atlantic (note that Pennsylvania and New York are both considered Great Lakes states rather than Atlantic states in this analysis) relevant employment levels are highest in Virginia and North Carolina, while Texas is home to the largest number of relevant employees in the Gulf Coast region.

Blade and nacelle enclosure manufacturing is most similar to industries that manufacture lightweight products such as fiberglass or foam. This also covers other manufacturing that goes in to the assembly such as glass, porcelain, or clay products. As shown in Figure 2-14, California has the largest number of workers (more than 100,000) who could potentially support manufacturing of these products for the offshore wind industry, followed by Ohio $(91,000)$, Texas $(74,000)$ and Illinois $(70,000)$. North Carolina $(37,000)$ has the highest number of blade and nacelle relevant employees on the Atlantic seaboard. For the purpose of comparing these data with potential locations of future demand, the distribution of offshore wind plants within each region as determined by NREL's ReEDs model and the theoretical regional allocations noted in Chapter 2.2.1 is included in Figure 2-14 and the other maps that follow for the other manufacturing supply chain categories. 


\section{NAVIGANT}

Figure 2-14. Current Employment in Sectors Relevant to Offshore Wind Blade Manufacturing

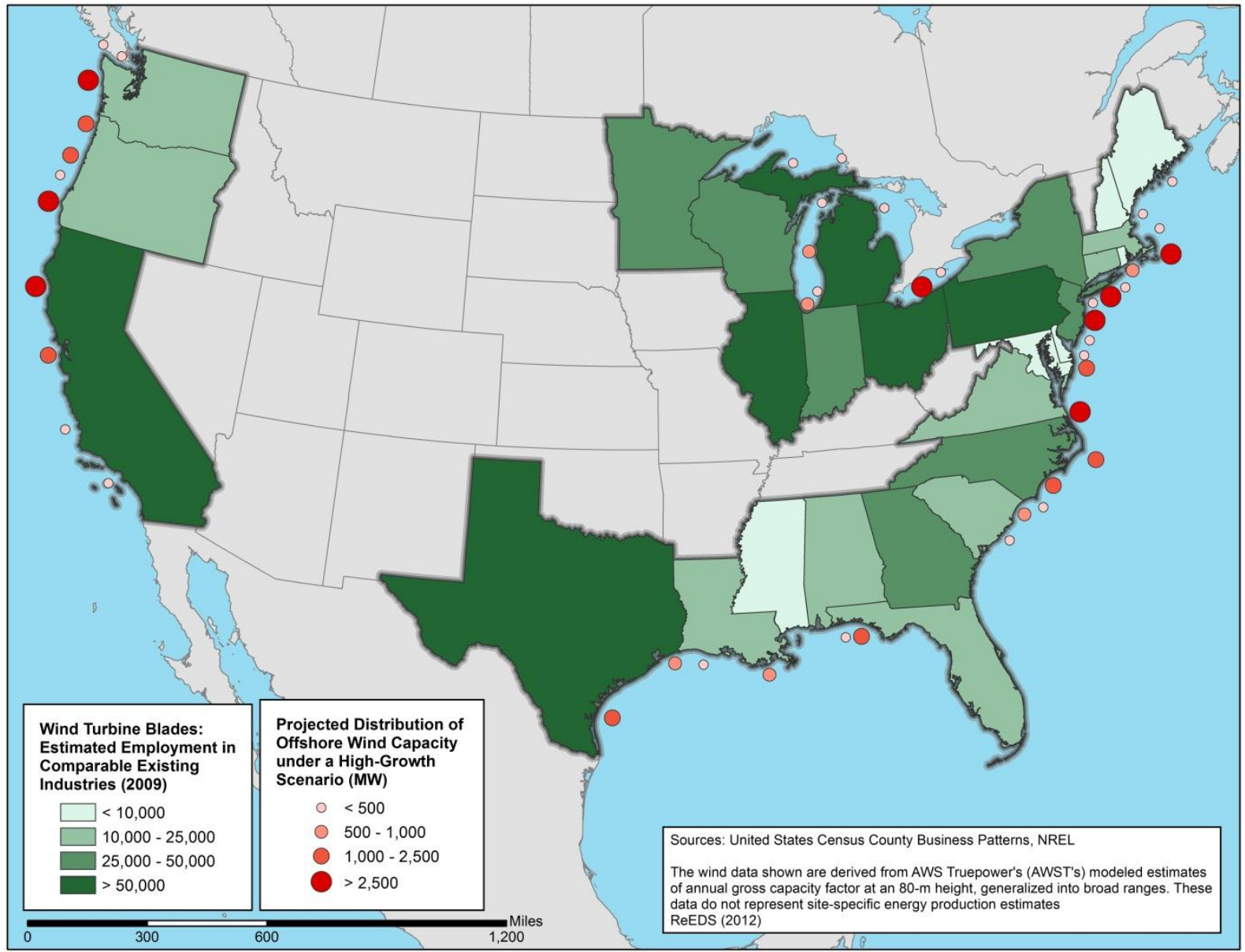

Source: Map courtesy of NREL 


\section{NAVIGANT}

The electronics systems category includes the turbine generator as well as other power electronics such as power converters, transformers, and cables. Once again, California has the highest number of employees $(23,000)$ within related sectors see Figure 2-15). It is followed closely by Pennsylvania $(20,000)$ in the Great Lakes region. Along the Atlantic Coast, North Carolina $(13,000)$ has the highest number of workers, while Texas $(14,000)$ has the highest number on the Gulf Coast.

Figure 2-15. Current Employment in Sectors Relevant to Offshore Wind Electrical Systems and Components

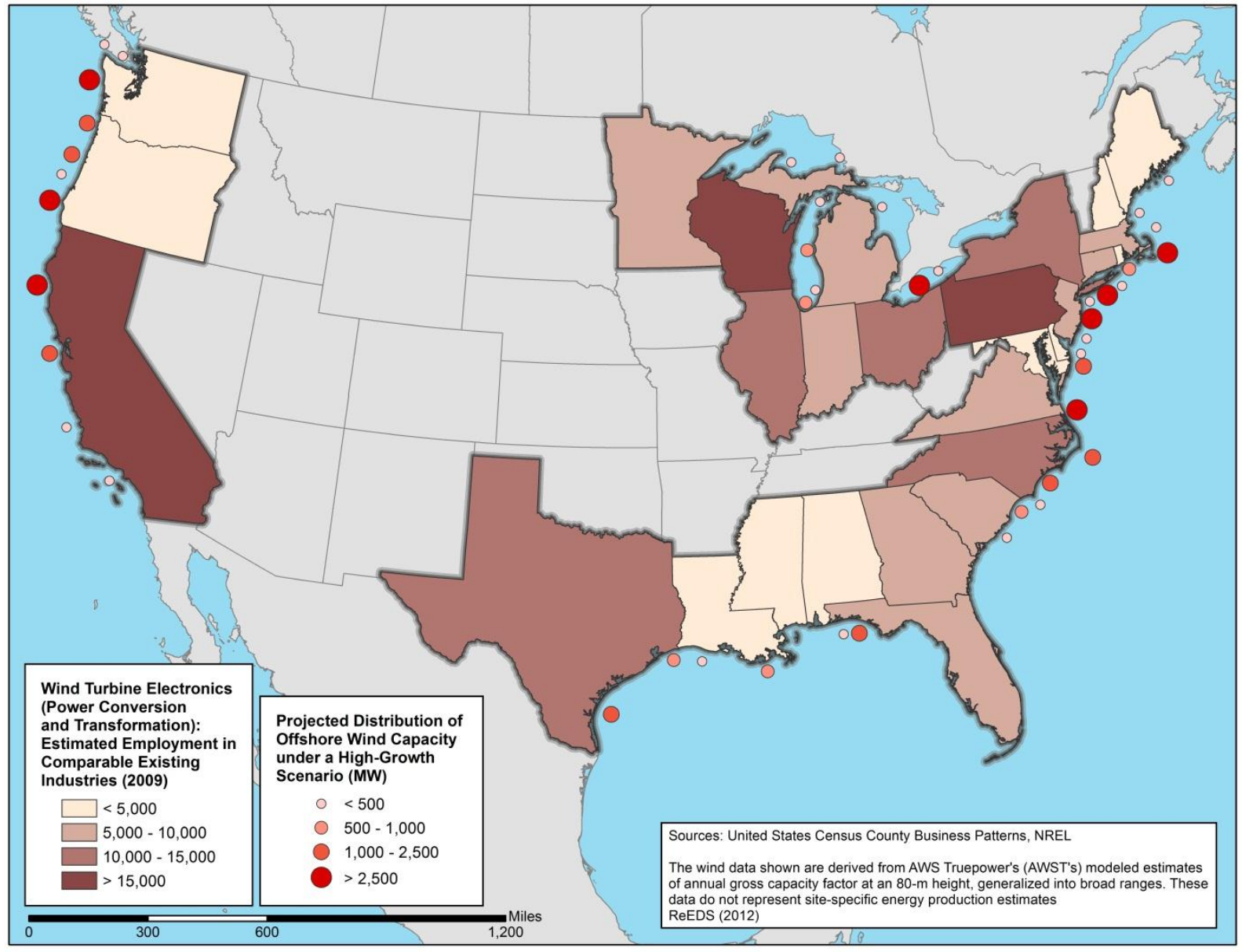

Source: Map courtesy of NREL 


\section{NAVIGANT}

As mentioned, employment at foundries was examined individually due to potential near-term supply shortages anticipated for large-scale castings and forgings required by the offshore wind market. As shown in Figure 2-16, the five states with the highest number of employees at foundries are in the Great Lakes region. These include Wisconsin $(14,000)$, Ohio $(14,000)$, Indiana $(9,000)$, Michigan $(9,000)$, and Pennsylvania $(8,000)$. Along the Pacific Coast, California $(7,000)$ has the highest number, while Alabama $(6,000)$ leads the Gulf States and Virginia $(2,000)$ leads the Atlantic region.

Figure 2-16. Current Employment at Foundries within the Contiguous United States

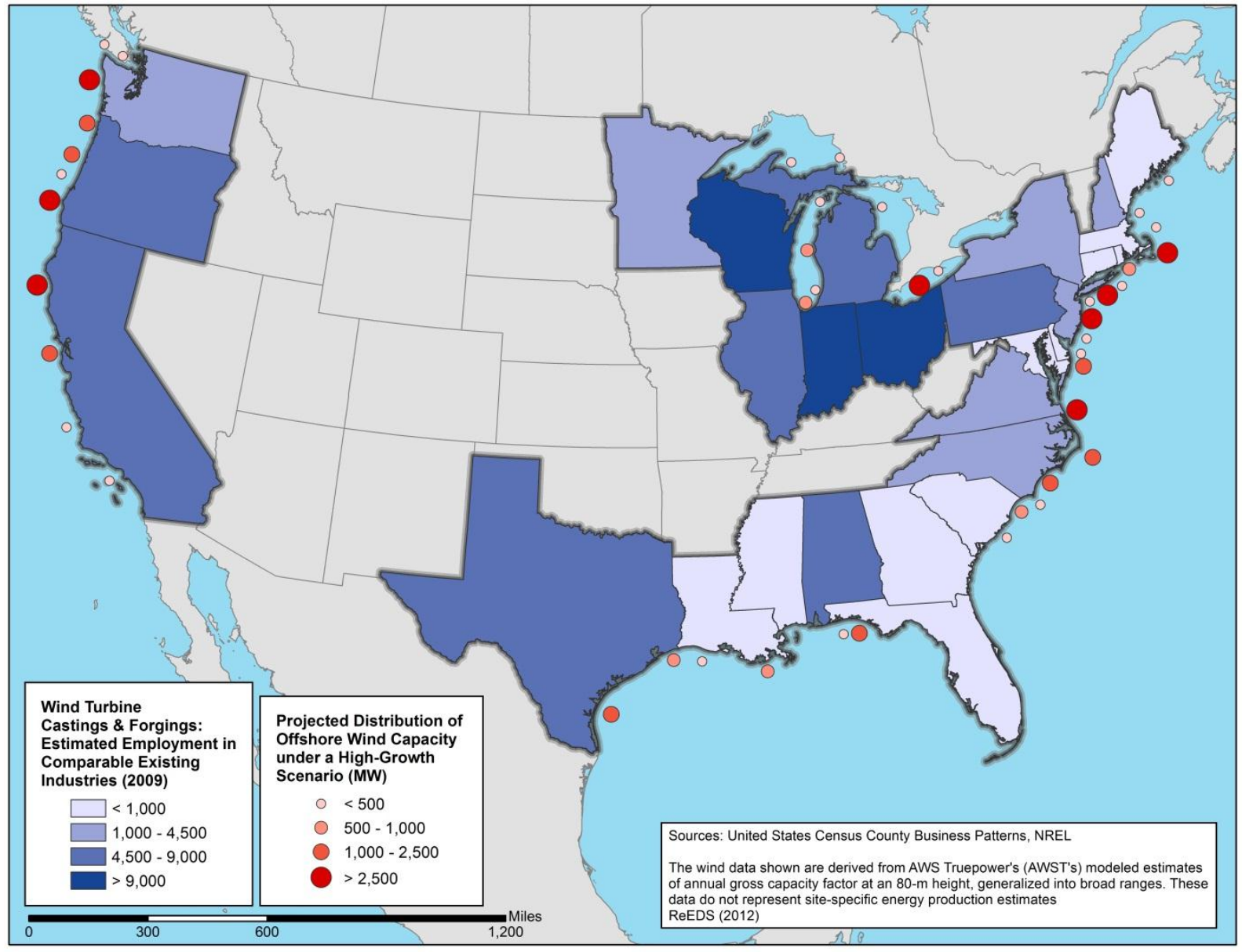

Source: Map courtesy of NREL 


\section{NAVIGANT}

Mechanical systems include shafts, main frames, hubs and bearings, pitch and yaw systems, brakes and gearboxes. As previously noted, employment in foundries was also included in this category. As shown in Figure 2-17, California $(145,000)$ has the highest number of workers in sectors relevant to turbine mechanical systems. Ohio $(138,000)$ and Michigan $(134,000)$ follow. Texas $(103,000)$ leads the Gulf Coast, while North Carolina $(50,000)$ leads the Atlantic.

Figure 2-17. Current Employment in Sectors Relevant to Offshore Wind Mechanical Systems and Components

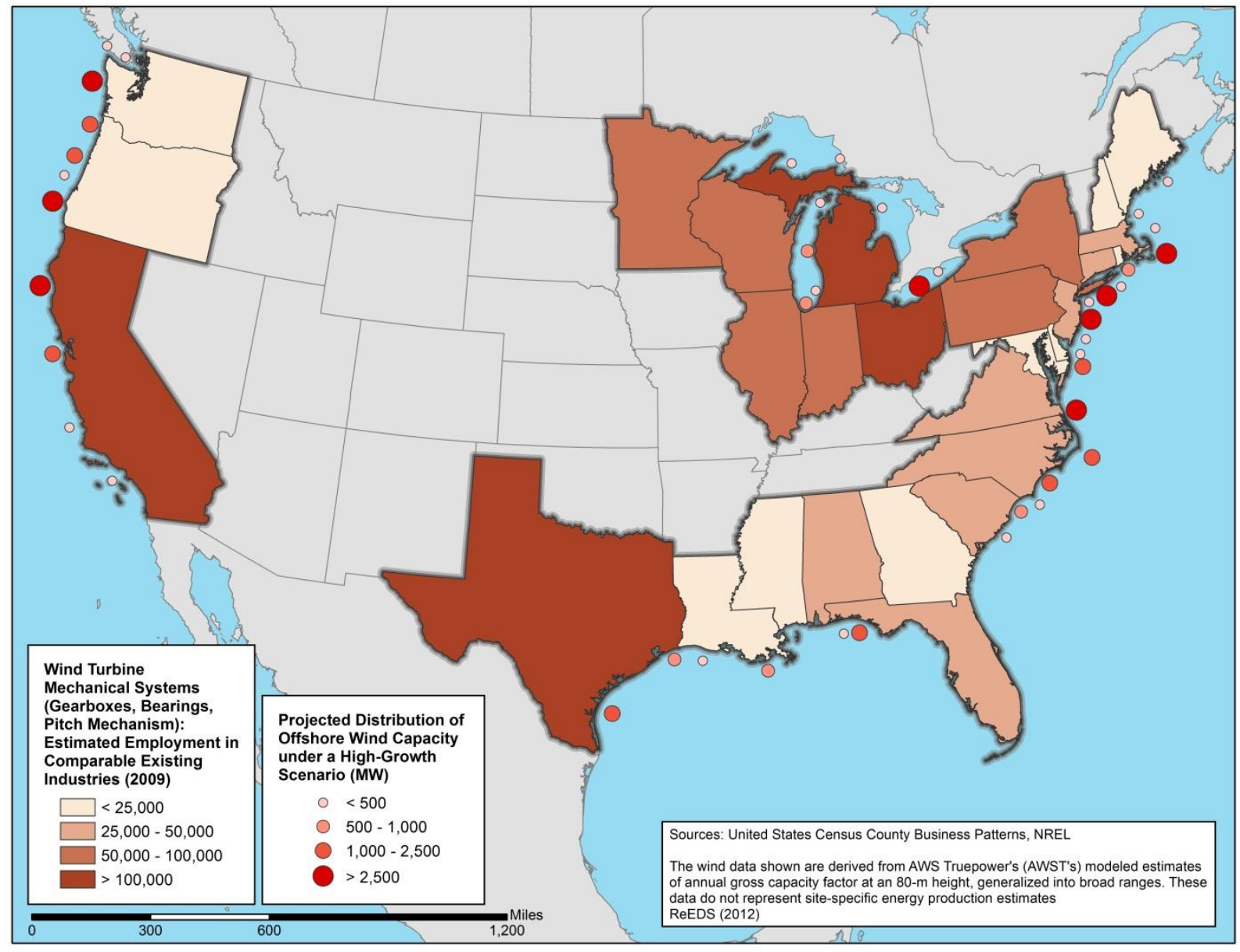

Source: Map courtesy of NREL 


\section{NAVIGANT}

Out of all component groups, towers and foundations includes industries that are most likely to locate in proximity to large ports. Besides ship and boat building, it also includes offshore oil and gas extraction an industry with the expertise to undertake the complicated construction of offshore wind farms. Texas $(121,000)$ has the highest number of these workers, followed by California $(119,000)$, Florida $(68,000)$, Pennsylvania $(57,000)$ and Virginia $(56,000)$.

Figure 2-18. Current Employment in Sectors Relevant to Offshore Wind Towers and Foundations

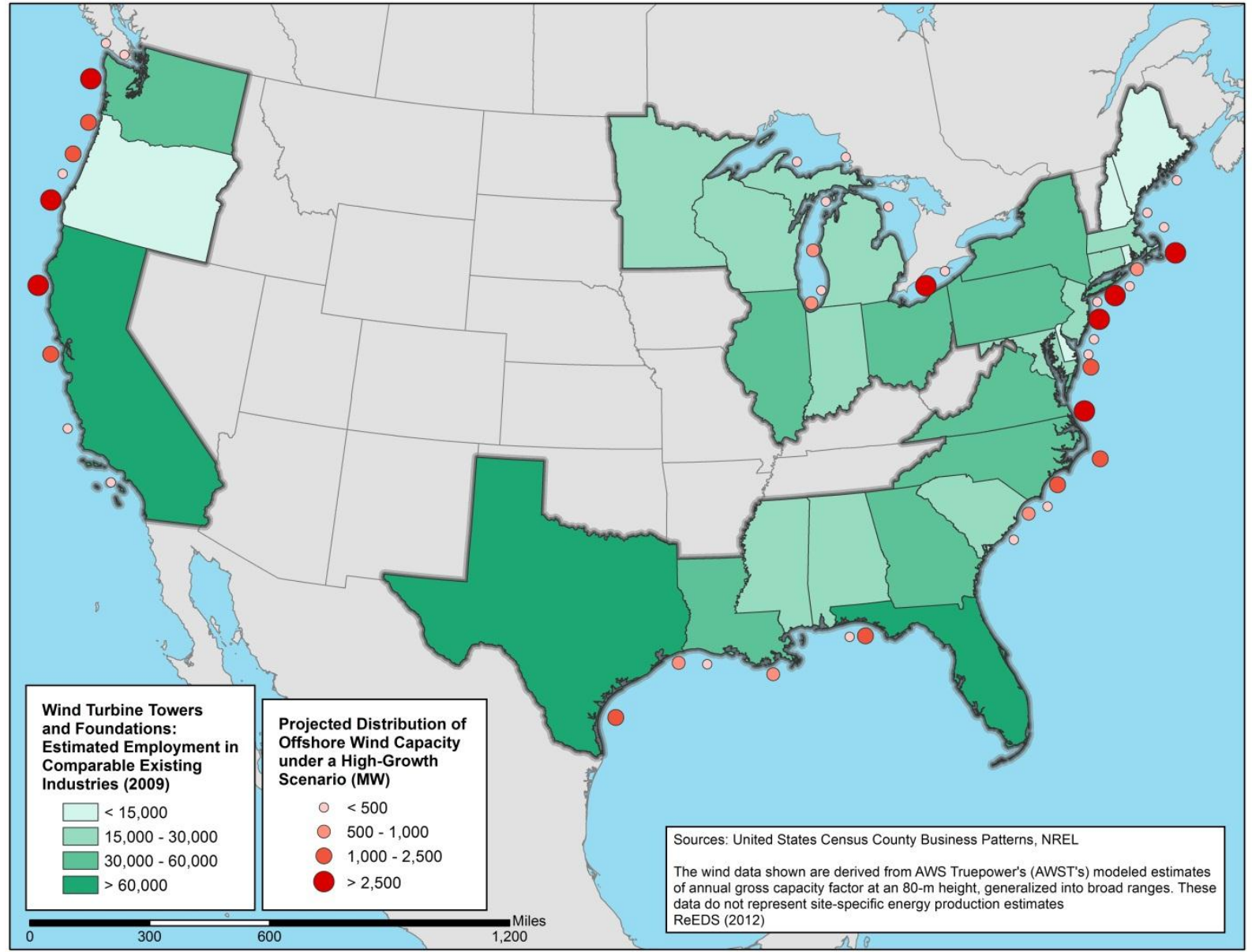

Source: Map courtesy of NREL

\section{Workforce Underutilization by Occupation}

With national unemployment at 8.3\% as of July 2012 (BLS 2012), a review of workers with occupations demanded by the offshore wind industry that are not currently employed can provide additional insights into the distribution of those with relevant skills that are currently underutilized. Occupations considered to be relevant to offshore wind in this analysis are shown in Table 2-52. 


\section{NAVIGANT}

Table 2-52. U.S. Census Occupations Sampled for Underutilization Analysis

\begin{tabular}{ll}
\hline Marine Engineers and Naval Architects & Structural Metal Fabricators and Fitters \\
\hline Petroleum, mining, and geological engineers & Miscellaneous assemblers and fabricators \\
\hline Geological and petroleum technicians & Machinists \\
\hline Structural iron and steel workers & Metal furnace operators, tenders, pourers, and casters \\
\hline Oil and gas derrick, rotary drill, and service unit operators & Welding, soldering, and brazing workers \\
\hline Earth drillers (not oil and gas) & Power plant operators, distributors, and dispatchers \\
\hline Mining machine operators & Adhesive bonding machine operators and tenders \\
\hline $\begin{array}{l}\text { Industrial, transportation, and utility electrical and electronics } \\
\text { repairers }\end{array}$ & Supervisors of transportation and material moving \\
\hline Industrial and refractory machinery mechanics & Sailors, marine oilers, and ship engineers \\
\hline Electrical power line installers and repairers & Ship and boat captains and operators \\
\hline Riggers & Dredge, excavating, and loading machine operators \\
\hline $\begin{array}{l}\text { Other installation, maintenance, and repair workers, including } \\
\text { wind turbine service }\end{array}$ & Misc. material moving workers including ship loaders \\
\hline Engine and other machine assemblers & \\
\hline
\end{tabular}

Using the above-referenced job categories, all five regions combined have over 76,000 residents who are not working but have skills that could be relevant to offshore wind (see Table 2-51). The number of underutilized residents is greatest in the Great Lakes region, with over 31,000 people having skills that could be useful to the offshore wind industry and are currently out of work. The Atlantic and Gulf Coast regions each have about 16,000 workers with relevant skills that are not currently working, while the Pacific region has about 13,000 . By state, California has the highest number of individuals with relevant skills that are not working, with less than 10,000 people; it is followed by Michigan $(6,951)$, Texas $(6,036)$, Ohio (5,412), and Florida (5,262). 


\section{NAVIGANT}

Table 2-53. Non-working Individuals with Skills Relevant to Offshore Wind by Region and State

\begin{tabular}{|c|c|c|c|}
\hline North Atlantic & 6,010 & Gulf Coast & 16,174 \\
\hline New Jersey & 1,509 & Texas & 6,036 \\
\hline Massachusetts & 1,348 & Florida & 5,262 \\
\hline Connecticut & 1,027 & Alabama & 2,390 \\
\hline Maryland & 786 & Louisiana & 1,337 \\
\hline New Hampshire & 405 & Mississippi & 1,149 \\
\hline Maine & 403 & Great Lakes & 31,190 \\
\hline Rhode Island & 384 & Michigan & 6,951 \\
\hline Delaware & 148 & Ohio & 5,412 \\
\hline South Atlantic & 9,638 & Illinois & 4,221 \\
\hline North Carolina & 3,983 & Pennsylvania & 3,501 \\
\hline Georgia & 2,625 & New York & 3,231 \\
\hline Virginia & 1,519 & Indiana & 3,156 \\
\hline South Carolina & 1,511 & Wisconsin & 2,857 \\
\hline Pacific Coast & 13,174 & Minnesota & 1,861 \\
\hline California & 9,758 & & \\
\hline Oregon & 1,892 & & \\
\hline Washington & 1,524 & & \\
\hline
\end{tabular}

Source: US Census American Community Survey (2012)

\section{Regional Ability to Address Potential Labor Demand}

Based on the direct labor requirements modeled in Chapters 2.4.2 and 2.4.3, the existing labor force and underutilized workforce data indicate that adequate regional labor pools exist within those industries most relevant to potential offshore wind manufacturing needs. While such skilled labor exists, however, the need to develop additional knowledge and training specific to the needs of the offshore wind industry is likely in order to attract manufacturers to a particular market.

In addition, the above data also highlight several areas of high labor concentration in relevant industries that manufacturers might consider during their initial assessment of a regional market's attractiveness. States or groups of adjacent states with high labor concentrations in several relevant categories could indicate the potential for a clustered or regional approach to future offshore wind supply chain development activities. 


\section{NAVIGANT}

\section{Strategy for Future Development}

Our survey of industry participants, combined with our other research, indicates that there are three major categories of barriers to development of the U.S. offshore wind market:

» High cost of offshore wind energy. Offshore wind energy has a higher LCOE than conventional and other renewable energy technologies.

»Infrastructure challenges. The infrastructure required to install and operate offshore wind farms, such as transmission and purpose-built ports and vessels, does not currently exist in the U.S.

» Regulatory challenges. Offshore wind projects in the U.S. are facing new and uncertain leasing and permitting processes.

These barriers combine to have a dampening effect on the development of the offshore wind supply chain in the U.S. The result is that U.S.-based suppliers have a competitive disadvantage versus their counterparts that are supplying offshore wind turbines and components in other parts of the world. The U.S. offshore wind industry faces a "chicken-and-egg" problem where plants will not be built unless the cost comes down, and local factories (which will help bring down the cost) will not be built until there is a proven domestic market.

This section provides estimates for the LCOE over time for U.S. offshore wind plants that are sourced domestically and from Europe. It also examines the criteria for investments in U.S. manufacturing facilities and estimates the domestic market share for each of the three scenarios discussed in Chapter 2.

Finally, it provides state and federal policy examples that have addressed barriers and improved the competitiveness of U.S. manufacturers.

Figure 3-1. Summary of Key Findings for Chapter 3

\section{Summary of Key Findings - Strategy for Future Development}

» LCOE of an offshore wind plant that is sourced domestically is likely to decrease from $\sim$ 197/MWh in 2015 to $\sim$ \$167/MWh or lower in 2030, dependent upon industry growth and innovation.

» U.S. domestic content is likely to increase from $~ 40 \%$ in 2015 to $53 \%-79 \%$ in 2030.

» U.S. offshore wind faces three significant challenges:

1) Relatively high cost (most critical near-term)

2) Lack of infrastructure (generally longer term;)

3) Uncertain regulatory processes 


\section{NAVIGANT}

\subsection{Levelized Cost of Energy (LCOE)}

A key measure of the competitiveness of offshore wind is LCOE. Considerable research has been performed on the LCOE of offshore wind, its various components, and its forecast (see Appendix B). We have produced a baseline forecast of LCOE of offshore wind in the U.S. based on the following inputs:

» Total current construction cost of approximately $\$ 6,080$ per $\mathrm{kW}$ installed. This total was developed from bottom-up cost estimates for individual project elements based on a $500 \mathrm{MW}$ reference plant in the mid-Atlantic to be completed in 2018 (Navigant 2012).

» Initial operations cost of approximately $\$ 135,000$ per $\mathrm{kW}$ per year (Navigant 2012)

» Costs are likely to decrease by at least $25 \%$ by 2030 (Lantz et al. 2012)

» Average Net Capacity Factor (NCF) is initially $40 \%$ and will grow over time, as forecasted in NREL's Renewable Energy Futures Study (NREL 2012)

Based on the above inputs, the LCOE of an offshore wind plant that is sourced domestically is estimated to be approximately $\$ 197 / \mathrm{MWh}$ in 2015 and approximately $\$ 167 / \mathrm{MWh}$ in 2030. LCOE estimates are used in this report to assess the potential value of the total offshore supply chain and key component groups under various industry growth scenarios. These baseline estimates may not reflect the long term targets of DOE, NREL, the Crown Estate (U.K.) and other organizations supporting initiatives intended to reduce offshore wind LCOE through technology innovation and market development.

Since there is very little offshore wind manufacturing in the U.S., most of the components will initially be sourced from Europe. Transportation costs for offshore wind turbine components sourced from Europe are expected to be $17 \%$ of the turbine costs (VCERC 2010). Therefore the corresponding LCOE of a U.S. offshore wind plant that is sourced in Europe is expected to be $17 \%$ higher than the domestic cost, or approximately \$205/MWh in 2015 and approximately \$174/MWh in 2030.

\subsection{Investments in U.S. Manufacturing Facilities}

As discussed above, a U.S.-based manufacturer will have a cost advantage over a European-based manufacturer due to savings in transportation costs. However, a manufacturer will not build a factory in the U.S. unless there is a stable and growing U.S. offshore wind market. Research shows that a demand of 100 to 150 turbines per year (or 500 to $800 \mathrm{MW}$ per year) for a minimum of five years is required to justify an investment in a turbine manufacturing plant (including

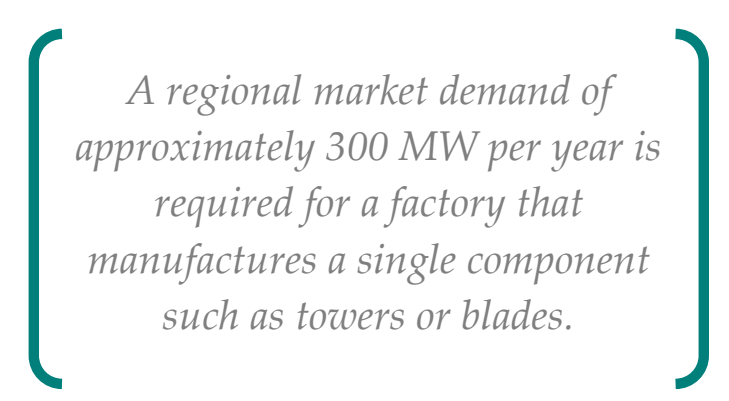
a foundry for large castings, and separate facilities for blade fabrication, tower fabrication, and nacelle assembly) (VCERC 2010). The Navigant Consortium estimates that a regional market demand of approximately $300 \mathrm{MW}$ per year is required for a factory that manufactures a single component such as towers or blades. These factory threshold estimates are confirmed with Return on Investment (ROI) calculations based on the assumptions shown in Table 3-1. 


\section{NAVIGANT}

Table 3-1. ROI for U.S. Manufacturers

\begin{tabular}{lcc} 
& Full WTG & \\
\hline Initial investment & Manufacturing & Single Component Manufacturing \\
\hline Initial annual revenue & $\$ 500$ million & $\$ 50$ million \\
\hline Regional market share & $\$ 1,835 / \mathrm{kW}$ & $\$ 975 / \mathrm{kW}$ \\
\hline Profit Before Taxes/Revenue & $50 \%$ & $50 \%$ \\
\hline Income tax rate & $10 \%$ & $10 \%$ \\
\hline After-tax ROla & $35 \%$ & $35 \%$ \\
\hline
\end{tabular}

(a) Calculated based on the above assumptions

However, these market-driven trigger points are only part of the decision criteria that affect a manufacturer's decision to invest; other criteria include levels of competition, geography constraints, and the ability to serve additional markets such as land-based wind or other industries.

\subsubsection{Low-Growth Scenario}

The LCOE and ROI assumptions can be combined with the MW scenarios outlined in Chapter 2 to estimate the timing of factories being built in the U.S. that are dedicated to offshore wind. Figure 3-2 shows that a single component plant could be started up in the Atlantic region in 2021, when that market reaches $300 \mathrm{MW}$ per year. A full WTG manufacturing facility could be started up in 2027, when the Atlantic market reaches $800 \mathrm{MW}$ per year. The three lines in Figure 3-2 represent the LCOE forecast for U.S. offshore wind plants that are sourced in the U.S., sourced in Europe, and a blended average. The blended average LCOE is expected to decrease from $\$ 202 / \mathrm{MWh}$ in 2015 to $\$ 170 / \mathrm{MWh}$ in 2030. Although certain factors may cause LCOE to decrease more rapidly, particularly in the high-growth scenario, this analysis is based on a common LCOE forecast for all scenarios, as discussed in Appendix B.

Figure 3-2. U.S. Manufacturing of Offshore Wind in the Low-Growth Scenario

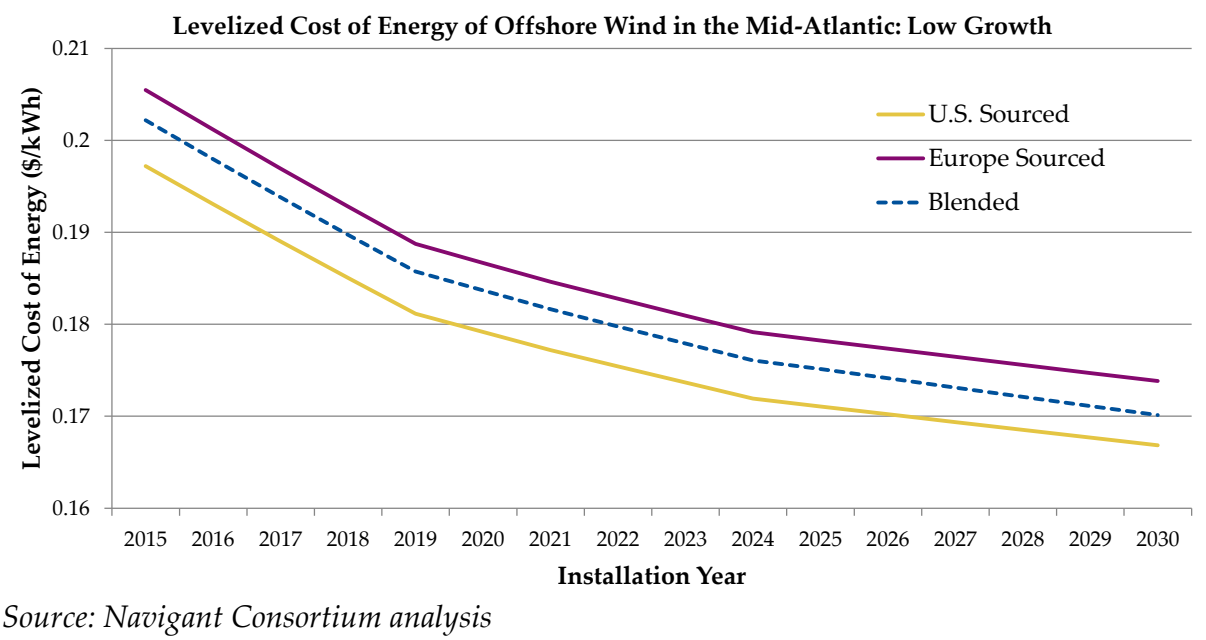

Figure 3-3 shows the estimated average U.S. domestic content for the low-growth scenario based on the threshold dates for factory investment as discussed above. Recognizing that investment decisions will 


\section{NAVIGANT}

not be made purely based on these market trigger points, percentages of domestic sourcing were estimated to slowly ramp up from $40 \%$ in 2015 to $53 \%$ in 2030. These domestic content percentages were used to calculate the blended average LCOE line in Figure 3-2. The team also estimated regional local content percentages for major component categories (nacelles, blades, towers, and foundations) for the three demand growth scenarios as shown in Appendix H.

Figure 3-3. Average Domestic Content in the Low-Growth Scenario

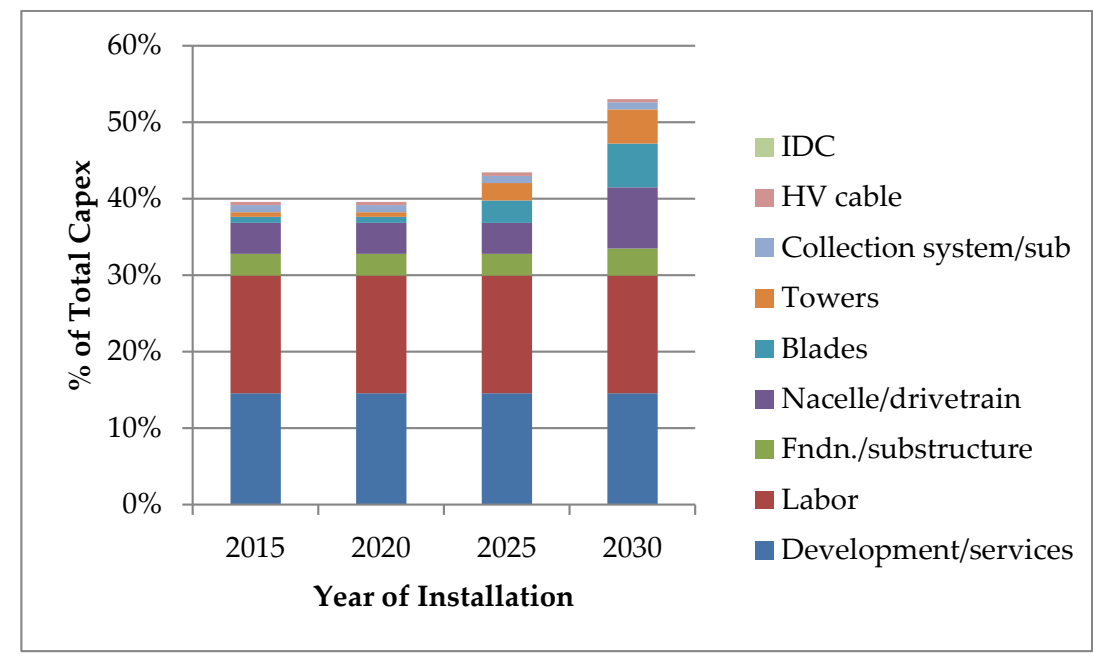

IDC $=$ interest during construction

Source: Navigant Consortium analysis

\subsubsection{Moderate-Growth Scenario}

Figure 3-4 shows that in the moderate-growth scenario, a single component plant could be started up in the Atlantic region in 2018, the Pacific region in 2021, and the Great Lakes and Gulf Coast regions in 2023, when those markets reach 300 MW per year. A full WTG manufacturing facility could be started up in the Atlantic region in 2023 and in the Pacific region in 2026, when those markets reach 800 MW per year. The resulting percentages of domestic sourcing for the moderate-growth scenario, after adjustments for smoothing the timing of investment decisions, range from $40 \%$ in 2015 to $70 \%$ in 2030 , as shown in Figure 3-5. 


\section{NAVIGANT}

Figure 3-4. U.S. Manufacturing of Offshore Wind in the Moderate-Growth Scenario

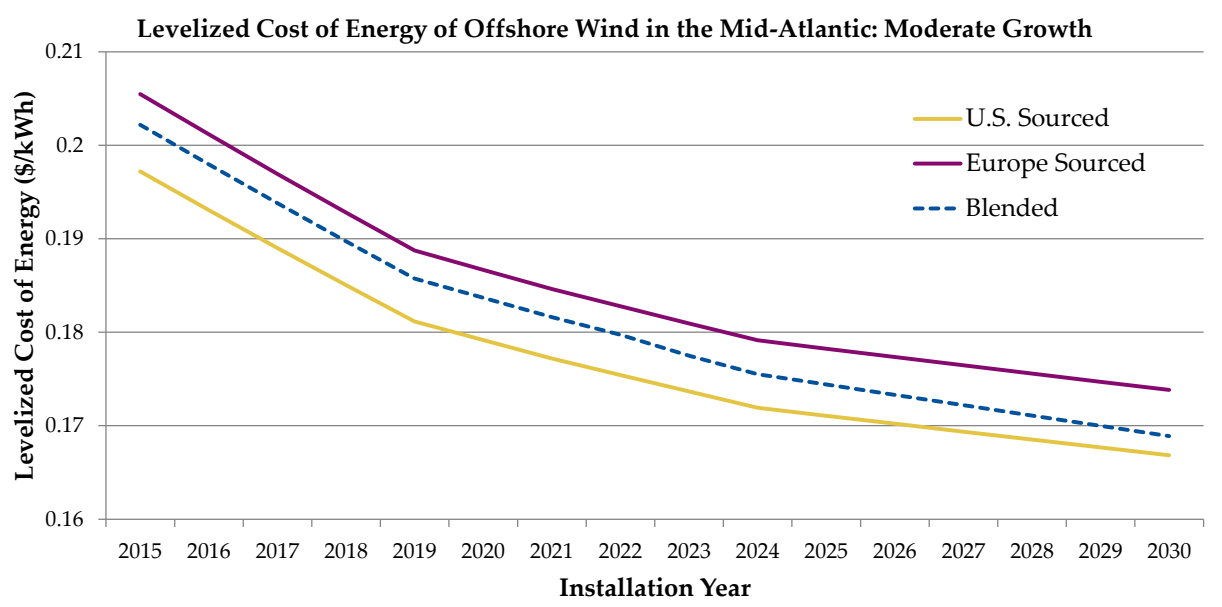

Source: Navigant Consortium analysis

Figure 3-5. Average Domestic Content in the Moderate-Growth Scenario

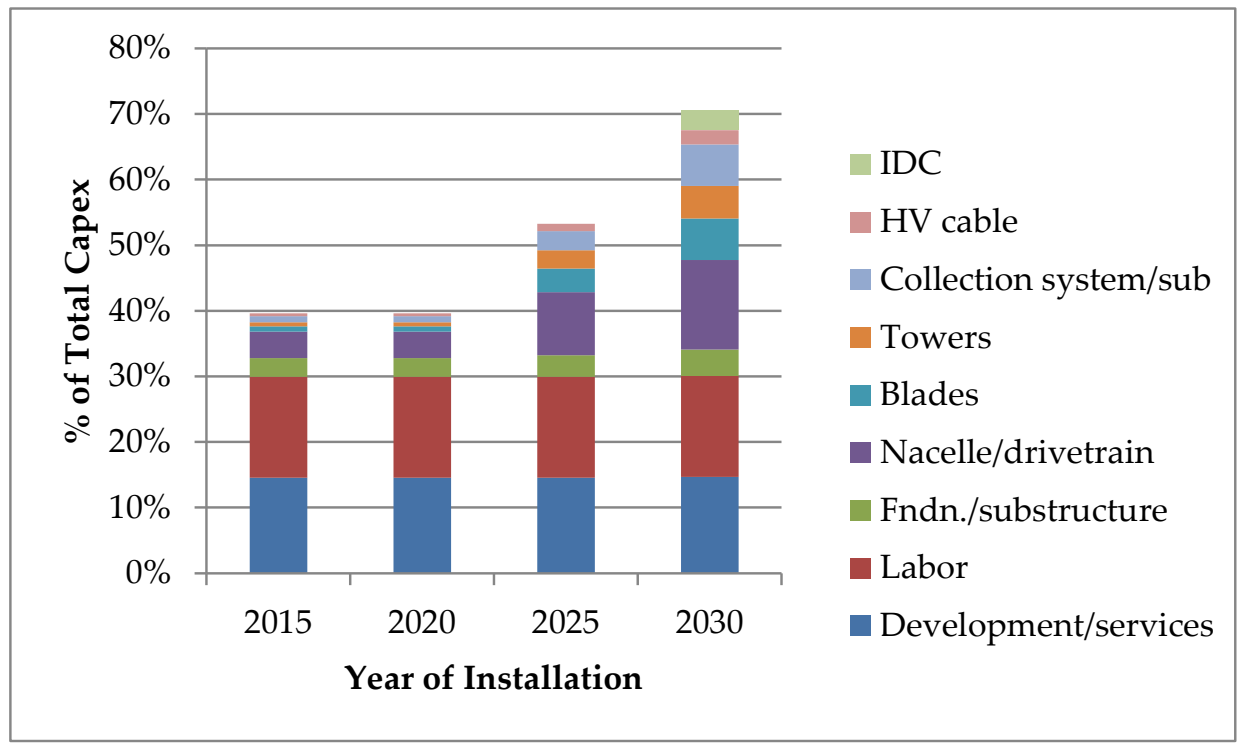

IDC $=$ interest during construction

Source: Navigant Consortium analysis

\subsubsection{High-Growth Scenario}

Figure 3-6 shows that in the high-growth scenario, a single component plant could be started up in the Atlantic region in 2015, the Great Lakes and Pacific regions in 2020, and the Gulf Coast region in 2023, when those markets reach 300 MW per year. A full WTG manufacturing facility could be started up in the Atlantic region in 2019 and in the Pacific region in 2022, when those markets reach 800 MW per year. The resulting percentages of domestic sourcing for the high-growth scenario, after adjustments for smoothing the timing of investment decisions, range from $40 \%$ in 2015 to $79 \%$ in 2030 , as shown in Figure 3-7. 


\section{NAVIGANT}

Figure 3-6. U.S. Manufacturing of Offshore Wind in the High-Growth Scenario

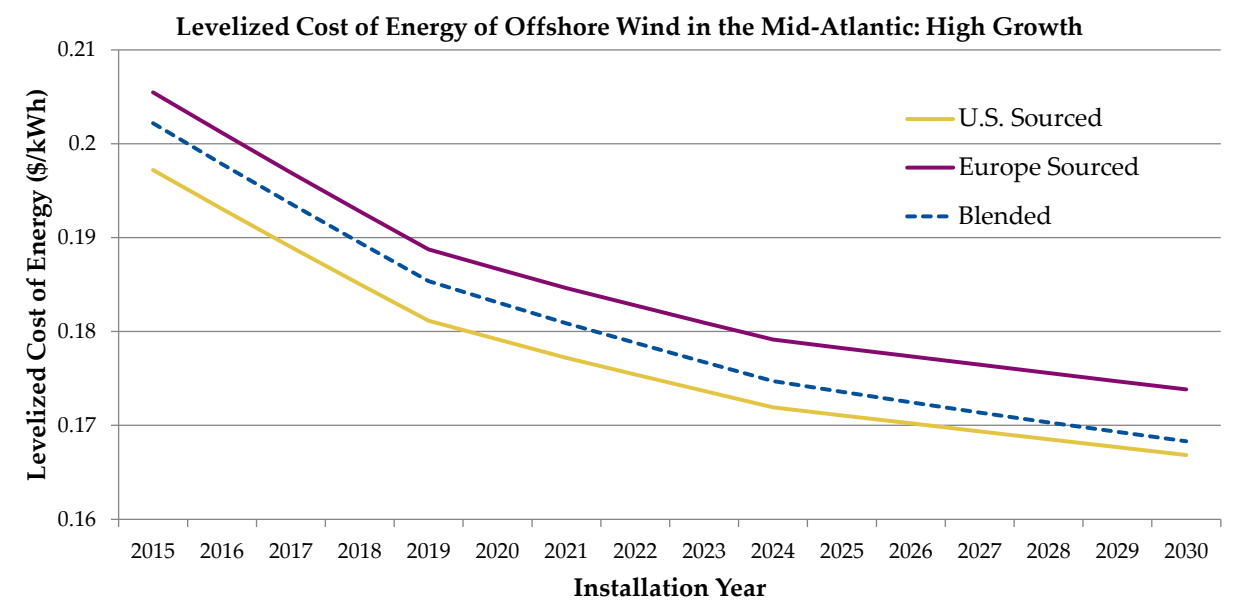

Source: Navigant Consortium analysis

Figure 3-7. Average Domestic Content in the High-Growth Scenario

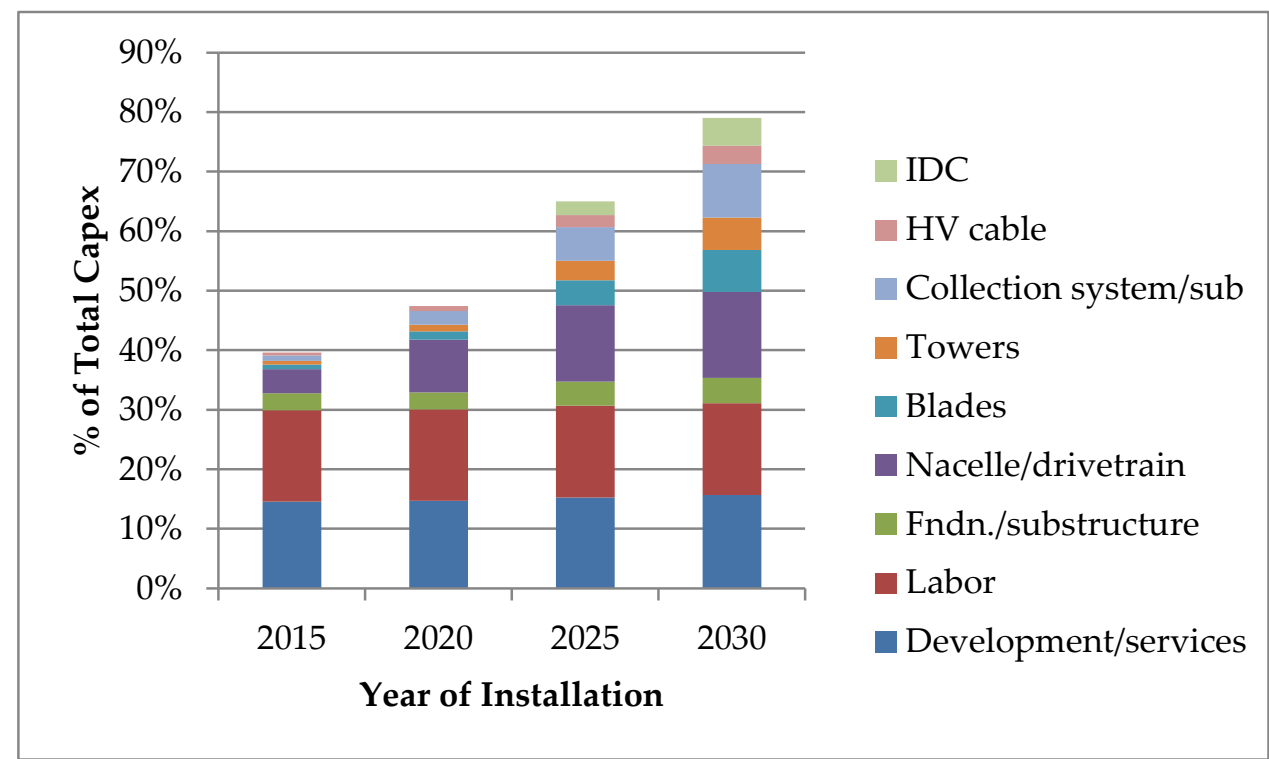

IDC $=$ interest during construction

Source: Navigant Consortium analysis

\subsection{Examples of Policies That Have Addressed the Barriers}

The policy examples listed in this section have been shown to be effective in reducing or removing the barriers that face offshore wind and therefore are drivers of manufacturing and supply chain growth. They have been successfully used either (a) in Europe, to promote offshore wind development, or (b) in the U.S., to promote land-based wind development. Collectively, they represent the policy examples that have been evaluated in the report "Offshore Wind Market and Economic Analysis; Annual Market 


\section{NAVIGANT}

Assessment - 2012" by Navigant for the DOE (Navigant 2012). A policy is determined to be efficient if it has relatively high effectiveness with relatively low effort or cost. The list of efficient policies can be considered by federal and state-level legislators and regulators as well as state and local economic development agencies.

\subsubsection{Policies That Address High Cost}

The seven policies listed below have been used to improve the competitiveness of offshore wind vs. other technologies. An example is a state Renewable Portfolio Standard (RPS) with an offshore wind carve-out, where a certain subset of the RPS installation requirements is reserved for offshore wind. To supplement the offshore windspecific policies, there are a few policies that apply to multiple technologies (e.g., accelerated depreciation) but nonetheless have been shown to promote the offshore wind market.

Another common theme is that in order to promote domestic manufacturing, a policy is more effective if it has a long enough term to give manufacturers and their investors confidence that the market is here to stay. A stop-start policy is often used to

The following policy examples may be effective in addressing the high cost of offshore wind based on experience in U.S. land-based wind and in offshore wind markets in Europe:

»Mandated long-term power contracts "RPS with an offshore wind carve-out » ITC or PTC

"Low-interest loans and loan guarantees for developers »Accelerated depreciation "State Feed-in Tariffs stimulate short-term demand, but manufacturers prefer long-term certainty when investing potentially hundreds of millions of dollars.

Below are policies that have been shown to be effective in addressing high cost in various jurisdictions. Note that the policies do not reduce the cost of offshore wind per se, but they have helped level the playing field so that its LCOE is closer to competing technologies.

» Long-term power contracts. Mandated buy programs that require utilities to enter into 15-20 year PPAs, similar to Massachusetts' Green Communities Act

» Offshore Renewable Energy Credits (ORECs). Mandatory credits for offshore wind energy production to meet state RPSs (such as in New Jersey) or a federal Clean Energy Standard. The most effective programs have longer terms and more stable prices.

"Investment Tax Credit (ITC) for developers. Similar to the current ITC of $30 \%$ of initial capital cost. The policy should be in place for at least six years, given the current time required to develop and build offshore wind projects.

» Production Tax Credit (PTC) for developers. Similar to the current PTC of \$22/MWh, with a premium for offshore wind. The policy would be in place for at least six years. Developers would have the option of using the ITC or the PTC, but not both.

"Low-interest loans and loan guarantees to developers. Similar to the recently expired Section 1704 DOE loan guarantee program 


\section{NAVIGANT}

» Accelerated depreciation for developers. Allow depreciation of initial capital investments in less than the five-year depreciation that is currently in place (e.g., the two-year bonus depreciation schedule that is due to expire for wind plants at the end of 2012)

" State FiTs. Major utilities or grid operators in participating states would be required to pay $\$ 50$ 100/MWh for offshore wind. Payments would continue at a guaranteed rate for 15-20 years for any given project. Payments to future offshore wind plants would be subject to a regular review based on market rates and growth of the offshore wind market. The level of the FiT would be roughly equal to the LCOE of offshore wind less the LCOE of conventional energy. The policy should be in place for at least six years.

Only one or two of these policies are typically implemented if they include sufficient levels of support and duration, although low-interest loans and loan guarantees and accelerated depreciation are often implemented in addition to any of the other examples.

\subsubsection{Infrastructure Policies}

The five policies listed below deal mainly with transmission infrastructure. They are based on existing state and federal programs and policies plus recommendations made in recent policy studies such as the Great Lakes Wind Collaborative's 2011 study Transmission-Related Policy Options to Facilitate Offshore Wind in the Great Lakes (Balachander et al, 2011).

¿ Establish clear permitting criteria and guidelines for transmission planning and siting. Examples include efforts by States governments and the U.S. government to "one-stop" permitting process such as those implemented by siting boards in Massachusetts, New York, Connecticut, and New Hampshire, and similar to the federalstate Memorandum of Understanding (MOU) signed by five Great Lakes states and ten federal agencies in March 2012. The MOU established a Great Lakes Offshore

The following policy examples have shown to be effective in addressing transmission infrastructure:

»Establish clear permitting and siting criteria and guidelines

»Establish consistent cost allocation and cost recovery mechanisms

" Promote utilization of existing transmission capacity reservations

»Designate offshore wind energy resources zones for targeted grid investments.

» Take into account public policy mandates, such as RPSs in offshore transmission planning

Wind Energy Consortium to support the efficient, expeditious, orderly and responsible review of proposed offshore wind energy projects in the Great Lakes.

"Establish clear and consistent cost allocation and cost recovery mechanisms for transmission development. FERC Order $1000^{15}$ directs Regional Transmission Organizations (RTOs) such as Independent System Operators (ISOs) to consider state and federal energy policies when planning expansion of their respective transmission systems and to consider cost allocation to all customers of new

${ }^{15}$ See http://www.ferc.gov/industries/electric/indus-act/trans-plan.asp. 


\section{NAVIGANT}

transmission for renewable generation. Ratepayers currently subsidize only new transmission demonstrated necessary to maintain system reliability. Offshore wind generation also strengthens grid reliability.. Ratepayers eventually pay for all transmission and generation costs, and it is more efficient to collect transmission costs from all ratepayers such as in Europe. RTOs, ISOs, and groups of regional planning authorities such as the Eastern Interconnection Planning Collaborative continue to model the impact on the grid of various policy options.

» Promote utilization of existing transmission capacity reservations to integrate offshore wind. RTOs, ISOs, and groups of regional planning authorities could consider using transmission capacity reservations of aging conventional shoreline generation facilities that are being operated below full capacity. Use of these capacity reservations and sites could serve as injection points and otherwise reduce interconnection costs for new offshore wind facilities.

"Designate offshore wind energy resource zones for targeted grid investments. Offshore wind energy zones could be designated for targeted grid investments for offshore wind interconnections. With input from its intergovernmental task forces, BOEM designates Wind Energy Areas (WEAs) that appear suitable for offshore wind development with the least amount of environmental and use conflicts. The developers of the potential Atlantic Wind Connection (AWC) project propose to interconnect with multiple wind facilities in the mid-Atlantic and gradually expand. The developer submitted an unsolicited request for a right of way grant to BOEM and after issuance of a Request for Competitive Interest, BOEM issued a Determination of No Competitive Interest for this cable Right of Way grant. (77 FR 28620, May 15, 2012). ${ }^{16}$ Similar cable

The following policy examples have shown to be effective in addressing regulatory challenges:

» Leasing: improve efficiency of 4phase BOEM Smart from Start process

» Permitting: Use programmatic environmental reviews for a broad geographic area followed by more limited, detailed EISs or EAs for specific projects projects could interconnect multiple wind farms in the Northeast, Southeast, and Great Lakes. Other BOEM intergovernmental task forces could identify large WEAs where multiple wind farms could be installed and from which independent transmission systems could collect energy. Hawaii has proposed ratepayer subsidies for a submarine cable network to carry renewable energy from land-based generation just as Texas and California have subsidized new transmission for land-based generation. Subsidies could be established for transmission cables to large WEAs such as the area designated by BOEM off Massachusetts and potential new areas off North Carolina. Multi-stakeholder collaboratives could designate offshore wind zones based on criteria such as wind resource quality, transmission needs, and social and environmental factors, similar to BOEM's "Smart from the Start" initiative on the Atlantic Coast and those established for Michigan waters of the Great Lakes by the Michigan Great Lakes Offshore Wind Council.

\footnotetext{
${ }^{16}$ The Notice of Determination is available here: http://www.gpo.gov/fdsys/pkg/FR-2012-05-15/pdf/2012-11823.pdf.
} 


\section{NAVIGANT}

" Offshore transmission planning which takes into account public policy mandates, such as RPSs. FERC Order $1000^{17}$ directs RTOs such as ISOs to consider state and federal energy policies when planning expansion of their respective transmission systems. RTOs and groups of regional planning authorities, such as the Eastern Interconnection Planning Collaborative, could identify transmission needs driven by public policy requirements and evaluate potential solutions. ISO New England, PJM Interconnection, NYISO, and Dominion Virginia Power have conducted numerous transmission studies to examine the integration of offshore wind into their respective grids. ${ }^{18}$ NREL also published the Eastern Wind Integration Transmission Study in 2010 showing how substantial quantities of offshore wind energy could be integrated into the Eastern Interconnect to help reach the federal renewable energy targets. ${ }^{19}$

\subsubsection{Regulatory Policies}

Regulatory policies that affect offshore wind include the following subcategories: site leasing, permitting, and operations. Described below are policies covering the three subcategories that have shown to be effective for their given purposes.

" BOEM Smart from the Start. BOEM has established a new planning and leasing process for offshore energy facilities. To summarize, BOEM's process is conducted in four stages: (1) planning and analysis, (2) leasing, (3) site characterization and assessment, and (4) commercial development.

Identification of wind energy areas (WEAs) can be informed by studies conducted by state entities that identify environmental constraints and engage in discussions with stakeholders with competing offshore uses. For example, Rhode Island and Massachusetts initiated their own offshore management planning processes, and the results informed BOEM's offshore wind planning process. BOEM also incorporated the results of early offshore studies by New Jersey into the identification of a WEA off the state. Upfront identification of all significant constraints and competing uses reduces the likelihood that a major constraint or competing use will arise later in the lease and permitting process and result in potentially lengthy delays.

Initiating a phased environmental review process expedites leasing and plan approval because National Environmental Policy Act (NEPA) reviews can be time consuming. For example, instead of waiting for the Site Assessment Plan (SAP) to be filed to trigger the SAP NEPA review, BOEM initiated a Regional Environmental Assessment (EA) for four Mid-Atlantic States (NJ, DE, MD, and VA) simultaneously. By covering all major site assessment and

\footnotetext{
${ }_{17}$ See http://www.ferc.gov/industries/electric/indus-act/trans-plan.asp.

${ }^{18}$ See "New England Wind Integration Study," 2010, http://www.isone.com/committees/comm_wkgrps/prtcpnts comm/pac/mtrls/2010/jan212010/newis.pdf; "PJM Wind Integration Study," 2010, available here: http://www.pjm.com/ /media/committees-groups/workinggroups/rppwg/20101217/20101217-item-03-wind-integration-study-scope.ashx; and "Virginia Offshore Wind Integration Study," 2010, available here: http://www.dmme.virginia.gov/DE/VOWDA/DominionOffShoreWindStudyReport.pdf.

19 The Eastern Wind Integration Transmission Study is available here: http://www.nrel.gov/wind/systemsintegration/ewits.html.
} 


\section{NAVIGANT}

characterization technologies and their anticipated impacts, this Regional EA is expected to enable more expeditious review of site assessment proposals by lessees offshore those states.

» BOEM's renewable energy regulatory process incorporates coordination with relevant federal and state agencies to facilitate an efficient approval processes. ${ }^{20}$ Coordination to recommend survey protocols is important to prevent unnecessary or duplicative surveys. Through an iterative process with other Federal agencies, BOEM recently prepared and posted biological and physical survey guidelines at: http://www.boem.gov/Renewable-EnergyProgram/Regulatory-Information/Index.aspx. Public meetings and hearings can facilitate an expedited approval process for all state and federal approvals by identifying issues early in the process.

"Use of programmatic environmental impact statement (PEIS) for construction in a broad geographic area followed by more limited, tiered, and detailed EISs or EAs for the COP for specific individual projects. A PEIS evaluates the impacts and identifies appropriate mitigation for a range of standard technologies to be installed in a relatively uniform environment. The completed PEIS provides guidance to developers and regulators for subsequent specific development proposals. If the same foundation technologies and installation techniques are proposed with the mitigation recommended by the PEIS, the subsequent tiered NEPA review of the COP can focus only on unique aspects of the specific technologies or environment at the proposed wind farm site and cable route, which may significantly reduce the NEPA review period. A PEIS for construction may take a couple of years to complete, but if it is initiated early during the initial WEA identification and competitive auction processes, it can significantly expedite final review of the winning leaseholder's project. This is especially true if programmatic EISs or EAs are conducted for WEAs simultaneous to the lengthy process to determine the winning bidders in areas where competitive interest exists.

The Council on Environmental Quality (CEQ) NEPA regulations specifically encourage tiering NEPA reviews off prior NEPA reviews:

"Agencies are encouraged to tier their environmental impact statements to eliminate repetitive discussions of the same issues and to focus on the actual issues ripe for decision at each level of environmental review" (Sec. 1508.28).

"Whenever a broad environmental impact statement has been prepared (such as a program or policy statement) and a subsequent statement or environmental assessment is then prepared on an action included within the entire program or policy (such as a site-specific action) the subsequent statement or environmental assessment need only summarize the issues discussed in the broader statement and incorporate discussions from the broader statement by reference and shall concentrate on the issues specific to the subsequent action. The subsequent document shall state where the earlier document is available. Tiering may also be appropriate for different stages of actions" (Section 1502.20).

Tiering is thus authorized to make NEPA reviews more efficient, reducing the analysis and time to complete subsequent reviews. As the same technologies are constructed and operated in 


\section{NAVIGANT}

similar environments, EISs can be gradually replaced by EAs and eventually, in some cases, by categorical exclusions.

BOEM issued a programmatic EIS for offshore energy development in 2007 prior to issuance of the Final Rule. When issuing the Final Rule, BOEM (then the Minerals Management Service, or MMS) stated:

"We will ensure that environmental analysis for OCS renewable energy proposals is proportional to the scope and scale of each proposal, is effectively tiered to programmatic NEPA documents, and efficiently incorporates other publicly available information by reference. The MMS will ensure timely and efficient coordination of the development and review of environmental documents with all agencies that have jurisdiction or special expertise to provide the decision makers. We will ensure that mitigation and monitoring information informs future decision-making processes." 74 FR 19638, 19643 (April 29, 2009).

In 2011, CEQ released final guidance on the "Appropriate Use of Mitigation and Monitoring and Clarifying the Appropriate Use of Mitigated Findings of No Significant Impact." This guidance explains when an EIS can be avoided by issuance of an EA with mitigating conditions sufficient to warrant a Finding of No Significant Impacts (FONSI). The guidance requires any agency issuing a mitigating FONSI to follow up and confirm that all such conditions are implemented.

As part of the Secretary's Smart from the Start initiative, BOEM conducted a Regional EA that analyzed the impacts associated with offshore wind lease issuance and site characterization and assessment activities that may take place in the areas identified by BOEM offshore New Jersey, Delaware, Maryland, and Virginia. Provided that the activities proposed by New Jersey, Maryland, and Virginia lessees fall within the scope of the activities analyzed in the Regional EA, additional NEPA review prior to the approval of Site Assessment Plans may not be necessary.

Similarly, routine activities could eventually be determined to be "categorical excluded" by BOEM, meaning they do not individually or cumulatively have a significant effect on the human environment and would require no EA or EIS. CEQ issued new guidance in 2011 on establishing and maintaining categorical exclusions for routine activities. Many oil and gas exploration activities have been granted categorical exclusions. Over time, site assessment activities, such as installing a meteorological tower, should become routine and warrant a categorical exclusion instead of an EA. 


\section{NAVIGANT}

» Self-monitoring of environmental and safety compliance by developers/operators. This option scores well in all categories, with the exception of possible conflicts of interest. This concern could be balanced with oversight in critical areas. For example, generic studies could provide more protection to birds and bats, and help identify whale mating, calving, and migratory areas to minimize exposure to construction and O\&M vessels supporting offshore wind farms. Developers would continue to fund and execute their own post-construction surveys for review by regulators.

\subsubsection{Summary of Effective Policies}

The policies described above are summarized in Table 3-2. A short-term policy is defined as being implemented within the next two years, although the terms of the policies will generally be much longer.

Table 3-2. Examples of Effective Offshore Wind Policies

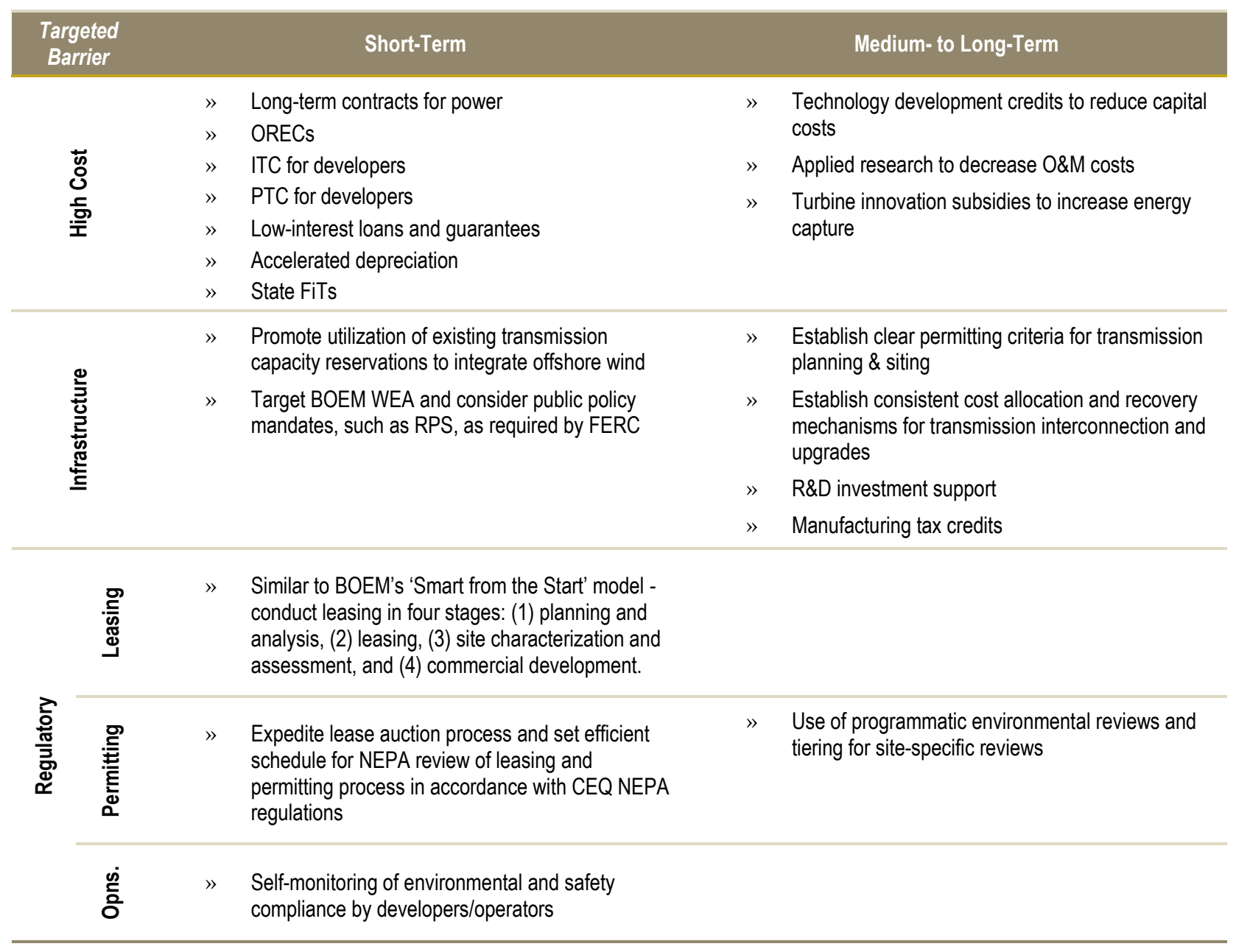

Although many policy alternatives are shown as short term, the most critical need is to stimulate demand (i.e., address the high cost of offshore wind). This critical need was addressed through a portfolio approach of policies that incorporate multiple policy elements, similar to the U.S. land-based 
wind market, which has been stimulated through a mix of PPAs with PTCs, ITCs, and RPSs. Other examples of policies that have addressed this critical need include the Feed-in Tariff, which many European countries have used to stimulate offshore wind demand.

Secondary to the need for demand is the need to ensure the demand can be filled. Policies that streamline siting and permitting processes and put in place critical infrastructure components such as transmission and ports have shown to be effective in addressing this need.

In the medium to long term, there is a need to instill confidence in the U.S. market. Manufacturers are unlikely to build new U.S.-based manufacturing capacity without confidence in U.S. long-term, stable demand. Only after the U.K. and Germany signaled that long-term demand would exist did manufacturers begin to build port-side manufacturing capacity in those countries, with the help of manufacturing incentives such as tax credits.

Finally, governments often provide R\&D investment support as a longterm policy. R\&D support helps to drive down the total installed system cost and the LCOE, which is critical to

Bremerhaven: A Success Story

Bremerhaven, one of Germany's largest ports, suffered a decline in the 1980s due to a decline in fishing and shipbuilding. In 2002, as it saw the coming growth of the offshore wind sector, the state government of Bremen began investing in upgrades to the port. Since then, Multibrid, now AREVA, and REpower, manufacturers of 5.0+ MW turbines, as well as blade supplier PowerBlades and tower supplier Ambau, have established production facilities at Bremerhaven (see Appendix F). the longer-term success of offshore wind market development. 


\section{NAVIGANT}

\section{Analysis of Market Entry Pathways}

\subsection{Introduction}

This chapter discusses entry into the U.S. offshore wind supply chain. Section 4.2 assesses the factors that will shape suppliers' decisions concerning entry into the market. Section 4.3 describes the criteria OEMs and Tier 1 suppliers are likely to use in evaluating potential suppliers for a U.S. offshore wind industry. Section 4.4 describes a typical process that suppliers will need to follow to successfully enter the offshore wind supply chain. Sections 4.5 and 4.6 address the barriers that may inhibit suppliers with U.S.-based operations from entering the supply chain and potential actions that could remove those barriers.

Figure 4-1 summarizes the key findings from this chapter.

Figure 4-1. Summary of Key Findings for Chapter 4

\section{Summary of Key Findings - Analysis of Market Entry Pathways}

» In deciding whether to enter the U.S. offshore wind market, potential suppliers will assess the supply and demand dynamics.

» If the U.S. offshore wind market were expected to show steady long-term growth, major turbine components as well as vessels would likely be built in the U.S.

» Domestic suppliers of offshore wind turbine and balance of plant components will be more likely to enter the U.S. offshore market in areas where the competitive rivalry is less fierce and where barriers to entry and risk are relatively lower.

» Wind turbine OEMs will take into account numerous criteria when evaluating potential suppliers for a U.S. offshore wind industry.

» Suppliers looking to sell components into a future U.S. offshore wind market will need to follow a similar qualification process found in other manufacturing sectors.

» Market barriers faced by new suppliers in the offshore wind industry fall into two primary categories: production planning and production facilities.

» Strong and consistent demand for offshore wind projects is the best antidote for most of the supply chain barriers.

\subsection{Suppliers' Decision-Making Process for Entering the Offshore Market}

In deciding whether to enter the U.S. offshore wind market, potential suppliers will assess the supply and demand dynamics. Suppliers will assess whether the market will be large enough to warrant dedicating manufacturing capacity to offshore wind-related products. European-based suppliers will use demand forecasts to determine whether it is financially attractive to build manufacturing plants in the U.S. On the supply side, potential suppliers will assess the competitive rivalry, the barriers to entry, and the risk for each component. Market entry will be more attractive with higher fragmentation, lower barriers to entry, and lower overall risk. 


\subsubsection{Market Demand: Market Size and Growth Rates}

The greatest driver for the development of a U.S.-based offshore wind supply chain is the existence of a strong U.S. offshore wind market. Until there is greater certainty around future demand in the U.S. offshore market, major turbine components will likely come from Europe or Asia. OEMs and major suppliers will be unwilling to invest in new, offshore-specific manufacturing capacity without greater market certainty.

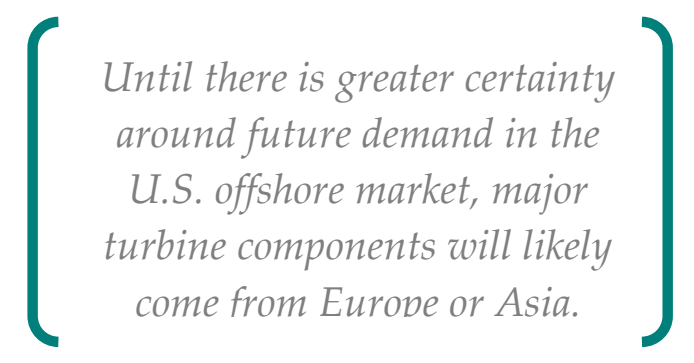

\subsubsection{Uncertain or small market}

Retooling existing onshore manufacturing facilities in the U.S. would also require significant risk. Even if these plants were retooled, overland transportation to ports of nacelles, blades, towers, and foundations of increasing sizes would likely be infeasible as many manufacturing facilities are west of the Mississippi River, 1,000-2,000 miles from the East Coast. Many offshore blades, for example, already exceed 50 meters in length.

In August 2011, a wind turbine blade suffered $\$ 275,000$ in damage when the semi-trailer truck transporting it crashed into another vehicle in a busy intersection in Dubuque, Iowa. ${ }^{21}$

Figure 4-2. Blade Damage During Land Transport

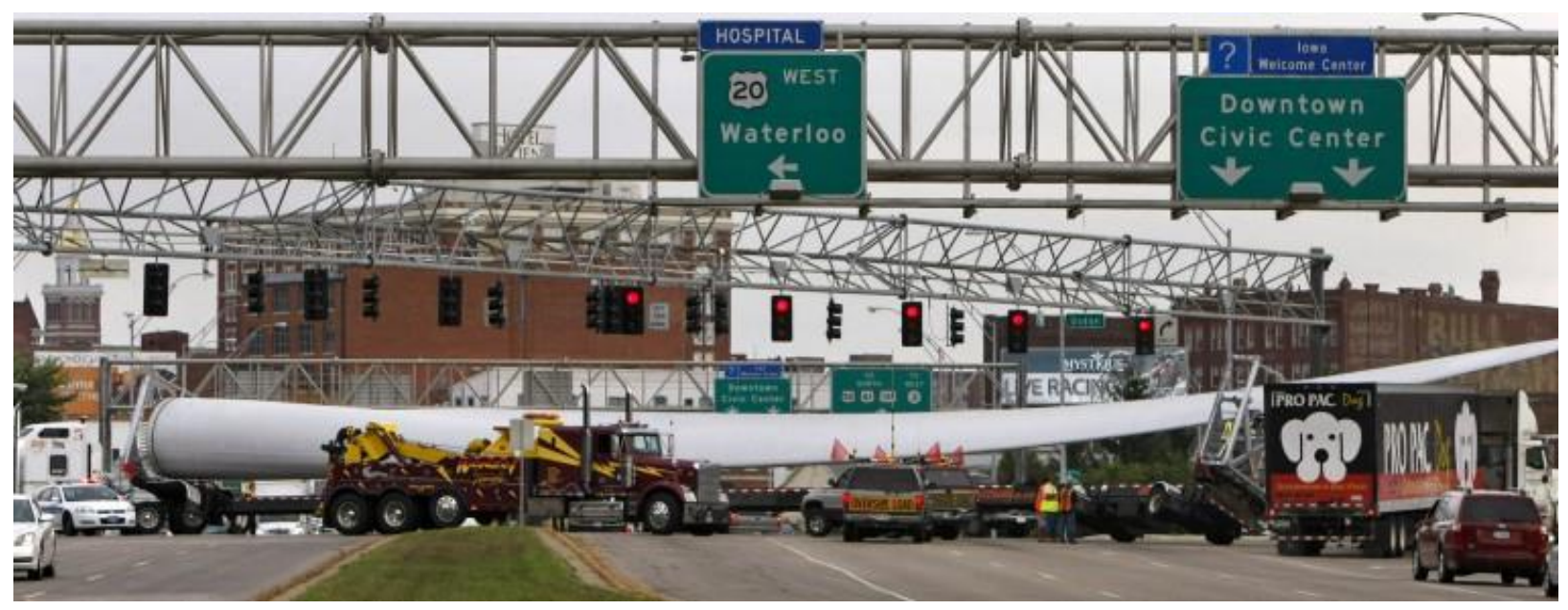

Source: Jeremy Portje

In addition to traffic congestion, overland transport of wind turbines can cause road damage, due to the repeated passage of heavy-load convoys. Moving wind turbine components also requires increasingly complex coordination. Scheduling between trucking companies, railroad and port operators, and city and state authorities can be very onerous. Moreover, as components grow larger, transportation costs will increase.

\footnotetext{
${ }^{21} \mathrm{http} / / /$ www.thonline.com/news/breaking/article_fe7deb6c-c8d5-11e0-9ab6-001a4bcf6878.html 


\section{NAVIGANT}

The size of offshore turbine foundations would normally necessitate local production. However, the lack of production capacity could force imports. While there is limited rolled steel production capacity on the East Coast of the U.S., for the Cape Wind project, Mass Tank plans to team with the German company EEW to make monopile foundations. The capabilities of the offshore oil and gas sector on the Gulf Coast could potentially provide foundations for a limited U.S. offshore wind market.

Without greater demand certainty, specialized installation vessels may come from Europe. Growing turbine sizes in the offshore market are beginning to necessitate the use of specialized vessels. The U.S. lacks such specialized vessels and investment in new vessels is unlikely without some demand certainty as purpose-built vessels are very costly. A shortage of vessels given strong offshore demand in Europe could limit availability for U.S. projects. While converted oil and gas vessels are often suboptimal for offshore wind projects, they may be used until the U.S. offshore market grows. The Cape Wind project plans to convert oil and gas barges in the Gulf of Mexico. U.S.-based projects may be required to use locally sourced vessels due to the Jones Act.

\subsubsection{Strong, steady market demand}

If the U.S. offshore wind market were expected to show steady long-term growth, major turbine components would likely be built in the U.S. When the U.S. land-based wind market began to show strong growth, OEMs and major suppliers invested in U.S. manufacturing facilities. Given the size and relative lack of intellectual property in towers, they are often the first components manufactured locally. Growing blade sizes will necessitate local manufacturing in a growing U.S. market. While the majority of land-based wind manufacturing facilities are located in the wind-heavy Midwest, offshore facilities will be located near ports, as they have been in Europe. Although the domestic content in wind turbines deployed in the U.S. has risen, some components will continue to be imported. High-value, complex nacelle internals such as gearboxes would likely be the last components to be sourced locally.

To meet Jones Act requirements, a thriving U.S. market could spark construction of U.S.-built vessels. U.S.-built and -flagged vessels would greatly facilitate the offshore construction process in U.S. waters. As converted oil and gas barges will be insufficient for offshore wind over the long run, U.S. shipbuilders will construct wind-specific vessels. These vessels will be similar to those currently being produced in China and South Korea.

\subsubsection{Supply: Competitive Rivalry, Barriers to Entry, and Risk}

\subsubsection{Existing and potential competition}

Domestic suppliers of offshore wind turbine and balance of plant components will be more likely to enter the U.S. offshore market in areas where the competitive rivalry is less fierce and where barriers to entry and risk are relatively lower. Below is an analysis of the global competitive rivalry and risk for offshore wind components. 


\section{NAVIGANT}

$\underline{\text { Blades }}$

The market concentration for wind turbine blades is high, as are the barriers to entry. The majority of OEMs manufacture blades in-house and/or source them from the major independent supplier LM Wind Power. Blades require sophisticated manufacturing expertise and are made of high-tech composites. Blades destined for the offshore market are growing to 80 meters in length as turbine sizes reach 6-7 MW. In addition, they must be able to handle larger loads. Successful suppliers are able to transport the blades to port locations, which typically involves building production facilities at port sites.

\section{Gearboxes}

The offshore market concentration for gearboxes is high as are the barriers to entry. As of 2011, over 40 gearbox suppliers were catering to the wind market, of which 12 were capable of supplying the offshore market. Few players will likely have the capability or the risk appetite to manufacture the gearboxes required by the largest offshore turbine sizes. It will take several years and significant capital to ramp up production for the largest offshore wind gearboxes. Even some significant players in the land-based gearbox market, such as Moventas, are avoiding the offshore market due to the increased risks. For some turbine OEMs, the gearbox is a component of the past. Siemens and Goldwind, for example, are producing direct-drive offshore turbines that will not require a supply of gearboxes.

\section{Generators}

The generator market is largely fragmented among regional suppliers with medium barriers to entry. Nearly $90 \%$ of generator suppliers identified are capable of producing DFIG generators, and with DFIG recently losing market share to PMG, it is unlikely that it will be in short supply over the next 3-4 years.

\section{Bearings}

The market concentration for the large bearings required in the offshore market is high, as are the barriers to entry. A number of Chinese suppliers have entered the bearings market but few are able to sustain production due to competition from major European suppliers such as SKF and FAG and concerns over quality. Despite lower raw material prices in Asia, most OEMs are reluctant to stray from reputable European and North American suppliers. Given the trend for larger turbines, pending take off of the offshore market, a lack of qualified suppliers, and an unfavorable investment climate, investment in the R\&D and technical machinery necessary to deliver the larger bearings to market is scarce. Assuming the current financial climate improves, strong demand over the next 3-5 years could result in a critical bottleneck in the extra-large bearings market.

\section{$\underline{\text { Power Converters }}$}

The market concentration for offshore power converters is high as are the barriers to entry. There have been no constraints in the power converter supply chain over the past two years. Considering the current market conditions, especially the concern for overcapacity in Europe, the U.S., and China, there is no sign that the supply of power converters will constrain the growth of the wind turbine market in the next 2-3 years. It is important to note that in-house production continues as the mainstream approach to power converters among the top 15 turbine OEMs, despite at least 50 independent suppliers worldwide, with all leading suppliers coming from Europe and the U.S. Of note is Spanish company Ingeteam's opening of a production facility in Milwaukee in 2011 to serve the North American wind market with power converters and generators. Only $25 \%$ of suppliers cater to the offshore market, with $\mathrm{ABB}$, Converteam, and Woodward as the leaders in the independent 5-6.5 MW class. 


\section{NAVIGANT}

\section{Power Transformers}

The transformer market catering to the wind industry includes over 45 players, with suppliers ABB, CG Power Systems, Schneider, SGB, Siemens, and GE sharing most of the European and North American market. For offshore applications, liquid transformers currently have the edge, with an estimated $53 \%$ of the market in 2010, increasing to over $90 \%$ when looking at the $>3$ MW class. Currently only six manufacturers have experience in supplying the offshore market.

\section{Towers}

The market concentration for towers is low and the barriers to entry are low. Tower suppliers exist in all regional markets. The intellectual property involved in tower production is low and the expertise required is generally widely available.

\section{Castings}

The market concentration for the large castings required by the offshore market is medium and the barriers to entry are high. Moving offshore, the turbines are growing larger, with the quality standards demanded by turbine and gearbox manufacturers increasing significantly. The potential for producing these large components (20+ tons for offshore wind) is limited, despite oversupply. A market assessment by BTM Consult in 2011 identified nearly 100 wind power casting suppliers distributed across Europe, Asia, and North America (BTM 2011). Less than 20\%, however, are capable of serving the offshore wind power market at present. Successful suppliers of large castings for the offshore market will be located at or near ports given transportation challenges.

\section{Forgings}

The market concentration for the large forgings required by the offshore market is medium and the barriers to entry are high. Partner selection still remains a key challenge in meeting the strict quality specifications, an issue of growing concern as quality requirements increase with the trend towards increasing turbine size. Of the top ten forgings suppliers to the global wind turbine industry, only one is in the U.S. and only one is in Europe. The other eight are located in South Korea and China. The hardest test will come when the offshore market takes off, as today's investment climate provides little confidence for the experienced Western suppliers. High raw material prices and labor costs are plaguing Europe/North America. Combined with the tough financial climate and new entrants from the AsiaPacific region, the result is a lack of long-term investment, implying a shortage of highly qualified suppliers to feed the multi-MW and offshore wind segments. Consolidation in the global market is expected, with the Chinese market leading the way. Fierce competition in quality and price will rule out new suppliers without experience and an established customer base.

\section{$\underline{\text { Resins }}$}

Epoxy resins are the basic material for most blades in all regions, with up to $85 \%$ of the market in China. Market supply of bisphenol A (BPA) has affected the price and supply of resins, with some tightness in supply settling in the short term but no major constraints expected in the long term. Momentive, Huntsman, and Dow lead the global epoxy resin market, which primarily consists of established players, as OEM designer qualifications are lengthy (up to several years) and complex. A number of Chinese players have entered the market, although only a select few meet Germanischer Lloyd standards, limiting their market reach. 


\section{NAVIGANT}

\section{$\underline{\text { Reinforcement Fibers }}$}

The global carbon fiber market is dominated by three Japanese manufacturers-Toray, Toho-Tenax, and Mitsubishi-Rayon - with a $>75 \%$ (est.) of the global PAN-based small tow production capacity, 55,000 tons (est.) in 2010. Despite high demand for carbon fiber, supply closely tracks demand, a trend expected to continue until 2015.

\section{$\underline{\text { Rare Earth Materials }}$}

Within two decades China has become the world's largest rare earth element market in the world, home to approximately $97 \%$ of the world's resource. Rare earth metals are in high demand as they are seen seminal to the development of advanced high-end clean technologies, as well as the defense and refinery industries. In 2010, 4,100 MW were required for permanent magnets, although the need for rare earth metals is anticipated to grow significantly with the expansion of the direct-drive PMG market.

In early 2012, Molycorp, the owner of the largest rare earth deposit in the U.S., reopened the Mountain Pass mine in California and started production of rare earths in February 2012. In March 2012, Molycorp made a downstream vertical integration play by acquiring processing company Neo Material, which has plants in Asia that serve Chinese and Japanese markets. The company expects to have the capacity to produce 40,000 metric tons of rare earth oxide (REO) equivalent annually from its Mountain Pass mine by mid-2013. Roughly $15-20 \%$ of this total, or 6,000-8,000 metric tons, is expected to be comprised of Neodymium. ${ }^{22}$

\section{Offshore Balance of Plant}

\section{Foundations}

The market concentration for offshore turbine foundations is high as are the barriers to entry.

Thus far, offshore wind foundations have primarily involved concrete, gravity-based foundations or steel monopiles, which currently account for $80 \%$ of installed offshore wind capacity (BVG 2009, BTM 2011). Gravity-based concrete structures have primarily been installed in Danish offshore wind projects. As such, most of the companies that have supplied concrete foundations to the offshore wind market are based in Denmark. However, as demand ramps up in expanding markets like Germany and China, new suppliers (primarily large construction firms with civil, infrastructure, and oil and gas project experience) in those countries have indicated plans to supply domestic projects (BTM 2011). Similarly, most suppliers of steel foundations and structures for the offshore wind market are based in those European countries with significant installed offshore capacity (e.g., Denmark, the Netherlands, the U.K. and Germany).

In terms of the near-term balance in supply and demand, a recent U.K. study anticipates adequate supply of monopiles for the European market. However, a lack of market continuity (i.e., due to inconsistent demand or policy support) may lead to shortfalls in the supply of steel jacket structures and concrete gravity-based foundations based on the significant investment required for new manufacturing facilities (BVG 2012). Particularly for emerging foundation designs, new manufacturing technologies and capacity takes time (up to two years) to plan, site, and bring online (BVG 2009). In addition, volatile steel

\footnotetext{
${ }^{22}$ Company website 


\section{NAVIGANT}

prices can add uncertainty to a developer or OEM's selection of the appropriate foundation type for a particular project (BVG 2009).

Cables

The market concentration for subsea cables is high as are the barriers to entry. Three companies, Nexans, Prysmian, and $\mathrm{ABB}$, control most of the cabling market for offshore wind. With the distance to offshore projects from the shore stretching beyond $80 \mathrm{~km}$, there is a trend towards HVDC technology. At present, availability of large export cables is a cause for concern

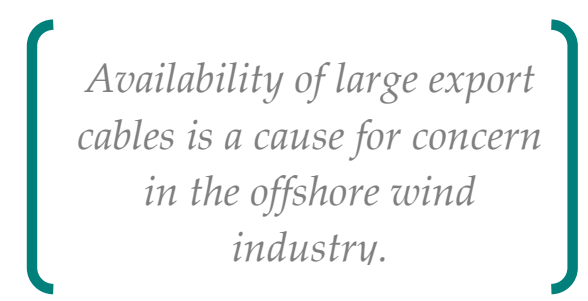
in the offshore wind industry. Most cable suppliers have plans to expand their production, but are unwilling to invest in new capacity without greater certainty around market demand. It typically takes two years to test and type-certify a new cable. Given the risk associated with sourcing from a new cable supplier, project developers do not anticipate a rapid ramp up in supply.

\section{Summary}

Market concentration and barriers to entry levels for all offshore wind turbine components are summarized in Table 4-1.

Table 4-1. Market Concentration and Barriers to Entry for Offshore Wind Components

\begin{tabular}{lcc}
\hline Component & Market Concentration & Barriers to Entry \\
\hline Blades & High & High \\
\hline Gearboxes & High & High \\
\hline Generators & Low & Medium \\
\hline Bearings & High & High \\
\hline Power Converters & High & High \\
\hline Power Transformers & High & High \\
\hline Towers & Low & Low \\
\hline Castings & Medium & High \\
\hline Forgings & Medium & High \\
\hline Resins & High & High \\
\hline Reinforcement Fibers & High & High \\
\hline Rare Earth Materials & High & High \\
\hline Foundations & High & High \\
\hline Cables & High & High \\
\hline
\end{tabular}

\subsection{WTG OEM Decision-Making Process for Evaluating Suppliers}

Wind turbine OEMs will take into account numerous criteria when evaluating potential suppliers for a U.S. offshore wind industry. 


\section{NAVIGANT}

Table 4-2. WTG OEM Decision-Making Drivers for Evaluating Suppliers

\begin{tabular}{ll} 
Driver & $\begin{array}{c}\text { Relative Degree of } \\
\text { Importance }\end{array}$ \\
\hline Track Record in Wind or Similar Sector & Primary \\
\hline High Quality and Reliability & Primary \\
\hline Available Capacity & Primary \\
\hline Solid Financial Footing & Primary \\
\hline Competitive Pricing & Primary \\
\hline On-Time Delivery & Primary \\
\hline Flexibility in Production Schedules and Ability to Meet Short Lead & Secondary \\
\hline Times & Secondary \\
\hline Robust Service Organization & Secondary \\
\hline Willingness to Engage in Joint Development with OEM & Secondary \\
\hline Technology Development & Secondary \\
\hline Localization/Geographic Footprint & \\
\hline
\end{tabular}

\subsubsection{Track Record in Wind or Similar Sector}

When selecting suppliers, wind turbine OEMs and Tier 1 suppliers look for companies with a proven track record of delivering quality components to the wind sector or another sector with similar requirements. If an OEM were to source from a supplier that has never manufactured components specifically for the wind sector, it would greatly increase the risk of its operations.

\subsubsection{High Quality and Reliability}

Procuring quality components is critical for wind turbine OEMs. Component failures can increase operating and maintenance costs and tarnish the reputation of turbine manufacturers, leading to reduced future sales. Purchasers of wind turbines need to be able to have confidence that turbines will perform as promised.

In 2008, Suzlon had to recall nearly all of its wind turbine blades in the U.S. due to a series of cracking incidents. The companies had rushed prototypes to the U.S. market without sufficient testing on the U.S. power grid. ${ }^{23}$ In October 2008, the company's shares dropped 39\% after a blade completely broke off a turbine in Illinois. ${ }^{24}$

OEMs are the most stringent in their selection of suppliers for highly specialized and critical

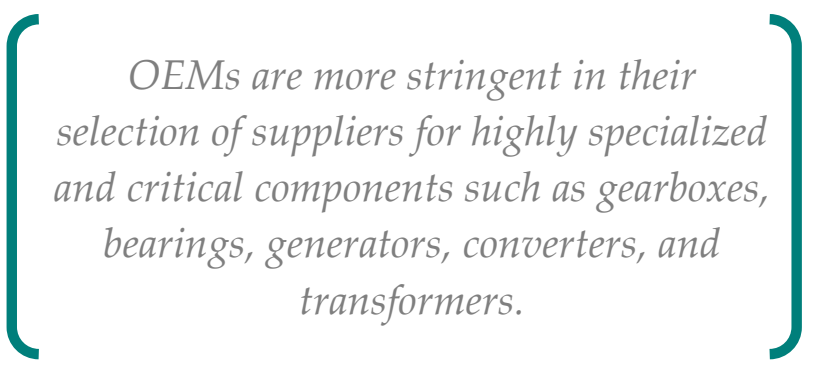

\footnotetext{
${ }^{23} \mathrm{http} / / /$ blogs.wsj.com/environmentalcapital/2008/06/30/headwind-asian-wind-power-upstarts-stumble/

${ }^{24} \mathrm{http}$ ://blogs.wsj.com/environmentalcapital/2008/10/24/wind-breakers-suzlon-shudders-after-wind-turbineaccident/
} 


\section{NAVIGANT}

components such as gearboxes, bearings, generators, converters, and transformers. Turbine OEMs typically rely on in-house capacity or dedicated existing suppliers for these components to ensure high levels of quality. A majority of problems leading to turbine malfunction are caused by gearbox and/or bearing problems. Because of the potential problems with failure, gearbox and wind turbine manufacturers are reluctant to use new suppliers.

Most OEMs require that a potential supplier demonstrate compliance with certain stringent international quality standards: ISO 9001:2008 (quality management), ISO 14001:2004 (environmental management), and/or OHSAS 18001 (occupational health and safety).

Reliability is more critical offshore than onshore due to multiple factors. The offshore environment can be much harsher, with high winds, significant wave loads, and corrosion-producing salt water. Offshore turbines must be manufactured to be able to withstand this environment. Harsh weather offshore not only threatens the performance of wind turbines, it can also inhibit access to turbines by maintenance staff. The inability to reach and repair sub-performing or inoperable turbines can cause significant lost power sales. Severe weather also increases safety concerns for maintenance crews.

Procurement for components with less intellectual property and with less impact on overall turbine quality such as towers, nacelle housings, and rotor hubs has less stringent requirements. OEMs are more likely to outsource these components. When possible, OEMs will source these components locally to reduce transportation costs. These areas of the supply chain present a better opportunity for new entrants. The expertise required to manufacture towers, for example, is relatively well disseminated.

While some European OEMs are still reluctant to stray from their established suppliers due to concerns over quality, downward price pressures are challenging turbine vendors, especially those who want to compete against Chinese manufacturers, to accept higher risks to stay in business.

Compared to the land-based wind market, the offshore wind market entails many more risks that increase the level of quality needed. The marine environment can be much harsher than a land-based site. Corrosion can damage external as well as internal areas of the turbine. Moreover, access constraints to an offshore site, often caused by poor weather or lack of availability of appropriate vessels, can increase O\&M costs as well as reduce revenue due to power losses. As gearbox failures have historically been the most common cause of turbine malfunction, some OEMs are eliminating the gearbox altogether, opting instead for direct-drive models.

\subsubsection{Available Capacity}

Turbine OEMs need to ensure that their suppliers have sufficient manufacturing capacity available to fill orders. A potential supplier may be able to produce a very high-quality prototype but not have the production process or capacity in place to meet the OEM's order needs.

\subsubsection{Solid Financial Footing}

Turbine OEMs, when selecting suppliers, want to work with dependable companies that will be able to back up their products with service and warranties. In addition, OEMs want to limit transactions costs by forming long-term agreements with key suppliers, as establishing supply agreements can entail 


\section{NAVIGANT}

significant transaction costs. Suppliers with solid financial footing will be more likely to be in business in the years ahead, as turbines age and are more likely to require service.

\subsubsection{Competitive Pricing}

As turbine OEMs compete with each other as well as with the LCOE of traditional power generation sources such as coal and natural gas, they are aggressively attempting to lower costs. Therefore, the price they pay for major components is critical. As there is often a trade-off between price and quality, suppliers must work with OEMs to find the optimal balance. While suppliers in low-cost manufacturing countries such as China can often produce components at lower prices than their North American and European competitors, they can sometimes fall short in quality levels and/or delivery times. As turbine sizes increase, components get larger. Consequently, procuring certain components from geographically distant locations can be less advantageous due to transportation costs.

\subsubsection{On-Time Delivery}

Wind turbine assembly requires that the OEM has all the necessary components on hand. If a supplier offers a superior product at an attractive price, it is of little use to the OEM if it is not delivered on time. Therefore, OEMs look for suppliers with a proven record of on-time deliveries.

\subsubsection{Flexibility in Production Schedules and Ability to Meet Short Lead Times}

The incentive-driven nature of the wind sector has often created boom and bust cycles. These large swings in demand for wind turbines make production planning difficult. Suppliers do not want to be left with extra inventory. OEMs do not want to lack the necessary components to fill their orders. In selecting suppliers, OEMs will look for companies with the flexibility to ramp production up and down as needed and the ability to meet short lead times.

\subsubsection{Robust Service Organization}

In addition to requiring high levels of quality, turbine OEMs want to make sure that, in case of any problems, suppliers can provide timely service.

\subsubsection{Willingness to Engage in Joint Development with OEM}

Thousands of individual components make up a wind turbine. They must all work together for the turbine to maintain the highest levels of availability. As such, the turbine must be designed as a complete system. As turbine OEMs outsource many components, joint development with key suppliers becomes necessary. Some OEMs may evaluate potential suppliers on their willingness to engage and invest in joint development.

\subsubsection{Technology Development}

Wind turbines are getting larger, especially in offshore applications. The marine environment can increase materials challenges relative to onshore. In addition, efforts to increase performance and reduce costs can require significant R\&D efforts. Turbine OEMs often seek suppliers who have demonstrated technical innovation with their products. OEMs want suppliers who can continue to evolve with the market. 


\section{NAVIGANT}

\subsubsection{Localization/Geographic Footprint}

The geographic footprint of a supplier can be critical for an OEM. Turbine OEMs often look to reduce transaction costs by establishing long-term relationships with global suppliers. When an OEM enters a new market, it prefers to have its key suppliers follow suit.

In the offshore wind sector, a supplier's location is even more critical than in the land-based sector as components are typically larger. Nacelle assembly and pre-assembly of the rotor typically occur in coastal areas at or near ports to reduce transportation costs. Suppliers closer in proximity to an OEM's assembly plant may be preferred if they are able to increase their competitiveness in terms of delivered price and delivery times.

\subsection{Current and Future Pathways to Market}

Suppliers looking to sell components into a future U.S. offshore wind market will need to follow a similar qualification process found in other manufacturing sectors. The steps below articulate a typical supplier qualification process. Different turbine manufacturers will likely use slightly varied processes. New suppliers to the industry may require one to two years from initial contact to production.

\subsubsection{Supplier and Manufacturer Make Initial Contact}

There are a number of ways in which a turbine OEM and a component supplier can make initial contact. Most OEMs contact potential suppliers through outbound efforts. OEMs frequently conduct research using supplier databases such as ThomasNet, through supplier networks such as the Global Wind Network, or by contacting trade associations like AWEA.

Successful inbound inquiries are less frequent. Potential

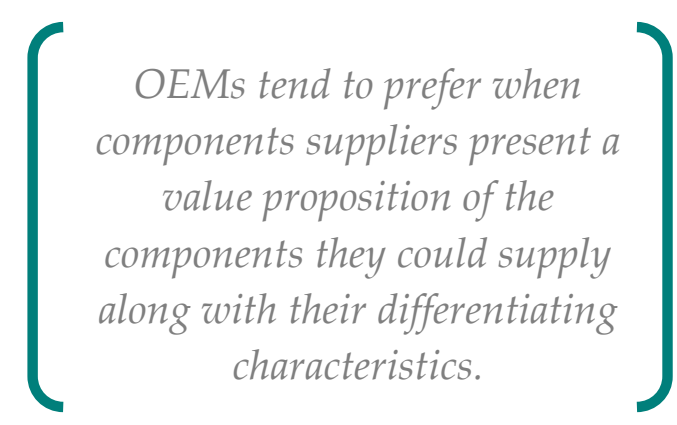
suppliers often make the mistake of contacting an OEM and asking, "What can I do for you?" With limited time to scan the market for potential suppliers, OEMs tend to prefer when components suppliers present a value proposition of the components they could supply along with the differentiating characteristics vis-à-vis potential competitors.

\subsubsection{Pre-Qualification}

If a supplier seems strong, the OEM will want to learn more about the supplier's operations and capabilities. The OEM may send the supplier a questionnaire with questions about areas such as production volumes, component sizes, industries the supplier is currently serving, and key customers. This is a self-assessment on the part of the supplier.

At this point, some OEMs may require that a potential supplier demonstrate compliance with certain international quality standards: ISO 9001:2008 (quality management), ISO 14001:2004 (environmental management), and/or OHSAS 18001 (occupational health and safety). 


\section{NAVIGANT}

\subsubsection{Confidentiality Agreement}

If the supplier looks promising after answering preliminary questions about its capabilities, the OEM will likely have the supplier sign a nondisclosure agreement. This will enable the OEM to share confidential information about its turbines with the supplier.

\subsubsection{OEM Sends Turbine Specifications to Supplier}

With a confidentiality agreement in place, the OEM will send the potential supplier drawings and specifications for the component in question. This will enable the supplier to indicate whether it has the proper equipment and capabilities to produce the component.

\subsubsection{Auditing}

The OEM will conduct tests of the supplier's product and conduct an audit of the supplier's processes. Auditing processes (e.g., production, quality assurance, and safety) in addition to products is critical for an OEM as a supplier could feasibly produce a compliant product but not have the adequate processes for performing serial production. The OEM will likely have a cross-functional team visit the supplier's facilities to perform the process audit.

\subsubsection{Prototyping}

The supplier produces a prototype or sample of the component and the OEM verifies whether the prototype is in accordance with the technical specifications.

\subsubsection{Field Testing}

If the prototype meets the expectations, the OEM will likely then test the component's performance in the field. The component may be incorporated in just a few turbines within a wind farm.

\subsubsection{Serial Production}

If field testing is successful, the OEM will likely purchase a limited batch of components from the new supplier. Although prototyping provides detailed information to turbine designers, reliability can only really be tested during a period of operation under a range of different climatic conditions. Once the robustness and reliability of the component's performance has been proven, full-scale series production begins. It may take anywhere from 1-3 years from the initial contact to series production.

\subsubsection{Monitoring}

Once a supply agreement is in place, the OEM will continue to monitor a supplier's quality levels. This typically includes all raw materials, components or services provided by the supplier. Any serious quality control issues that arise repeatedly will typically lead to the OEM removing the supplier from the supplier list and terminating the supply agreement. 


\section{NAVIGANT}

\subsection{Market Barriers}

\subsubsection{Production Planning}

\subsubsection{Low production volumes}

The wind sector and the offshore segment in particular require lower volumes than many other manufacturing sectors. This makes achieving economies of scale challenging. Part of this issue stems from the lack of standardization. Historically, turbine producers have increasingly developed their own solutions in an attempt to achieve a competitive advantage. These dedicated and specialized solutions, however, have created a challenge for the upstream supply chain. Component manufacturers struggle with a relatively large number of variants at relatively low volumes. Another cause of low production volumes is the trend toward localized manufacturing. When new wind markets show growth, turbine manufacturers often build factories in these new markets to reduce transportation costs or to comply with domestic content requirements. This geographically dispersed production limits economies of scale. An additional cause of low production volumes is the fast pace of technology advancement, including turbine sizes. While larger turbines can sometimes improve project economics, the development costs of continually manufacturing new, larger components are significant. In the end, suppliers may be reluctant to enter the market as shifting production capacity away from larger volume products may prove financially unattractive.

\subsubsection{Batch production}

The wind sector requires a relatively small batch production process with more ordering and receiving cycles, leading to high inventory turnover. The nimbleness required for this type of production can be challenging for many suppliers.

\subsubsection{Widely fluctuating demand}

The incentive-driven nature of the wind sector has often created boom and bust cycles. These large swings in demand for wind turbines make production planning difficult. Suppliers do not want to be left with extra inventory. OEMs do not want to lack the necessary components to fill their orders.

In Figure 4-3 below, it is clear that wind investments in the U.S. have dramatically declined when the PTC has been allowed to expire, specifically prior to 2000, 2002, and 2004. 
Figure 4-3. U.S. Annual Wind Capacity Additions (MW)

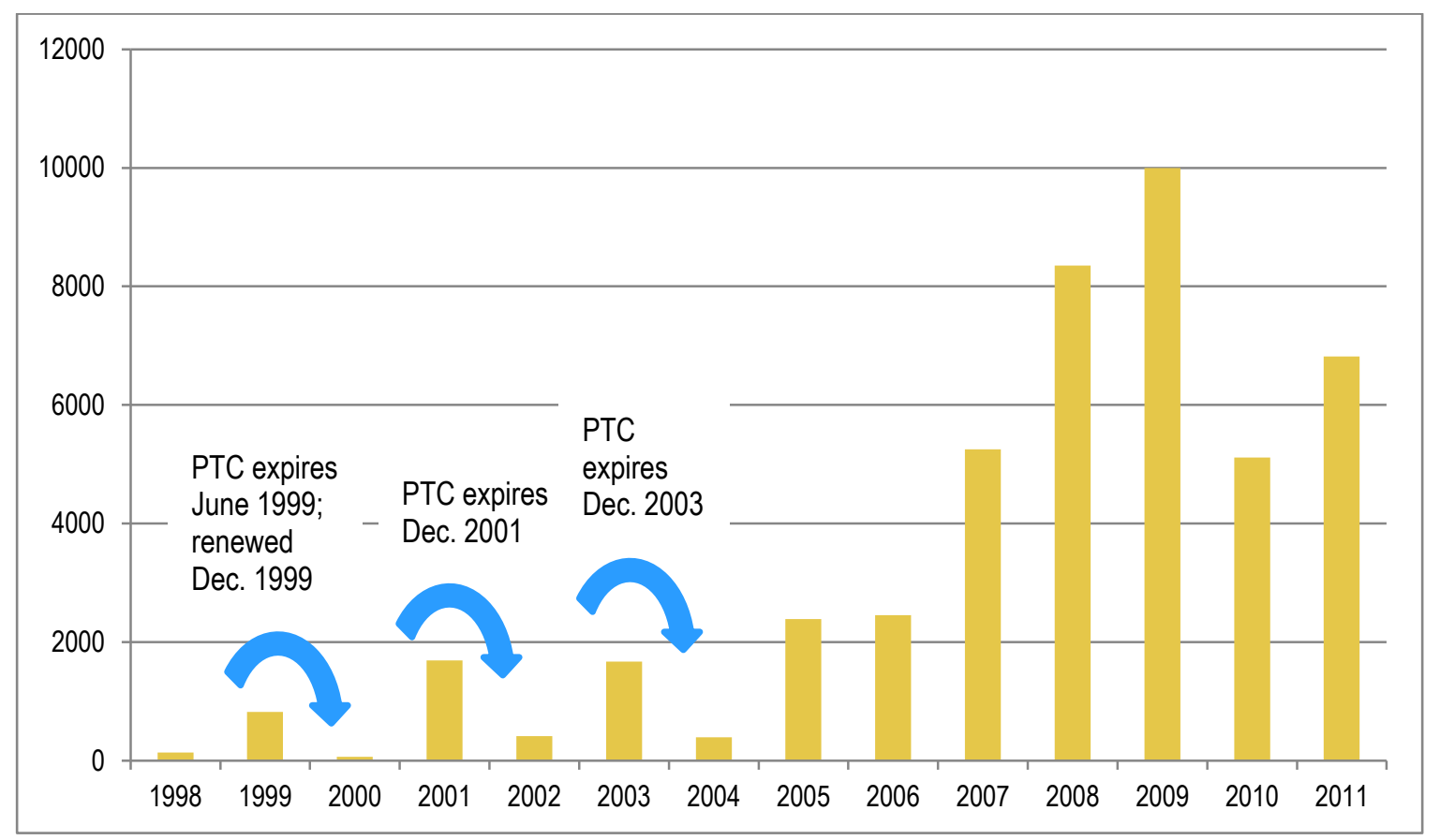

Source: AWEA

\subsubsection{Production Facilities}

\subsubsection{Equipment size}

Offshore turbines are typically larger than land-based turbines and are growing even larger. Suppliers must have manufacturing equipment large enough to produce these large components. This can often prove difficult as some castings and forgings can weigh over 10 tons.

Table 4-3. Comparison of Major Land-based and Offshore Turbine Component Weights (tons)

\begin{tabular}{lcc} 
Component & $\begin{array}{c}\text { Land-based } \\
\text { (Siemens 2.3-101) }\end{array}$ & $\begin{array}{c}\text { Offshore } \\
\text { (RePower 6M: 6.15 MW) }\end{array}$ \\
\hline Rotor & 62 & 156 \\
\hline Nacelle & 82 & 316 \\
\hline Tower & 162 & 285 \\
\hline Total Assembly & 306 & 757 \\
\hline
\end{tabular}

\subsubsection{Capital requirements}

Many potential suppliers could find it difficult to secure the capital necessary to retool a manufacturing plant for the production of offshore wind components. Lending institutions may be reluctant to make a loan for capital improvements without firm orders. 


\section{NAVIGANT}

\subsubsection{Logistics challenges}

As mentioned in Chapter 1, growth of offshore wind turbines and their components is anticipated to make it increasingly difficult, if not impossible, to move turbine components over land. Coastal manufacturing for blades and nacelle assembly as well as tower, foundation, and substructure fabrication may be an effective industry requirement in the future. As the industry moves from prototype to commercial to serial production, manufacturing facilities will likely employ increasing levels of automation to drive down defects and allow for tighter design margins in order to minimize component mass (Cohen et al. 2008). Under ideal circumstances, component storage and staging activities would occur alongside manufacturing and fabrication at an integrated manufacturing and port facility. However, this will require very large swaths of coastal land-Vestas' recently abandoned Sheerness U.K. proposed facility was planned to be on the order of 70 hectares (Vestas 2011a). Even with fully integrated manufacturing and port facilities, it is likely that component designers will be increasingly forced to consider more modular storage-oriented concepts such as segmented blades (UpWind 2011).

Future manufacturing and staging concepts could follow an incremental investment path with a set of dispersed facilities each serving a niche within the industry. To some extent this could parallel port development that has occurred in Germany along the North and Baltic Seas (Brautigam 2011). Alternatively, manufacturing and staging could follow a more centralized regional hub model along the lines of the concepts in various stages of planning in the U.K. (NLC 2010; Vestas 2011b) or potentially the German facility in Bremerhaven (Brautigam 2011). In the near-term, insufficient industry volume is likely to result in significant imports of turbines and electrical equipment, although with close analogs in the oil and gas industry, foundation and substructure equipment could be domestically sourced even with modest offshore wind demand.

\subsection{Recommendations to Remove the Identified Barriers}

\subsubsection{Strong and Consistent Market Demand}

Strong and consistent demand for offshore wind projects is the best antidote for most of the supply chain barriers. The previous chapter, Strategy for Future Development, discusses approaches for driving demand. These approaches deal with lowering the cost of offshore wind, lowering or removing technical and infrastructure-related challenges, and removing regulatory challenges involved with siting and permitting of projects.

\subsubsection{Production planning}

Thriving U.S. and global markets will create sufficient demand for new suppliers to enter the market. Consistent policy will reduce the market fluctuation and supply chain disruptions seen with the on-again off-again application of the PTC.

The PTC was allowed to expire in 2003, which led to only 397 MW in installations in 2004. The PTC was renewed in 2004 and

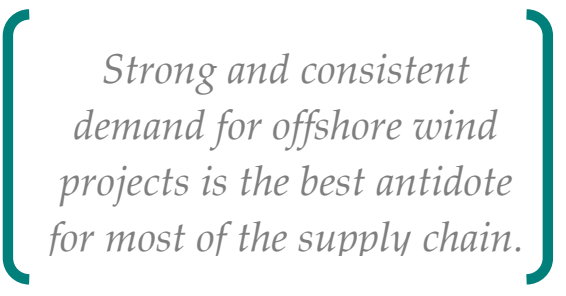




\section{NAVIGANT}

in subsequent years to keep it in effect through December 2012. Consequently, the U.S. wind market increased to over $2 \mathrm{GW}$ per year for 2005 and 2006. The market then remained between 5-10 GW between 2007 and 2011.

In 2005, Gamesa established its U.S. manufacturing presence in Pennsylvania. The lack of extension of the PTC by mid-2012, however, led Gamesa to furlough 165 workers across two plants. ${ }^{25}$ In 2007, Vestas began to open four factories in Colorado. Similar to Gamesa, it was forced to fire workers at two of its production facilities due to a lack of steady policy. ${ }^{26}$

In Spain, the wind sector claims to have lost over 10,000 jobs since 2009 due to a lack of regulatory certainty beyond 2012. ${ }^{27}$

\subsubsection{Production facilities}

Strong and consistent demand will also make it more attractive for banks to lend to suppliers who want to invest in new equipment to build the larger components required by the offshore market. With a strong backlog of orders, suppliers will find it attractive to build port-side manufacturing facilities to reduce transportation costs and improve delivery times.

In Denmark, the Port of Esbjerg's board of directors has developed a strategic plan through 2019 that includes DKK 1 billion (\$183 million) of investment for new infrastructure and reconfiguring the port's facilities to create additional space for wind turbines in a new south harbor. ${ }^{28}$ Esjberg is home to the Offshore Center Danmark, the country's official competence and innovation center for the offshore industry. Through more than 240 member companies and institutions, the Center works to develop the areas of oil and gas and offshore wind. ${ }^{29}$

In Germany, the Federal State of Bremen has stated a goal of making Bremerhaven and Bremen into the leading competence center and production area for offshore wind energy in North West Germany. ${ }^{30}$ In 2002, having recognized the emerging potential of offshore wind, the state government of Bremen decided to invest €20 million on infrastructure upgrades and other incentives to help the Port of Bremerhaven benefit from the significant wind development already approved for in the German North Sea. ${ }^{31}$ The state of Bremen was the first in northern Germany to implement such a policy for offshore

\footnotetext{
${ }^{25} \mathrm{http}$ //www.newsworks.org/index.php/local//healthscience/41109-wind-turbine-maker-gamesa-furloughing-165pa-workers

${ }^{26} \mathrm{http}: / /$ www.bizjournals.com/denver/news/2012/08/21/vestas-cuts-jobs-in-brighton-says.html

${ }^{27}$ http://www.windpowermonthly.com/channel/businessfinance/news/1132827/Gamesa-continues-Spanish-cutsfactory-closure/

${ }^{28} \mathrm{http}$ //www.investindk.com/News-and-events/News/2009/Offshore-wind-farms-mean-big-business-for-the-Portof-Esbjerg

${ }^{29} \mathrm{http}: / /$ www.offshorecenter.dk/

${ }^{30} \mathrm{http}: / / \mathrm{www} \cdot$ power-

cluster.net/AboutPOWERcluster/ProjectPartners/BremerhavenEconomicDevelopmentCompany/tabid/624/Default.a $\operatorname{spx}$

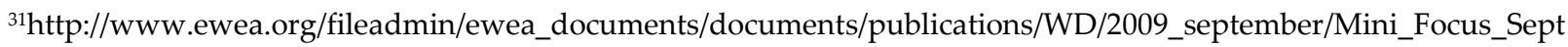
ember_2009.pdf
} 


\section{NAVIGANT}

wind. ${ }^{32}$ Policy actions have included R\&D and investment support schemes, as well as support for networks and offshore-oriented infrastructure. The state's policy reserved certain areas for offshore activities and invested in port upgrades to accommodate these activities. Regional policymakers in Bremen strongly recruited companies to relocate or set up their offshore activities in the state. In subsequent years, AREVA (Multibrid), Repower, Powerblade, and Weser Wind established manufacturing facilities at the Port of Bremerhaven.

In October 2010, to support the achievement of its renewable energy targets for 2020, the U.K.'s DECC and The Crown Estate announced a $£ 60$ million investment to establish world-class offshore wind manufacturing at ports sites. ${ }^{33}$ On publication of its country's first National Infrastructure Plan (NIP), the Prime Minister said, "We need thousands of offshore turbines in the next decade and beyond yet neither the factories nor these large port sites currently exist. And that, understandably, is putting off private investors. So we're stepping in." 34

\footnotetext{
${ }^{32} \mathrm{http}: / /$ druid8.sit.aau.dk/acc_papers/16vikj17dhdajdhyxsi7vymf446q.pdf

${ }^{33}$ http://www.decc.gov.uk/en/content/cms/news/pn10_111/pn10_111.aspx

${ }^{34}$ http://www.decc.gov.uk/en/content/cms/news/pn10_111/pn10_111.aspx 


\section{NAVIGANT}

\section{References}

Andersen, P.B.; Mac Gaunaa, C.B.; Buhl, T. (2006). "Load Alleviation on Wind Turbine Blades Using Variable Airfoil Geometry." In proceedings of the 2006 European Wind Energy Conference and Exhibition, Athens, Greece, February 27-March 2, 2006.

Ashwill, T.D. (2009). “Materials and Innovations for Large Blade Structures: Research Opportunities in Wind Energy Technology." 50th AIAA/ASME/ASCE/AHS/ASC Structures, Structural Dynamics, and Materials Conference, Palm Springs, CA, May 2009. Reston, VA: American Institute of Aeronautics and Astronautics (AIAA).

Balachander, A., A. Batchman, C. Gustafson, J. Mulligan, and M. Segraves (2011). “Transmission-Related Policy Options to Facilitate Offshore Wind in the Great Lakes," Great Lakes Wind Collaborative, April 2011. http://www.glc.org/energy/wind/publications/pdfs/Transmission-Policies-for-GLOffshore-Wind_FINAL.pdf

Bureau of Ocean Energy Management (BOEM). (2012). “Unsolicited Application for an OCS Renewable Energy Commercial Lease." http://www.boem.gov/uploadedFiles/BOEM/Renewable_Energy_Program/ State_Activities/Statoil\%20Unsolicited\%20Lease\%20Request\%20Public\%20Version.pdf. (Accessed July 2, 2012).

Berg, D.E.; Wilson, D.G.; Barone, M.F.; Resor, B.R.; Berg, J.C.; Paquette, J.A.; Zayas, J.R.; Kota, S.; Ervin, G.; Maric, D. (2009). "The Impact of Active Aerodynamic Load Control on Fatigue and Energy Capture at Low Wind Speed Sites." European Wind Energy Association. Marseille, France, March 16-19, 2009.

Bolinger, M.; Wiser, R. (2011). "Understanding Trends in Wind Turbine Prices Over the Past Decade." LBNL-5119E. Berkeley, CA: Lawrence Berkeley National Laboratory.

Brautigam, A. (2011). "German port locations for the northern European offshore wind industry." Germany Trade \& Invest GmbH. Berlin, Germany.

BTM Consult - a part of Navigant. (2010). “International Wind Energy Development - Offshore Report 2010."

http://www.navigant.com/insights/library/energy/reports/international $\% 20$ wind $\% 20$ energy $\% 20$ development $\% 20$ offshore\%20report/.

BTM Consult - a part of Navigant. (2011). “International Wind Energy Development - Supply Chain Assessment 2012-2015." http://www.navigant.com/insights/library/industry news/btm supply chain assessment/. 


\section{NAVIGANT}

BTM Consult - a part of Navigant. (2012). “International Wind Energy Development - World Market Update 2011." http://www.navigant.com/windreport/.

Buhl, T.; Gaunaa, M.; Bak, C. (2005). "Potential Load Reduction Using Airfoils with Variable Trailing Edge Geometry." Journal of Solar Energy Engineering (127:4); pp. 503-516.

BVG Associates. (2009). “Toward Round 3: Building the Offshore Wind Supply Chain." Prepared for the Crown Estate.

http://www.thecrownestate.co.uk/media/277427/towards round 3 building the offshore wind supply chain.pdf. (Accessed June 22, 2012).

BVG Associates. (2012). “Toward Round 3: The Offshore Wind Supply Chain in 2012." Prepared for the Crown Estate.

http://www.bvgassociates.co.uk/PublicationsForm.aspx?filename=http://www.bvgassociates.co. uk/Portals/0/publications/BVG\%20TCE\%20Gap\%20analysis\%202012\%20report.pdf. (Accessed June 27, 2012).

Carbon Trust. (2008). “Offshore Wind Power: Big Challenge, Big Opportunity: Maximizing the Environmental, Economic, and Security Benefits." London, U.K.: The Carbon Trust.

Chapman, J.; Lantz, E.; Denholm, P.; Felker, F.; Heath, G.; Mai, T.; Tegen, S. (2012). "Wind Energy Technologies," Chapter 11. National Renewable Energy Laboratory. Renewable Electricity Futures Study, Vol. 2, Golden, CO: National Renewable Energy Laboratory; pp. 11-1 - 11-63.

Cohen, J.; Schweizer, T.; Laxson, A.; Butterfield, S.; Schreck, S.; Fingersh, L.; Veers, P.; Ashwill, T. (2008). "Technology Improvement Opportunities for Low Wind Speed Turbines and Implications for Cost of Energy Reduction." NREL/TP-500-41036. Golden, CO: National Renewable Energy Laboratory.

Cutler, H. and Davies, S. (2007). The Impact of Specific-Sector Changes in Employment on Economic Growth, Labor Market Performance and Migration. Journal of Regional Science, 47(5) p. 935-963.

Doyle, G.; Borkowski, G.; Vansiotis, G.; Dodds, J.; Critten, S. (2011). “Costs of Low-Carbon Generation Technologies." Bristol, U.K.: Mott McDonald and the Committee on Climate Change.

Ernst \& Young. (2009). "Cost of and Financial Support for Offshore Wind." The U.K. Department of Energy and Climate Change.

European Wind Energy Association (EWEA). (2011). “Wind in our Sails, The coming of Europe's offshore wind energy industry."

http://www.ewea.org/fileadmin/ewea documents/documents/publications/reports/23420 Offsh ore report web.pdf. (Accessed June 22, 2012).

Ferioli, F.; Schoots, K; Van der Zwaan, B.C.C. (2009). “Use and limitations of learning curves for energy technology policy: A component-learning hypothesis." Energy Policy, 37: pp. 2525- 2535. 


\section{NAVIGANT}

Global Wind Energy Council (GWEC). (2012). “Global Wind Report: Annual Market Update 2011.” http://www.gwec.net/fileadmin/documents/NewsDocuments/Annual report 2011 lowres.pdf. (Accessed June 22, 2012).

Greenacre, P.; Gross, R.; Heptonstall, P. (2010). “Great expectations: The cost of offshore wind in U.K. waters - Understanding the past and projecting the future." London, U.K.: U.K. Energy Research Centre.

Johnson, S., C.P. van Dam, and D. Berg. (2008). "Active Load Control Techniques for Wind Turbines." Sandia National Laboratories. http://windpower.sandia.gov/other/084809.pdf. (Accessed June 22, 2012).

Junginger, M.; Faaij, A. Turkenburg, W.C. (2004). "Cost Reduction Prospects for Offshore Wind Farms." Wind Engineering, 28: pp. 97-118.

Lackner, M.; van Kuik, G. (2009). “A Comparison of Smart Rotor Control Approaches Using Trailing Edge Flaps and Individual Pitch Control." 47th AIAA Aerospace Sciences Meeting and Exhibit, Orlando, Florida, January 5-8, 2009. Miami, FL: AIAA.

Lantz, E.; Wiser, R.; Hand, M. (2012). “The Past and Future Cost of Wind Energy." NREL/TP-6A2053510. Golden, CO: National Renewable Energy Laboratory.

Loomis, D., J. Carlson, and J. Payne. (2010). “Illinois Wind Turbine Supply Chain Report.” Illinois State University - Center for Renewable Energy. http://renewableenergy.illinoisstate.edu/wind/publications/2010\%20FINAL\%20Wind\%20Turbin e\%20Supply\%20Chain\%20Report.pdf. (Accessed June 22, 2012).

Maples, B.; Hand, M.; Musial, W. (2010). “Comparative Assessment of Direct Drive High Temperature Superconducting Generators in Multi-Megawatt Class Wind Turbines." NREL/TP-5000-49086. Golden, CO: National Renewable Energy Laboratory.

Musial, W.; Butterfield, S. (2004). "Future for offshore wind energy in the United States." NREL CP-50036313. Golden, CO: National Renewable Energy Laboratory.

Musial, W.; Ram, B. (2010). “Large-Scale Offshore Wind Power in the United States: Assessment of Opportunities and Barriers." TP-500-40745. Golden, CO: National Renewable Energy Laboratory.

National Renewable Energy Laboratory. (2010). “Large-Scale Offshore Wind Power in the United States - Assessment of Opportunities and Barriers." http://www.nrel.gov/wind/pdfs/40745.pdf. (Accessed June 22, 2012).

National Renewable Energy Laboratory. (2012). "Renewable Electricity Futures Study.” Hand, M.M.; Baldwin, S.; DeMeo, E.; Reilly, J.M.; Mai, T.; Arent, D.; Porro, G.; Meshek, M.; Sandor, D. eds. 4 


\section{NAVIGANT}

vols. NREL/TP-6A20-52409. Golden, CO: National Renewable Energy Laboratory. http://www.nrel.gov/analysis/re futures/.

Navigant Consulting, Inc (2012). “Offshore Wind Market and Economic Analysis; Annual Market Assessment - 2012," for the U.S. Department of Energy.

Nemet, G. (2009). "Interim monitoring of cost dynamics for publicly supported energy technologies." Energy Policy, 37: 825-835.

Nielsen, P.; Lemming, J.; Morthorst, P.E.; Clausen, N.E.; Lawetz, H.; Lindboe, H.H.; James-Smith, E.; Bang, N.C.; Strøm, S.; Larsen, J. (2010). "Vindmøllers Økonomi (The Economy of Wind Power)." "EUDP 33033-0196. Prepared by EMD International, Aalborg, Denmark.

North Lincolnshire Council (NLC) (2010). “ $£ 400$ offshore wind investment - triggers 5,100 new South Humber jobs." North Lincolnshire Council Press Release. http://www.ablehumberport.com/pdfs/NLC\%20RELEASE\%208th\%20July\%202010.pdf

Ove Arup \& Partners Ltd. (ARUP). (2011). "Review of the Generation Costs and Deployment Potential of Renewable Electricity Technologies in the U.K." Department of Energy and Climate REP001, Prepared by Ove Arup \& Partners Ltd. London, U.K.

Principle Power (2011). “First WindFloat Successfully Deployed Offshore." Press Release. http://www.principlepowerinc.com/news/press_PPI_WF_deployment.html. Accessed June 20, 2012.

Siemens. (2011). "Siemens starts operating its first 6 megawatt wind turbine." Press Release. http://www.siemens.com/press/en/pressrelease/?press=/en/pressrelease/2011/renewable_energy/ ere201106070.htm. Accessed June 20, 2012.

Siemens. (2012). "Record-Size Rotor Blades Transported to Destination" Press Release. http://www.siemens.com/innovation/en/news/2012/e_inno_1226_2.htm. Accessed October 17, 2012.

Statoil. (2011). “Hywind - The World's First Full-Scale Floating Wind Turbine." http://www.statoil.com/en/TechnologyInnovation/NewEnergy/RenewablePowerProd uction/Offshore/Hywind/Pages/HywindPuttingWindPowerToTheTest.aspx. Accessed March 1, 2012.

Tegen, S.; Hand, M.; Maples, B.; Lantz, E.; Schwabe, P.; Smith, A. (2012). “2010 Cost of Wind Energy Review." NREL TP-5000-52920. Golden, CO: National Renewable Energy Laboratory.

Turkel, T. (2012). "Norwegian company touts plan for wind farm off Maine Coast." Portland Press Herald. http://www.pressherald.com/news/interest-of-wind-farm-company-runs-deep_2012-0615.html. Accessed June 20, 2012. 


\section{NAVIGANT}

UpWind. (2011). “Design Limits and Solutions for Very Large Turbines.” European Commission, Sixth Framework Programme.

U.S. Census Bureau. (2012). American Community Survey 2010, 5 Year Population File (PUMS). Retrieved fromhttp://www2.census.gov/acs2010_5yr/pums/.

U.S. Census Bureau. (2011). County Business Patterns. Retrieved from http://www.census.gov/econ/cbp/index.html.

U.S. Department of Energy (U.S. DOE). (2008). “20\% Wind Energy by 2030: Increasing Wind Energy's Contribution to U.S. Electricity Supply." DOE/GO-102008-2567. Washington, DC: U.S. DOE.

van Bussel, G.; Bierbooms, W. (2003). "The DOWEC Offshore Reference Windfarm: Analysis of Transportation for Operation and Maintenance." Wind Engineering (27:5); pp. 381-392.

van der Zwaan, B.; Rivera-Tinoco, R.; Lensink, S.; van den Oosterkamp, P. (2012). “Cost reductions for offshore wind power: Exploring the balance between scaling, learning and R\&D." Renewable Energy (41); pp. 389-393.

Vestas (2011a). "Vestas signs option agreement for land at the Port of Sheerness, Kent in the U.K." Press Release. http://www.vestas.com/en/media/news/news-display.aspx?action=3\&NewsID=2662. Accessed June 20, 2012.

Vestas. (2011b). “V164-7.0 MW turbine launched." Press Release. http://www.vestas.com/Default.aspx?ID=10332\&action=3\&NewsID=2624. Accessed June 20, 2012.

Virginia Coastal Energy Research Consortium, (2010). “Virginia Offshore Wind Studies, July 2007 to March 2010," Final Report.

http://www.vcerc.org/VCERC_Final_Report_Offshore_Wind_Studies_Full_Report_new.pdf.

Vita, L.; Paulsen, U.S.; Pedersen, T.F.; Madsen, H.A.; Rasmussen, F. (2009). “A Novel Floating Offshore Wind Turbine Concept." Proceedings of the European Wind Energy Conference. Roskilde, Denmark: Risø-DTU Technical University of Denmark.

Wiser, R.; Bolinger, M. (2011). 2010 Wind Technologies Market Report. DOE/GO-102011-3322. Washington, DC: U.S. Department of Energy Office of Energy Efficiency and Renewable Energy.

Wiser, R.; Lantz, E.; Bolinger, M.; Hand, M. (2012). "Recent Developments in the Levelized Cost of Energy From U.S. Wind Power Projects." Presentation February 2012. http://eetd.lbl.gov/ea/ems/reports/wind-energy-costs-2-2012.pdf.

Wiser, R.; Yang, Z.; Hand, M.; Hohmeyer, O.; Infield, D.; Jensen, P.H.; Nikolaev, V.; O’Malley, M.; Sinden, G.; Zervos, A. (2011). “Wind Energy. In IPCC Special Report on Renewable Energy Sources and Climate Change Mitigation" [O. Edenhofer, R. Pichs-Madruga, Y. Sokona, K. 


\section{NAVIGANT}

Seyboth, P. Matschoss, S. Kadner, T. Zwickel, P. Eickemeier, G. Hansen, S. Schlömer, C. von Stechow (eds)]. Cambridge, U.K. and New York, NY, USA: Cambridge University Press. 


\section{NAVIGANT}

\section{Appendix A. Project and Turbine Cost Assumption Details}

Table A-1. Project Capital Cost Breakdown Estimate

\begin{tabular}{|c|c|c|c|}
\hline Cost Category & Cost & $\%$ of Cost & $\begin{array}{l}\% \text { of Cost (before } \\
\text { financing) }\end{array}$ \\
\hline Turbine & $\$ 1,017,500,000$ & $33 \%$ & $38 \%$ \\
\hline Nacelle/Drivetrain & $\$ 487,500,000$ & & \\
\hline Rotor/Blades & $\$ 242,500,000$ & & \\
\hline Towers & $\$ 187,500,000$ & & \\
\hline Decommissioning bonding & $\$ 100,000,000$ & & \\
\hline \multicolumn{4}{|c|}{ Note: Includes ground transportation (to project staging area/port) and warranty terms and costs. } \\
\hline Support Structure/Foundation & $\$ 660,394,750$ & $22 \%$ & $25 \%$ \\
\hline Basic Construction (e.g., concrete, rebar, gravel) & $\$ 4,500,000$ & & \\
\hline Foundation & $\$ 86,800,000$ & & \\
\hline Substructure (steel costs) & $\$ 58,200,000$ & & \\
\hline Foundation Assembly & $\$ 326,972,640$ & & \\
\hline Substructure Assembly (assembly of pipes into structure) & $\$ 183,922,110$ & & \\
\hline Electrical Infrastructure & $\$ 364,305,800$ & $12 \%$ & $14 \%$ \\
\hline Project Collection System & $\$ 52,588,300$ & & \\
\hline HV Cable (project site to point of grid interconnection) & $\$ 89,780,000$ & & \\
\hline Converter Stations (for DC line to land) & $\$ 134,000,000$ & & \\
\hline Substation (including transportation) & $\$ 87,937,500$ & & \\
\hline Logistics and Installation & $\$ 590,421,050$ & $19 \%$ & $22 \%$ \\
\hline Turbine Erection/Installation & $\$ 189,231,600$ & & \\
\hline Electrical Infrastructure Labor & $\$ 179,434,200$ & & \\
\hline $\begin{array}{l}\text { Insurance during construction (CAR/third party liability/business } \\
\text { interruption etc.) }\end{array}$ & $\$ 67,000,000$ & & \\
\hline Ports and Staging & $\$ 125,000,000$ & & \\
\hline Air Transportation (personnel or materials) & $\$ 8,190,000$ & & \\
\hline $\begin{array}{l}\text { Marine Transportation (personnel or materials, includes vessel } \\
\text { mobilization) }\end{array}$ & $\$ 21,565,250$ & & \\
\hline Project Costs (Development/Services) & $\$ 54,794,000$ & $2 \%$ & $2 \%$ \\
\hline Management/Supervision Labor & $\$ 8,500,000$ & & \\
\hline Engineering (project/interconnection facility design) & $\$ 15,000,000$ & & \\
\hline Legal Services & $\$ 3,000,000$ & & \\
\hline Public Relations & $\$ 900,000$ & & \\
\hline Site Certificate/Permitting & $\$ 10,000,000$ & & \\
\hline Other Misc. & $\$ 17,394,000$ & & \\
\hline Construction Financing & $\$ 353,463,073$ & $12 \%$ & \\
\hline Interest during construction ( $7 \%$ of construction costs) & $\$ 178,928,512$ & & \\
\hline Due diligence costs & $\$ 16,900,000$ & & \\
\hline Reserve accounts: MRA/DSRA & $\$ 103,956,007$ & & \\
\hline Bank fees & $\$ 53,678,554$ & & \\
\hline TOTAL & & $\$ 3,040,878,673$ & $\$ 2,687,415,600$ \\
\hline
\end{tabular}

Note: Assumes a $500 \mathrm{MW}$ plant comprising $1005 \mathrm{MW}$ turbines. See Table 1-1 for additional assumptions. 


\section{NAVIGANT}

\section{Appendix B. Learning Curve and Cost-Reduction Estimates}

Learning curves have been broadly applied to land-based wind technology. A recent literature review examining 18 different studies found that among those studies completed since 2004 and focused on total capital cost and global installations, the range of estimated learning rates varied from of $9 \%-19 \%$ (Wiser et al. 2011). In the offshore space, applications of learning curves have been rarer. This is primarily a function of limited historical deployment from which to calculate a given learning rate and the significantly less mature status of the offshore market segment (Wiser et al. 2011).

However, some published estimates exist. Using wind turbine pricing data, Musial and Butterfield (2004) approximated a learning rate for offshore wind of $12 \%$. Junginger et al. (2004) determined that over a decade and a half, offshore wind capital cost and LCOE reductions could be as much as $39 \%$. Also drawing on data from analogous industries, the Carbon Trust (2008) estimated learning rates of 9\%-15\% for offshore wind. More recently, van der Zwaan et al. (2012) estimated a learning rate of only 3\% after controlling for commodity price volatility and up to $5 \%$ after controlling for upward price pressures resulting from limited offshore wind construction capacity.

Despite past reliance on learning curves to understand turbine and land-based wind costs, the approach has its limitations. First, it requires long-term historical data. In addition, as applied to wind technology, learning curves have often focused only on turbine or project capital costs even though it is the delivered cost of power-a function of both capital costs and project performance-that is most relevant (Wiser et al. 2011; Lantz et al. 2012). It could be the case that turbine performance is improving and the LCOE is falling even as capital costs remain flat or increase modestly. Such a scenario would mask improvements in the LCOE when only examining turbine pricing or capital cost trends. Also, cost reductions may not be an exclusive function of cumulative deployment. Targeted R\&D, economies of scale, and other factors may be captured by learning curves when in reality such market and industry dynamics may vary independently of cumulative deployment. Finally, learning curves (in theory) are assumed to extend indefinitely into the future when in actuality declining returns are possible (Ferioli et al. 2009; Nemet 2009).

To supplement the insights offered by learning curves, analysts have often incorporated expert insights and engineering modeling into their projections to better understand the potential for and specific sources of future cost reduction (Lantz et al. 2012; Tegen et al. 2012). The former entails querying industry executives, engineers, or other technology experts on the likely or expected impact of specific component- or system-level technology improvement opportunities. By combining estimates from a variety of experts across an array of innovations, one can gain additional insights into how the technology may change and its likely cost impact over time without requiring a long-term empirical dataset of project-level costs and performance. Of course, expert insights are also inherently subjective (Lantz et al. 2012). Engineering models can also be used to quantitatively model the impact of specific (and simultaneous) technological advancements on future material use, technology cost, and performance. Both approaches allow analysts to estimate how capital cost and performance impacts will affect the delivered cost of power. Unlike engineering models, which only examine concrete changes in 


\section{NAVIGANT}

technology, expert elicitation provides for the consideration of dynamic market variables such as industry supply and demand, commodity prices, and system-level dynamics (Lantz et al. 2012).

Learning curves, expert interviews, and engineering modeling each have strengths and weaknesses. Accordingly, future projections of offshore wind costs typically involve some combination of these three trends. In addition, analysts will at times apply declining learning rates as the technology advances and matures (EWEA 2009). Tegen et al. (2012) evaluated 25 different offshore wind cost projections published in 12 recent studies that cover both pessimistic and optimistic scenarios (see Figure B-1). Their analysis, which examined forecast changes in LCOE over two decades from 2011 to 2030, found that projections ranged from an increase in LCOE of more than $20 \%$ to a reduction of more than $50 \%$ (Tegen et al. 2012). Between these extremes, the $20^{\text {th }}$ and $80^{\text {th }}$ percentiles suggested cost reductions ranging from $17 \%$ to $47 \%$. Reductions in LCOE were observed to be most rapid from 2011 to 2020, with cost reductions falling to $2.5 \%$ per year or less by the late $2020 \mathrm{~s}$.

Figure B-1. Projected Changes in the LCOE of Offshore Wind over Time

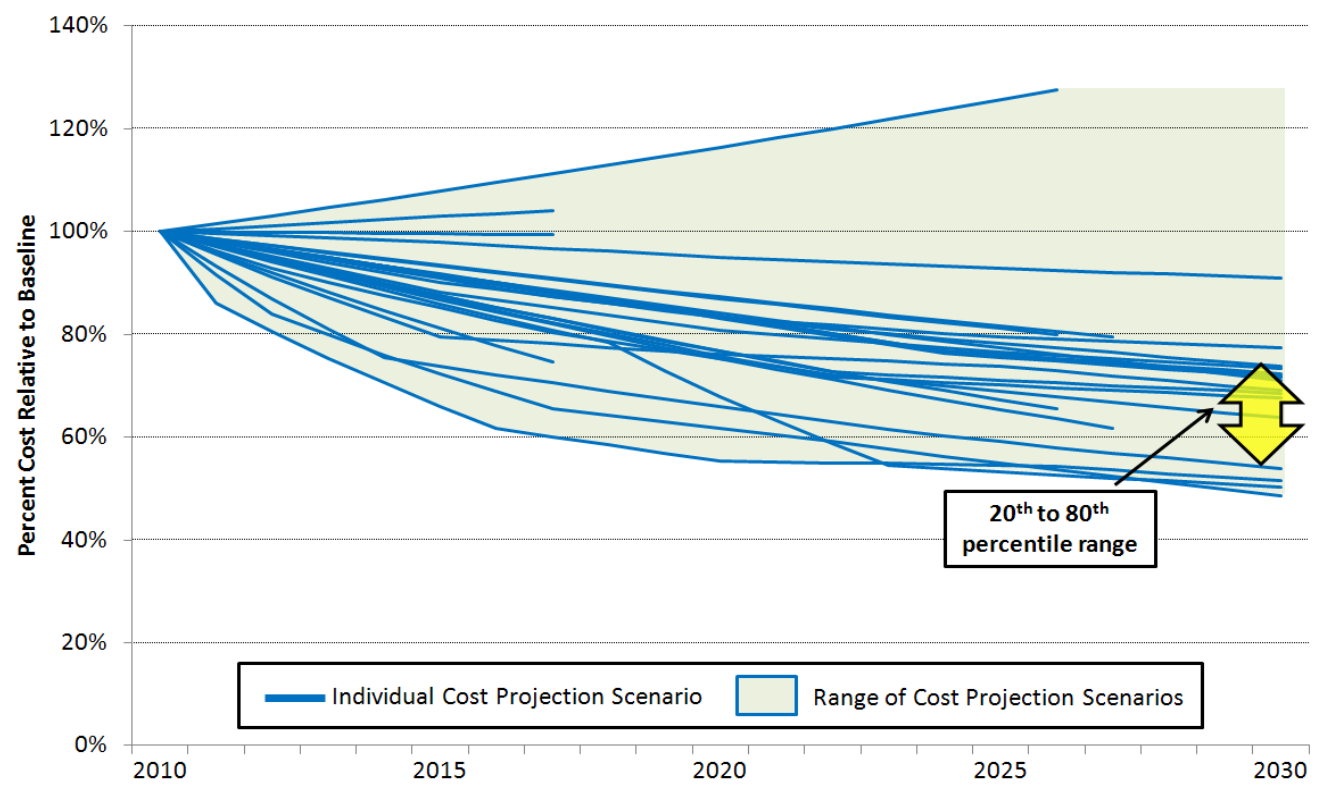

Source: Tegen et al. 2012 


\section{NAVIGANT}

\section{Appendix C. Technology Trend Ranking Methodology}

The specific innovation opportunities considered for this analysis are listed in Table C-1.

Table C-1. Technology Innovation Opportunities Considered for Ranking

\begin{tabular}{|c|c|}
\hline Technology Category & Innovation Type/Trend \\
\hline \multirow{5}{*}{ Turbine } & 5-7 MW Turbines \\
\hline & 7-10 MW Turbines \\
\hline & Hurricane tolerance \\
\hline & Sea-/surface-ice tolerance \\
\hline & Vertical-axis turbines \\
\hline \multirow{8}{*}{ Rotor Concepts } & Advanced materials (e.g., composites including carbon fiber) \\
\hline & Enhanced structural \& aerodynamic design (e.g., alternative airfoil shapes) \\
\hline & Increased use of passive controls (e.g., bend-twist coupling) \\
\hline & $\begin{array}{l}\text { Sophisticated active controls } \\
\text { (e.g., single- and partial-blade pitch mechanisms, trailing edge flaps, "smart blades") }\end{array}$ \\
\hline & Downwind rotors \\
\hline & Two-bladed rotors \\
\hline & Higher tip speed/lower acoustics (coupled with lower acoustics concerns) \\
\hline & Segmented or folding blades (to simplify transport and storage) \\
\hline \multirow{3}{*}{ Tower Concepts } & Alternative/advanced materials (e.g., composites, concrete, hybrid concrete and steel) \\
\hline & Alternative design architectures (e.g., larger diameter to reduce steel content). \\
\hline & Self-erecting towers \\
\hline \multirow{5}{*}{ Drivetrain technology } & $\begin{array}{l}\text { Distributed loads/reduced gear loading in conventional high-speed geared drivetrains } \\
\text { (e.g., Clipper multi-generator concept or Winergy's multi-duored gearbox) }\end{array}$ \\
\hline & Direct-drive generators \\
\hline & Hybrid drive - medium-speed geared drivetrains \\
\hline & Hydraulic drivetrains \\
\hline & Superconducting generators \\
\hline \multirow{2}{*}{$\begin{array}{l}\text { Power Electronics/Power } \\
\text { Conversion }\end{array}$} & Higher voltage circuitry/power converters \\
\hline & Enhanced frequency and voltage control (i.e., better, lower-cost grid service capabilities) \\
\hline \multirow{3}{*}{ Resource assessment } & Real-time resource assessment and pre-emptive turbine response to wind conditions \\
\hline & Enhanced array impacts modeling for improved micro-siting; advanced fluid dynamics models \\
\hline & Enhanced remote sensing and offshore wind resource modeling capacity \\
\hline \multirow{4}{*}{ Vessel Trends/Concepts } & Innovative blade transport/storage capabilities \\
\hline & Purpose-built dedicated vessels \\
\hline & Assembly-line vessel capabilities \\
\hline & Alternative design cable lay vessels (e.g., replaceable cable reel) \\
\hline
\end{tabular}




\begin{tabular}{|c|c|}
\hline Technology Category & Innovation Type/Trend \\
\hline \multirow{3}{*}{$\begin{array}{l}\text { Substructure/ Foundation } \\
\text { Trends }\end{array}$} & Transitional water-depth foundations (30-60m) (e.g., jackets, tripiles, tripods) \\
\hline & Single turbine floating substructures (>60m) (e.g., spar buoy, tension leg platform) \\
\hline & Multi-turbine floating foundations \\
\hline \multirow{5}{*}{ Electrical Infrastructure } & Standardized modular substations with multiple transformer capacity \\
\hline & Tow out, self-elevating substations \\
\hline & Standardized modular AC/DC convertor stations \\
\hline & HVDC trunk lines (e.g., AWC) \\
\hline & High-capacity inter-array cables \\
\hline \multirow{2}{*}{ Port Trends } & Wind exclusive berths \\
\hline & Regional hub model with quayside manufacturing and staging (e.g., Bremerhaven or Hull) \\
\hline \multirow{3}{*}{ Manufacturing } & Commercial followed by serial production volumes \\
\hline & Increased automation leading to higher component consistency and reduced failure modes \\
\hline & Innovative methods for staging and storage of blades, towers, nacelles, and foundations \\
\hline \multirow{5}{*}{ O\&M Strategy } & $\begin{array}{l}\text { Intelligent drivetrain sensors allowing for enhanced condition monitoring, self-diagnosis, and real-time load } \\
\text { response }\end{array}$ \\
\hline & Turbines designed for enhanced access and lower-cost in-situ repairs \\
\hline & Hotel type accommodation vessels or ships \\
\hline & Increased reliance on helicopters for rapid-response servicing \\
\hline & Improved weather forecasting to facilitate planned outages or downtime \\
\hline
\end{tabular}

For each innovation, respondents were asked to rank the expected impact of a particular innovation on three key variables: LCOE, probability of impact within 5 years, within 10 years, and in more than 10 years, and developable area. Rankings were assigned based on the guidance summarized below in Table C-2.

Table C-2. Summary of Impact Ranking Scheme

\begin{tabular}{|c|c|c|c|c|}
\hline & \multirow[b]{2}{*}{ Scale } & \multicolumn{3}{|c|}{ Ranking Guidance } \\
\hline & & Probability of Realization & LCOE & Developable Area/Markets \\
\hline High & 4 & $\begin{array}{l}\text { Working prototype with demonstrated economics } \\
\text { and commercial orders to support serial } \\
\text { production are in place }\end{array}$ & $\begin{array}{l}\geq 20 \% \text { reduction } \\
(\geq \$ 40 / \mathrm{MWh})\end{array}$ & $\begin{array}{c}\text { Opens new markets across the } \\
\text { globe }\end{array}$ \\
\hline Medium & 3 & Conceptual or partial scale prototype in testing & $\begin{array}{c}10 \%<x<20 \% \text { reduction } \\
\quad(\$ 20-\$ 40 / \mathrm{MWh})\end{array}$ & Opens up $1-2$ new regional markets \\
\hline Low & 2 & $\begin{array}{l}\text { Basic design work being done by commercial } \\
\text { companies }\end{array}$ & $\begin{array}{c}1 \%<x<10 \%(\$ 10- \\
\$ 20 / M W h)\end{array}$ & $\begin{array}{l}\text { Opens up new portions of an } \\
\text { existing regional market }\end{array}$ \\
\hline Zero & 1 & Not expected to result in change in technology & No expected change & $\begin{array}{l}\text { Does not impact developable } \\
\text { area/markets }\end{array}$ \\
\hline
\end{tabular}

Respondents were asked to rank each primary variable independently. Probability of impact was intended to capture the likelihood of realization, long-run impact to LCOE was intended to capture the fully optimized commercialized impact on LCOE regardless of the likelihood of success, and impact to 


\section{NAVIGANT}

developable area was intended to capture the ability of a specific innovation to open up new areas to development regardless of likelihood or impacts to cost. Respondents were also asked to rank the probability of impact independently for each time period noting that rankings for later time periods should not fall below the probability of impact assigned to the immediately preceding time period (i.e., if an innovation his high probable within 5 years it will not be less probable in 10 years). Respondents were also asked to provide some data on the presumed source of cost reduction (i.e., that element of offshore wind costs that will be affected). A simple binary "yes" or "no" as to whether a specific innovation could be anticipated to affect materials use, installation costs, financing cost, performance or efficiency, or operations expenditures was solicited.

If a specific innovation was not ranked by a respondent it was not considered in the analysis results. After collecting the responses, the data were cleaned of erroneous inputs and innovations that were not ranked by a given respondent were removed. The data were averaged across all respondents for each innovation. In addition to computing an average response for each variable a composite ranking or score was determined that considered the impact across the three key variables (impact to LCOE, impact to developable area, and probability of impact) for each of the time periods that the probability of realization was reported. This resulted in a combined composite score for each innovation within the next 5 years, within the next 10 years, and for more than 10 years. All scores were converted to an indexed value (between 0-1) in order to facilitate comparisons among the various responses and more clearly differentiate the level of impact anticipated by this sample of industry analysts. 


\section{Appendix D.Assumptions Supporting Supply Chain Analysis}

\section{D.1 Detailed Deployment Scenario Assumptions}

Table D-1. Technology Profile Key for Deployment Scenarios

\begin{tabular}{|c|c|c|c|c|c|}
\hline Metric & $\begin{array}{c}\text { Today's } \\
\text { Standard } \\
\text { Technology }\end{array}$ & $\begin{array}{l}\text { Next-Generation } \\
\text { Technology }\end{array}$ & $\begin{array}{c}\text { Future } \\
\text { Advanced } \\
\text { Technology }\end{array}$ & $\begin{array}{l}\text { 1st Generation } \\
\text { Floating } \\
\text { Technology* }\end{array}$ & $\begin{array}{c}\text { 2nd Generation } \\
\text { Floating } \\
\text { Technology }\end{array}$ \\
\hline Nameplate Capacity (MW) & $3-6$ & $5-7$ & $7-10$ & $2-5$ & $7-10$ \\
\hline Hub Height (meters) & $70-90$ & $>90$ & $>100$ & $70-90$ & $>100$ \\
\hline Rotor Diameter (meters) & $90-130$ & $120-170$ & $150-225$ & $90-110$ & $150-225$ \\
\hline Water Depth (meters) & $10-40$ & $10-50$ & $10-60$ & $>60$ & $>60$ \\
\hline Monopile Foundations & yes & no & no & $\mathrm{n} / \mathrm{a}$ & $\mathrm{n} / \mathrm{a}$ \\
\hline Jacket Foundations & yes & yes & yes & $\mathrm{n} / \mathrm{a}$ & $\mathrm{n} / \mathrm{a}$ \\
\hline Tripod Foundations & yes & yes & yes & $\mathrm{n} / \mathrm{a}$ & $\mathrm{n} / \mathrm{a}$ \\
\hline Gravity Base Foundations & yes & yes & yes & $\mathrm{n} / \mathrm{a}$ & $\mathrm{n} / \mathrm{a}$ \\
\hline Proximity to Staging Area** & $<100$ miles & $>100$ miles & $>100$ miles & $<100$ miles & $>100$ miles \\
\hline Proximity to Interconnection ${ }^{* *}$ & $<50$ miles & $>50$ miles & $>50$ miles & $<50$ miles & $>50$ miles \\
\hline Proximity to Service Port** & $<30$ miles & $>30$ miles & $>30$ miles & $<30$ miles & $>30$ miles \\
\hline Project Size (MW) & $200-300$ & $500-1,000$ & $>1,000$ & $5-10$ & $>1,000$ \\
\hline Max Nacelle Weight*** & $\begin{array}{l}215 \text { metric tons }(5 \\
\text { MW) }\end{array}$ & $\begin{array}{l}410 \text { metric tons }(7 \\
\mathrm{MW})\end{array}$ & $\begin{array}{l}650 \text { metric tons } \\
(10 \mathrm{MW})\end{array}$ & $\begin{array}{l}215 \text { metric tons }(5 \\
\text { MW) }\end{array}$ & $\begin{array}{l}550 \text { metric tons } \\
(10 \mathrm{MW})\end{array}$ \\
\hline \multicolumn{6}{|l|}{ Max Nacelle Footprint } \\
\hline \multicolumn{6}{|c|}{ *Proof of commercial viability (one step from prototype testing) } \\
\hline \multicolumn{6}{|c|}{$\begin{array}{l}\text { **Based loosely on staging area distances for planned German installations but recognizing that US installations are likely to be closer to } \\
\text { shore }\end{array}$} \\
\hline \multicolumn{6}{|c|}{$\begin{array}{l}\text { ***The nacelle is typically the heaviest component, however heavier lifts may be required depending on the number of tower sections and the } \\
\text { installation method (e.g., total turbine lift) }\end{array}$} \\
\hline
\end{tabular}


Table D-2. Modeled Incremental Capacity Additions (MW) by Region: High-Growth Scenario

\begin{tabular}{|c|c|c|c|c|c|c|}
\hline Year & $\begin{array}{l}\text { Atlantic } \\
\text { (North) }\end{array}$ & $\begin{array}{l}\text { Atlantic } \\
\text { (South) }\end{array}$ & $\begin{array}{l}\text { Great } \\
\text { Lakes }\end{array}$ & Gulf Coast & $\begin{array}{l}\text { Pacific } \\
\text { Coast }\end{array}$ & TOTAL \\
\hline 2015 & 192 & 108 & 50 & 150 & 0 & 500 \\
\hline 2016 & 255 & 145 & 75 & 150 & 0 & 625 \\
\hline 2017 & 383 & 217 & 125 & 175 & 50 & 950 \\
\hline 2018 & 479 & 271 & 200 & 175 & 100 & 1,225 \\
\hline 2019 & 575 & 325 & 250 & 175 & 250 & 1,575 \\
\hline 2020 & 671 & 379 & 300 & 175 & 600 & 2,125 \\
\hline 2021 & 798 & 452 & 350 & 225 & 750 & 2,575 \\
\hline 2022 & 990 & 560 & 400 & 275 & 900 & 3,125 \\
\hline 2023 & 1,182 & 668 & 450 & 325 & 1,050 & 3,675 \\
\hline 2024 & 1,373 & 777 & 500 & 375 & 1,200 & 4,225 \\
\hline 2025 & 1,565 & 885 & 550 & 425 & 1,350 & 4,775 \\
\hline 2026 & 1,693 & 957 & 550 & 475 & 1,500 & 5,175 \\
\hline 2027 & 1,820 & 1,030 & 550 & 475 & 1,650 & 5,525 \\
\hline 2028 & 1,948 & 1,102 & 550 & 475 & 1,800 & 5,875 \\
\hline 2029 & 1,980 & 1,120 & 550 & 475 & 1,900 & 6,025 \\
\hline 2030 & 1,980 & 1,120 & 550 & 475 & 1,900 & 6,025 \\
\hline 2020 Cumulative (GW) & 2.6 & 1.4 & 1.0 & 1.0 & 1.0 & 7.0 \\
\hline 2030 Cumulative (GW) & 17.9 & 10.1 & 6.0 & 5.0 & 15.0 & 54.0 \\
\hline
\end{tabular}


Table D-3. Modeled Incremental Capacity Additions (MW) by Region: Moderate-Growth Scenario

\begin{tabular}{ccccccc}
\hline Year & $\begin{array}{c}\text { Atlantic } \\
\text { (North) }\end{array}$ & $\begin{array}{c}\text { Atlantic } \\
\text { (South) }\end{array}$ & $\begin{array}{c}\text { Great } \\
\text { Lakes }\end{array}$ & Gulf Coast & $\begin{array}{c}\text { Pacific } \\
\text { Coast }\end{array}$ & TOTAL \\
\hline $\mathbf{2 0 1 5}$ & 123 & 27 & 50 & 50 & 0 & $\mathbf{2 5 0}$ \\
\hline $\mathbf{2 0 1 6}$ & 164 & 36 & 50 & 50 & 0 & $\mathbf{3 0 0}$ \\
\hline $\mathbf{2 0 1 7}$ & 225 & 50 & 75 & 75 & 50 & $\mathbf{4 7 5}$ \\
\hline $\mathbf{2 0 1 8}$ & 287 & 63 & 75 & 75 & 100 & $\mathbf{6 0 0}$ \\
\hline $\mathbf{2 0 1 9}$ & 348 & 77 & 100 & 100 & 150 & $\mathbf{7 7 5}$ \\
\hline $\mathbf{2 0 2 0}$ & 492 & 108 & 150 & 150 & 200 & $\mathbf{1 , 1 0 0}$ \\
\hline $\mathbf{2 0 2 1}$ & 553 & 122 & 200 & 200 & 300 & $\mathbf{1 , 3 7 5}$ \\
\hline $\mathbf{2 0 2 2}$ & 614 & 136 & 250 & 250 & 400 & $\mathbf{1 , 6 5 0}$ \\
\hline $\mathbf{2 0 2 3}$ & 676 & 149 & 300 & 300 & 500 & $\mathbf{1 , 9 2 5}$ \\
\hline $\mathbf{2 0 2 4}$ & 737 & 163 & 350 & 350 & 600 & $\mathbf{2 , 2 0 0}$ \\
\hline $\mathbf{2 0 2 5}$ & 799 & 176 & 400 & 400 & 700 & $\mathbf{2 , 4 7 5}$ \\
\hline $\mathbf{2 0 2 6}$ & 860 & 190 & 400 & 400 & 800 & $\mathbf{2 , 6 5 0}$ \\
\hline $\mathbf{2 0 2 7}$ & 922 & 203 & 400 & 400 & 900 & $\mathbf{2 , 8 2 5}$ \\
\hline $\mathbf{2 0 2 8}$ & 983 & 217 & 400 & 400 & 1,000 & $\mathbf{3 , 0 0 0}$ \\
\hline $\mathbf{2 0 2 9}$ & 1,024 & 226 & 400 & 400 & 1,100 & $\mathbf{3 , 1 5 0}$ \\
\hline $\mathbf{2 0 3 0}$ & 1,024 & 226 & 400 & 400 & 1,200 & $\mathbf{3 , 2 5 0}$ \\
\hline $\mathbf{2 0 2 0}$ Cumulative (GW) & $\mathbf{1 . 6}$ & $\mathbf{0 . 4}$ & $\mathbf{0 . 5}$ & $\mathbf{0 . 5}$ & $\mathbf{0 . 5}$ & $\mathbf{3 . 5}$ \\
\hline $\mathbf{2 0 3 0}$ Cumulative (GW) & $\mathbf{9 . 8}$ & $\mathbf{2 . 2}$ & $\mathbf{4 . 0}$ & $\mathbf{4 . 0}$ & $\mathbf{8 . 0}$ & $\mathbf{2 8 . 0}$ \\
\hline
\end{tabular}


Table D-4. Modeled Incremental Capacity Additions (MW) by Region: Low-Growth Scenario

\begin{tabular}{|c|c|c|c|c|c|c|}
\hline Year & $\begin{array}{l}\text { Atlantic } \\
\text { (North) }\end{array}$ & $\begin{array}{l}\text { Atlantic } \\
\text { (South) }\end{array}$ & $\begin{array}{l}\text { Great } \\
\text { Lakes }\end{array}$ & Gulf Coast & $\begin{array}{l}\text { Pacific } \\
\text { Coast }\end{array}$ & TOTAL \\
\hline 2015 & 118 & 32 & 0 & 0 & 0 & 150 \\
\hline 2016 & 118 & 32 & 0 & 0 & 0 & 150 \\
\hline 2017 & 118 & 32 & 0 & 0 & 0 & 150 \\
\hline 2018 & 138 & 37 & 0 & 0 & 0 & 175 \\
\hline 2019 & 138 & 37 & 0 & 0 & 0 & 175 \\
\hline 2020 & 158 & 42 & 0 & 0 & 0 & 200 \\
\hline 2021 & 237 & 63 & 50 & 50 & 0 & 400 \\
\hline 2022 & 316 & 85 & 50 & 50 & 0 & 500 \\
\hline 2023 & 394 & 106 & 50 & 75 & 0 & 625 \\
\hline 2024 & 473 & 127 & 75 & 100 & 0 & 775 \\
\hline 2025 & 532 & 143 & 100 & 105 & 0 & 880 \\
\hline 2026 & 592 & 158 & 110 & 120 & 0 & 980 \\
\hline 2027 & 651 & 174 & 125 & 125 & 0 & 1,075 \\
\hline 2028 & 710 & 190 & 140 & 125 & 0 & 1,165 \\
\hline 2029 & 808 & 217 & 150 & 125 & 0 & 1,300 \\
\hline 2030 & 808 & 217 & 150 & 125 & 0 & 1,300 \\
\hline 2020 Cumulative (GW) & 0.8 & 0.2 & 0.0 & 0.0 & 0.0 & 1.0 \\
\hline 2030 Cumulative (GW) & 6.3 & 1.7 & 1.0 & 1.0 & 0.0 & 10.0 \\
\hline
\end{tabular}




\section{NAVIGANT}

\section{D.2 Component and Material Requirement Assumptions}

Table D-5. Component and Material Assumptions Used to Estimate Market Sizes (by Technology Profile)

\begin{tabular}{|c|c|c|c|c|c|c|}
\hline Component & Unit & $\begin{array}{l}\text { Today's } \\
\text { Standard }\end{array}$ & Next Generation & Future Advanced & $\begin{array}{l}1^{\text {st }} \text { Generation } \\
\text { Floating }\end{array}$ & $\begin{array}{c}2^{\text {nd }} \text { Generation } \\
\text { Floating }\end{array}$ \\
\hline Scenario Year (High and Medium Growth) & & $2015-2017$ & $2018-2021$ & $2022-2030$ & $2015-2017$ & $2018-2030$ \\
\hline Scenario Year (Low Growth) & & $2015-2017$ & $2018-2030$ & $\mathrm{~N} / \mathrm{A}$ & $\mathrm{N} / \mathrm{A}$ & $\mathrm{N} / \mathrm{A}$ \\
\hline Turbine Size (Average) & MW & 4 & 6 & 8 & 4 & 8 \\
\hline Average Project Size & MW & 250 & 750 & 1000 & 8 & 1000 \\
\hline \multicolumn{7}{|l|}{ Rotors/Blades } \\
\hline Rotor Diameter (Average) & meters & 110 & 150 & 175 & 110 & 175 \\
\hline Share of Blades: All-glass Fiber & $\%$ & $30 \%$ & $50 \%$ & $20 \%$ & $30 \%$ & $20 \%$ \\
\hline Overall weight per blade & tonnes/blade & 16.00 & 26 & 43.75 & 16.00 & 43.75 \\
\hline Resin (weight per blade) & tonnes/blade & 6.40 & 10.40 & 17.50 & 6.40 & 17.5 \\
\hline Glass Fiber (weight per blade) & tonnes/blade & 8.48 & 13.78 & 23.19 & 8.48 & 23.1875 \\
\hline Other (cores, metal fittings) & tonnes/blade & 1.12 & 1.82 & 3.06 & 1.12 & 3.06 \\
\hline Share of Blades - Carbon Fiber & $\%$ & $70 \%$ & $50 \%$ & $80 \%$ & $70 \%$ & $80 \%$ \\
\hline Overall weight per blade & tonnes/blade & 12.8 & 26 & 35 & 12.8 & 35 \\
\hline Resin (weight per blade) & tonnes/blade & 6.4 & 10.4 & 17.50 & 6.4 & 17.5 \\
\hline Glass Fiber (weight per blade) & tonnes/blade & 4 & 6.5 & 10.94 & 4 & 10.94 \\
\hline Carbon Fiber (weight per blade) & tonnes/blade & 1.28 & 2.08 & 3.50 & 1.28 & 3.5 \\
\hline Other (cores, metal fittings) & tonnes/blade & 1.12 & 1.82 & 3.06 & 1.12 & 3.06 \\
\hline Share of Blades - Total Check & $\%$ & $100 \%$ & $100 \%$ & $100 \%$ & $100 \%$ & $100 \%$ \\
\hline \multicolumn{7}{|l|}{ Drivetrains } \\
\hline \% Conventional Gearbox (no Permanent Magnets) & $\%$ & $90 \%$ & $50 \%$ & $15 \%$ & $90 \%$ & $15 \%$ \\
\hline$\%$ Gearbox w/ medium or high-speed PMG & $\%$ & $10 \%$ & $30 \%$ & $45 \%$ & $10 \%$ & $45 \%$ \\
\hline \% Direct Drive w/ PMG & $\%$ & $0 \%$ & $20 \%$ & $40 \%$ & $0 \%$ & $40 \%$ \\
\hline Bearings & & & & & & \\
\hline
\end{tabular}




\section{NAVIGANT}

\begin{tabular}{|c|c|c|c|c|c|c|}
\hline Component & Unit & $\begin{array}{l}\text { Today's } \\
\text { Standard }\end{array}$ & Next Generation & Future Advanced & $\begin{array}{c}1^{\text {st }} \text { Generation } \\
\text { Floating }\end{array}$ & $\begin{array}{c}2^{\text {nd }} \text { Generation } \\
\text { Floating }\end{array}$ \\
\hline Number of Slewing Bearings per Turbine (Pitch) & \#/turbine & 3 & 3 & 3 & 3 & 3 \\
\hline Number of Slewing Bearings per Turbine (Yaw) & \#/turbine & 1 & 1 & 1 & 1 & 1 \\
\hline \multicolumn{7}{|l|}{ Number of Other Bearings (shaft, generator, gearbox) } \\
\hline for Conventional Gearbox & \#/turbine & 6 & 6 & 6 & 6 & 6 \\
\hline for Geared-PMG Gearbox & \#/turbine & 6 & 6 & 6 & 6 & 6 \\
\hline for Direct-Drive Generator & \#/turbine & 3 & 3 & 3 & 3 & 3 \\
\hline \multicolumn{7}{|l|}{ Towers } \\
\hline Tower Height & meters & 86 & 100 & 120 & 86 & 120 \\
\hline Assumed Tower Head Mass & tonnes/turbine & 245 & 350 & 550 & 245 & 550 \\
\hline For floating foundations & & & & & & 0 \\
\hline Steel (average weight per tower) & tonnes/turbine & 385 & 748 & 1050 & 385 & 1050 \\
\hline \multicolumn{7}{|l|}{ For grounded foundations } \\
\hline \% Tubular/Conical Steel & $\%$ & $100 \%$ & $100 \%$ & $90 \%$ & $\mathrm{~N} / \mathrm{A}$ & $\mathrm{N} / \mathrm{A}$ \\
\hline Steel (average weight per tower) & tonnes/turbine & 385 & 748 & 1050 & $\mathrm{~N} / \mathrm{A}$ & $\mathrm{N} / \mathrm{A}$ \\
\hline$\%$ Hybrid Steel/Concrete & $\%$ & $0 \%$ & $0 \%$ & $10 \%$ & $\mathrm{~N} / \mathrm{A}$ & $\mathrm{N} / \mathrm{A}$ \\
\hline Steel (average weight per tower) & tonnes/turbine & N/A & $N / A$ & 350 & $\mathrm{~N} / \mathrm{A}$ & $\mathrm{N} / \mathrm{A}$ \\
\hline Concrete (average weight per tower) & tonnes/turbine & N/A & $N / A$ & 900 & $\mathrm{~N} / \mathrm{A}$ & $\mathrm{N} / \mathrm{A}$ \\
\hline \multicolumn{7}{|l|}{ Foundation/Substructure } \\
\hline Water Depth (average design depth) & meters & 20 & 25 & 30 & $>60$ & $>60$ \\
\hline \multicolumn{7}{|l|}{ Monopile } \\
\hline Steel (weight per foundation) & tonnes/turbine & 780 & 1820 & 1820 & $\mathrm{~N} / \mathrm{A}$ & $\mathrm{N} / \mathrm{A}$ \\
\hline Secondary Steel (weight per foundation) & tonnes/turbine & 25 & 25 & 25 & $\mathrm{~N} / \mathrm{A}$ & $\mathrm{N} / \mathrm{A}$ \\
\hline \multicolumn{7}{|l|}{ Gravity Base } \\
\hline Design 1 (GL GH/NREL) - Steel (weight per foundation) & tonnes/turbine & 746 & 857 & 1591 & $\mathrm{~N} / \mathrm{A}$ & $\mathrm{N} / \mathrm{A}$ \\
\hline Design 1 (GL GH/NREL) - Concrete (weight per foundation) & tonnes/turbine & 2869 & 3295 & 6118 & $\mathrm{~N} / \mathrm{A}$ & $\mathrm{N} / \mathrm{A}$ \\
\hline Design 1 (GL GH/NREL) - Ballast (usually sand) (weight per foundation) & tonnes/turbine & 3148 & 3774 & 7541 & $\mathrm{~N} / \mathrm{A}$ & $\mathrm{N} / \mathrm{A}$ \\
\hline
\end{tabular}




\section{NAVIGANT}

\begin{tabular}{|c|c|c|c|c|c|c|}
\hline Component & Unit & $\begin{array}{l}\text { Today's } \\
\text { Standard }\end{array}$ & Next Generation & Future Advanced & $\begin{array}{c}1^{\text {st }} \text { Generation } \\
\text { Floating }\end{array}$ & $\begin{array}{c}2^{\text {nd }} \text { Generation } \\
\text { Floating }\end{array}$ \\
\hline Design 2 (COWI) - Steel (weight per foundation) & tonnes/turbine & 212 & 250 & 300 & $\mathrm{~N} / \mathrm{A}$ & $\mathrm{N} / \mathrm{A}$ \\
\hline Design 2 (COWI) - Concrete (weight per foundation) & tonnes/turbine & 3700 & 5000 & 6000 & N/A & $\mathrm{N} / \mathrm{A}$ \\
\hline Design 2 (COWI) - Ballast (usually sand) (weight per foundation) & tonnes/turbine & 3148 & 3774 & 7541 & $\mathrm{~N} / \mathrm{A}$ & $\mathrm{N} / \mathrm{A}$ \\
\hline Secondary Steel (weight per foundation) & tonnes/turbine & 25 & 25 & 25 & $\mathrm{~N} / \mathrm{A}$ & $\mathrm{N} / \mathrm{A}$ \\
\hline \multicolumn{7}{|l|}{ Jacket (e.g., Talisman) } \\
\hline Primary Steel (weight per foundation) & tonnes/turbine & 392 & 577.5 & 763 & $\mathrm{~N} / \mathrm{A}$ & $\mathrm{N} / \mathrm{A}$ \\
\hline Secondary Steel (weight per foundation) & tonnes/turbine & 70.4 & 69.4 & 73.4 & $\mathrm{~N} / \mathrm{A}$ & $\mathrm{N} / \mathrm{A}$ \\
\hline \multicolumn{7}{|l|}{ Floating (water >60m) } \\
\hline Steel (weight per foundation) - Low Estimate & tonnes/turbine & N/A & $\mathrm{N} / \mathrm{A}$ & $N / A$ & 1000 & 1000 \\
\hline Steel (weight per foundation) - High Estimate & tonnes/turbine & N/A & N/A & N/A & 8000 & 8000 \\
\hline Secondary Steel (weight per foundation) & tonnes/turbine & $N / A$ & $\mathrm{~N} / \mathrm{A}$ & $\mathrm{N} / \mathrm{A}$ & 25 & 25 \\
\hline \multicolumn{7}{|l|}{ Castings (hubs, main frames) } \\
\hline \# of large castings per turbine & \#/turbine & 4 & 4 & 4 & 4 & 4 \\
\hline Cast iron weight (per MW) & tonnes/MW & 26.2 & 30.3 & 33.2 & 26.2 & 33.2 \\
\hline Cast iron weight (per turbine) & tonnes/turbine & 104.8 & 181.8 & 265.6 & 104.8 & 265.6 \\
\hline \multicolumn{7}{|l|}{ Forgings (main shafts, large flanges and rings) } \\
\hline Steel alloy weight (per MW) & tonnes/MW & 13.9 & 15.9 & 17.3 & 13.9 & 17.3 \\
\hline Forgings (tonnes) per turbine & tonnes/turbine & 55.6 & 95.4 & 138.4 & 55.6 & 138.4 \\
\hline \multicolumn{7}{|l|}{ Cable } \\
\hline \multicolumn{7}{|l|}{ Internal Cable between Turbines } \\
\hline Cable required per turbine & meters/turbine & 1137 & 2068 & 2784 & 1137 & 2784 \\
\hline \multicolumn{7}{|l|}{ Export Cable } \\
\hline Average Distance to Shore & miles/project & 30 & 50 & 75 & 30 & 75 \\
\hline \multicolumn{7}{|l|}{ Substations } \\
\hline MW per substation & MW/unit & 200 & 400 & 500 & 200 & 500 \\
\hline Substations per Project & \#/project & 2 & 2 & 2 & 1 & 2 \\
\hline
\end{tabular}




\section{NAVIGANT}

\section{D.3 Approach to Top-Down Estimates of Component Values}

For a component-level breakdown of turbine capital costs, the team did not attempt an independent bottom-up analysis. Ideally, such cost breakdowns would rely upon a query of developers and suppliers involved in previously installed projects; however, no projects have yet been installed in U.S. waters. Other potential approaches the team considered-extrapolating possible offshore turbine costs from land-based turbine cost models or soliciting manufacturer and developer estimates for a hypothetical offshore turbine design-raised reliability concerns. Instead, the team relied on a recent analysis conducted for the U.K. offshore wind market by BVG Associates (BVG 2010). Importantly, that report used the same general plant (500 MW) and turbine capacity (5 MW) assumptions as this study. By adding up the individual component cost estimates listed in the report, the team was able to generate a detailed turbine cost breakdown. Table D-6 shows the detailed cost breakdown from the BVG study. 


\section{NAVIGANT}

Table D-6. Detailed Estimate of Turbine Capital Costs by Component for the U.K. Market (2010£)

\begin{tabular}{|c|c|c|c|c|c|}
\hline \multirow[b]{2}{*}{ Component } & \multicolumn{2}{|c|}{ Cost (2010£) } & \multicolumn{3}{|c|}{ Share } \\
\hline & Low & High & Low & High & Average \\
\hline \multicolumn{6}{|l|}{ Nacelle } \\
\hline Bedplate & 100,000 & 120,000 & $2.1 \%$ & $2.4 \%$ & $2.3 \%$ \\
\hline Main bearing & 60,000 & 80,000 & $1.3 \%$ & $1.6 \%$ & $1.4 \%$ \\
\hline Main shaft & 100,000 & 100,000 & $2.1 \%$ & $2.0 \%$ & $2.1 \%$ \\
\hline Gearbox & 700,000 & $1,000,000$ & $14.9 \%$ & $20.0 \%$ & $17.5 \%$ \\
\hline Generator & 200,000 & 250,000 & $4.3 \%$ & $5.0 \%$ & $4.6 \%$ \\
\hline Power take off & 400,000 & 400,000 & $8.5 \%$ & $8.0 \%$ & $8.2 \%$ \\
\hline Control system & 70,000 & 70,000 & $1.5 \%$ & $1.4 \%$ & $1.4 \%$ \\
\hline Yaw system & 100,000 & 100,000 & $2.1 \%$ & $2.0 \%$ & $2.1 \%$ \\
\hline Yaw bearing & 40,000 & 50,000 & $0.9 \%$ & $1.0 \%$ & $0.9 \%$ \\
\hline Auxiliary system & 53,100 & 65,100 & $1.1 \%$ & $1.3 \%$ & $1.2 \%$ \\
\hline Nacelle cover & 60,000 & 90,000 & $1.3 \%$ & $1.8 \%$ & $1.5 \%$ \\
\hline Fasteners & 10,000 & 15,000 & $0.2 \%$ & $0.3 \%$ & $0.3 \%$ \\
\hline Monitoring System & 10,000 & 20,000 & $0.2 \%$ & $0.4 \%$ & $0.3 \%$ \\
\hline Other & 596,900 & 139,900 & $12.7 \%$ & $2.8 \%$ & $7.6 \%$ \\
\hline Rotor \& Blades & $1,200,000$ & $1,500,000$ & & & \\
\hline Blades & 750,000 & $1,050,000$ & $16.0 \%$ & $21.0 \%$ & $18.6 \%$ \\
\hline Hub Casting & 80,000 & 80,000 & $1.7 \%$ & $1.6 \%$ & $1.6 \%$ \\
\hline Blade Bearings & 40,000 & 50,000 & $0.9 \%$ & $1.0 \%$ & $0.9 \%$ \\
\hline Pitch System & 100,000 & 150,000 & $2.1 \%$ & $3.0 \%$ & $2.6 \%$ \\
\hline Spinner & 20,000 & 30,000 & $0.4 \%$ & $0.6 \%$ & $0.5 \%$ \\
\hline Auxiliary System & 3,000 & 10,000 & $0.1 \%$ & $0.2 \%$ & $0.1 \%$ \\
\hline Fabricated Steel & 500 & 20,000 & $0.0 \%$ & $0.4 \%$ & $0.2 \%$ \\
\hline Other & 206,500 & 110,000 & $4.4 \%$ & $2.2 \%$ & $3.3 \%$ \\
\hline Tower & $1,000,000$ & $1,000,000$ & $21.3 \%$ & $20.0 \%$ & $20.6 \%$ \\
\hline TOTAL & $4,700,000$ & $5,000,000$ & $100 \%$ & $100 \%$ & $100 \%$ \\
\hline
\end{tabular}

Note: Power take off includes the turbine's power converter, power transformer, switchgear and cable.

Source: BVG Associates (2010).

The team then generated approximate per-MW cost estimates for nearly two dozen individual components and subcomponents by applying the average proportional cost breakdown estimates from the BVG study to the high-level turbine cost estimates used in this study (\$917.5 million for a $500 \mathrm{MW}$ plant, see Appendix A). These per-MW cost estimates appear in Table D-7. We then applied these component cost estimates to the expected 2020 regional or national capacity demand in the moderategrowth scenario to approximate the potential market value for each component. 


\section{NAVIGANT}

Table D-7. Per-MW Turbine Component Costs for Hypothetical U.S. Offshore Wind Project

\begin{tabular}{|c|c|c|}
\hline Component & $\begin{array}{l}\text { Share of Turbine } \\
\text { CapEx }\end{array}$ & $\begin{array}{l}\text { Estimated Cost } \\
\qquad(\$ / M W)\end{array}$ \\
\hline Turbine & $100.0 \%$ & $\$ 1,835,000$ \\
\hline Nacelle & $53.1 \%$ & $\$ 975,000$ \\
\hline Bedplate & $2.34 \%$ & $\$ 42,900$ \\
\hline Main bearing & $1.49 \%$ & $\$ 27,300$ \\
\hline Main shaft & $2.13 \%$ & $\$ 39,000$ \\
\hline Gearbox & $18.07 \%$ & $\$ 331,500$ \\
\hline Generator & $4.78 \%$ & $\$ 87,750$ \\
\hline Power Converter & $4.46 \%$ & $\$ 81,753$ \\
\hline Power Transformer & $3.19 \%$ & $\$ 58,582$ \\
\hline Cables & $0.85 \%$ & $\$ 15,665$ \\
\hline Control System & $1.49 \%$ & $\$ 27,300$ \\
\hline Yaw System & $2.13 \%$ & $\$ 39,000$ \\
\hline Yaw Bearing & $0.96 \%$ & $\$ 17,550$ \\
\hline Auxiliary System & $1.26 \%$ & $\$ 23,049$ \\
\hline Nacelle Cover & $1.59 \%$ & $\$ 29,250$ \\
\hline Fasteners & $0.27 \%$ & $\$ 4,875$ \\
\hline Monitoring System & $0.32 \%$ & $\$ 5,850$ \\
\hline Other/Misc. & $7.83 \%$ & $\$ 143,676$ \\
\hline Rotor \& Blades & $26.4 \%$ & $\$ 485,000$ \\
\hline Blades & $17.62 \%$ & $\$ 323,333$ \\
\hline Hub Casting & $1.57 \%$ & $\$ 28,741$ \\
\hline Blade Bearings & $0.88 \%$ & $\$ 16,167$ \\
\hline Pitch System & $2.45 \%$ & $\$ 44,907$ \\
\hline Spinner & $0.49 \%$ & $\$ 8,981$ \\
\hline Auxiliary System & $0.13 \%$ & $\$ 2,335$ \\
\hline Fabricated Steel & $0.20 \%$ & $\$ 3,682$ \\
\hline Other/Misc. & $3.10 \%$ & $\$ 56,853$ \\
\hline Tower & $20.4 \%$ & $\$ 375,000$ \\
\hline
\end{tabular}

Note: Assumes 500-MW plant with 100 5-MW turbines

Source: Adapted from BVG 2010.

For non-turbine components (e.g., foundations and substructures and electrical infrastructure), the team extrapolated approximate per-MW costs using the bottom-up cost assumptions that appear in Appendix A. Per-unit material cost assumptions were based on internal projections that used historical commodity cost data available through the U.S. Bureau of Labor Statistics. Table D-8 provides the final set of assumptions that were used to calculate the market value estimates in Chapter 2.3. 


\section{NAVIGANT}

Table D-8. Cost Assumptions Used to Estimate Component and Material Market Values

\begin{tabular}{|c|c|c|c|c|c|}
\hline Component & Unit & Value & Source & Cost components & Notes \\
\hline WTG & $\$ / M W$ & $\$ 1,835,000$ & Appendix A & $\begin{array}{l}\text { Nacelle/Drivetrain; } \\
\text { Rotors/Blades; Towers }\end{array}$ & \\
\hline Gearbox \& Generators & \$/MW & $\$ 419,250$ & Table D-7 & Gearbox + Generator & $\begin{array}{l}\text { Ignores potential } \\
\text { split between } \\
\text { different drivetrain } \\
\text { types }\end{array}$ \\
\hline Power Converters & $\$ / M W$ & $\$ 81,753$ & Table D-7 & Power converter & \\
\hline Power Transformers & \$/MW & $\$ 58,582$ & Table D-7 & Power transformer & \\
\hline $\begin{array}{l}\text { Bearings for Main Shaft, } \\
\text { Gearboxes and Generators }\end{array}$ & $\$ / M W$ & $\$ 43,467$ & Table D-7 & $\begin{array}{l}\text { Main bearings }+ \text { blade } \\
\text { bearings }\end{array}$ & $\begin{array}{l}\text { Blade bearings } \\
\text { used to } \\
\text { approximate value } \\
\text { of smaller gearbox } \\
\text { and generator } \\
\text { bearings }\end{array}$ \\
\hline $\begin{array}{l}\text { Slewing Bearings for Pitch and } \\
\text { Yaw Systems }\end{array}$ & \$/MW & $\$ 33,717$ & Table D-7 & Yaw \& Blade bearings & \\
\hline Pitch Systems & $\$ / M W$ & $\$ 44,907$ & Table D-7 & Pitch systems & \\
\hline Yaw Systems & \$/MW & $\$ 39,000$ & Table D-7 & Yaw systems & \\
\hline $\begin{array}{l}\text { Cast Iron (e.g., hubs, main } \\
\text { frames) }\end{array}$ & $\$ / M W$ & $\$ 100,891$ & Table D-7 & $\begin{array}{l}\text { Bed plate, Nacelle cover, } \\
\text { Hub casting }\end{array}$ & \\
\hline $\begin{array}{l}\text { Forged Material (main shafts, } \\
\text { large flanges and rings) }\end{array}$ & $\$ / M W$ & $\$ 39,000$ & Table D-7 & Main shaft only & \\
\hline Blades & \$MW & $\$ 323,333$ & Table D-7 & Blades only & \\
\hline Epoxy or Polyester Resin & \$/tonne & $\$ 4,659$ & BLS Statistics & $\begin{array}{l}\text { Index for Thermosetting } \\
\text { Plastics and Resins }\end{array}$ & \\
\hline Glass Fiber & \$/tonne & $\$ 2,353$ & BLS Statistics & Index for Glass Fiber Mat & \\
\hline Carbon Fiber & \$/tonne & $\$ 46,972$ & BLS Statistics & Index for Carbon Fiber & \\
\hline Towers & $\$ / M W$ & $\$ 375,000$ & Table D-7 & & \\
\hline Steel for Towers & \$/tonne & $\$ 1,297$ & BLS Statistics & $\begin{array}{l}\text { Index for Cold Rolled } \\
\text { Steel }\end{array}$ & \\
\hline Foundations/Substructures & \$/MW & $\$ 1,320,790$ & Appendix A & $\begin{array}{l}\text { Basic Construction, } \\
\text { Foundation, } \\
\text { Substructure, Foundation } \\
\text { Assembly, Substructure } \\
\text { Assembly }\end{array}$ & $\begin{array}{l}\text { Ignores potential } \\
\text { split between } \\
\text { different foundation } \\
\text { types }\end{array}$ \\
\hline Primary Steel & \$/tonne & $\$ 1,297$ & BLS Statistics & $\begin{array}{l}\text { Index for Cold Rolled } \\
\text { Steel }\end{array}$ & \\
\hline Secondary Steel & \$/tonne & $\$ 1,297$ & BLS Statistics & $\begin{array}{l}\text { Index for Cold Rolled } \\
\text { Steel }\end{array}$ & \\
\hline Concrete & \$/tonne & $\$ 68$ & BLS Statistics & $\begin{array}{l}\text { Index for Ready Mix } \\
\text { Concrete }\end{array}$ & \\
\hline Inter-Array and Export Cable & \$/MW & $\$ 284,737$ & Appendix A & $\begin{array}{l}\text { Project collection system } \\
+ \text { HV Cable }\end{array}$ & \\
\hline Substations & \$MW & $\$ 175,875$ & Appendix A & $\begin{array}{l}\text { Substation (including } \\
\text { transportation) }\end{array}$ & \\
\hline
\end{tabular}




\section{NAVIGANT}

\section{Appendix E. Sample Demand Growth Curves}

Figure E-1. Modeled Annual Turbine Demand: High-Growth Scenario

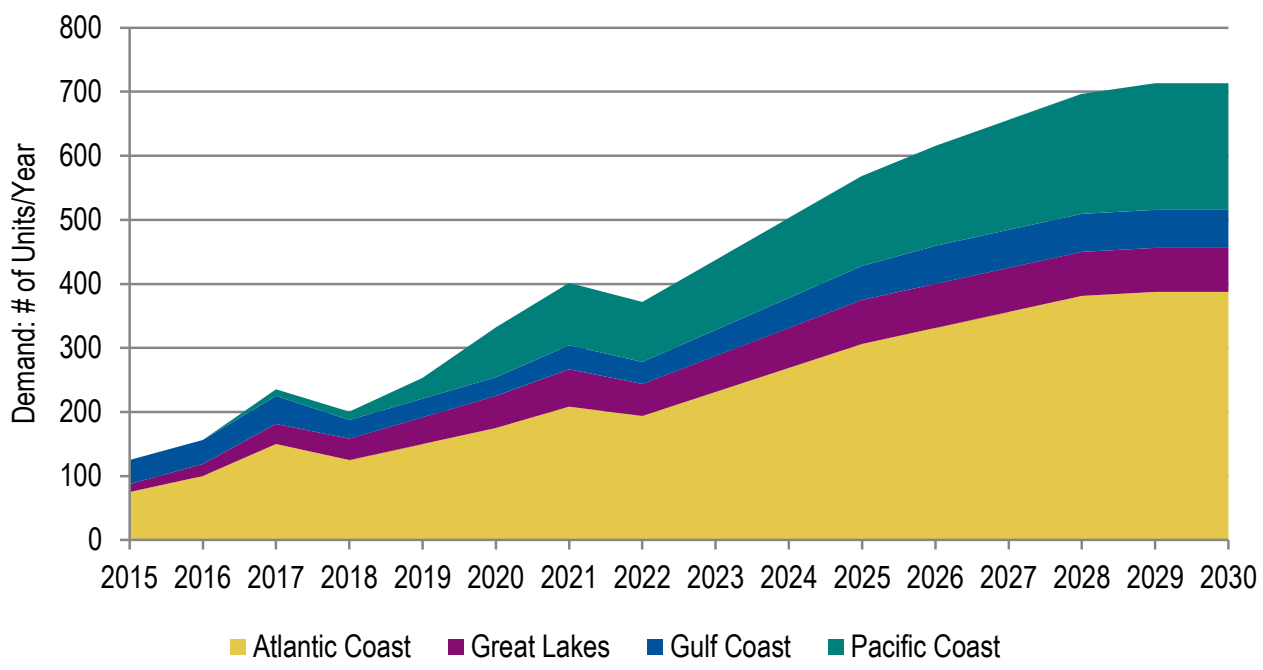

Figure E-2. Modeled Annual Turbine Demand: Low-Growth Scenario

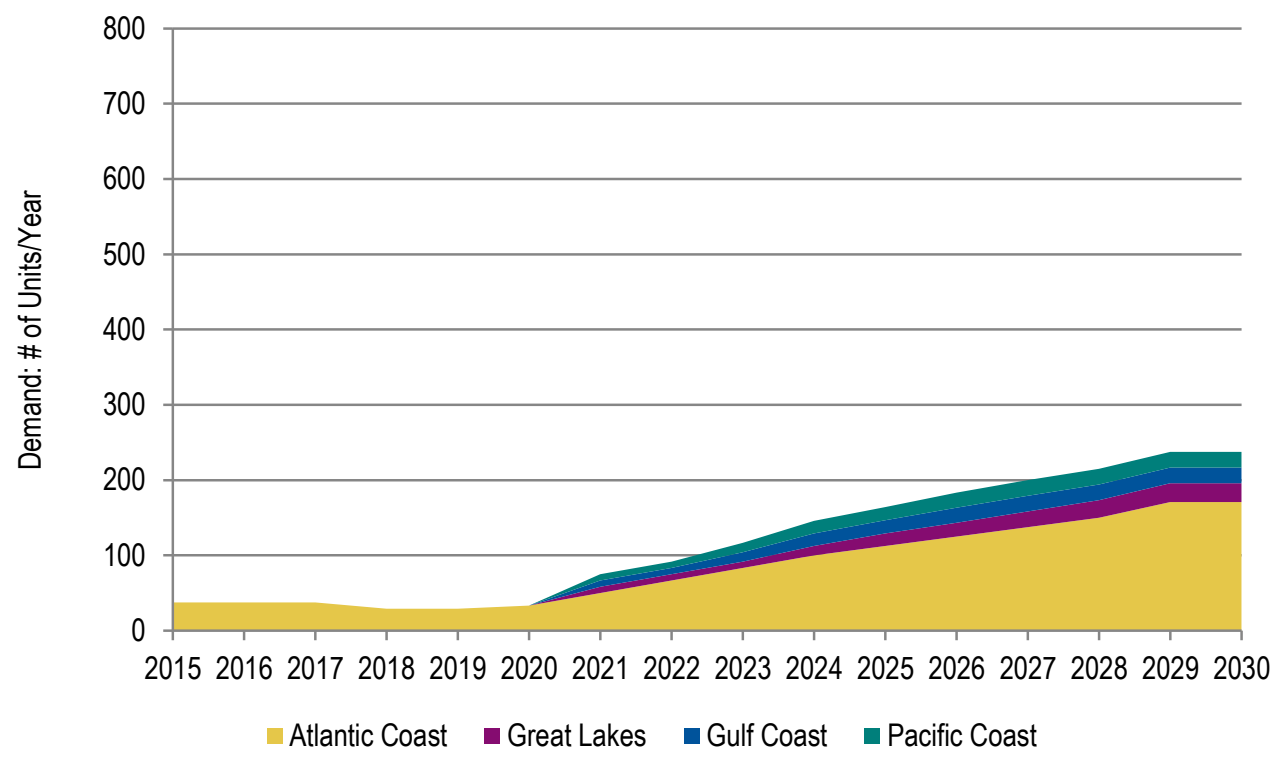




\section{NAVIGANT}

\section{Appendix F. Port Industry Trends and the Offshore Wind Market}

\section{F.1 Basic Port Selection Criteria and Industry Trends among Existing Facilities}

Selecting ports to serve the domestic offshore wind industry will be a function of both technical and market considerations. In addition to size and load capacity, other technical considerations might include a desire for sheltered geography in order to reduce construction risks and minimize the effects of variable weather conditions. Non-technical considerations such as exclusive access to wharfs, workforce availability, educational and training facilities, business and regulatory climate and other factors will also influence how port siting and investment decisions are made. Of course, proximity to project sites will also be a key criterion (see Figure 2-3 in Chapter 2.2.1 for a map of potential locations for offshore wind capacity based on the scenarios modeled in this report).

Based on these factors, many ports in the U.S. could potentially host offshore wind activity. Theoretically, a new port could also be constructed, although utilizing existing infrastructure may help minimize costs, which include both monetary and environmental considerations from activities such as dredging and piling. Large, high-capacity ports are especially suitable, as they can handle large ships that require deep water and wide channels; have existing capital such as heavy-duty cranes or derricks; and typically have an existing labor force with skills suited to offshore wind development.

Notably, worldwide demand for large ports is increasing as ship sizes continue to expand. At over 1,300feet in length, the container vessel Emma Maersk, for example, is longer than the U.S. Navy's longest aircraft carrier. Many shippers limit their vessel size to conform to the size constraints imposed by the Panama Canal - a key link in global maritime transport. These ships, known as Panamax, are common in the Atlantic and Gulf of Mexico due to trade with China. As previously noted, however, upgrades to the Panama Canal will allow larger vessels, known as post-Panamax, to ship goods to and from China and ports on the East Coast and Gulf of Mexico by the end of 2014).

As a result, many of the larger ports around the country have already completed upgrades to accommodate both larger vessels and increased traffic (Schwartz 2012). Such improvements will largely be necessary in order to continue accommodating global cargo flows. The U.S. Army Corps of Engineers estimates that 64 percent of all container ships will be post-Panamax by 2030 (USACE 2012). As of 2012, four ports on the Atlantic and four on the Pacific, listed in Table F-1 can accommodate post-Panamax ships. No ports on the Gulf of Mexico can accommodate these vessels at this time. Table F-1 also lists large ports in each region that are not post-Panamax capable. 


\section{NAVIGANT}

Table F-1. Large Ports in the Continental U.S. and Vessel Size Capabilities

\begin{tabular}{lll}
\hline Region & Port & Post-Panamax Capable \\
\hline Atlantic & Boston & \\
\hline & Delaware & \\
\hline & Savannah & \\
\hline Jacksonville & \\
\hline Everglades & \\
\hline Miami & $\mathrm{X}$ \\
\hline New York-Newark & $\mathrm{X}$ \\
\hline Baltimore & $\mathrm{X}$ \\
\hline Virginia (Norfolk) & $\mathrm{X}$ \\
\hline Charleston & \\
\hline Portland & $\mathrm{X}$ \\
\hline Tacoma & $\mathrm{X}$ \\
\hline Sreat Lakes & Seattle & $\mathrm{X}$ \\
\hline Oulf of Mexico & Oakland & $\mathrm{X}$ \\
\hline & Los Angeles & \\
\hline Long Beach & \\
\hline Mobile & \\
\hline & New Orleans & \\
\hline & Houston & \\
\hline & Chicago & \\
\hline & & \\
\hline & & \\
\hline & & \\
\hline & & \\
\hline
\end{tabular}

Source: Army Corps of Engineers (2012), World Port Source (2012)

These post-Panamax ports have the key advantage of existing infrastructure that is similar to that required by the offshore wind industry; however, it is likely that other ports will invest in similar

Combining the needs of larger container ships and the offshore

wind industry in to a

comprehensive port upgrade plan

could leverage overlapping needs

and economies of scale in

construction and development

activities. upgrades in the near future. Combining the needs of larger container ships and the offshore wind industry in to a comprehensive port upgrade plan could leverage overlapping needs and economies of scale in construction and development activities.

Despite these encouraging trends in port capabilities, however, ports and port authorities must also consider the opportunity costs of such investments. Even if a given port contains infrastructure suitable for use by the offshore wind industry, overcrowding or operating at capacity can make it difficult to satisfy the offshore

wind industry's needs, for example, for offshore-exclusive use of a berth. Optimal use of a port's

35 The Port of Chicago was identified using World Port Source and was not included in the U.S. Army Corps of Engineers report. 


\section{NAVIGANT}

capacity has been observed to be at or around 70\% (Halambides 2002). Presently, the ports of Charleston, Savannah, and Virginia have utilizations of their berthing spaces above $70 \%$ of capacity. However, while the ports of Charleston and Savannah have high berth usage, their container yards are only being used at $25 \%$ and $26 \%$ of capacity, respectively. Eighty-three percent of The Port of Virginia's container yards are, on average, in use. Container yard utilization at the port of Los Angeles/Long Beach as well as New York/New Jersey is 75 percent. All other ports listed in Table F-1 have berth and container yard use that is less than 70 percent (U.S. Army Corps of Engineers 2012). ${ }^{36}$

Heavy use, especially of container yards, does not preclude a port's use by the offshore wind industry. Logistics are different for container shipping and receiving than for offshore wind components, which are more similar to bulkbreak cargo. Even heavy traffic and high berth utilization do not mean that existing berths cannot be used. Additional berths were constructed at the Port of Bremerhaven and are planned at the Port of Humber, two European ports used to inform infrastructure investment scenarios analyzed in this report.

\section{F.2 Examples of Required Port Investments for Serving Offshore Wind}

Investment in offshore wind in the U.S. has already begun. Many states or agencies, including Massachusetts, New Jersey, and Maryland, have proactively commissioned studies analyzing the suitability of regional ports for the offshore wind industry. The Port of Virginia, Virginia Economic Development Authority, and Virginia Governor's Office combined efforts to encourage the formation of Poseidon Atlantic, an offshore wind turbine testing facility. South Carolina's Clemson University recently received a $\$ 45$ million federal grant to build an offshore wind test facility, which will likely utilize the Port of Charleston.

The investment required to upgrade a port for use by the offshore wind industry can vary. Making a port suitable as a staging area may take relatively little investment, while a substantially larger investment will likely be required for a fully integrated tower, blade, and nacelle manufacturing facility. As an example, Tetra Tech identified Dry Dock \#4 in the Port of Boston as needing a relatively modest $\$ 20$ million in repairs and upgrades to be a suitable staging point for offshore wind development (2010). An array of other ports throughout the northeastern U.S. in Maine, Massachusetts, Rhode Island, and New Jersey have received grants or initiated investments of broadly similar magnitude in order to advance their capability to serve the offshore wind industry (Williamson 2011; Mass.gov 2010; Knapschaefer and Russell 2011; AAPA 2010).

In contrast, European investment in ports intended for use by the offshore industry - especially OEM and component manufacturers - tends to be significantly greater. The German port of Cuxhaven on the North Sea is one such example. The European Union, the German Federal State of Lower Saxony, and the City of Cuxhaven collectively invested $€ 116$ million (about $\$ 150$ million) in upgrades to two terminals and a heavy-load platform. Table F-2 shows details of the installation.

\footnotetext{
${ }^{36}$ For a more complete set of potential port selection criteria, see the forthcoming set of reports specific to the development of U.S. ports for offshore wind being prepared by GL Garrad Hassan, expected to be available by the end of 2012.
} 


\section{NAVIGANT}

Table F-2. Selected Cuxhaven Details

\begin{tabular}{llll} 
& Draft & Length & Load Capacity \\
Terminal I & $31 \mathrm{ft}$ & $1,200 \mathrm{ft}$ & \\
\hline Terminal II & $45 \mathrm{ft}$ (maximum) & $2,400 \mathrm{ft}$ & \\
\hline Heavy-Load Platform & $52 \mathrm{ft}$ & & $18,400 \mathrm{lbs} / \mathrm{ft}^{2}$ \\
\hline
\end{tabular}

Source: Bräutigam (2011)

Additional investments were made in roads leading to the two terminals, while space needs were addressed through the development of 21 acres of land, with more than 250 additional acres slated for future use. As a result of these investments, Cuxhaven is now home to several companies, listed in Table F-3. Its deep channels and high load capacities make it particularly suitable for foundation and heavy steel component manufacturing and construction.

Table F-3. Offshore Wind-Related Industrial Activity at or Near the Port of Cuxhaven

\begin{tabular}{ll}
$\begin{array}{l}\text { Activity Category / Company } \\
\text { Heavy Construction and Manufacturing }\end{array}$ & Specific Components or Activities \\
\hline AMBAU GmbH & Steel towers, foundations \\
\hline BARD Group - Cuxhaven Steel Construction GmbH & Foundations, misc. components \\
\hline Ed. Züblin AG & Foundations \\
\hline $\begin{array}{l}\text { Development, Operations and Maintenance } \\
\text { PNE Wind AG }\end{array}$ & Development, operations, and maintenance \\
\hline DL Helicopter GmbH & Transportation services, winch operation, logistics \\
\hline Cuxport GmbH & Heavy crane operation, storage \\
\hline Otto Wulf GmbH \& Co. KG & Transportation services, logistics \\
\hline Education and Consulting & \\
\hline DEWl-OCC Offshore and Certification Centre GmbH & Project and component analysis, consulting \\
\hline Offshore Kompeteenzzentrum Cuxhaven & Education \\
\hline
\end{tabular}

Source: Bräutigam (2011), Bremerhavener Gesellschaft für Investitionsförderung und Stadtentwicklung mbH (2009)

Both public and private sources also recently invested heavily in the German Port of Bremerhaven. On the North Sea to the west of Cuxhaven, this port underwent upgrades to three terminals and added a new terminal (Table F-4). Approximately $€ 60$ million in public funds from the state of Bremen were used to upgrade the Labradorhafen terminal. The upgrade of Containerterminal I, the ABC Halbinsel terminal, and the new Offshore Terminal Bremerhaven (OTB) were financed by private companies. 


\section{NAVIGANT}

Table F-4. Selected Bremerhaven Details

\begin{tabular}{lccc} 
Terminal & Depth & Length & Load capacity \\
\hline Labradorhafen & $25 \mathrm{ft}$ & $3,500 \mathrm{ft}$ & $10,000 \mathrm{lbs} / \mathrm{ft}^{2}$ \\
\hline Containerterminal I & $40 \mathrm{ft}$ & $1,500 \mathrm{ft}$ & $1,000 \mathrm{lbs} / \mathrm{ft}^{2}$ \\
\hline ABC Halbinsel & $35 \mathrm{ft}$ & $3,000 \mathrm{ft}$ & \\
\hline OTB (planned) & $45 \mathrm{ft}$ & $1,500 \mathrm{ft}$ & \\
\hline
\end{tabular}

Source: Bräutigam (2011)

Total estimates of the investment in Bremerhaven and future investments vary, but a German consultancy tasked with quantifying the impacts of the construction put the public-private total infrastructure investment (excluding commercial investments) between $€ 385$ and $€ 441$ million (\$536 to $\$ 614$ million; Prognos 2011). The Port of Bremerhaven is now a thriving hub of offshore wind-related economic activity. Table F-5 shows companies that chose to locate facilities on or around the port. 


\section{NAVIGANT}

Table F-5. Offshore Wind-Related Industrial Activity at or Near the Port of Bremerhaven

\begin{tabular}{|c|c|}
\hline Activity Category / Company & Specific Components or Activities \\
\hline \multicolumn{2}{|l|}{ Turbines, Blades and Nacelle Components } \\
\hline AREVA Multibrid & Turbines \\
\hline PowerBlades & Blades \\
\hline REPower Systems & Turbines \\
\hline PowerWind $\mathrm{GmbH}$ & Generators \\
\hline \multicolumn{2}{|l|}{ Heavy Construction and Structure Manufacturing } \\
\hline WeserWind & Foundations \\
\hline Nordseetaucher GmbH & Welding, subsurface preservation \\
\hline EnergieKontor AG & Development \\
\hline WindMW GmbH & Development, operations \\
\hline \multicolumn{2}{|l|}{ Other Specialized Equipment } \\
\hline meteocontrol $\mathrm{GmbH}$ & Meteorological equipment, consulting \\
\hline THERMOWIND Safety \& Supply GmbH & Equipment sales and thermal imaging \\
\hline Rolf Lübbe Hebe und Zurrsysteme e.K. & Lifting devices, accessories, and components \\
\hline \multicolumn{2}{|l|}{ Research and Education } \\
\hline Deutsche Windguard & Research, training, consulting \\
\hline Fraunhofer Institute for Wind Energy and Energy System Technology & Blade, foundation research \\
\hline interface.group $\mathrm{GmbH}$ & Consulting \\
\hline $\begin{array}{l}\text { Technologiekontor Bremerhaven F\&E Gesellschaft für die Nutzung } \\
\text { regenerativer Energien } \mathrm{mbH}\end{array}$ & Consulting \\
\hline Energy \& meteo systems $\mathrm{GmbH}$ & Research and consulting \\
\hline Logistik-Service-Agentur & Logistics consulting \\
\hline BLG LOGISTICS Solutions GmbH & Logistics \\
\hline Falck Nutec A/S & Training \\
\hline wind:research & Research \\
\hline DOC Deutsche Offshore Consult & Consulting \\
\hline
\end{tabular}

Source: Bremerhavener Gesellschaft für Investitionsförderung und Stadtentwicklung mbH

In the U.K., two other upgrades of similar scope occurred under public-private agreements. In 2012, Gamesa entered into an agreement with Forth Ports, the operator of the Scottish Port of Leith, in which Gamesa agreed to invest $£ 125$ million (\$200 million) while the Scottish Government's National Renewable Infrastructure Plan (NRIP) is expected to contribute $£ 35$ million or $\$ 56$ million (Greener Leith 2012). Gamesa plans to operate two facilities at the port that will collectively employ 800 people. One facility is planned to manufacture blades and nacelles, while the other will provide for logistics, operations, and maintenance (Business Green 2012). This investment will also serve to integrate production facilities with Gamesa's existing research and development facilities in Scotland (Gamesa 2012).

Siemens entered a similar agreement with Associated British Ports (ABP) to build an $£ 80$ million (\$128 million U.S.) blade manufacturing facility at the Port of Hull, located on the Humber estuary. ABP will 


\section{NAVIGANT}

invest $£ 100$ million ( $\$ 160$ million) in port upgrades, of which $£ 20$ million (\$32 million) will come from the British government. Siemens expects the plant to employ 700. The project is also adjacent to 200 acres of undeveloped land owned by ABP. This land, which is zoned for industrial use and classified as a port, could be developed to provide production and services similar or complementary to Siemens (DOE and Climate Change 2009).

At present, investment at the Port of Paulsboro in New Jersey is the only U.S. example that approaches comparability with European offshore wind ports. Thus far, nearly $\$ 200$ million in grants and bonds to support infrastructure improvements targeting the offshore wind industry have been secured. Recent activities include demolition of outdated infrastructure, dredging, and road and bridge construction (Knapschaefer and Russell 2011). Notably these are improvements that could support the ability of the Port of Paulsboro to serve both offshore wind and other potential port users.

Current levels of U.S. investment are generally perceived to be insufficient to support the level of offshore wind installations that might be associated with a robust and thriving offshore wind industry. In principle, however, any port along the eastern seaboard could be upgraded to handle offshore energy development activity similar to its European counterparts with enough investment. 


\section{NAVIGANT}

\section{Appendix G. Details on Indirect Job Impacts of Modeled Port Facility Investments}

\section{G.1 Distribution of Indirect Employment by Industry}

The indirect and induced jobs that arise from the above impacts can be further analyzed to determine which industries will be most affected. The distribution of these indirect jobs is similar, but not identical, across the three investment scenarios. For example, differences in the low scenario may be attributable to the fact that it did not involve the construction of an industrial manufacturing facility. These differences, however, are relatively small. Figure G-1 illustrates the average distribution of indirect employment arising from the materials, equipment, and supply chain categories.

Figure G-1. Distribution of Average Supply Chain and Material Input Jobs (FTE) by Sector

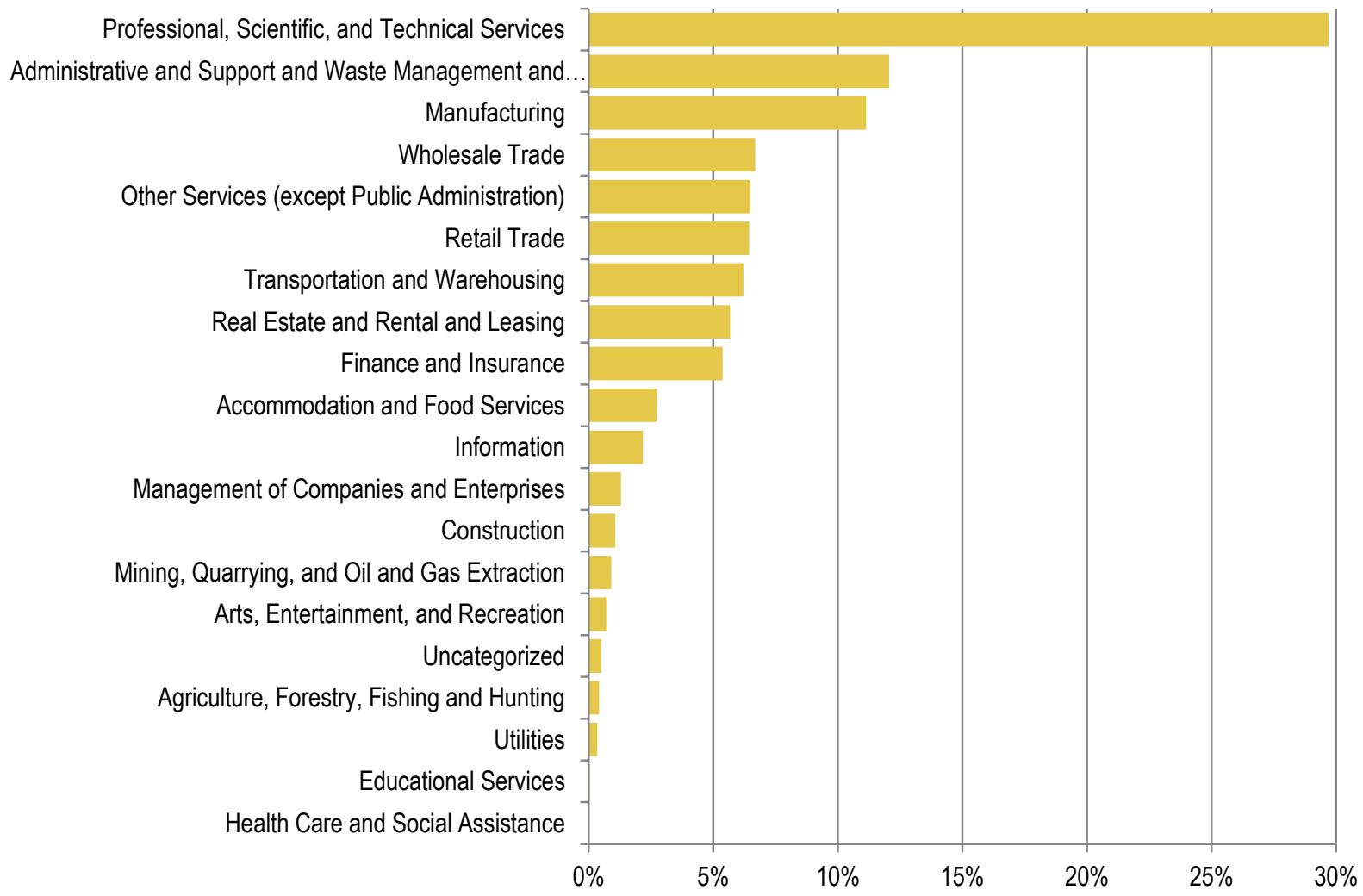

Across investment scenarios, the greatest number of supply chain jobs supported is in the professional, scientific, and technical services sector. This includes companies that provide accounting, legal, engineering, public relations, and advertising services, as well as companies that may provide computer support services or other consultancies. Other top sectors with indirect employment along the supply chain include (in descending order):

» Administrative support and waste management: includes staffing organizations and other onsite services such as building maintenance or security 


\section{NAVIGANT}

" Manufacturing: tends to be specialized and is highly dependent on what exists in the state where the facilities are constructed. On average, this category represents around $10 \%$ of indirect jobs but could increase or decrease considerably if local inputs exist and are utilized

"Wholesale trade: represents the sale of an input and not necessarily the production of that input

" Other services: includes repair services, religious, civic, and other non-profit organizations, and personal care services

Figure G-2 shows the average distribution of induced jobs from local expenditure. The health care and social assistance sector represents the most jobs created as a result of local expenditures. Note that these jobs include service providers only and specifically exclude the health care insurance industry.

Figure G-2. Distribution of Average Job (FTE) Impacts from Local Expenditures by Sector

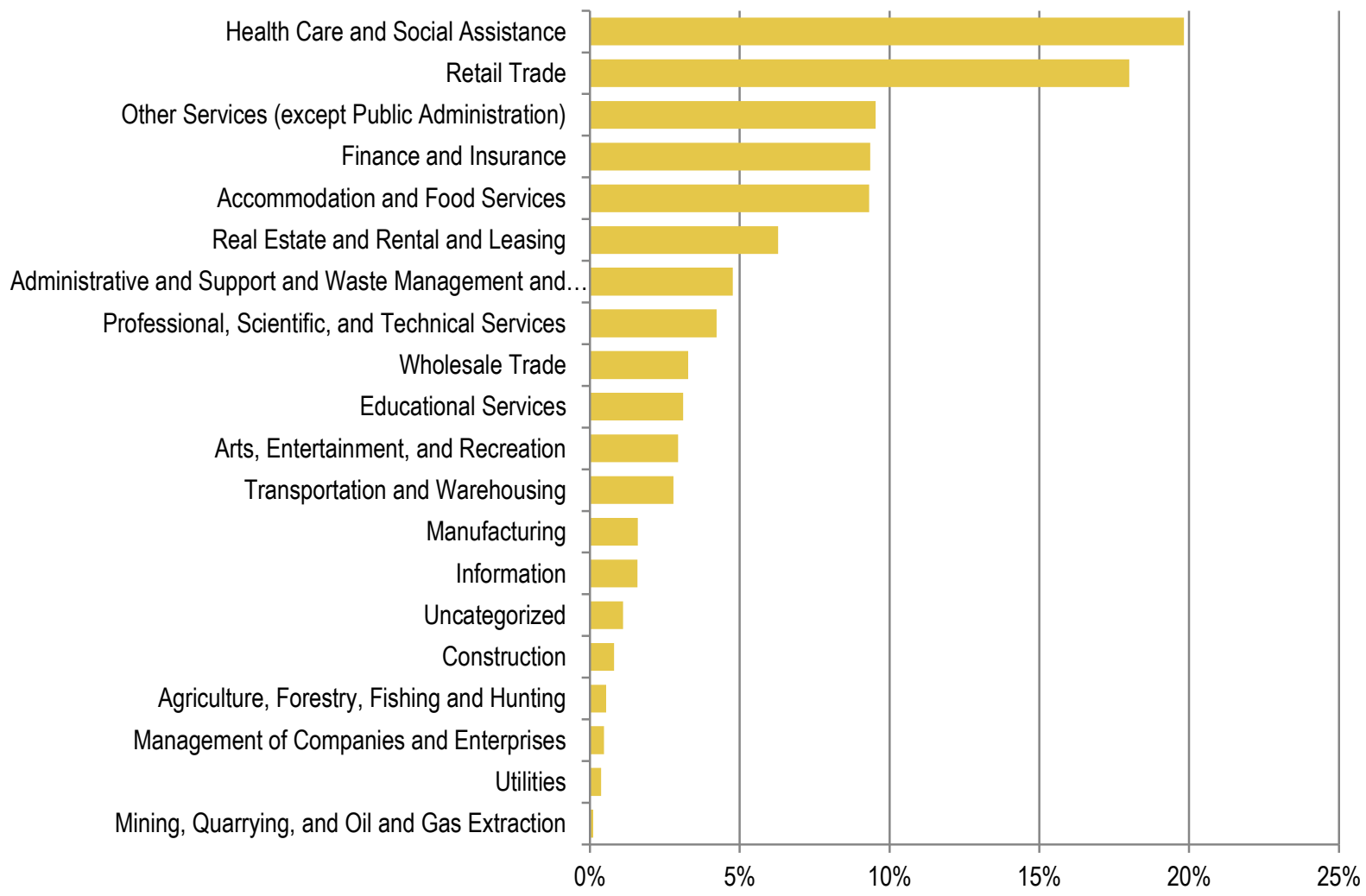

Other top sectors with induced local employment include (in descending order):

» Retail trade: nearly as significant as the health care sector in terms of FTEs

» Other services: includes repair services, religious, civic, and other non-profit organizations, and personal care services

» Finance and insurance: includes local employers such as insurance agents or financial planners. Insurance purchased during construction may support local jobs, but it is important to make the distinction that having a local agent does not necessarily mean that policy is underwritten locally or that revenue from the policy will be realized locally. 


\section{NAVIGANT}

Accommodation and food services: largely consists of restaurants and bars; includes temporary housing such as boarding houses and hotels 
Appendix H.Local Content Assumptions for Modeling Labor Requirements

Table H-1. Regional Local Content Assumptions for Modeling Labor Requirements: Nacelles

\begin{tabular}{|c|c|c|c|c|c|c|c|c|c|}
\hline \multirow[b]{2}{*}{ Region } & \multicolumn{3}{|c|}{ Low Growth } & \multicolumn{3}{|c|}{ Moderate Growth } & \multicolumn{3}{|c|}{ High Growth } \\
\hline & 2020 & 2025 & 2030 & 2020 & 2025 & 2030 & 2020 & 2025 & 2030 \\
\hline North Atlantic & $32 \%$ & $41 \%$ & $80 \%$ & $35 \%$ & $75 \%$ & $95 \%$ & $65 \%$ & $88 \%$ & $100 \%$ \\
\hline South Atlantic & $0 \%$ & $0 \%$ & $0 \%$ & $0 \%$ & $0 \%$ & $25 \%$ & $35 \%$ & $80 \%$ & $95 \%$ \\
\hline Great Lakes & $0 \%$ & $0 \%$ & $0 \%$ & $0 \%$ & $35 \%$ & $45 \%$ & $25 \%$ & $35 \%$ & $50 \%$ \\
\hline Gulf Coast & $0 \%$ & $0 \%$ & $0 \%$ & $0 \%$ & $33 \%$ & $45 \%$ & $0 \%$ & $33 \%$ & $45 \%$ \\
\hline Pacific Coast & $0 \%$ & $0 \%$ & $0 \%$ & $25 \%$ & $65 \%$ & $95 \%$ & $50 \%$ & $85 \%$ & $100 \%$ \\
\hline United States & $25 \%$ & $25 \%$ & $50 \%$ & $25 \%$ & $60 \%$ & $85 \%$ & $55 \%$ & $80 \%$ & $90 \%$ \\
\hline
\end{tabular}

Note: Each output represents the share of that region's content that is supplied within that region in the year shown.

Table H-2. Regional Local Content Assumptions for Modeling Labor Requirements: Blades and Towers

\begin{tabular}{|c|c|c|c|c|c|c|c|c|c|}
\hline \multirow{2}{*}{ Region } & \multicolumn{3}{|c|}{ Low Growth } & \multicolumn{3}{|c|}{ Moderate Growth } & \multicolumn{3}{|c|}{ High Growth } \\
\hline & 2020 & 2025 & 2030 & 2020 & 2025 & 2030 & 2020 & 2025 & 2030 \\
\hline North Atlantic & $13 \%$ & $61 \%$ & $95 \%$ & $25 \%$ & $60 \%$ & $95 \%$ & $30 \%$ & $60 \%$ & $95 \%$ \\
\hline South Atlantic & $0 \%$ & $0 \%$ & $0 \%$ & $0 \%$ & $0 \%$ & $25 \%$ & $10 \%$ & $60 \%$ & $95 \%$ \\
\hline Great Lakes & $0 \%$ & $0 \%$ & $0 \%$ & $0 \%$ & $30 \%$ & $50 \%$ & $0 \%$ & $30 \%$ & $50 \%$ \\
\hline Gulf Coast & $0 \%$ & $0 \%$ & $0 \%$ & $0 \%$ & $30 \%$ & $50 \%$ & $0 \%$ & $30 \%$ & $50 \%$ \\
\hline Pacific Coast & $0 \%$ & $0 \%$ & $0 \%$ & $0 \%$ & $50 \%$ & $95 \%$ & $25 \%$ & $50 \%$ & $95 \%$ \\
\hline United States & $10 \%$ & $37 \%$ & $72 \%$ & $10 \%$ & $45 \%$ & $80 \%$ & $18 \%$ & $53 \%$ & $88 \%$ \\
\hline
\end{tabular}

Note: Each output represents the share of that region's content that is supplied within that region in the year shown.

Table H-3. Regional Local Content Assumptions for Modeling Labor Requirements: Substructures and Foundations

\begin{tabular}{|c|c|c|c|c|c|c|c|c|c|}
\hline \multirow{2}{*}{ Region } & \multicolumn{3}{|c|}{ Low Growth } & \multicolumn{3}{|c|}{ Moderate Growth } & \multicolumn{3}{|c|}{ High Growth } \\
\hline & 2020 & 2025 & 2030 & 2020 & 2025 & 2030 & 2020 & 2025 & 2030 \\
\hline North Atlantic & $0 \%$ & $0 \%$ & $30 \%$ & $0 \%$ & $25 \%$ & $50 \%$ & $0 \%$ & $45 \%$ & $70 \%$ \\
\hline South Atlantic & $0 \%$ & $0 \%$ & $0 \%$ & $0 \%$ & $0 \%$ & $0 \%$ & $0 \%$ & $25 \%$ & $50 \%$ \\
\hline Great Lakes & $0 \%$ & $0 \%$ & $0 \%$ & $0 \%$ & $0 \%$ & $0 \%$ & $0 \%$ & $0 \%$ & $0 \%$ \\
\hline Gulf Coast & $0 \%$ & $100 \%$ & $100 \%$ & $100 \%$ & $100 \%$ & $100 \%$ & $100 \%$ & $100 \%$ & $100 \%$ \\
\hline Pacific Coast & $0 \%$ & $0 \%$ & $0 \%$ & $0 \%$ & $0 \%$ & $45 \%$ & $0 \%$ & $40 \%$ & $65 \%$ \\
\hline United States & $60 \%$ & $60 \%$ & $74 \%$ & $60 \%$ & $69 \%$ & $84 \%$ & $60 \%$ & $85 \%$ & $90 \%$ \\
\hline
\end{tabular}

Note: Each output represents the share of that region's content that is supplied within that region in the year shown. 